\title{
Verbal learning in school-aged children and the influence of child-related factors, test-related factors and natural context
}

Citation for published version (APA):

Meijs, C. J. C. (2008). Verbal learning in school-aged children and the influence of child-related factors, test-related factors and natural context. [Doctoral Thesis, Maastricht University]. NeuroPsych Publishers. https://doi.org/10.26481/dis.20080612cm

Document status and date:

Published: 01/01/2008

DOI:

10.26481/dis.20080612cm

Document Version:

Publisher's PDF, also known as Version of record

Please check the document version of this publication:

- A submitted manuscript is the version of the article upon submission and before peer-review. There can be important differences between the submitted version and the official published version of record.

People interested in the research are advised to contact the author for the final version of the publication, or visit the DOI to the publisher's website.

- The final author version and the galley proof are versions of the publication after peer review.

- The final published version features the final layout of the paper including the volume, issue and page numbers.

Link to publication

\footnotetext{
General rights rights.

- You may freely distribute the URL identifying the publication in the public portal. please follow below link for the End User Agreement:

www.umlib.nl/taverne-license

Take down policy

If you believe that this document breaches copyright please contact us at:

repository@maastrichtuniversity.nl

providing details and we will investigate your claim.
}

Copyright and moral rights for the publications made accessible in the public portal are retained by the authors and/or other copyright owners and it is a condition of accessing publications that users recognise and abide by the legal requirements associated with these

- Users may download and print one copy of any publication from the public portal for the purpose of private study or research.

- You may not further distribute the material or use it for any profit-making activity or commercial gain

If the publication is distributed under the terms of Article $25 \mathrm{fa}$ of the Dutch Copyright Act, indicated by the "Taverne" license above, 


\section{Verbal learning in school-aged children and the influence of child- related factors, test-related factors, and natural context}

Neuropsych Publishers, Maastricht, the Netherlands 
(C) C.J.C. Meijs, Roermond/Maastricht 2008

ISBN 978-90-75579-50-5

Gedrukt door: Holbox BV te Echt

Omslag: $\quad$ m.m.v. Ron Mengelers

Neuropsych Publishers is a non-profit organisation, which aims at promoting the science of 'Brain and Behavior' and improving the application of the products of this science in health care and education. Neuropsych Publishers accomplishes these aims by publishing books, dissertations and other products of scientific activity, by disseminating educational materials and publication of tests, assessment scales and other psychometric instruments in the field of Neurpsychology, Neuropsychiatry and other areas within the domain of Brain and Behavior.

Postal address: Neuropsych Publishers

Department of Psychiatry and Neuropsychology

Maastricht University

P.O. Box 616

6200 MD Maastricht

The Netherlands

www.np.unimaas.nl 


\section{Verbal learning in school-aged children and the influence of child- related factors, test-related factors, and natural context}

\section{PROEFSCHRIFT}

ter verkrijging van de graad van doctor aan de Universiteit Maastricht, op gezag van de Rector Magnificus, Prof. mr. G.P.M.F. Mols volgens het besluit van het College van Decanen, in het openbaar te verdedigen op donderdag 12 juni 2008 om 12.00 uur

door

Celeste J.C. Meijs 
Promotor:

Prof.dr. J. Jolles

Copromotor:

Dr. P.P.M. Hurks

Beoordelingscommissie

Prof.dr. R. Wiers (voorzitter)

Prof.dr. P. van Geert (Rijksuniversiteit Groningen)

Dr. L. Krabbendam

Prof.dr H.B.M. Uylings (Universiteit Amsterdam)

Prof.dr. M. Westenberg (Universiteit Leiden)
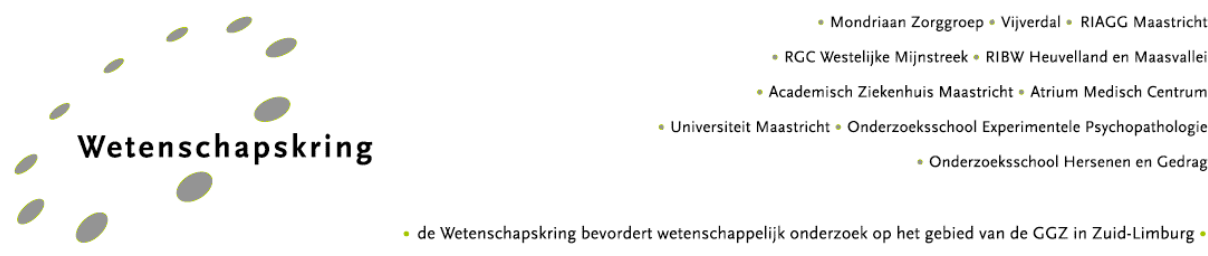

de Wetenschapskring bevordert wetenschappelijk onderzoek op het gebied van de GGZ in Zuid-Limburg .

Financial support for the publication of this thesis has been kindly provided by Sigma Tau BV, Eli Lilly Nederland BV and Lundbeck BV. 


\section{Contents}

$\begin{array}{lll}\text { Chapter } 1 \quad \text { Introduction } & 7\end{array}$

Chapter 2 Verbal learning performance and the relation with efficient strategy use in children aged 5-15: the influence of age, sex, the level of parental education, and the presentation modality

Chapter 3 Differential development of learning strategies on a Pictorial Verbal Learning Test (PVLT) in primary school children

Chapter 4 Auditory and pictorial verbal learning compared: A cross-sectional study of children aged $5-15$

Chapter 5 The influence of the presentation modality, the recall demands, and the content of information on verbal learning performance in children aged $6-16$

Chapter 6 The relationship between recreational computer use and age, sex, and the level of parental education in children aged 5-16

Chapter 7 The relationship between gaming and verbal learning:

A large-scale cross-sectional study in 200 children aged $5-15$ years

Chapter 8 Concluding Remarks

Summary

Samenvatting

Dankwoord

Curriculum Vitae

Publicaties 



\section{Chapter 1}

\section{Introduction}

Recent advances in neurosciences and cognitive sciences have provided powerful insights into the mechanisms that underlie learning processes. In the past decade, international consensus has been reached that the neuroscientific perspective has the potential to add a new and important dimension to the study of learning in relation to education. The Centre of Educational Research and Innovation (CERI) from the organisation of the Economic Collaboration and Development (OECD) has added that fundamental neuro- and cognitive sciences could also yield insights that are of applied value for the domain of education. Interestingly, there could be an information exchange where educational knowledge could help redirect the topics and scientific questions that are under investigation in neuroscience and cognitive science domains in such a direction, that it provides a win-win situation in which scientists can profit from the experience and insights from educational practitioners (OECD, 2002, 2007). The 2007 publication of the CERI has the title 'Birth of a learning science' and has a positive view regarding a possible convergence between various scientific disciplines that are involved in the large domain of learning and education. According to the publication, the process of convergence should eventually lead to a trans-disciplinary research discipline. The term 'trans-disciplinary' refers to a fusion of completely different disciplines resulting in a new discipline that is integrative in nature.

In the past decade, notably in the years 2002-2007, there has been a rapid increase in the number of scientific studies in major journals that perform scientific studies on the domain of neuroscience, learning, and education. The scientific evidence given supports the notion that insight into the relationship between brain processes and learning could have potential for application in educational settings. There are numerous studies that describe such relationships, such as the neuroscientific mechanisms underlying language and language acquisition, the cognitive neuroscience of attentional processes, the neuroscience of dyslexia and other learning problems, and the neural circuitry underlying reading and numeracy (Ansari \& Coch, 2006; Goswami, 2004, 2006; Posner \& Rothbart, 2005). Other studies use evidence from brain research to understand how the learning process is mediated by environmental factors and by context. An example of the latter is the vast domain of studies into sleep and its importance for learning, the studies into family composition in relation to cognitive performance and the development of ADHD and related developmental dysfunctions (Hurks, 2003; Kalff et al., 2001). Likewise, recent studies into social cognitive neuroscience in relation to development of executive control in adolescence are pertinent to the topic of 'learning' and education (see also the OECD report for further reading of major lines of thinking in this regard; OECD, 2007). Finally, the recent formation of the International Mind, Brain, and Education Society in 2006 is also an example of the rapid development of this interdisciplinary -and possible trans-disciplinary- field (see for more information www.imbes.org). 
The research in this thesis is based upon the premise that neuropsychology can contribute to the trans-disciplinary domain mentioned. Neuropsychology itself is a multi-disciplinary field in which knowledge and insights from brain structures and functions are used to further our insights into psychological processes, skills and attitudes. Neuropsychologists are interested in brain processes and in neuropsychological variables; even psychosocial factors, such as social interactions, beliefs, motivations, and affect, are of importance to understand psychological functioning, behaviour and skills. Also, the knowledge about biological factors related to brain development, the influence of sleep, psychological stress and related biopsychological factors are important to more fully understand 'learning' as a process and as a dependent variable in applied settings. Up until now, studies on the role of the brain and the neurocognitive factors that are involved in learning and learningrelated processes, in a developmental perspective, indicate that our focus needs to be multi-dimensional. This means that there is more than just 'learning', 'memory' or performance on a specific cognitive test. It is imperative to look at several factors that are the major determinants of learning (OECD, 2007). Three important domains that can be discerned in this regard are child-related factors, test-related factors, and biopsychosocial factors (e.g., context, family composition, genes, and the biological factors). In order to understand learning in more depth, we need to take the age of the child and his or her developmental stage into consideration, as well as the psychosocial environment in which the child has been raised (Kalff et al., 2001). The important consequence of the fact that there is a multitude of influences that all act upon learning, is that there are individual patterns in cognitive development and in learning. Children who are very similar in biological and/or psychosocial make-up will not learn exactly the same things during education, even if they attend the same classes (OECD, 2007). There is evidence from twin studies that children with the same genes can become different because of different experiences in their environment (Boomsma, Busjahn, \& Peltonen, 2002). Therefore, it is imperative that the influence of factors that are determinants for the nature and effectiveness of learning are established. This is especially important for the eventual translation of this scientific knowledge in order to guide the process of implementation into educational settings.

The age-range in which the development of verbal learning has to be studied has to include several developmental 'milestones'. Anderson (2002) was one of the first to describe that there are patterns in the development of several cognitive functions and these are probably aligned with the development of the (areas within the) prefrontal cortex. He mentioned the periods of rapid growth of the prefrontal cortex, which have been related to the number and strength of frontal lobe connections, a point also made by other authors (Blakemore \& Frith, 2005). With respect to particular neurocognitive functions and their development, Anderson suggested that the period between birth and 5 years is important for the development of attentional control. The period between 7 and 9 years has been related to the development of information processing, cognitive flexibility, and goal setting. The period between 11 and 13 years has been related to a maturity of the four executive 
domains and the emergence of 'executive control'. Even though these spurts have been reported to end at age 13, the development (and thus neurocognitive development) still continues until, at least, well into the third decade of life (Alvarez \& Emory, 2006; Giedd et al., 1999; Gogtay et al., 2004; Klingberg, 2006; Paus, 2005). Thus, the most interesting changes in brain development have been found until at least middle adolescence. This indicates that studies into the neuropsychological processes and factors that are expected to have some implications for learning in applied settings -such as school- should take a broad age-range -at least 5 to 16 years- into consideration. This is the age-range that was included in the studies that are described in this thesis.

The research described here has been devised from the neuropsychological viewpoint described above. It aims at providing more insight into the influence of the three important groups of factors that have been mentioned to be relevant for learning in school-children aged 5 to 16 years: (1) child-related factors, (2) test-related factors, and (3) learning in a natural context. The studies were conducted to further our insights into learning processes in relevant multi-dimensional domains, notably the educational setting. The research was motivated by the findings and objectives of the CERI/OECD, and has the potential to contribute to the development of a transdisciplinary science and the professional domain of 'educational neuropsychology'. Educational neuropsychology could be an important contribution to education with possible contributions for children both with and without learning problems and for associated cognitive development, psychosocial consequences, and social-emotional development. As the OECD indicates in the report 'The birth of a learning science', this is of great potential for future application in educational settings (for more information see www.oecd.org).

Before describing the concrete aims of the research performed in this thesis, brief background information will be given on the various factors mentioned above. Thus, insight will be provided into the choices made and the approaches used in the experimental studies. The influences of the factors will be described in relation to verbal learning and memory. This is because memory is a necessary cognitive process underlying many different forms of learning. In addition, the consolidation of newly learnt information is possible thanks to brain processes, memory strategies, and the presence of a putative 'working memory'. The latter concept is conceived as a 'temporary holding device'. The two processes of learning and memory have such a profound relationship that memory is subject to the same factors as those influencing learning (OECD, 2007). There is even a notion that states that learning and memory are two sides of the same coin (see for more information in Ormrod, 1999). In the present thesis, we chose to study verbal learning, because most information that has to be learnt during education is verbal in nature. Moreover, a wealth of knowledge exists both on cognitive psychological aspects of verbal memory and about the neuroscientific aspects of verbal learning, as assessed in clinical neuropsychological studies and experiments in cognitive neuroscience. The major tests that are used in this thesis are derived from a verbal learning test (VLT), a word span test (WS) and a digit span test (DS). 


\section{Description of the factors}

\section{Child-related factors}

This paragraph gives a description of four child-related factors that are pertinent to consider in the study of the development of learning in school-aged children. The first child-related factor is age. It is widely known that verbal learning performance develops with age (see for more information in Bjorklund \& Douglas, 1997; Schneider, Knopf, \& Stefanek, 2002; Schneider \& Pressley, 1997; Siegler \& Wagner Alibali, 2005). We focused on children in the age-range of 5 to 16 years. The advantage of the inclusion of such a broad age-range is that it provides insight into the learning processes that take place in primary school and secondary school. This includes insight into what happens in cognitive and psychological processes during the transition from primary to secondary school. Indications that there are differences in development with age come from studies that show a rapid increase in performance on tests until about 8 years and a levelling-of in the increase in performance that takes place between 9 and 12 years of age (Korkman, Kemp, \& Kirk, 2001). It is, furthermore, relevant to study this age range because of the differential development of some major cognitive functions, such as attention, information processing, and strategy use. Some of these functions, such as particular attentional functions, are at a mature level at approximately 12 years. Other functions, such as strategy use, develop up until -at least- middle adolescence, i.e., about 15 years (Anderson, 2002) and the brain has been reported to develop until at least early adulthood (Alvarez \& Emory, 2006; Giedd et al., 1999; Gogtay et al., 2004; Klingberg, 2006; Paus, 2005). It could very well be that the differential development of these functions is related to the development of verbal learning within the age-range of 5 to 16 years. One argument is that strategy use is linked to verbal learning performance. Therefore, it is necessary to include this broad age-range in this thesis.

The second child-related factor is sex. Differences between boys and girls have been reported in several areas of brain and/or psychological development. There is rapidly accumulating evidence that girls, in general, show a faster maturation of the brain than boys (Blakemore \& Frith, 2005; De Bellis et al., 2001; Giedd et al., 1999; Overman, 2004). In addition, boys have more grey and white matter than girls. Furthermore, the developmental differences in the brain areas that have been reported to be related to verbal learning appear to be areas in the prefrontal cortex and the parietal lobe (Giedd et al., 1999). Also, there is now a considerable body of scientific knowledge that girls -generally- perform better on tests that are verbal in nature, whereas boys appear to perform better on tests with a spatial nature (Lowe, Mayfield, \& Reynolds, 2003; Overman, 2004). The issue is not totally set, however, as with regard to verbal learning, in that some studies do not find an effect of sex (Bishop, Knights, \& Stoddart, 1990; Forrester \& Geffen, 1991; Van den Burg \& Kingma, 1999), whereas others have concluded that a relationship between sex and verbal learning does exist (Vakil, Blachstein, \& Sheinman, 1998). Possibly, differences in verbal learning between boys and girls might be related to sex differences in strategy use. Girls have been reported to make better use of strategies (Cox \& 
Waters, 1986; Kramer, Delis, Kaplan, O'Donnel, \& Prifitera, 1997). Thus, the influence of sex on verbal learning is, up to now, not clear enough, but very relevant to study because of the putative differences between boys and girls in the development of the brain areas that are most important for verbal learning.

The third child-related factor is the level of parental education (LPE). The LPE is an indication of the intellectual climate within a family, the complexity of the language used, the books read, and the level of ambitions against which the parents position their developing child. The importance of the family environment of the child is that it has a large impact on his or her psychological -and thus cognitive and socialemotional- development. An earlier study in our institute has reported that living in a deprived neighbourhood or living in a single-parent household has a negative effect on the child's mental health (Kalff et al., 2001). As mentioned, the influence of the LPE is potentially an important factor because of the intellectual values that may determine the intellectual behaviour and social interactions within the family. Consequently, it can have a major influence on cognitive development. In a number of studies, the LPE has also been used as part of a measure for socio-economic status (SES) (Greenberg, Lengua, Coie, \& Pinderhughes, 1999). It is relevant in this respect that SES has been shown to influence verbal learning and memory performance in children (Bukatko \& Daehler, 1998; Santrock, 2001; Schneider \& Sodian, 1997; Siegler \& Wagner Alibali, 2005) and school-performance in general (Berk, 1998; Santrock, 2001). This is in line with the finding that children with a lower SES have more problems at schools and at home and that this can potentially lead to barriers for learning (Santrock, 2001). This is a second indication that the LPE -now as part of SES- is an important factor to consider in the study of verbal learning. More detailed studies than scheduled in the current thesis need to be executed to establish whether the influence of the LPE is comparable to the influence of SES. Thus, we are interested in the influence of the LPE, because we assume that this is a valuable measure for an 'age-extrinsic' factor for cognitive/psychological development, because it is based on the relationship with intellectual values and the stimulating atmosphere in the family.

The fourth child-related factor is verbal IQ (VIQ) of the child. VIQ has been studied as an estimate of general verbal ability. Overall, IQ is related to the speed and efficiency in which information is perceived and manipulated, and the effectiveness with which strategies are applied and problems are solved (Berk, 1998). This possibly explains why children with a higher VIQ have reported to experience better verbal learning and memory performance: they have better strategy use (Bjorklund \& Douglas, 1997; Schneider et al., 2002; Schneider \& Pressley, 1997). Indeed, Bjorklund \& Douglas (1997) indicated that it is not enough to note differences between high- and low-ability children in this perspective, but that the cognitive reasons behind these differences need to be considered. They state that, with respect to memory strategies, many of the factors that influence the development of strategic memory also contribute to individual differences in strategic memory among same-aged children (Bjorklund \& Douglas, 1997). 
In addition, verbal ability and the LPE appear to be related. Berk (1998) described that social background influences IQ performance given that children from parents with a low income scored on average 9 points lower than children of parents with a middle income on tests of IQ. Thus, the findings that have been reported for the LPE and SES might be overlapping with these for VIQ. The findings in the literature suggest that care should be taken with the correlation between the LPE and VIQ in order to decide whether one or both factors should be included as main variables when studying the relative influences of these factors in more detail.

The influences of all four child-related factors on verbal learning are of great importance in the understanding of learning processes. However, the relationship between these factors and the interactions with other factors such as test-related factors and learning in a natural context is what determines verbal learning performance in even more detail. These multi-dimensional relationships will be described in the following paragraphs.

\section{Test-related factors}

The test-related factors that we focused on in the current thesis were strategy use, the presentation modality, the recall demands (i.e., whether the information needs to be recalled in a specific order or not), and the content of the information that has to be remembered. First, a brief description of each of the test-related factors is given. This is followed, per test-related factor, by descriptions of its relationship with the childrelated factors in order to give an overview of what is already known about the multidimensional influences on verbal learning and memory.

\section{Strategy use}

The first test-related factor is strategy use. Strategies are mentally effortful, goal directed processes that are applied to enhance memory performance. Learning strategies, such as memory rehearsal or memory organization, are used as a means to improve the processes of consolidation or retrieval of information (Cowan \& Hulme, 1997). Learning performance is, at least partly, determined by the efficient use of strategies. Thus, this is an important factor to consider when studying verbal learning performance.

With increasing age, the use of learning strategies becomes more efficient, and the benefit in terms of better performance thereof rises (Bjorklund \& Douglas, 1997; Gaultney, Bjorklund, \& Goldstein, 1996; Schlagmuller \& Schneider, 2002; Siegler \& Booth, 2004). Older children are able to use more diverse and also more complex strategies than younger children (Bjorklund \& Douglas, 1997; Schlagmuller \& Schneider, 2002; Siegler \& Wagner Alibali, 2005). However, most studies have limitations. Therefore, we focused on three specific topics that fill the gap in our knowledge until know. The first topic is multiple strategy use, which is the use of more than one strategy on a test. The second topic is the development of strategy use with progression of the test. By studying this, we investigate the pattern of strategy use with repeated presentations of information, instead of focusing on total strategy use. The third topic is the study of whether strategy use is beneficial at all times or whether 
there has to a certain level of strategy performance or execution before it becomes beneficial. This was studied by means of separating strategy use (regardless of how well it was executed) from the level of strategy execution.

The second factor that is potentially relevant for strategy use is male/female sex. Boys have been reported to lag behind in development as compared to girls in the processing of verbal material. This is reported to be caused by a delay in the use and subsequent generalisation in the organization of verbal information (e.g., subjective clustering). This means that, according to this study, boys start to use organizational strategies later in life than girls (Cox \& Waters, 1986). A study that used semantically related words also found that girls were better in the organization of words based on the semantic categories that the words belong to (Kramer et al., 1997). Additionally, Cox and Waters (1986) reported that sex differences were also found in the organization in memory for prose and in the use of elaborative strategies during learning of words that were paired. However, more studies need to be executed on this topic to get more insight in the effects of sex on strategy use. Therefore, sex differences in strategy use will be studied in this thesis.

One of the focuses in this thesis is on the influence of the LPE on strategy use. Children with a higher SES have been reported to use more strategies than children with a lower SES. This effect was assumed to be related to stimulation for their children to use strategies by parents with a higher SES (Santrock, 2001). The relationship between the LPE and simple, passive and complex, organizational strategy use is investigated in this thesis.

Some studies report that the relationship between VIQ and verbal learning is mediated by strategy use. Children with a higher VIQ benefit more from the use of strategies (Bjorklund, Miller, Coyle, \& Slawinsky, 1997), because they are more stable in their strategy use. This is the result of the fact that they know what strategies are the best to use on a specific task, whereas children with a lower IQ have to discover this through trial-and-error (Coyle, Read, Gaultney, \& Bjorklund, 1998). High IQchildren do not always use or have to use strategies. This depends on the task. For instance, if strategy use is not needed to reach a certain performance or when strategy use would need too much processing capacity and thus would result in a lower performance, children with a high IQ do not use them. More insight is needed into the relationship between strategy use and VIQ, and this is therefore a topic that is incorporated in the research in this thesis.

Not only child-related factors can influence test-related factors. The presentation modality (a test-related factor) can possibly have an influence on the test-related factor strategy use. Also, learning in natural contexts -the example given in a later paragraph is recreational computer use- can possibly influence strategy use via an indirect route. These relationships will be described in the paragraphs below, because detailed information about the presentation modality and learning in natural contexts is needed for the description of the relationship between strategy use and these factors. 


\section{Presentation modality}

The presentation modality is the mode in which information is offered. Information, such as words, can be offered as pictures, auditory, and written words. It will be clear that it might make a difference whether words that have to be remembered are presented as words written on paper, as words that are presented by earphones or as text presented by a lecturer or schoolteacher in front of the class. Effects of the presentation modality on verbal learning are reported to be the result of differences in the amount of processing that is caused by the various modalities. Words that are presented auditory automatically are in a phonological-verbal code. Visually presented words -pictorially and written words- induce more processing than words that are presented auditory. This is because they lead to dual processing, namely in the visual and the auditory system. Paivio first described this in the dual coding theory (Beacham, Elliott, Alty, \& Al-Sharrah, 2002; Brown, Forbes, \& McConnel, 2006; Ginns, 2005; Kelley et al., 1998). He stated that processing in two modalities -generallyleads to better performance than processing in one modality, because the connections between the auditory and the visual processing stream lead to a better recall. The difference between words presented pictorially and words that are presented in written form is that pictorially presented words need to be labelled or recoded into a phonological code by the articulatory rehearsal process in the phonological loop (Baddeley, 1997). This recoding leads to deeper processing, and hence, to a better recall, according to the theory.

The involvement of the articulatory rehearsal system for the labelling or recoding leads to developmental differences. This system becomes active around the age of seven. A differential influence of the presentation modality before and after the age of seven has been reported for working memory tests (Cowan, 1998; Kemps, De Rammelaere, \& Desmet, 2000; Palmer, 2000). In working memory, information is simultaneously maintained and manipulated for a short period of time (Baques, Saiz, \& Bowers, 2004). In the current thesis, the differential influence of the presentation modality was -next to working memory- studied for other aspects of verbal learning, such as learning with repeated presentations, delayed recall, and recognition performance. Possibly, working memory is related to these aspects of verbal learning. Therefore, the same influences that have been found for working memory could be found for these aspects of verbal learning. On the other hand, the other aspects of verbal learning could be less intensively related to working memory because they also require processes such as a retrieval of words from long-term memory or retrieval of words based on cues. If this is the case, other influences of the presentation modality could be found for the verbal learning aspects other than working memory. This is studied in this thesis.

To our knowledge, no studies have been executed on sex differences in children in relation to presentation modality. As described in an earlier paragraph, girls have been reported to outperform boys in tests of verbal ability (such as verbal learning and the use of verbal strategies), whereas boys have been reported to outperform girls on tests that involve spatial abilities, although not consistently (Lowe et al., 2003; Overman, 2004). This could have implications for sex differences if a 
spatial component would be involved in the processing of the concrete pictures. It is therefore possible that boys perform better than girls on the tests that involved pictures, whereas girls could perform better on the auditory tests because of their verbal ability which have -as described before- been found to be consistently better. Sex differences in the influence of the presentation modality on verbal learning could therefore be expected and will be investigated in this thesis.

As described in the paragraph on strategy use, there might be a relationship between strategy use and the presentation modality. This has, at least to our knowledge, not been studied in children in the past. Verbal learning performance is -mostly- better with a pictorial presentation modality than with an auditory, if there is free recall (Lezak, 1995). Thus, besides the processing differences of information presented in several modalities, there could also be differences in strategy use that are related to the presentation modality. Therefore, the relationship between the presentation modality and strategy use is included as one of the foci.

A final test-related factor that is possibly related to the influences of the presentation modality is the specific way the information has to be recalled (i.e., recall demands). An example is the order in which the information has to be recalled. There is a free recall of the items from memory, in case the order of the information during the recall is not relevant. However, the order can also be predefined such as during serial recall. As an example, this is the case when the memorised information has to be recalled in the same order as it was presented. The next paragraph gives some background information on recall demands. This information is needed to describe the relationship with the presentation modality.

\section{Recall demands}

As described above, the 'recall demands' refer to the specific way the information has to be recalled. In this thesis, we focus on the relationship between the recall demands: free recall (i.e., a condition in which the order in which information is recalled is not relevant for performance) and serial recall (i.e., a condition in which the order of recall is predefined, such as a recall of the information in the same order as presented or in reversed order). In free recall, only information about the content of the words has to be remembered, whereas in serial recall, next to information about the content of the words, also information about the place of the word in the presentation list has to be remembered (Majerus, Poncelet, Elsen, \& Van der Linden, 2006; Majerus, Poncelet, Greffe, \& Van der Linden, 2006). Thus, serial recall requires that the subjects remember more information (i.e., higher processing load) and thereby leads to a lower performance on tasks that have a serial recall as compared to tasks that have a free recall. Differential correlations between serial recall tests and free recall tests with scholastic performance have been reported. Mukunda and Hall (1992) reported that free recall tests are not correlated with standardised reading and math scores, whereas the digit-span (i.e., a test with a serial recall) was. They describe that it is specifically the aspect of memory for order that is related to tests with achievement and intelligence (Mukunda \& Hall, 1992). Almost no studies have been performed that have been dedicated to the relationship between the influence of recall demands and 
child- and test-related factors. A literature search revealed few studies that included both free and serial recall. One of these studies also included differences in the content of information (explained in the paragraph on the content of information) that had to be recalled, making it impossible to separate between the effects of the recall demands and the effects of the content of information (i.e., words vs. digits) (Harvey \& Beaman, 2007). Therefore (almost) no literature on these subjects will be reported in the descriptions in the next paragraphs.

Verbal learning has been reported to increase with age, as described above. However, less is known about a possible differential developmental pattern between performance with a free and a serial recall. Additionally, the relationship between sex, the LPE, VIQ and the influence of the recall demands has, at least to our knowledge, not been studied before. Because of the differences that have been found in verbal learning performance between boys and girls and children with various LPE's and VIQ's by some studies (as described before), it is possible that this leads to differences in the effects of the recall demands. Additionally, the recall demands of the test relate to the influence of the presentation modality (Stenberg, 2006). Because test performances are sometimes compared in clinical settings and research without considering the recall demands, this is imperative to study, especially in children. Therefore, the study of the effects of respectively age, sex, the LPE, VIQ, and the presentation modality on performance on tests with free and serial recall demands is one of the aims. Age and sex differences in the relationship between recall demands and the presentation modality can be expected because of the developmental differences and differences between boys and girls in verbal learning performances, as described above. Therefore, this is also investigated.

\section{Content of information}

The content of information reflects whether the information that has to be remembered are words, letters or digits and has an influence on performance in adults (Harvey \& Beaman, 2007). In normal adults, the span is reported to be larger for digits than for words (Martin \& Ayala, 2004). Harvey and Beaman describe that performance is dependent on the amount of information that has to be remembered for the recall. Digits form a closed pool of possibilities, namely 0 to 9 , whereas words are from an unlimited pool. Thus, words require that more information needs to be remembered. Similarly, Jefferies et al. (2004) describe that digits are recalled better, because digits are drawn from a closed semantic set, whereas words can be drawn from many semantic categories. They additionally describe that digits are recalled better than words because numbers form an ordered sequence whereas words do not (Jefferies, Patterson, Jones, Bateman, \& Lambon Ralph, 2004). This is slightly related to the explanation in Lezak, Howieson, and Loring, who describe that digits are recalled better than words because digits are easier to chunk (Lezak, Howieson, \& Loring, 2004). These latter two explanations ascribe the better performance with digits to a higher opportunity to use an organizational strategy with digits than with words. 
How this is related to age and sex is less clear. This is studied in this thesis, because both tests with digits and words are sometimes used in the clinical setting and research without considering the influence of the content of information on performance. Developmental differences can be expected based on two assumptions. The first assumption is that digits become automated later in life compared to words, because words are used and understood earlier in life. The second assumption is that if digits are easier to cluster than unrelated words, then the performance difference between unrelated words and digits would become larger around the age that subjective clustering (i.e., organizational strategy use) becomes active. Sex differences can be expected based on the indications that girls are better on tests with verbal information than boys as described above.

\section{Learning in a natural context}

A possibly influential factor on verbal learning that has become very important lately is recreational computer use, also described under the term 'gaming'. Over the last decade, children spend increasingly more time gaming and this can have an influence on their psychological and cognitive development. The children who are presently below the age of 16 have grown up with the remote control and joy-sticks (Veen, 2000). Veen refers to this generation as the 'e-generation' or the 'Homo Zappiens' (see for more information http://elearning.surf.nl/e-learning/onderzoek/1833), whereas others refer to these children as the 'game-generation' (Sauer \& Fransen, 2006). Since so many children play games, presenting information that has to be learned in a game-format, is one of the most promising alternatives in education (Cagiltay, 2007; Garris, Ahlers, \& Driskell, 2002; Mumtaz, 2001; Pillay, Brownlee, \& Wilss, 1999). In addition, it is very relevant to study the influence of gaming on the development of neuropsychological functions and verbal learning, in particular in relation to the kinds of games that children play.

Gaming involves several higher-order, effortful neuropsychological functions (Pillay et al., 1999). For example, gaming can require the game-player to simultaneously: (1) pay attention to relevant topics, (2) integrate incoming auditory and visual information, (3) store incoming information and manipulate it in working memory, (4) solve cognitive problems by using strategies, and (5) enact a motor response as quickly as possible. Possibly, the differential neuropsychological functions that underlie performance on a certain game (e.g., fighting games vs. educational games) influence the child's preference for a specific game or cluster of games. It is less fun to play a game in which you cannot succeed, if you do not have the skills that are required to play. While most games recruit similar cognitive functions, there are specific cognitive functions that are needed more for one particular game than for another. For instance, sensorimotor games (such as Formula One and DOOM) require that incoming sensory information has to be judged and turned into a fine motor response performed using a keyboard or game-controller, mostly under pressure of time. These types of games, probably stimulate processing speed, more than other types of games, because of the time pressure that is involved in these games. As processing speed influences the efficiency at which information is 
processed in working memory (Fry \& Hale, 2000), the faster information is processed or words are articulated, the better the working memory performance.

Another category of recreational computer use exists as information-exchange activities (i.e., educational games, 'chatting', surfing the Internet, or joining Internet forums). These are characterized by a structured approach that guides the child during playing. The core component of these games is communication. Active problem solving by the gamer (Jenson \& De Castell, 2002), strategy search and information processing speed are of minor importance. The need to use language to communicate may stimulate the availability of words in memory. If more words are available in memory (i.e., larger vocabulary), more words may be retrieved from semantic memory, which enhances memory (Majerus, Poncelet, Greffe et al., 2006).

A third category of games exists as strategic-planning games (i.e., strategyadventure games, such as Lord of the Rings, and simulation games, such as The Sims). These games draw heavily on specific higher cognitive functions, namely, planning, making priorities, cognitive shifting, execution of strategies, and problem solving, but also make demands on fine motor functions. These games could stimulate strategy execution and metamemory, factors known to improve memory (DeMarie \& Ferron, 2003). Because the games are played in real-time, there is less time pressure than with games in the sensorimotor category.

Factors that have an influence on recreational computer use are age, sex, and SES (Comber, Colley, Hargreaves, \& Dorn, 1997; Jenson \& De Castell, 2005; Mumtaz, 2001; Wright et al., 2001). With increasing age, the amount of time used with the computer increases and there are indications that there is a strong relationship with the sex of the child. Recreational computer use increases among boys and girls up till age 12 (Wright et al., 2001). Among girls gaming has been described to decrease when they become older (Comber et al., 1997; Jenson \& De Castell, 2005; Mumtaz, 2001). The exact age of the onset of this decrease is not clear and depends on the included age-range in the study. In the early nineties, Subrahmanyam and Greenfield (1994) noted that boys made more use of computers than girls. More recently, it appeared that games that recruit sensorimotor functions are played more often with increasing age, and that this is most often seen in boys (Scantlin, 2000). Girls are reported to prefer role-playing and collaboration in games, but they are often restricted by their parents, who stimulate them to play educational games (Jenson \& De Castell, 2002). However, most of the reported studies can be regarded as 'outdated' because of the rapidly changing availability of computers and include limitations such as small sample sizes, the inclusion of narrow age-ranges, or the inclusion of only children of one sex. Therefore, the influences of age and sex on recreational computer use are investigated further in this thesis.

The LPE (as part of a composite SES measure in some studies) has been reported to influence game-behaviour of children. Children with a lower SES make less use of computers as compared to children with a higher SES (Li \& Atkins, 2004; Wright et al., 2001). However, these studies were executed in 1997 and 2001-2002 respectively, and as described above, economic changes have since occurred that have possibly led, amongst others, to an increase in the availability of computers. 
Additionally, also based on these older data, children with a lower SES played more games that included violence (Wright et al., 2001). It is possible that these latter findings were the result of stimulation by parents with a higher SES to play games without violence, such as educational games (Attewel \& Battle, 1999; Mumtaz, 2001; Wright et al., 2001). In contrast, Nikken and Jansz $(2006,2007)$ reported that parents who were highly educated paid less attention to suitability ratings of games and were less restrictive in gaming than lower educated parents. Also, highly educated parents have been reported to be less interested in content descriptions of games because they expect that their children will not be influenced by playing the games. This can be explained by the finding that parents with a lower education play more games themselves. Because of this, they are more aware of the (negative) contents of the games, and are therefore, more restrictive of their children when it comes to playing games with violent content (Nikken, Jansz, \& Schouwstra, 2007). The influence of the LPE on recreational computer use is included as a factor in this thesis to study whether the relationship between the LPE and recreational computer use has changed over time.

Gaming stimulates neuropsychological functions such as visual short-term memory, reaction time, spatial abilities, and strategies for the allocation of attention (Green \& Bavelier, 2006; Greenfield, DeWinstanley, Kilpatrick, \& Kaye, 1994; Subrahmanyam \& Greenfield, 1994). It is known that working memory can be ameliorated by explicit training (Bjorklund \& Douglas, 1997; Bjorklund et al., 1997; Schneider \& Pressley, 1997; Siegler \& Wagner Alibali, 2005). This has not been studied before for incidental training, such as possibly during gaming. Therefore, the relationship between recreational computer use and verbal learning is studied in this thesis. This is related to a possible stimulation of, amongst others, strategy use, from which we know that it enhances verbal learning.

An important remark that has to be kept in mind is that we assume that playing certain kinds of games is related to the sex-dependent neuropsychological functions that are needed to play the game and which have developed through the period of childhood and youth. In addition, we assume that playing the game stimulates the neuropsychological functions that are needed to play. Thus, perhaps children choose to play games they succeed in, and then become even better in the neuropsychological skill that is needed for playing that game. This could lead to larger differences in these functions between children that play different games. In this thesis, we are not able to evaluate whether children choose the games that need neuropsychological functions that they are better in, or whether their neuropsychological functions increase because of playing the games. 


\section{Aim}

The aim of this thesis is to study the multi-dimensional influences of child-related and test-related factors and learning in a natural context, on verbal learning. The childrelated factors we focused on are: age, sex, the level of parental education (LPE), and verbal ability (VIQ). The test-related factors are: strategy use, the presentation modality, the recall demands, and the content of information that has to be recalled. Learning in a natural context is studied by means of recreational computer use. However, not only do we study the individual influences of these factors on verbal learning, but the interactions between these factors as well. The studied relationships and the chapters in which these are studied can be seen in Table 1.

\section{Approach of the studies}

To evaluate the effects of the factors described above, two large studies were designed and executed, each involving a different population of children. The first was a cross-sectional Cognitive Development Study that included 107 healthy Primary school-aged children (CDSP). These children attended kindergarten to grade six (age 6 to 12 years) of a regular primary school in Maastricht, The Netherlands. The parents of the children filled out a questionnaire and the children performed a neuropsychological test battery (used for the study described in Chapter 3 ).

The second population was a large cross-sectional and longitudinal cognitive development study in school-aged children (abbreviation in Dutch: COOS which stands for 'Cognitief Ontwikkelings Onderzoek bij Schoolgaande kinderen', i.e., cognitive development study in school-aged children) and included healthy children aged 5 to 16 years. The first stage included questionnaire data of 910 children (used for the study described in Chapter 6) and neuropsychological test-data of 431 children (used for the studies described in Chapters 2, 4, and 7). These were children in kindergarten and grades 2, 4, 6, 7, and 8 from 29 regular primary and secondary schools in Maastricht and surrounding region. During the second stage, which was one year after original inclusion in the study, 313 children from the first data collection round participated again (used for the study described in Chapter 5). From these children, we received additional questionnaire data and they performed a second neuropsychological assessment. 
Table 1. Outline of the studied influences and interactions and the chapters of the studies

\begin{tabular}{|c|c|c|}
\hline Factor & Relationship & Chapter \\
\hline \multicolumn{3}{|c|}{ Verbal learning } \\
\hline \multicolumn{3}{|c|}{ Child-related factors } \\
\hline & Age & $2,4,5$ \\
\hline & Sex & $2,4,5$ \\
\hline & LPE & $2,4,5$ \\
\hline & $\overline{V I Q}$ & $2,4,5$ \\
\hline \multicolumn{3}{|c|}{ Test-related factors } \\
\hline & Strategy use & 2,3 \\
\hline & Presentation modality & $2,4,5$ \\
\hline & Content of information & 5 \\
\hline \multicolumn{3}{|c|}{ Natural context } \\
\hline & Recreational computer use & 7 \\
\hline \multicolumn{3}{|c|}{ Strategy use } \\
\hline \multicolumn{3}{|c|}{ Child-related factors } \\
\hline & Age & 2,3 \\
\hline & Sex & 2 \\
\hline & LPE & 2 \\
\hline & VIQ & 2 \\
\hline \multicolumn{3}{|c|}{ Test-related factors } \\
\hline & Presentation modality & 2 \\
\hline \multicolumn{3}{|c|}{ Natural context } \\
\hline & Recreational computer use & 7 \\
\hline \multicolumn{3}{|c|}{ Presentation modality } \\
\hline \multicolumn{3}{|c|}{ Child-related factors } \\
\hline & Age & 4,5 \\
\hline & Sex & 4,5 \\
\hline \multicolumn{3}{|c|}{ Test-related factors } \\
\hline & Strategy use & 2 \\
\hline & Recall demands & 5 \\
\hline \multicolumn{3}{|c|}{ Recall demands } \\
\hline \multicolumn{3}{|c|}{ Child-related factors } \\
\hline & Age & 5 \\
\hline & Sex & 5 \\
\hline & VIQ & 5 \\
\hline & LPE & 5 \\
\hline \multicolumn{3}{|c|}{ Test-related factors } \\
\hline & Presentation modality & 5 \\
\hline \multicolumn{3}{|c|}{ Content of information } \\
\hline \multicolumn{3}{|c|}{ Child-related factors } \\
\hline & Age & 5 \\
\hline & Sex & 5 \\
\hline \multicolumn{3}{|c|}{ Recreational computer use } \\
\hline & Age & 6 \\
\hline & Sex & 6 \\
\hline & LPE & 6 \\
\hline \multicolumn{3}{|c|}{ Test-related factors } \\
\hline & Strategy use & 7 \\
\hline
\end{tabular}




\section{Outline}

The remainder of this thesis consists of seven chapters. Chapters 2 and 3 describe the development of efficient strategy use in relation to verbal learning. Chapters 4 and 5 describe the relationship of the presentation modality, the recall demands and the content of information with verbal learning and memory performance. Chapters 6 and 7 describe the influence of age, sex, and the LPE on recreational computer use (i.e., gaming). In addition, these chapters describe a possible incidental stimulation of neuropsychological functions that potentially influence verbal learning by playing specific kinds of games. Chapter 8 gives some concluding remarks in which the findings that have been described in the preceding chapters are evaluated against the major aims given in the present introductory chapter.

Chapter 2: Verbal learning performance and the relation with efficient strategy use in children aged 5-15: the influence of age, sex, the level of parental education, and the presentation modality.

This chapter describes the development of efficient multiple strategy use (i.e., the use of more than one strategy) and the influence of sex, the LPE, and the presentation modality on efficient strategy use. In total, 431 children aged 5 to 15 years performed a verbal learning test (VLT). The development of efficient strategy use was studied by the calculation of the strategy execution level of two strategies during the recall of the VLT. These were serial clustering (a relatively simple, passive strategy) and subjective clustering (a more complex, organizational strategy). We corrected for VIQ by use of the Vocabulary subtest of the Wisc-Rn.

Chapter 3: Differential development of learning strategies on a Pictorial Verbal Learning test (PVLT) in primary school children.

This chapter describes the development of efficient multiple strategy use during a multi-trial pictorial verbal learning test (PVLT). This study was a more detailed, in focus study, that can be coupled with the study described in Chapter 2. In total, 79 children, aged 6 to 12 years, performed a PVLT. The focus was on the pattern of strategy use with repeated presentations of the information that has to be remembered. All children included in the study had a relatively high LPE in order to facilitate the assessment of strategy use, because of the reported stimulation of strategy use by parents with a higher SES (Santrock, 2001). The same strategies were studied as in the study that was described in Chapter 2. 
Chapter 4: Auditory and Pictorial Verbal Learning Compared: A Cross-sectional Study of Children aged $5-15$.

This chapter describes the differential development of the influence of the presentation modality (pictorial and auditory) on the verbal learning aspects: working memory, learning with repeated presentations, delayed recall, and long-term recognition memory and the influence of sex. In total, 431 children (aged 5 to 15 years) were included in the study. The children executed a verbal learning test (VLT), which is a test with a free recall. Half of the children performed a pictorial VLT (PVLT) and the other half of the children performed an auditory VLT (AVLT). VIQ and the LPE were included as factors in the prediction of the aspects of verbal learning. We corrected for VIQ by use of the Vocabulary subtest of the Wisc-Rn.

Chapter 5: The influence of the presentation modality, the recall demands, and the content of information on verbal learning performance in children aged 6-16

This chapter describes the differential influence of the presentation modality (pictorial, auditory and written words) on tests with different recall demands: free recall vs. serial recall. Additionally, the influence of content of information (words vs. digits) on performance was studied. These aims were studied in relation to age and sex. In total, 313 children (aged 6 to 16 years) were included. They performed a verbal learning test (VLT), a working memory test with words and a serial recall (WS), and the Digit Span subtest of the WISC-Rn (DS). Half of the children in Grade 1 performed the VLT and WS in a pictorial presentation modality and the other half an auditory presentation modality. None of the children in this age group performed these tests in a written presentation modality (i.e. reading the words) because reading is not automated at this age. A third of the children of Grades 3 and higher performed the tests in a pictorial presentation modality, the second third performed the tests in auditory presentation modality and the other third of the children performed the test in a written presentation modality. VIQ and the LPE were included as factors in the prediction of performance on the free and serial recall tests. VIQ was studied by use of the Vocabulary subtest of the Wisc-Rn.

Chapter 6: The relationship between recreational computer use and age, sex, and the level of parental education in children aged 5-16.

This chapter describes the relationship between age, sex, the LPE, and recreational computer use (i.e. what games children play). The games were divided into three categories: sensorimotor games (including fighting/sports/race and shooting games), information-exchange activities (including educational games, chatting, and surfing the Internet), and strategic-planning games (including adventure and simulation games). In total, the caregivers of 910 children (aged 5 to 16 years) filled out the questions that inquired recreational computer use and what games the children played. The category of recreational computer use of the children was related to the neuropsychological functions the games require, the parental influence, and the level of parental education. 
Chapter 7: The relationship between gaming and verbal learning: A large-scale crosssectional study in 200 children aged $5-15$

This chapter is coupled with the study described in Chapter 6 and describes whether playing games in spare time was related to better verbal learning. In total, 200 children (aged 5 to 15 years), who played one category of games only, were included in the current study. The possible influence of gaming was studied by a comparison of the performance of these children on a verbal learning test (VLT) and on tests that measured the verbal learning-influencing factors: strategy execution, metamemory, processing speed, and retrieval of words from semantic memory.

\section{Chapter 8: Concluding Remarks}

This chapter discusses the major findings of the studies described in the chapters in relation to the central aim of the dissertation. Overall conclusions regarding the multidimensional influences of the factors and the possible implications for a transdisciplinary approach for 'educational neuropsychology' in future research will be given. 


\section{References}

Alvarez, J. A., \& Emory, E. (2006). Executive function and the frontal lobes: A meta-analytic review. Neuropsychology Review, 16, 17-42.

Anderson, P. (2002). Assessment and development of executive function (EF) during childhood. Child Neuropsychology, 8, 71-82.

Ansari, D., \& Coch, D. (2006). Bridges over troubled waters: Education and cognitive neuroscience. Trends in Cognitive Sciences, 10, 146-151.

Attewel, P., \& Battle, J. (1999). Home computers and school performance. The Information Society, 15(1), $1-10$.

Baddeley, A. D. (1997). Human Memory: Theory and Practice, Revised Edition. Hove: Psychology Press.

Baques, J., Saiz, D., \& Bowers, J. S. (2004). Effects of working memory load on long-term word priming. Memory, 12, 301-313.

Beacham, N. A., Elliott, A. C., Alty, J. L., \& Al-Sharrah, A. (2002). Media combinations and learning styles: A dual coding approach. Paper presented at the ED-MEDIA 2002 World Conference on Educational Multimedia, Hypermedia \& Telecommunications, Denver, Colorado.

Berk, L. E. (1998). Development Through the Lifespan. Needham Heights, MA: Allyn \& Bacon.

Bishop, J., Knights, R. M., \& Stoddart, C. (1990). Rey Auditory - Verbal learning Test: Performance of English and French children aged 5 to 16. The Clinical Neuropsychologist, 4, 133-140.

Bjorklund, D. F., \& Douglas, R. N. (1997). The development of memory strategies. In N. Cowan \& C. Hulme (Eds.), The Development of Memory in Childhood (pp. 201-246). Hove, East Sussex, UK: Psychology Press.

Bjorklund, D. F., Miller, P. H., Coyle, T., R., \& Slawinsky, J. L. (1997). Instructing children to use memory strategies: Evidence of utilization deficiencies in memory training studies. Developmental Review, $17,411-441$.

Blakemore, S. J., \& Frith, U. (2005). The Learning Brain: Lessons for Education. Oxford: USA: Blackwell Publishing.

Boomsma, D., Busjahn, A., \& Peltonen, L. (2002). Classical twin studies and beyond. Nature Reviews Genetics, 3, 972-882.

Brown, L. A., Forbes, D., \& McConnel, J. (2006). Limiting the use of verbal coding in the visual patterns test. The Quarterly Journal of Experimental Psychology, 59, 1169-1176.

Bukatko, D., \& Daehler, M. W. (1998). Child Development: a Thematic Approach (3rd ed.). Boston: Houghton Mifflin Company.

Cagiltay, N. E. (2007). Teaching software engineering by means of computer-game development: Challenges and opportunities. British Journal of Educational Technology, 38, 405-415.

Comber, C., Colley, A., Hargreaves, D. J., \& Dorn, L. (1997). The effects of age, gender and computer experience upon computer attitudes. Educational Research, 39, 123-133.

Cowan, N. (1998). Visual and auditory working memory capacity. Trends in Cognitive Sciences, 2, 77-78.

Cowan, N., \& Hulme, C. (1997). The Development of Memory in Childhood. Hove, East Sussex, UK: Psychology Press.

Cox, D., \& Waters, H. S. (1986). Sex differences in the use of organisation strategies: A developmental analysis. Journal of Experimental Child Psychology, 41, 18-37.

Coyle, T., R., Read, L., E., Gaultney, J. F., \& Bjorklund, D., F. (1998). Giftedness and variability in strategic processing on a multitrial memory task: Evidence for stability in gifted cognition. Learning and Individual Differences, 10, 274-290.

De Bellis, M. D., Keshavan, M. S., Beers, S. R., Hall, J., Frustaci, K., Masalehdan, A., et al. (2001). Sex differences in brain maturation during childhood and adolescence. Cerebral Cortex, 11, 552-557.

DeMarie, D., \& Ferron, J. (2003). Capacity, strategies, and metamemory: Test of a three-factor model of memory development. Journal of Experimental Child Psychology, 84, 167-193.

Forrester, G., \& Geffen, G. (1991). Performance measures of 7- to 15-year-old children on the Auditory Verbal Learning Test. The Clinical Neuropsychologist, 5, 345-359.

Fry, A. F., \& Hale, S. (2000). Relationships among processing speed, working memory and fluid intelligence in children. Biological Psychology, 54, 1-34.

Garris, R., Ahlers, R., \& Driskell, J. E. (2002). Games, motivation, and learning: A research and practice model. Simulation \& Gaming, 33, 441-467.

Gaultney, J. F., Bjorklund, D., F., \& Goldstein, D. (1996). To be young, gifted and strategic: Advantages for memory performance. Journal of Experimental Child Psychology, 61, 33-66. 
Giedd, J. N., Blumenthal, J., Jeffries, N. O., Castellanos, F. X., Liu, H., Zijdenbos, A., et al. (1999). Brain development during childhood and adolescence: A longitudinal MRI study. Nature Neuroscience, 2, 861-863.

Ginns, P. (2005). Meta-analysis of the modality effect. Learning and Instruction, 15, 313-331.

Gogtay, N., Giedd, J. N., Lusk, L., Hayashi, K. M., Greenstein, D., Vaituzis, A. C., et al. (2004). Dynamic mapping of human cortical development during childhood through early childhood. Proceedings of the National Academy of the Sciences, 101, 8174-8179.

Goswami, U. (2004). Neuroscience and education. British Journal of Educational Psychology, 74, 1-14.

Goswami, U. (2006). Neuroscience and education: From research to practice. Nature Reviews Neuroscience, $7,406-413$.

Green, C. S., \& Bavelier, D. (2006). The cognitive neuroscience of video games. In P. Messaris \& L. Humphreys (Eds.), Digital media: Transformations in Human Communication. New York: Peter Lang.

Greenberg, M. T., Lengua, L. J., Coie, J. D., \& Pinderhughes, E. E. (1999). Predicting developmental outcomes at school entry using a multiple-risk model: Four American communities. The Conduct Problems Prevention Research Group; Developmental Psychology, 35, 403-417.

Greenfield, P. M., DeWinstanley, P., Kilpatrick, H., \& Kaye, D. (1994). Action video games and informal education: Effects on strategies for dividing visual attention. Journal of Applied Developmental Psychology, 15, 105-123.

Harvey, A., \& Beaman, C. P. (2007). Input and output modality effects in immediate serial recall. Memory, 7, 693-700.

Hurks, P. P. M. (2003). The influence of environment, behavior, and attention deficits on cognitive development in school-aged children. Maastricht University, Maastricht, The Netherlands.

Jefferies, E., Patterson, K., Jones, R. W., Bateman, D., \& Lambon Ralph, M. A. (2004). A category-specific advantage for numbers in verbal short-term memory: Evidence from semantic dementia. Neuropsychologica, 42, 639-660.

Jenson, J., \& De Castell, S. (2002). Serious Play: Challenges of educational game design. Paper presented at the AERA Annual Meeting, New Orleans, Louisiana.

Jenson, J., \& De Castell, S. (2005). Her own boss: Gender and the pursuit of incompetent play. Paper presented at the DiGRA 2005 Conference: Changing Views - Worlds in Play, Vancouver: Vancouver University.

Kalff, A. C., Kroes, M., Vles, J. S. H., Bosma, H., Feron, F. J. M., Hendriksen, J. G. M., et al. (2001). Factors affecting the relation between parental education as well as occupation and problem behavior in Dutch 5- to 6- year- old children. Social Psychiatry and Psychiatric Epidemiology, 36, 324-331.

Kelley, W. M., Miezin, F. M., McDermott, K. B., Buckner, R. L., Raichle, M. E., Cohen, N. J., et al. (1998). Hemispheric specialisation in human dorsal frontal cortex and medial temporal lobe for verbal and nonverbal memory encoding. Neuron, 20, 927-936.

Kemps, E., De Rammelaere, S., \& Desmet, T. (2000). The development of working memory: Exploring the complementarity of two models. Journal of Experimental Child Psychology, 77, 89-109.

Klingberg, T. (2006). Development of a superior frontal-intraparietal network for visuo-spatial working memory. Neuropsychologica, 44, 2171-2177.

Korkman, M., Kemp, S. L., \& Kirk, U. (2001). Effects of age on neurocognitive measures of children ages 5 to 12: A cross-sectional study on 800 children from the United States. Developmental Neuropsychology, 20, 331-354.

Kramer, J. H., Delis, D. C., Kaplan, E., O'Donnel, L., \& Prifitera, A. (1997). Developmental sex differences in verbal learning. Neuropsychology, 11, 577-584.

Lezak, M. D. (1995). Neuropsychological Assessment (3rd ed.). New York: Oxford University Press.

Lezak, M. D., Howieson, D. B., \& Loring, D. W. (2004). Neuropsychological Assessment (4th ed.). New York: Oxford University Press.

Li, X., \& Atkins, M. S. (2004). Early childhood computer experience and cognitive and motor development. Pediatrics, 113, 1715-1722.

Lowe, P. A., Mayfield, J. W., \& Reynolds, C. R. (2003). Gender differences in memory test performance among children and adolescents. Archives of Clinical Neuropsychology, 18, 865-878.

Majerus, S., Poncelet, M., Elsen, B., \& Van der Linden, M. (2006). Exploring the relationship between new word learning and short-term memory for serial order recall, item recall and item recognition. European Journal of Cognitive Psychology, 18, 848-873. 
Majerus, S., Poncelet, M., Greffe, C., \& Van der Linden, M. (2006). Relations between vocabulary development and verbal short-term memory: The relative importance of short-term memory for serial order and item information. Journal of Experimental Child Psychology, 93, 95-119.

Martin, N., \& Ayala, J. (2004). Measurements of auditory-verbal STM span in aphasia: Effects of item, task, and lexical impairment. Brain and Language, 89, 464-483.

Mukunda, K. V., \& Hall, V. C. (1992). Does performance on memory for order correlate with performance on standardized measures of ability? A meta analyses. Intelligence, 16, 81-97.

Mumtaz, S. (2001). Children's enjoyment and perception of computer use in the home and the school. Computers \& Education, 36, 347-362.

Nikken, P., Jansz, J., \& Schouwstra, S. (2007). Parents' interest in videogame ratings and content descriptors in relation to game mediation. European Journal of Communication, 22, 315-336.

OECD. (2002). Understanding the Brain: Towards a New Learning Science. Paris: OECD

OECD. (2007). Understanding the Brain: The Birth of a Learning Science. Paris: OECD.

Ormrod, J. E. (1999). Human Learning (3rd ed.). Upper Saddle River, NJ: Prentice-Hall Inc.

Overman, W. H. (2004). Sex differences in early childhood, adolescence, and adulthood on cognitive tasks that rely on orbital prefrontal cortex. Brain and Cognition, 55, 134-147.

Palmer, S. (2000). Working memory: A developmental study of phonological recoding. Memory, 8, $179-193$.

Paus, T. (2005). Mapping brain maturation and cognitive development during adolescence. Trends in Cognitive Sciences, 9, 60-68.

Pillay, H., Brownlee, J., \& Wilss, L. (1999). Cognition and recreational computer games: Implications for educational technology. Journal of Research on Computing in Education, 32, 203-216.

Posner, M. I., \& Rothbart, M. K. (2005). Influencing brain networks: Implications for education. Trends in Cognitive Sciences, 9, 99-103.

Santrock, J. W. (2001). Educational Psychology. New York: McGraw-Hill.

Sauer, I., \& Fransen, J. (2006). Deelonderzoeken naar de virtuele wereld: Het leren van games [Partial studies to the virtual world: Learning from games]. In G. Wijngaards, J. Fransen \& P. Swager (Eds.), Jongeren en hun Digitale Wereld (pp. 24-39). Assen: Van Gorcum.

Scantlin, R. M. (2000). Interactive media: An analysis of children's computer and video game use. Dissertation Abstracts International: Section B: The Sciences and Engineering, 60, 6400.

Schlagmuller, M., \& Schneider, W. (2002). The development of organizational strategies in children: Evidence from a microgenetic longitudinal study. Journal of Experimental Child Psychology, 81, 298-319.

Schneider, W., Knopf, M., \& Stefanek, J. (2002). The development of verbal memory in childhood and adolescence: Findings from the Munich Longitudinal Study. Journal of Educational Psychology, $94,751-761$.

Schneider, W., \& Pressley, M. (1997). Memory Development Between Two and Twenty (2nd ed.). Mahwah, NJ: Lawrence Erlbaum Associates.

Schneider, W., \& Sodian, B. (1997). Memory strategy development: Lessons from longitudinal research. Developmental Review, 17, 442-461.

Siegler, R. S., \& Booth, J. L. (2004). Development of numerical estimation in young children. Child Development, $75,428-444$.

Siegler, R. S., \& Wagner Alibali, M. (2005). Children's Thinking (4th ed.). Upper Saddle River, NJ: Pearson Prentice Hall.

Stenberg, G. (2006). Conceptual and perceptual factors in the picture superiority effect. European Journal of Cognitive Psychology, 18, 813-847.

Subrahmanyam, K., \& Greenfield, P. M. (1994). Effect of video game practice on spatial skills in girls and boys. Journal of Applied Developmental Psychology, 15, 13-32.

Vakil, E., Blachstein, H., \& Sheinman, M. (1998). Rey AVLT: Developmental norms for children and the sensitivity of different memory measures to age. Child Neuropsychology, 4, 161-177.

Van den Burg, W., \& Kingma, A. (1999). Performance of 225 Dutch school children on Rey's Auditory Verbal Learning Test (AVLT): Parallel test-retest reliabilities with an interval of 3 months and normative data. Archives of Clinical Neuropsychology, 14, 545-559.

Veen, W. (2000). Flexibel onderwijs voor nieuwe generaties studerenden [Flexible education for new generations of students]. TU Delft.

Wright, J. C., Huston, A. C., Vandewater, E., A., Bickham, D. S., Scantlin, R. M., Kotler, J. A., et al. (2001). American children's use of electronic media in 1997. Journal of Applied Developmental Psychology, 22, 31-47. 


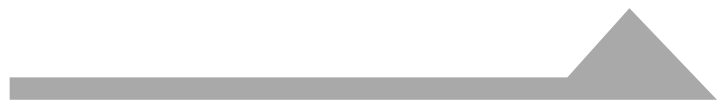




\title{
Chapter 2
}

\section{Verbal learning performance and the relation with efficient strategy use in children aged 5-15: the influence of age, sex, the level of parental education, and the presentation modality}

\begin{abstract}
The influence of age, sex, the level of parental education (LPE), and the presentation modality on efficient strategy use and the relation with verbal learning was studied by administering a verbal learning test (VLT) to normally developing children aged 5-15 ( $n=408$ ). Serial clustering (a relatively simple, passive strategy) and subjective clustering (a more complex, organizational strategy) during the VLT were assessed. Our findings showed that: (a) for both strategies, efficient strategy use was predicted by age, quadratic age, and/or VIQ, but not by sex, the LPE, or the presentation modality, and (b) efficient use of serial and subjective clustering strategies predicted VLT performance differentially with age. The findings indicate that VLT performance can be improved by the stimulation of efficient use of the serial and subjective clustering strategies and those children with a low VIQ are most likely to benefit from this stimulation.
\end{abstract}




\section{Introduction}

Verbal learning performance can be improved if a person uses memory strategies (Bjorklund \& Douglas, 1997; Bukatko \& Daehler, 1998; DeMarie \& Ferron, 2003; Ornstein, 1999; Schneider, Knopf, \& Stefanek, 2002; Siegler \& Booth, 2004), such as rehearsal and organization of the to-be-remembered information into groups. Children with learning problems often have a poor memory performance (Bjorklund \& Douglas, 1997), probably because they make less efficient use of strategies (Gaultney, Bjorklund, \& Goldstein, 1996). Training children to use strategies improves verbal memory in normal children (Bjorklund \& Douglas, 1997) and may help children with learning problems that are caused by ineffective strategy use. To be able to detect these children, we studied the normal development of efficient strategy use and the influence of multiple strategy use, sex, the level of parental education (LPE), and the presentation modality.

Strategy use does not always lead to a better performance. For example, there is often no benefit when a strategy is used for the first time, because it requires too much effort, which leads to inefficient strategy use (Bjorklund \& Douglas, 1997; Gaultney, 1998; Gaultney et al., 1996; Ornstein, 1999; Schlagmuller \& Schneider, 2002; Siegler \& Booth, 2004). As strategy use increases with age and becomes less effortful (Bjorklund \& Douglas, 1997; Gaultney et al., 1996; Schlagmuller \& Schneider, 2002; Siegler \& Booth, 2004), it could be expected that the benefit of strategy use increases. We therefore separately investigated the benefit of strategy use (regardless of how well the strategy was executed) and the benefit of the level of strategy execution (how well the strategy was executed). Strategy use was defined as a dichotomous variable: no use (execution level of the strategy below chance level) versus use (execution level above chance level). Level of strategy execution was defined as a continuous variable with the outcome of the strategy calculations as range. The term 'efficient strategy use' refers to a combination of a correct use when it is beneficial (i.e. in the appropriate situation) and a correct execution (i.e., high level of strategy execution). We expected that the predictive value of efficient strategy use on verbal learning performance would increase with age.

Efficient strategy use is influenced by several factors. During the preschool years, children use very simple, rudimentary learning strategies, such as looking at the location where an object is hidden by an experimenter. As children become older, they use more diverse and more complex strategies, such as verbal rehearsal, which is first used at about 5 years, or organizational strategies (i.e. grouping of information for recall), which are first used at about 10 years of age (Bjorklund \& Douglas, 1997; Bukatko \& Daehler, 1998; Schlagmuller \& Schneider, 2002; Schneider \& Sodian, 1997; Siegler \& Booth, 2004). Older children are not only able to use more difficult strategies, but often use more than one strategy during the execution of a task or test (Bjorklund \& Douglas, 1997; Kuhn, 2000; Ornstein, 1999; Schlagmuller \& Schneider, 2002; Siegler \& Wagner Alibali, 2005). We therefore studied the development with age of the use of two strategies, namely serial clustering and subjective clustering during the execution of one task. In serial clustering, words are recalled in the same order as 
they were presented, thus the words were not actively organized. In subjective clustering, the person actively connects two words in a for him/her meaningful way, and these words are recalled one after another. This clustering enhances recall, because if one word of the group is recalled, the other word(s) is more readily recalled as well.

Another age-related factor that influences efficient strategy use is multiple strategy use. Multiple strategy use influences whether a strategy is used and how well it is executed as a result of competition (Ornstein, 1999; Siegler \& Wagner Alibali, 2005). We expected that, with increasing age, the efficient use of serial clustering would first increase (from age 6 onward), and then decline as subjects started to use subjective clustering (starting around the age of 10). Additionally, we expected that the efficient use of subjective clustering would increase from initial use on. Since subjective clustering measures the coupling of words based on any kind of meaning, this implies that we also investigated the use of complex couplings such as these based on elaboration and/or imagery. In elaboration, the to-be-remembered information is embedded in larger units such as in a story or picture (imagery). This is a complex strategy, and although not explicitly tested, we expected to find an increase in efficient subjective clustering use after the age of 15.

Efficient strategy use can also be influenced by the subject's sex. Boys lag behind girls in the processing of verbal material and in the subsequent generalisation of organization of verbal information (e.g., subjective clustering) (Cox \& Waters, 1986; Kramer, Delis, Kaplan, O'Donnel, \& Prifitera, 1997). However, this has not been studied with the distinction between strategy use and level of strategy execution. We expected that the developmental trajectory of efficient strategy use would occur earlier in girls than in boys.

The level of parental education (LPE) also possibly influences efficient strategy use. The LPE is an approximation ('proxy') of the intellectual climate within a family, the complexity of the language used, the books read, and the level of ambitions against which the parents position their developing child. In a number of studies, it has also been used as a proxy for socio-economic status (SES) (Greenberg, Lengua, Coie, \& Pinderhughes, 1999). A lower SES is associated with less stimulation of strategy use at home (Bukatko \& Daehler, 1998; Santrock, 2001). To the best of our knowledge, the influence of the LPE on the development of efficient -multiple- strategy use has not been studied before. We expected that the developmental trajectory of efficient strategy use would occur earlier in the children of parents with a high LPE than in the children of parents with a low LPE.

A last factor that could influence efficient strategy use is how the information that has to be remembered is presented. Verbal learning performance is better when information is presented as pictures as compared to words (Lezak, 1995). To our knowledge, no studies have investigated the influence of the presentation modality on serial and subjective clustering in children. We expected that efficient use of both strategies would be better with a pictorial presentation than with an auditory presentation. 
This is the first study that aimed to determine the influence of sex, the LPE, and the presentation modality on the development of efficient use of serial and subjective clustering during a verbal learning test (VLT). We first studied the influence of age, sex, the LPE and the presentation modality on strategy use and strategy execution level (i.e. efficient strategy use), and then we studied whether efficient strategy use enhanced VLT performance for both strategies. We corrected for VIQ, which influences both verbal learning and strategy use (Berk, 1998).

\section{Method}

\section{Procedure}

The current study was part of a large cross-sectional and longitudinal Cognitive Development Study of School-aged children (abbreviation in Dutch: COOS which stands for 'Cognitief Ontwikkelings Onderzoek bij Schoolgaande kinderen', i.e., cognitive development study in school-aged children), performed by the School for Mental Health and Neuroscience of Maastricht University (Wassenberg et al., in press). Only cross-sectional data were used in the current study. Participants were recruited from 29 regular primary and secondary schools in the city of Maastricht and surroundings (The Netherlands). The parents/caregivers (referred to as caregivers hereafter) of the children in kindergarten, grades 2, 4, 6 (primary schools), and 7 and 8 (secondary schools; ranging from lower secondary professional education to preuniversity education) received an information package via the school describing the purpose of the study, a request to participate, a questionnaire, a form to give consent for the child to participate, and a stamped-addressed envelope.

All children completed a battery of neuropsychological tests including tests measuring general verbal ability (including VIQ), memory, language comprehension, and time estimation. The children were tested individually in a room at their schools by well-trained psychological assistants (i.e., undergraduate psychology students). Testing took approximately 1.5 hours; all tests were administered in the same order for each child. The Ethics Committee of the Faculty of Psychology of Maastricht University approved the study protocol.

\section{Participants}

Of the 1086 caregivers who replied, $892(82 \%)$ gave consent for their child to participate. Children who met the following criteria were eligible for participation: the child (1) had not repeated and/or skipped a grade (indication for 'normal' development), (2) had the Dutch nationality (in view of fluency in Dutch), and (3) did not use medication that is known to influence cognitive performance (for instance, asthma medications). We attempted to select children by school-grade and sex per grade and to include children from a range of socioeconomic backgrounds. In total, 431 children (215 boys, 216 girls) aged 5.67 to 15.08 years participated in the Cognitive Development Study of School-aged children. 


\section{Instruments}

\section{$V L T$}

A verbal learning test (VLT) was administered to measure verbal learning, strategy use and strategy execution level. This test is often used in clinical settings and memory research, and is one of the most sensitive verbal memory tests. Its test-retest reliability is reported to be high (Lezak, 1995; Van der Elst, Van Boxtel, Van Breukelen, \& Jolles, 2005). The test was administered as described previously (Brand \& Jolles, 1985; Van der Elst et al., 2005). The words used in the test have been checked for their frequency of use (Linschoten, 1963) and imageability (Van LoonVervoorn, 1989). Half of the children performed a pictorial verbal learning test (PVLT) in which the words were presented as pictures, and the other children performed an auditory verbal learning test (AVLT), in which the words were presented auditory. The same words were used for both presentation modalities. Per grade, the children were divided at random over the presentation modalities; the procedure was the same for both modalities. Both consisted of 5 trials of presentations of 15 words or pictures (both will be called items hereafter) of familiar objects. The items were presented by use of a computer. The auditory-presented items were recorded by an experienced, native male speaker. The presentation duration of the pictures and the written words was the average duration of pronunciation time of the auditory presented words. The items were presented one every 2 seconds. All items were words acquired before six years of age (Van der Elst et al., 2005). They were presented to the children in the same order in each trial (immediate recall). After each presentation of all items, the children had to verbally recall as many items as they could. After about 15 to 20 minutes, during which no memory interfering tests were administered, the children were asked to recall as many items as possible from the list, without prompting (delayed recall). This was followed by a recognition trial, in which 30 items were presented, of which 15 items were from the immediate recall task and 15 were new items. The children had to answer 'Yes' or 'No' to whether the item belonged to the list of items presented to them in the immediate recall task. Because of the longitudinal set-up of the Cognitive Development Study for School-aged children, three statistically parallel test versions were used in both presentation modalities. Total number of correctly recalled words summed over trials 1 to 5 was used in the current study as the measure of verbal learning. The clustering measures serial and subjective clustering, were calculated based on the order of the words during the recall of the trials of the immediate recall of the VLT.

\section{Serial clustering}

Serial clustering was used to study passive strategy execution. It was calculated by dividing the number of observed serial clusters by the number of serial clusters that could be expected by chance. The number of observed serial clusters was the number of times that two items that were presented sequentially were recalled sequentially. The number of chance serial clusters in a trial was the maximum number of possible serial clusters divided by the sum of the number of items recalled correctly, plus the number of repetitions and intrusions (i.e., items that did not belong to the presented 
items) on that trial. The maximum number of possible serial clusters was calculated as follows. All items were given a ranking (1 to 15) according to the place of the item in the presentation order. Intrusions had no ranking, because they were not in the presentation list and repetitions had the same ranking as the first recall of that particular item. Then, the recalled items were placed in ascending order according to their ranking. If there were adjacent numbers in the ranking, this was a possible serial cluster. The number of possible item clusters was divided by the total number of items recalled correctly, plus the number of repetitions and intrusions. For example, if item 5 , item 7 , item 8 , item 2 , item 15 , and item 1 were recalled (in that order) and placed according to their ranking in the order $1-2-5-7-8-15$, then two possible item clusters were recalled, namely, items 1 and 2, and items 7 and 8 . The maximum number of possible serial clusters in this example was 2 . Thus the number of chance clusters in this example is $2 / 6=.33$. The number of observed clusters in this sample is 1 (items 7 and 8 in the recall order). This leads to a serial clustering of $1 / .33=$ 3.03. This calculation is a modification of the calculation described by Saan and Deelman (1996), in that we included intrusions in the calculation, in order to limit 'noise' in the serial clustering calculation. The 'noise' can be caused by the false detection of serial clusters because of the omission of intrusive items between otherwise adjacent words. There were five serial clustering calculations, one for each trial of the VLT. In the current study, the sum of the serial clustering calculations over the trials was used.

\section{Subjective clustering}

Subjective clustering was used to study organizational strategy execution. It was calculated as follows:

$\mathrm{SC}=\mathrm{ITR}-\frac{2 \mathrm{C}(\mathrm{C}-1)}{\mathrm{H} \times \mathrm{K}}$

In this calculation: (1) SC stands for Subjective Clustering; (2) ITR stands for the number Inter-Trial Repetitions (i.e., the number of groups of two clustered items that were recalled on trial $t$ and the subsequent trial $t+1$ ) that were no serial clusters; (3) $C$ stands for the number of items recalled on trial $t$ but also on trial $t+1$; (4) $\mathrm{H}$ stands for the sum of the number of items recalled correctly, repetitions, and intrusions on trial $t$; and (5) $\mathrm{K}$ stands for the sum of the number of items recalled correctly, repetitions, and intrusions on trial $t+1$. The calculation was a modification of the calculation described by Saan and Deelman (1996) and Sternberg and Tulving (1977), in that we included intrusions in the calculation in order to limit 'noise' in the subjective clustering calculation that could be caused by the false detection of subjective clusters because of the omission of intrusive items between otherwise clustered items. Additionally, in order to distinguish between serial and subjective clustering, couples of words that were clustered based on word order (i.e., serial clustering) were excluded from the subjective clustering measure. There were four subjective clustering calculations, one for each trial-pair of the VLT, because the recall-orders of two adjacent trails were compared. In the current study, the sum of the subjective clustering calculations over the trial pairs was used. 
The level of parental education (LPE)

Caregivers indicated their highest level of education attained on a commonly used Dutch educational rating scale ranging from primary school (1) to university degree (8) (De Bie, 1987; Kalff et al., 2001). This system is similar to the International Standard Classification of Education (United Nations Educational Scientific and Cultural Organisation (UNESCO), 1997).

\section{Verbal ability (VIQ)}

The estimate of verbal ability (VIQ) was the standard score of the Vocabulary subtest of the Dutch Wechsler Intelligence Scales Revised (WISC-Rn) (De Bruin et al., 1986). The WISC-Rn, rather than the WISC-III, was used because the latter became available in the Netherlands after the study had started (Wassenberg et al., in press). In this test, the children have to explain words, ranging from easy to complex. The standard score ranges from 1 to 19 (mean $=10, S D=3$ ). The reliability and validity have been described as average to good (De Bruin et al., 1986).

\section{Statistics}

Before data analyses, we checked for unreliable testing, missing data and extreme values. First, we checked for unreliable testing, as indicated by the testers. The data of the children for whom the test administration of the VLT was unreliable or not executed $(n=23)$ were excluded from the analyses, resulting in the inclusion of data for 408 children. Unreliability was due to several factors including technical problems such as failure of equipment, refusal of the child to cooperate, low motivation (for instance due to fatigue), or missing data due to time constraints. These missing data were not replaced because about $5 \%$ of data were missing per measure (Croy \& Novins, 2005). Then, we checked for extreme values, defined as values minimally three times the interquartile distance above the $75^{\text {th }}$ percentile or below the $25^{\text {th }}$ percentile (Huizingh, 2002). These were not found.

Analyses were performed in two stages. In stage 1 we investigated whether age, sex, the LPE, and the presentation modality were predictive of serial and subjective clustering use and strategy execution level, by use of step-down hierarchical logistic and linear regression analyses with serial and subjective clustering use and strategy execution level as dependent variables. Strategy use of both strategies was defined as a dichotomous variable (no use $=0$; use $=1$ ), and level of strategy execution of both strategies was defined as a continuous variable, namely the outcome of the clustering calculations. The main predictors were age, quadratic age (to study differential predictions with age), sex, the LPE and the presentation modality. An interaction term 'age $x$ sex' was included to study whether these factors interacted in predicting efficient strategy use.

In stage 2, we investigated whether the use and execution level of the two strategies predicted VLT performance, using two step-down hierarchical linear regression analyses with VLT performance as dependent variable. The effect of strategy use on VLT performance was studied first, followed by the study of the effect 
of the level of strategy execution of both strategies. The main focus was on the predictors: serial and subjective clustering use or serial and subjective clustering execution level (both as defined above) and interactions between serial and subjective use or serial and subjective execution level. Additional predictors were: age, quadratic age, sex (boys = 0; girls = 1), the LPE (level of parental education; range 1 [lowest] to 8 [highest]), and the presentation modality (pictorial $=0$; auditory $=1$ ). These were included in the analyses because verbal learning performance could be influenced by these factors. Interactions of serial and subjective clustering use and execution level with age, quadratic age, sex, and the LPE were included to study interactions between these factors and efficient strategy use. VIQ was included as predictor, to correct for possible influences thereof.

In order to avoid multicollinearity, age was centred (calendar age minus mean calendar age) before quadratic age and interaction terms were computed. Multicollinearity can lead to technical problems when estimating regression coefficients (Kleinbaum, Kupper, Muller, \& Nizam, 1998). Main predictors, although sometimes not significant, were included in the model, if a significant interaction term or quadratic term including that main predictor was in the final model. Normality was checked by inspection of the distribution of the residuals.

\section{Results}

Stage 1: The influence of age, sex, the LPE, and the presentation modality on efficient strategy use

Strategy use

Serial clustering use was predicted by age and VIQ, but not by sex, the LPE, or the presentation modality (see Table 1 ). More than $80 \%$ of the 6 -year old children used serial clustering, as did almost all 11-year old children (see Figure 1). Children that did not use serial clustering had a lower VIQ. Subjective clustering use was predicted by age, but not by the other factors that were investigated (see Table 1). Use of this strategy increased gradually with age and had not reached a peak by the age of 15 years (see Figure 1).

Table 1. Multiple logistic regression models for serial and subjective clustering use

\begin{tabular}{lrrrrrr}
\hline Predictor & $B$ & SE & Wald & & Exp $(B)$ & Nagelkerke $R^{2}$ \\
\hline \multicolumn{2}{l}{ Serial clustering use } & & & & & \\
Age & .650 & .184 & 12.452 & $* * *$ & 1.915 & .261 \\
VIQ & .225 & .109 & 4.239 & $*$ & 1.252 & \\
Constant & 2.143 & 1.154 & 3.447 & & 8.522 & \\
Subjective clustering use & & & & & \\
Age & .146 & .046 & 10.223 & $* *$ & 1.157 & .041 \\
Constant & 1.465 & .130 & 127.405 & $* * *$ & 4.327 & \\
\hline
\end{tabular}


Figure 1. Percentage of children who used serial and subjective clustering by age

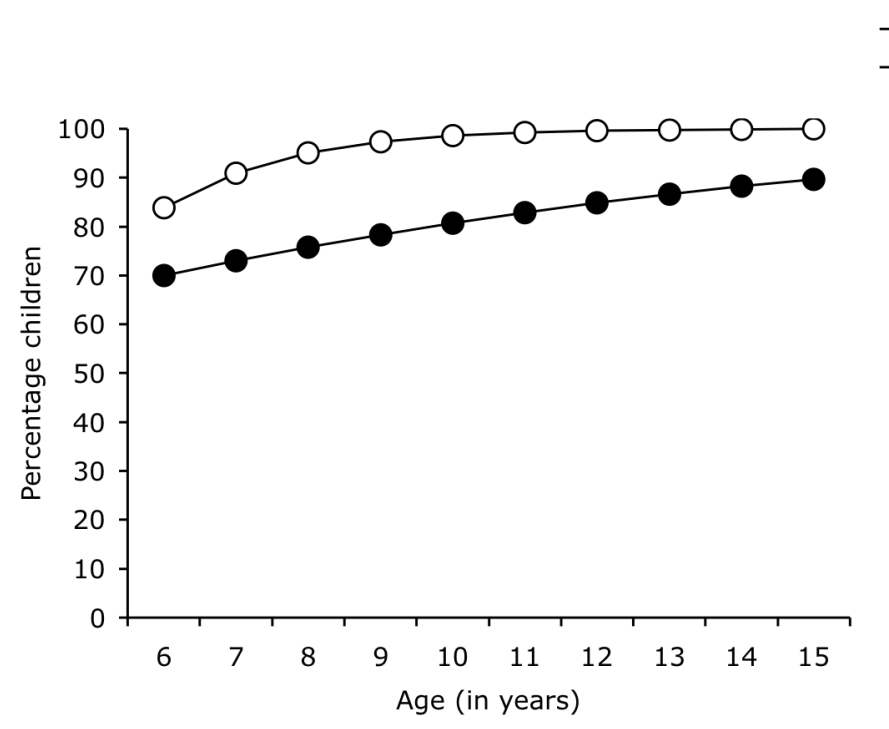

Level of strategy execution

Level of execution of serial clustering was predicted by quadratic age and age, but not by sex, the LPE, the presentation modality, or VIQ (see Table 2). The execution level of this strategy improved up till age 11 and then stabilized (see Figure 2). The execution level of subjective clustering was predicted by age and VIQ, but not by quadratic age, sex, the LPE, or the presentation modality (see Table 2). It improved with age, possibly beyond the age of 15 (see Figure 3) and was better in children with a higher VIQ.

Table 2. Multiple linear regression models for serial and subjective clustering execution level

\begin{tabular}{ccccccc}
\hline Predictor & $B$ & $S E$ & $T$ & & $\beta$ & Adjusted $R^{2}$ \\
\hline Serial clustering execution level & & & & & \\
Constant & 12.050 & .520 & 23.189 & $* * *$ & & .066 \\
Age & .623 & .117 & 5.314 & $* * *$ & .257 & \\
Quadratic Age & -.109 & .049 & -2.207 & $* *$ & -.107 & \\
Subjective clustering & execution level & & & & \\
Constant & 1.153 & .6 .08 & 1.896 & & & .046 \\
Age & .218 & .050 & 4.319 & $* * *$ & .223 & \\
VIQ & .122 & .057 & 2.162 & $*$ & .112 & \\
\hline
\end{tabular}

Note. ${ }^{*} p<.05 ;{ }^{* *} p<.01 ;{ }^{* * *} p<.001$ 
Figure 2. Predicted level of execution of serial clustering by age

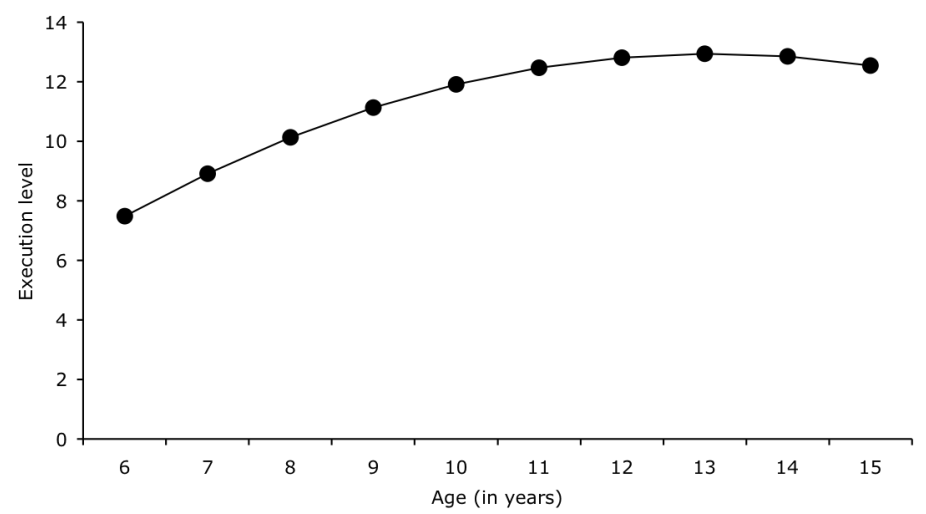

Figure 3. Predicted level of execution of subjective clustering execution level by age

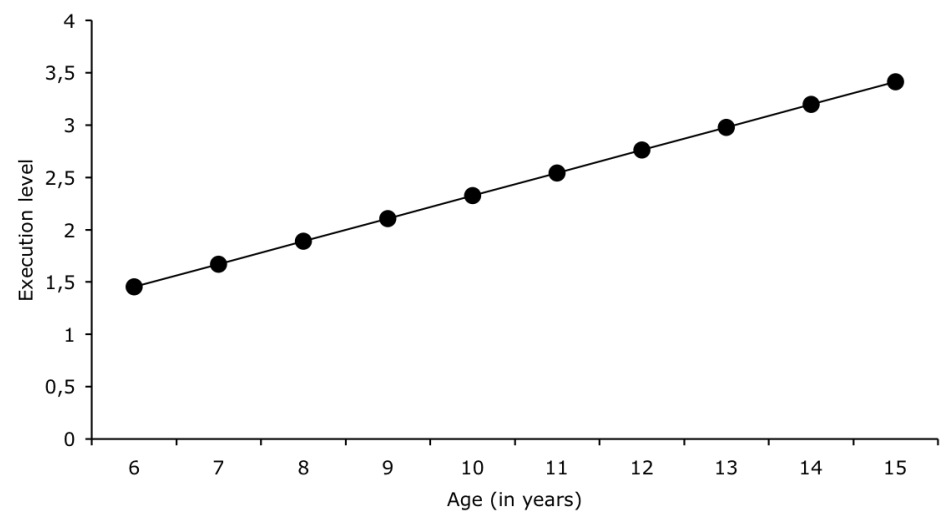

Stage 2: The influence of efficient strategy use on verbal learning performance Strategy use

VLT performance was predicted by the interaction terms 'serial $x$ subjective clustering use', and 'subjective clustering use $x$ age', subjective clustering use, serial clustering use, quadratic age, age, the presentation modality and VIQ (see Table 3). VLT performance was worst if no strategy was used and was best if both strategies were used, although the additional benefit of using serial clustering in addition to subjective clustering was modest (see Figure 4). Use of subjective clustering only predicted a better VLT performance than use of serial clustering only. The predictive value of the 
use of serial clustering on VLT performance was the same at each age, whereas the predictive value of the use of subjective clustering decreased with age. VLT performance increased with age, but the performance increment decreased with age, was better with the pictorial VLT, and was better in children with a higher VIQ. The interaction terms 'strategy use $x$ sex', 'strategy use $x$ the LPE', or 'strategy use $x$ presentation modality' were not predictive of VLT performance and neither were sex and the LPE. The interaction term 'serial clustering use $x$ age' was excluded from the analyses due to a high correlation with age (i.e., multicollinearity; Pearson Correlation coefficient $=.976, n=407, p=.000$ ).

Table 3. Multiple linear regression model of the prediction of serial and subjective clustering use on verbal learning performance

\begin{tabular}{lrrrrrr}
\hline Predictor & \multicolumn{1}{c}{$B$} & \multicolumn{1}{c}{$S E$} & \multicolumn{1}{c}{$T$} & & $\beta$ & Adjusted $R^{2}$ \\
\hline Constant & 28.269 & 4.548 & 6.216 & $* * *$ & & .573 \\
Serial x subjective clustering use & -11.690 & 5.154 & -2.268 & ${ }^{*}$ & -.421 & \\
Serial clustering use & 12.924 & 4.421 & 2.924 & ${ }^{* *}$ & .198 & \\
Subjective clustering use & 16.580 & 5.047 & 3.285 & ${ }^{* *}$ & .571 & \\
Subjective clustering use x age & -.889 & .354 & -2.512 & ${ }^{*}$ & -.198 & \\
Age & 3.358 & .310 & 10.825 & ${ }^{* * *}$ & .845 & \\
Quadratic age & -.230 & .059 & -3.912 & ${ }^{* * *}$ & -.138 & \\
Presentation modality & -5.434 & .754 & -7.208 & ${ }^{* * *}$ & -.246 & \\
VIQ & .453 & .157 & 2.892 & $* *$ & .101 & \\
\hline Note. ${ }^{*} p<.05 ;{ }^{* *} p<.01 ;{ }^{* * *} p<.001$ & & & & & &
\end{tabular}

Figure 4. Predicted verbal learning performance on the pictorial VLT, separate lines for no use and use of serial and subjective clustering use, by age

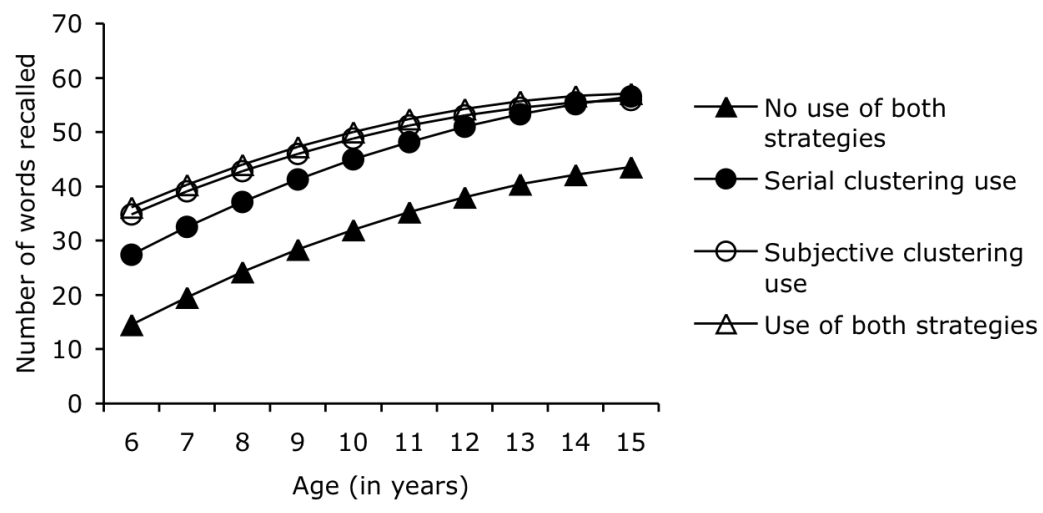

Note. Only the lines for the pictorial VLT are displayed. Even though the number of words recalled on the pictorial VLT was higher than on the auditory VLT, the patterns of the lines over age were the same 


\section{Level of strategy execution}

VLT performance was predicted by the interaction term 'subjective clustering execution level $x$ age', subjective clustering execution level, serial clustering execution level, age, quadratic age, sex, the presentation modality and VIQ (see Table 4). A higher level of execution of subjective clustering predicted a better VLT performance at all ages, but the influence decreased with age, whereas a higher level of execution of serial clustering predicted a better VLT performance to the same extent in all ages (see Figure 5). Additionally, as was found for strategy use, VLT performance increased with age, but stabilized in the older children, was better in girls than in boys, was better in the pictorial VLT, and was better in children with a higher VIQ. The interaction terms 'strategy use $x$ sex ', strategy use $x$ the LPE, strategy use $x$ the presentation modality, and the LPE did not predict VLT performance.

\section{Discussion}

The aim of the current study was to determine whether the efficient use of serial and subjective clustering influences VLT performance and whether age, sex, the level of parental education (LPE) and the presentation modality affect efficient strategy use. Efficient strategy use is considered to be a combination of strategy use and the level of strategy execution.

We expected that serial clustering would first be used as a strategy during the VLT at about 6 years of age and that its use would decline as children started to use subjective clustering as strategy at about 10 years of age (Bjorklund \& Douglas, 1997; Bukatko \& Daehler, 1998; Schlagmuller \& Schneider, 2002; Schneider \& Sodian, 1997; Siegler \& Booth, 2004). We found that $80 \%$ of the 6 -year-old children used serial clustering as strategy and that nearly all the 11-year-old children did. The level of execution of this strategy increased up till approximately 11 years and stabilized thereafter. On the other hand, we expected that the initial use of subjective clustering as a strategy would be later in life, at about 10 years of age, and that its use would increase up till at least 15 years. We found that about $70 \%$ of the 6 -year-old children used subjective clustering as strategy and that both strategy use and its level of execution increased with age. The age at which we expected children to first use the organizational strategy was based on the age that children use semantic clustering (about 10 years) (Bjorklund \& Douglas, 1997). However, semantic clustering requires knowledge of semantic categories and is more complex than some forms of subjective clustering, which requires the ability to actively form groups of items in any way logical or meaningful to the person performing the test, and as such may be used at an earlier age. 
Table 4. Multiple linear regression model of the prediction of serial and subjective clustering execution level on verbal learning performance

\begin{tabular}{lrrrrrc}
\hline Predictor & \multicolumn{1}{c}{$B$} & \multicolumn{1}{c}{$S E$} & \multicolumn{1}{c}{$T$} & & $\beta$ & Adjusted $R^{2}$ \\
\hline Constant & 38.044 & 1.841 & 20.663 & ${ }^{* * *}$ & & .633 \\
Serial clustering EL & .333 & .055 & 6.038 & ${ }^{* * *}$ & .206 & \\
Subjective clustering EL & 1.271 & .148 & 8.580 & ${ }^{* * *}$ & .314 & \\
Subjective clustering EL x age & -.196 & .054 & -3.595 & ${ }^{* * *}$ & -.133 & \\
Age & 2.327 & .142 & 16.331 & ${ }^{* * *}$ & .586 & \\
Quadratic age & -.166 & .057 & -2.914 & ${ }^{* *}$ & -.100 & \\
Sex & 1.571 & .708 & 2.219 & ${ }^{*}$ & .071 & \\
Presentation Modality & -5.148 & .707 & -7.277 & ${ }^{* * *}$ & -.233 & \\
VIQ & .340 & .148 & 2.301 & $*$ & .076 & \\
\hline$\quad$ Note. EL $=$ execution level. & & & & & & \\
$\quad{ }^{*} p<.05 ;{ }^{* *} p<.01 ;{ }^{* * *} p<.001$ & & & & & &
\end{tabular}

Figure 5. Predicted verbal learning performance for the pictorial VLT, of subjects with an average $\mathrm{VIQ}$, separate lines for high and low serial and subjective clustering execution level, by age

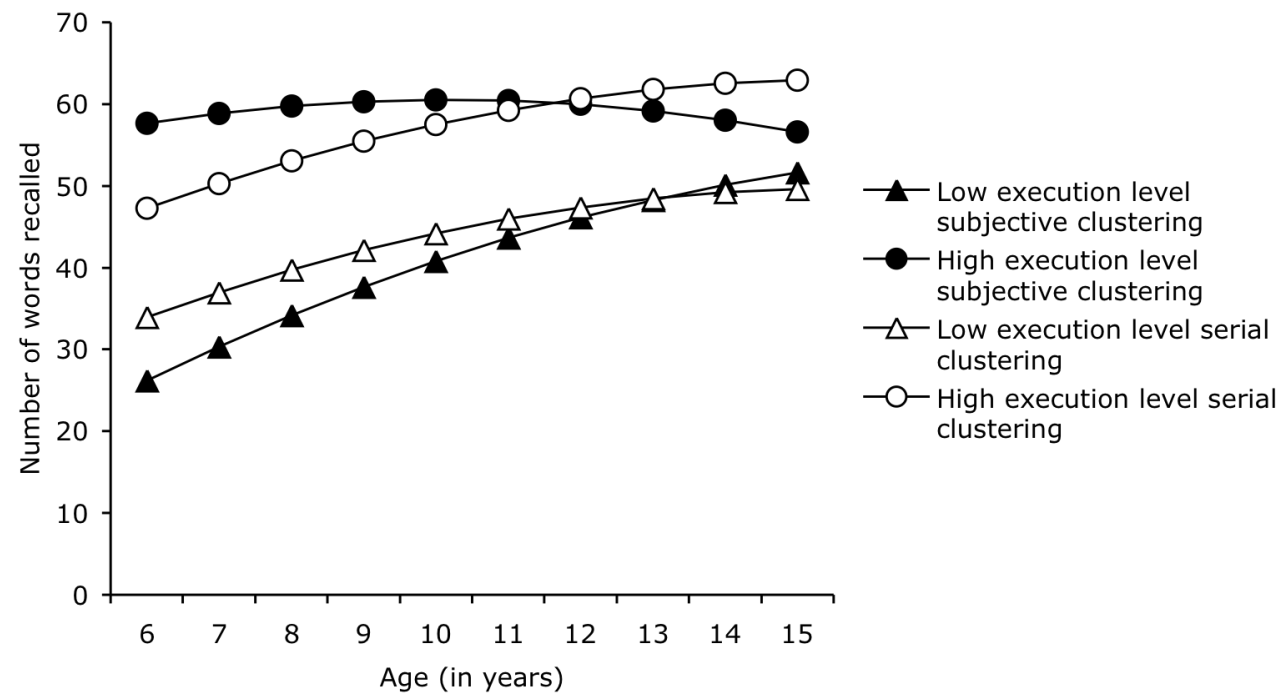

Note. Only the lines for the pictorial VLT are displayed. Even though the number of words recalled on the pictorial VLT was higher than on the auditory VLT, the patterns of the lines over age were the same 
Our findings suggested that the use and level of execution of subjective clustering continued to increase beyond the age of 15 (at which approximately $85 \%$ of the children used subjective clustering), which can probably be ascribed to the development of more complex connections between words. Examples of these are imagery (i.e., making a mental picture in mind that includes representations of the words) or elaboration (i.e., making, for instance, a story that contains the words) or combinations of these. Subjective clustering is a more complex strategy than serial clustering, and the extent to which children make use of the two strategies changes with age, possibly in relation to the development of executive functions needed to execute these strategies. Executive functions develop differentially, with some functions continuing to develop until adolescence. Among the functions that mature last are strategic organization, planning, and conceptual reasoning, which are functions that we assume to be important for fine-tuning of the ways to cluster information (Anderson, 2002).

We hypothesized that there would be a competition, from age 10 on, between the efficient use of both strategies (Ornstein, 1999) because older children have more strategies that they can choose from (such as a more efficient managing of the time that is spent on unfamiliar information instead of on familiar information) and will therefore use more diverse strategies than younger children during the same task (Bjorklund \& Douglas, 1997; Kuhn, 2000, Schlagmuller \& Schneider, 2002; Siegler \& Wagner Alibali, 2005). With increasing age, less enhancing strategies are accompanied or even replaced by more enhancing strategies, which are often more complex. This leads to a competition between the strategies, for use and the level of strategy execution. We found that serial clustering was used by all children beyond the age of 11 and subjective clustering use still raised up till at least 15 years of age. Thus, both strategies were used, and serial clustering was accompanied rather than replaced by subjective clustering use. The level of execution of serial clustering remained approximately at the same level after age 11, while the level of execution of subjective clustering gradually increased. The stabilization around the age of 11 of the execution level of serial clustering can be explained by the competition with the execution of the organizational strategy, but it also possible that at that age the optimal performance level of this strategy is reached. A combination of both options is perhaps the best explanation, primarily because the initial use and the execution of subjective clustering started earlier than we expected. We take this to indicate that efficient subjective clustering use is a measure that taps on executive functions as described above (Anderson, 2002). We found that this development continues beyond the age of 15 , probably related to the development of the needed executive functions.

We hypothesized that the predictive value of strategy use and level of execution for VLT performance would increase with increasing age. However, we found that efficient use of the serial clustering strategy enhanced VLT performance to the same extent in children of all ages and that the predictive value of the use of the subjective clustering strategy on VLT performance decreased with age. VLT performance was better as either or both strategies were used than if no strategy was used (see Figure 4) and was best if both strategies were used. If only one strategy 
was used, VLT performance was better when the subjective clustering strategy was used, at least up till age 14. Thereafter, using the serial, the subjective or both clustering strategies lead to approximately the same amount of enhancement. Thus, at that age, using a strategy was still enhancing, but which one of whether both strategies were used, was of less importance.

The difference between a high and low level of execution of serial clustering on VLT performance was, regardless of age, 13 words (note: total VLT score is maximum 75 words). In contrast, the difference between a high and low level of execution of subjective clustering on VLT performance was about 32 words at age 6 and about 5 words at age 15. Thus, although the use and execution level of subjective clustering increased beyond the age of 15, the relevance of the efficient use of subjective clustering use to VLT performance decreased with age, whereas the relevance of efficient serial clustering, the use and level of execution level of which stabilized at about 11 years, remained at the same level. This remains unexplained. It is unlikely that the children reached a ceiling in VLT performance because we then would have expected to find similar results for the efficient use of both serial and subjective clustering.

We hypothesized that the developmental trajectory of efficient strategy use would occur earlier in girls than in boys (Cox \& Waters, 1986; Kramer et al., 1997). However, we found (a) no sex differences in strategy use and level of execution of both strategies, and (b) that efficient strategy use predicted VLT performance to the same extent for boys and girls. Thus, boys and girls do not differ in efficient strategy use, nor do boys lag behind girls.

We also hypothesized that the children of parents with a high LPE would make efficient use of strategies earlier than the children of parents with a low LPE, because parents with a higher SES are reported to stimulate strategy use more than parents with a low SES (Bukatko \& Daehler, 1998; Santrock, 2001). We did not find this to be the case, because there was no interaction between efficient strategy use and the LPE in predicting VLT performance. Thus, while children with highly educated parents (as part of the indication of SES) may be stimulated more to make efficient use of strategies, this does not automatically lead to more and better strategy use or an earlier development of this. Possibly, the studies mentioned above focused on the use of other strategies. Stimulation of the use of one kind of strategy does not imply that other strategies are also used more. Another possibility is that the LPE is not related to strategy use, but to one of the other factors that are included in the indication of SES. Future studies should resolve these questions.

We hypothesized that the efficient use of both strategies would be better with a pictorial presentation than with an auditory presentation of the VLT. The presentation modality influences verbal learning performance, with VLT performance being better with a pictorial presentation of words (Lezak, 1995). This better performance with a pictorial presentation is thought to be due to a deeper and better processing of pictorial information compared with auditory information. We did not find the presentation modality to be predictive of strategy use or execution and there was no relation between efficient strategy use and the presentation modality in the 
prediction of verbal learning performance. Thus, the difference in VLT performance seen with the two presentation modalities is not mediated by differences in strategy use.

VIQ (although in the first place only included as a covariate in the current study) influenced both efficient strategy use and VLT performance. Children with a higher VIQ made more use of serial clustering and had a higher level of execution of subjective clustering. It is, however, not clear why the use of subjective clustering and the level of execution of serial clustering were not predicted by VIQ, and this should be a topic in future research.

\section{Conclusion and implications}

Efficient strategy use contributes to better verbal learning, measured as VLT performance. While stimulation of efficient serial clustering may contribute to a better VLT performance, it is probably more effective to stimulate efficient subjective clustering, at least up till age 14. The use and execution level of serial clustering peaked at the age of 11 , whereas the use and the execution level of subjective clustering continued to increase after the age of 15 . Thus, children with a lower VLT performance, due to improper strategy use, could be trained to make more efficient use of serial and subjective clustering to enhance VLT performance, at least up till age 14. Because children with a lower VIQ had a lower level of execution of subjective clustering, we assume that these children would benefit most from subjective clustering training. Sex, the LPE, and the presentation modality did not affect efficient strategy use and the relationship with VLT performance. 


\section{References}

Anderson, P. (2002). Assessment and development of executive function (EF) during childhood. Child Neuropsychology, 8, 71-82.

Berk, L. E. (1998). Development Through the Lifespan. Needham Heights, MA: Allyn \& Bacon.

Bjorklund, D. F., \& Douglas, R. N. (1997). The development of memory strategies. In N. Cowan \& C. Hulme (Eds.), The Development of Memory in Childhood (pp. 201-246). Hove, East Sussex, UK: Psychology Press.

Brand, N., \& Jolles, J. (1985). Learning and retrieval rate of words presented auditory and visually. The Journal of General Psychology, 112, 201-210.

Bukatko, D., \& Daehler, M. W. (1998). Child Development: a Thematic Approach (3rd ed.). Boston: Houghton Mifflin Company.

Cox, D., \& Waters, H. S. (1986). Sex differences in the use of organisation strategies: A developmental analysis. Journal of Experimental Child Psychology, 41, 18-37.

Croy, C. D., \& Novins, D. K. (2005). Methods for addressing missing data in psychiatric and developmental research. Journal of American Academy of Child \& Adolescent Psychiatry, 44, 1230-1240.

De Bie, S. E. (1987). Standaardvragen 1987: Voorstellen voor uniformering van vraagstellingen naar de achtergrondkenmerken en interviews [Standard questions 1987: Proposal for the uniformization of questions regarding background variables and interviews] (2nd ed.). Leiden, The Netherlands: Leiden University Press.

De Bruin, E. E. J., Van der Steene, R. G., Van Haasen, P. P., Coetsier, P., Pijl, Y. L., Spelders-Claes, R., et al. (1986). Wechsler Intelligence Scale for Children (WISC-R). Lisse, The Netherlands: Swets \& Zeitlinger

DeMarie, D., \& Ferron, J. (2003). Capacity, strategies, and metamemory: Test of a three-factor model of memory development. Journal of Experimental Child Psychology, 84, 167-193.

Gaultney, J. F. (1998). Utilization deficiencies among children with learning disabilities. Learning and Individual Differences, 10, 13-28.

Gaultney, J. F., Bjorklund, D., F., \& Goldstein, D. (1996). To be young, gifted and strategic: Advantages for memory performance. Journal of Experimental Child Psychology, 61, 33-66.

Greenberg, M. T., Lengua, L. J., Coie, J. D., \& Pinderhughes, E. E. (1999). Predicting developmental outcomes at school entry using a multiple-risk model: Four American communities. The Conduct Problems Prevention Research Group; Developmental Psychology, 35, 403-417.

Huizingh, E. (2002). Inleiding SPSS 11 voor Windows [Introduction SPSS 11 for Windows]. Schoonhoven, The Netherlands: Academic Service.

Kalff, A. C., Kroes, M., Vles, J. S. H., Bosma, H., Feron, F. J. M., Hendriksen, J. G. M., et al. (2001). Factors affecting the relation between parental education as well as occupation and problem behavior in Dutch 5- to 6- year- old children. Social Psychiatry and Psychiatric Epidemiology, 36, 324-331.

Kleinbaum, D. G., Kupper, L. L., Muller, K. E., \& Nizam, A. (1998). Applied Regression Analysis and Other Multivariable Methods (3rd ed.). New York: Duxbury Press.

Kramer, J. H., Delis, D. C., Kaplan, E., O'Donnel, L., \& Prifitera, A. (1997). Developmental sex differences in verbal learning. Neuropsychology, 11, 577-584.

Kuhn, D. (2000). Does memory development belong on an endangered topic list? Child Development, 71(1), 21-25.

Lezak, M. D. (1995). Neuropsychological Assessment (3rd ed.). New York: Oxford University Press.

Linschoten, J. (1963). De La Court's Frequentietellingen van Nederlandse Woorden [De la Court's Frequency Counts of Dutch Words]. (Report 6301). Utrecht, The Netherlands: University of Utrecht, Psychologisch Laboratorium.

Ornstein, P. A. (1999). Comments: Towards an understanding of the development of memory. In F. E. Weinert \& W. Schneider (Eds.), Individual Development from 3 to 12: Findings from the Munich Longitudinal Study (pp. 94-105). Cambridge, England, UK: Cambridge University Press.

Saan, R. J., \& Deelman, B. G. (1986). Nieuwe 15-woorden test A en B (15WT-A en 15WT-B) [New 15words test A and B (15WT-A and 15 WT-B)]. In A. Bouma, J. Mulder \& J. Lindeboom (Eds.), Neuropsychologisch Handboek (pp. 13-28). Amsterdam: Swets \& Zeitlinger.

Santrock, J. W. (2001). Educational Psychology. New York: McGraw-Hill.

Schlagmuller, M., \& Schneider, W. (2002). The development of organizational strategies in children: Evidence from a microgenetic longitudinal study. Journal of Experimental Child Psychology, 81, 298-319. 
Schneider, W., Knopf, M., \& Stefanek, J. (2002). The development of verbal memory in childhood and adolescence: Findings from the Munich Longitudinal Study. Journal of Educational Psychology, $94,751-761$.

Schneider, W., \& Sodian, B. (1997). Memory strategy development: Lessons from longitudinal research. Developmental Review, 17, 442-461.

Siegler, R. S., \& Booth, J. L. (2004). Development of numerical estimation in young children. Child Development, 75, 428-444.

Siegler, R. S., \& Wagner Alibali, M. (2005). Children's Thinking (4th ed.). Upper Saddle River, NJ: Pearson Prentice Hall.

Sternberg, R. J., \& Tulving, E. (1977). The measurement of subjective organization in free recall. Psychological Bulletin, 84, 539-566.

United Nations Educational Scientific and Cultural Organisation (UNESCO). (1997). International Standard Classification of Education (ISCED). Paris: UNESCO.

Van der Elst, W., Van Boxtel, M. P. J., Van Breukelen, G., J. P., \& Jolles, J. (2005). Rey's Verbal Learning test: normative data for 1,855 healthy participants aged 24-81 years and the influence of age, sex, education, and mode of presentation. Journal of the International Neuropsychological Society, 11, 290-302.

Van Loon-Vervoorn, W. A. (1989). Voorstelbaarheidswaarden van Nederlandse Woorden [Imageability Ratings of Dutch Words]. Lisse, The Netherlands: Swets \& Zeitlinger.

Wassenberg, R., Hurks, P. P. M., Hendriksen, J. G. M., Feron, F. J. M., Meijs, C. J. C., Vles, J. S. H., et al. (in press). Age-related improvement in complex language comprehension: Results of a crosssectional study with 361 children aged 5 to 15 . Journal of Clinical and Experimental Neuropsychology. 


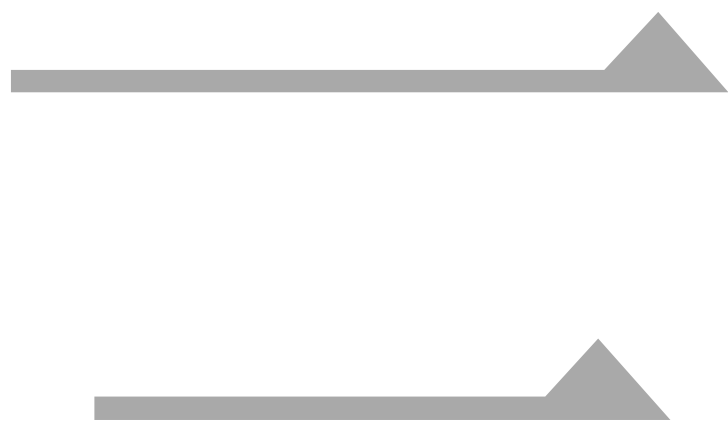


\title{
Chapter 3
}

\section{Differential development of learning strategies on a Pictorial Verbal Learning Test (PVLT) in primary school children}

\begin{abstract}
The aim of this study was to test the hypothesis that developmental differences exist in the use of learning strategies. Serial and subjective clustering in a multi-trial Pictorial Verbal Learning Test (PVLT) were compared in 79 children aged 6-12. Correlation analyses indicated that serial clustering yielded better performance when information was presented on the initial trials of the test. Subjective clustering was superior when information was presented repeatedly, i.e., after three or more trials. Analyses of variance indicated that subjective clustering was used more often in older children with repeated presentations. On the other hand, there was no increase in the use of serial clustering with age and with repeated presentations. The findings imply that training in the use of proper strategies could be beneficial for children who use an inefficient learning strategy and/or have a learning problem. In addition, they point to the importance of the factor 'age' in relation to the way information is presented to children.
\end{abstract}




\section{Introduction}

In verbal learning performance, both immediate and delayed recall are known to improve by the use of memory strategies (Bjorklund \& Douglas, 1997; Bukatko \& Daehler, 1998; DeMarie \& Ferron, 2003; Ornstein, 1999; Schneider, Knopf, \& Stefanek, 2002; Siegler \& Wagner Alibali, 2005). On the other hand, children with learning problems are often characterised by less efficient strategy use (Gaultney, 1998) and impaired performance on memory tests (Bjorklund \& Douglas, 1997). The present paper elaborates on the notion that children who use a proper learning strategy will have a better performance on tests of verbal learning. As this in turn will lead to better scholastic performance in educational settings, the notion has potential for application. It is therefore important to improve our insight into the use of strategies in schoolchildren of various ages. Such knowledge may be useful in school settings for devising the optimal method and procedures for presenting information that children are required to remember. The aim of the current study was to test the hypothesis that developmental differences exist in the use of strategies, during a multi-trial Verbal Learning Test (VLT).

It is well known that very simple strategies, such as looking at a location where an object has been hidden by the experimenter, are already used by preschool children. With increasing age, more complex strategies are used. Also, the repertoire of strategies that is available for the children to use increases. From approximately age 5 on, children use simple strategies such as rehearsal. Around the age of 10 , children are also able to use more complex strategies such as organization of to-beremembered information (Bjorklund \& Douglas, 1997; Schlagmuller \& Schneider, 2002; Siegler \& Wagner Alibali, 2005). Most studies evaluate the use of only one memory-enhancing strategy during a test. However, during the execution of one test, several strategies can be employed for better performance (Bjorklund \& Douglas, 1997; Kuhn, 2000; Schlagmuller \& Schneider, 2002; Siegler \& Wagner Alibali, 2005). Therefore, in the current study, two strategies were studied. Serial clustering was used for the study of a relatively simple, passive strategy. In this strategy, the order of the recall of the words is the same as the order in which they were presented. Thus, the information is not actively handled or rearranged by the child. Because it is a relatively simple strategy, younger children, around the age of six, are expected to be able to use it. Subjective clustering was used as a more complex organizational strategy in which active organization of the information takes place. In this strategy, the presented words are grouped or coupled based upon subjective criteria. The use of this more complex strategy has been reported to be operational around the age of 10 (Bjorklund \& Douglas, 1997). Developmental differences between these two strategies are, amongst others, the result of the development of various executive functions (Anderson, 2002; Brocki \& Bohlin, 2004; Casey, Giedd, \& Thomas, 2000). These functions, such as working memory and planning, are needed to execute the strategies. 
Some strategies are more potent in enhancing learning and memory performance than others (Kirchhoff \& Buckner, 2006). Additionally, this profit varies within a test and with age (Bjorklund \& Douglas, 1997; DeMarie \& Ferron, 2003; Schlagmuller \& Schneider, 2002; Siegler \& Wagner Alibali, 2005). For instance, the strategy that is most profitable for the first part of a test does not have to be the strategy that is most profitable for the second part of a test. This has, to our knowledge, not extensively been studied before in children. In the current study, we therefore studied the strategies during a multi-trial test, that is, a test that has repeated presentations of the to-be-learned information. This enabled the investigation of a possible switch in strategy use over repeated presentations. We also studied the coherence between the use of the strategy and verbal learning performance. Thus, inferences are possible with respect to the strategy that is most profitable on a specific moment during verbal learning with repeated presentations.

In the current study, we attempted to create the most optimal situation for the study of strategy use by means of two factors. The first factor was the pictorial presentation modality of the to-be-remembered information. Verbal learning on these tests is known to be better with a pictorial presentation as compared to an, often used, auditory presentation (Lezak, Howieson, \& Loring, 2004). By making use of a pictorial presentation, we ensured a better performance. If performance is better, this can be the result of more efficient use of strategies. Therefore, by using a pictorial presentation, there was a higher chance of spontaneous strategy use. The second factor was the inclusion of children with only highly educated parents/caregivers. The LPE is an approximation ('proxy') of the intellectual climate within a family, the complexity of the language used, the books read, and the level of ambitions against which the parents position their developing child. In a number of studies, it has also been used as a proxy for socio-economic status (SES) (Greenberg, Lengua, Coie, \& Pinderhughes, 1999). It is known that a high SES has a positive influence on IQ (Berk, 1998) and on school performances (Santrock, 2001). Furthermore, parents with a high SES stimulate their children more to the use of strategies (Bjorklund \& Douglas, 1997). If strategies were used and if this strategy use correlated with better performance, then the current situation had the best chance to detect this.

The aim of the current study was to test the hypothesis that developmental differences exist in the use of strategies, i.e. serial and subjective clustering, during a multi-trial Pictorial Verbal Learning Test (PVLT). We hypothesized that all children in all trials would use serial clustering, whereas subjective clustering would be used by the children of the age of 10 and older and that this use increased with repeated presentations. 


\section{Method}

\section{Procedure}

The current study was part of a cross-sectional study into learning and neurocognitive development of children in primary schools. Participants were recruited from a regular primary school in Maastricht, the Netherlands. The parents or caregivers of the children (referred to as caregivers in the following) in kindergarten and grades 1 to 6 received an information-package via the school. This package contained a letter with information on the purpose of the study, a request to participate, a questionnaire, a form to give consent for the child to participate and an addressed-stamped envelope. All caregivers signed a written consent form before participation of their child in the study.

The children received an extensive neuropsychological test battery that included tests for the measurement of e.g. general ability, memory and language skills. From these, we selected the Pictorial Verbal Learning Test (PVLT) for use in the current study. Problems due to fatigue or a relapse of attention were prevented because the PVLT was the first test that was administered. Three psychologists tested the children individually in a test room at their school. Administration of the complete neuropsychological battery took approximately 2.5 hours; all tests were administered in the same order for each child. A break halfway through the testing was included for the children in the youngest group, if necessary. The Medical Ethical Review Committee of the Academic Hospital Maastricht approved the protocol of the study.

\section{Participants}

Of the 107 children that were tested, 79 children (38 boys, 41 girls) were selected for the current study, based on the inclusion criteria: (1) no repetition or skipping of a grade, (2) mastery of the Dutch language, (3) no visual or perceptual disabilities, (4) no serious motor problems, (5) no serious neurological or psychiatric disorders, and (6) a high Level of Parental Education (LPE). The age of the participating children ranged from 6.28 years (kindergarten) to 12.37 years (grade 6). There was approximately the same number of children per grade. The numbers of boys and girls per grade were not significantly different: $\chi^{2}(2, n=79)=2.968, p=.243$. The children in the grades did not differ in verbal IQ: $\chi^{2}(24, n=78)=24.724, p=.311$ (see Table 1).

Table 1. Demographics and characteristics of the 79 children

\begin{tabular}{cccccccc}
\hline & \multicolumn{2}{c}{ Group 1 } & \multicolumn{2}{c}{ Group 2 } & \multicolumn{2}{c}{ Group 3 } \\
\cline { 2 - 7 } Grade & $\mathrm{K}$ & 1 & 2 & 3 & 4 & 5 & 6 \\
Age $(S D)$ & $6.51(.14)$ & $7.17(.33)$ & $8.12 .25)$ & $9.15(.33)$ & $10.19(.30)$ & $11.02(.23)$ & $12.01(.23)$ \\
Boys, Girls & 2,5 & 6,9 & 7,6 & 4,8 & 7,6 & 7,6 & 5,1 \\
Boys, Girls & \multicolumn{2}{c}{8,14} & \multicolumn{2}{c}{11,14} & & 19,13 & \\
VIQ $(S D)$ & \multicolumn{1}{c}{$10.76(2.19)$} & \multicolumn{2}{c}{$10.48(2.68)$} & & $11.44(2.24)$ \\
\hline
\end{tabular}

Note. $\mathrm{K}=$ kindergarten. 


\section{The level of parental education (LPE)}

Caregivers indicated their highest level of education attained on a commonly used Dutch educational rating scale ranging from primary school (1) to university degree (8) (De Bie, 1987; Kalff et al., 2001) that was included in the questionnaire. This system is similar to the International Standard Classification of Education (United Nations Educational Scientific and Cultural Organisation (UNESCO), 1997). All included children had at least one caregiver with some level of higher education (i.e. school for higher vocational education and higher).

\section{Instruments}

\section{PVLT}

A pictorial verbal learning test (PVLT) was administered to measure verbal learning. Verbal learning tests are among the most often-used neuropsychological tests in applied settings and memory research. Word list learning is one of the most sensitive verbal memory tests and the test-retest reliability is reported to be high (Lezak, 1995; Van der Elst, Van Boxtel, Van Breukelen, \& Jolles, 2005). The test administration was similar to earlier studies that used verbal learning tests (VLTs) (Brand \& Jolles, 1985; Van der Elst et al., 2005). This test consisted of five trials: each trial consisting of the presentation of the same 15 pictures of familiar objects that were controlled for frequency of use (Linschoten, 1963), number of syllables and imageability (Van LoonVervoorn, 1989). All words represented by the pictures were early-acquired words, that is, words acquired before the age of six years. The pictures were presented to the children in the same order on each trial. The children were told before the first trial that they had to remember the pictures. During the first trial, the children were required to name the pictures, to make sure that the objects were clear. After each complete presentation, the children had to verbally recall as many pictures as they remembered, regardless of the order that they were recalled in. After a period of approximately 15 to 20 minutes, in which no memory interfering tests were administered, there was a delayed recall. The children had to recall as many words as possible from the list without prompting. This was followed by a recognition trial where 30 pictures were shown. Of these, 15 pictures were from the trials in the immediate recall and 15 were new pictures. The children had to answer 'Yes' or 'No' to whether the picture belonged to the list of pictures presented in the immediate recall. Performance per trial and performance summed over five trials were used as measures of verbal learning with a pictorial presentation for the study of the coherence between performance and strategy use. Serial and subjective clustering performance per trial and trial-pair were used in the current study as measures of strategy use. The calculations used for the measurement of clustering are described in the next sections. 


\section{Serial clustering}

Serial clustering was used to study passive strategy execution. It was calculated by dividing the number of observed serial clusters by the number of serial clusters that could be expected by chance. The number of observed serial clusters was the number of times that two words (called items hereafter) that were presented sequentially were recalled sequentially. The number of chance serial clusters in a trial was the maximum number of possible serial clusters divided by the sum of the number of items recalled correctly, plus the number of repetitions and intrusions (i.e., items that did not belong to the presented items) on that trial. The maximum possible number of serial clusters was calculated as follows. All items were given a ranking (1 to 15) according to the place of the item in the presentation order. Intrusions had no ranking, because they were not in the presentation list. Repetitions had the same rankings as the first recall of that particular item, because the place in the presentation list determines the ranking. Then, the recalled items were placed in ascending order according to their ranking. If there were adjacent numbers in the ranking, this was a possible serial cluster. The number of possible item clusters was divided by the total number of items recalled correctly, plus the number of repetitions and intrusions. For example, if item 5 , item 7 , item 8 , item 2 , item 15 , and item 1 were recalled (in that order) and placed according to their ranking in the order $1-2-5-7-8-15$, then two possible item clusters were recalled, namely, items 1 and 2, and items 7 and 8 . The maximum number of possible serial clusters in this example was 2 . Thus, the number of chance clusters in this example is $2 / 6=.33$. The number of observed clusters in this sample is 1 (items 7 and 8 in the recall order). This leads to a serial clustering of $1 / .33=$ 3.03. This calculation is a modification of the calculation described by Saan and Deelman (1996), in that we included intrusions in the calculation, in order to limit 'noise' in the serial clustering calculation. Noise could be caused by the false detection of serial clusters because of the omission of intrusive items between otherwise adjacent words. There were five serial clustering calculations, one for each trial of the PVLT. In the current study, the average serial clustering per trial ranged from 1.8 to 2.4 .

Subjective clustering

Subjective clustering was used to study organizational strategy execution. It was calculated as follows:

$\mathrm{SC}=\mathrm{ITR}-\left[\frac{2 \mathrm{C}(\mathrm{C}-1)}{\mathrm{H} \times \mathrm{K}}\right]$

In this calculation: (1) SC stands for Subjective Clustering; (2) ITR stands for the number Inter-Trial Repetitions (i.e., the number of groups of two clustered items that were recalled on trial $t$ and the subsequent trial $t+1$ ) that were not serial clusters; (3) $\mathrm{C}$ stands for the number of items recalled on trial $t$ but also on trial $t+1 ;(4) \mathrm{H}$ stands for the sum of the number of items recalled correctly, repetitions, and intrusions on trial $t$; and (5) $\mathrm{K}$ stands for the sum of the number of items recalled correctly, 
repetitions, and intrusions on trial $t+1$. The calculation was a modification of the calculation described by Saan and Deelman (1996) and Sternberg and Tulving (1977), in that we included intrusions in the calculation in order to limit 'noise' in the subjective clustering calculation that could be caused by the false detection of subjective clusters because of the omission of intrusive items between otherwise clustered items. Additionally, in order to distinguish between serial and subjective clustering, couples of words that were clustered based on word order (i.e., serial clustering) were excluded from the subjective clustering measure. There were four subjective clustering calculations, one for each trial-pair of the PVLT, because a comparison between the recall-orders of two adjacent trails was made. In the current study, the average subjective clustering per trial-pair ranged from .3 to 1.2 .

\section{Statistics}

The independent variable was 'group'. For the analyses, the children were divided in three groups, based on their grade. This division was made based on the development of strategy use. The first group consisted of the children in kindergarten and grade 1 (ages 6 and 7). These children were assumed to be able to use the relatively simple strategy of serial clustering. After this age, the more complex organizational strategy of subjective clustering was assumed to develop, but in a gradual way. Therefore, the children in grades 2 and 3 were placed in the second group (ages 8 and 9). Around the age of 10, the organizational strategy was assumed to be operational for most children. Therefore, the children in grades 4,5 and 6 , were placed in the third group (ages 10 to 12) (see Table 1).

First, correlations between serial clustering (per trial) and the number of words recalled (in that same trial and summed over five trials) were analyzed. Second, correlations between subjective clustering (per trial-pair) and the average number of words recalled (on that trial-pair and summed over five trials) were analyzed. A Pearson correlation of $.10, .30$, and .50 were considered a low effect size, a moderate effect size, and a high effect size, respectively (Cohen, 1992). The correlation analyses were corrected for group.

Next, development of strategy use over repeated trials was analyzed using two GLM Repeated Measures analyses with serial clustering outcome per trial (1 to 5) and subjective clustering per trial-pair (1 to 4 ) as within subject variables, and group as the between subjects variable. Sex and VIQ were not included in the analyses as covariates because boys, girls and VIQ were distributed approximately evenly over the groups (see Table 1). 


\section{Results}

\section{Correlation analyses}

Significant correlations were found between serial clustering in trials 1 and 2, verbal learning performance in these trials, and total verbal learning performance (see Table 2).

Table 2. Partial correlations between serial clustering and verbal learning performance

\begin{tabular}{lccccc}
\hline \multirow{2}{*}{ Verbal learning performance per trial $^{\mathrm{a}}$} & ${\text { Serial } 1^{\mathrm{b}}}$ & Serial 2 & Serial 3 & Serial 4 & Serial 5 \\
\cline { 2 - 6 } & .26 & .26 & $\mathrm{~ns}$ & $\mathrm{~ns}$ & $\mathrm{~ns}$ \\
\hline Total verbal learning performance & .36 & $(.028)$ & & & \\
\hline
\end{tabular}

Note. $N$ for all correlation analyses was 72. Expressed by the Pearson correlation coefficient and the $p$ value. Corrected for group

${ }^{a}$ Verbal learning performance on respectively Trials 1 to 5 from left to right. ${ }^{b}$ Serial clustering per trial

The correlations were also significant between subjective clustering in trial-pairs 3-4 and $4-5$, and average verbal learning performance in these trial-pairs, and total verbal learning performance (see Table 3 ).

Table 3. Partial correlation between subjective clustering and verbal learning performance

\begin{tabular}{|c|c|c|c|c|}
\hline & Subjective $1-2^{b}$ & Subjective 2-3 & Subjective 3-4 & Subjective 4-5 \\
\hline $\begin{array}{l}\text { Average verbal learning performance } \\
\text { on the trial-pairs }{ }^{a}\end{array}$ & ns & ns & $\begin{array}{c}.29 \\
(.011)\end{array}$ & $\begin{array}{c}.48 \\
(<.001)\end{array}$ \\
\hline Total verbal learning performance & ns & ns & $\begin{array}{c}.30 \\
(.008)\end{array}$ & $\begin{array}{c}.43 \\
(<.001)\end{array}$ \\
\hline
\end{tabular}

Note. $N$ for all correlation analyses was 72 . Expressed by the Pearson correlation coefficient and the $p$ value. Corrected for group

${ }^{a}$ Verbal learning performance on the PVLT on respectively Trial-pairs 1-2 to 4-5 from left to right. ${ }^{b}$ Subjective clustering per trial-pair

\section{Strategy use with repeated presentations}

No significant effects were found for serial clustering with repeated trials, with respect to the interaction between group and serial clustering over trials (Pillai's trace $=.05, F$ $(8,140)=.45, p=.886$, Partial Eta Square $=.02)$ and the main effect of serial clustering over trials (Pillai's trace $=.07, F(4,69)=1.33, p=.226$, Partial Eta Square $=.07$ ). This indicates that serial clustering did not differ as a function of age and over trials (see Figure 1). 
Chapter 3

Figure 1. Serial clustering per trial, separate lines for the groups

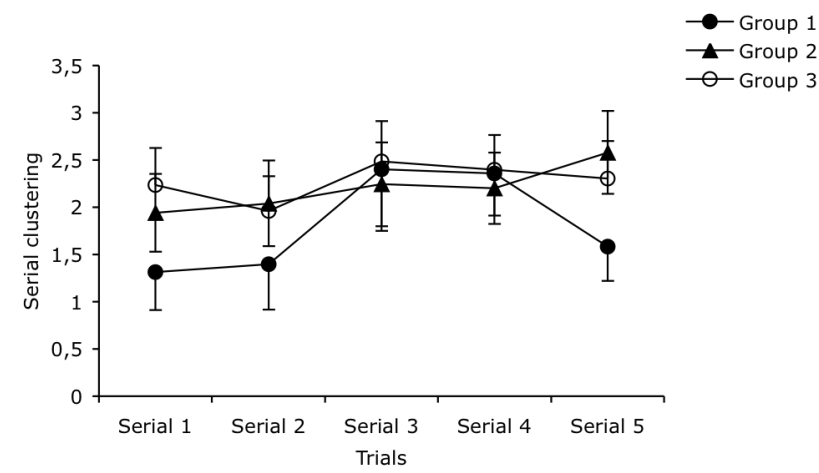

Note. Error bars reflect standard error.

A significant interaction between subjective clustering and group (Pillai's trace $=.17, F(6,142)=2.22, p=.044$, Partial Eta Square $=.09)$ and a significant main effect of subjective clustering over trials (Pillai's trace $=.27, F(3,70)=8.86, p<.001$, Partial Eta Square $=.27$ ) were found. This indicates that there was an increase in subjective clustering with repeated trials but that this was different for the children in the different groups. Figure 2 shows that the oldest children already had an increase in subjective clustering from trials 1-2 on, the children in the middle age group had an increase in subjective clustering from trials 2-3 on, and that the youngest children had only a small increase in subjective clustering.

Figure 2. Subjective clustering per trial-pair, separate lines for the groups

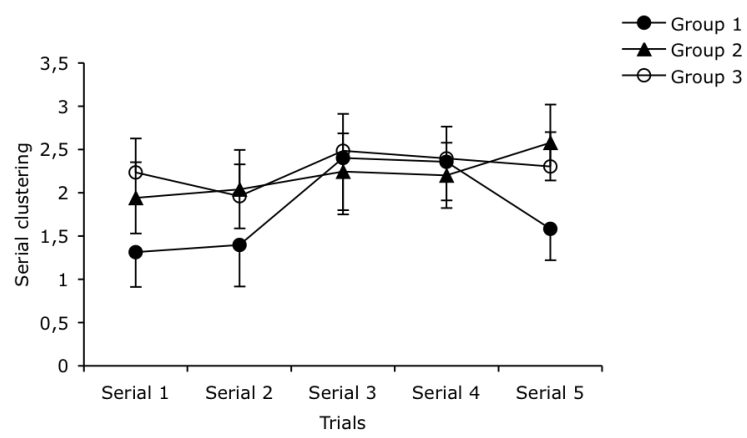

Note. Error bars reflect standard error. 


\section{Discussion}

The aim of the current study was to test the hypothesis that developmental differences exist in the use of strategies, i.e. serial and subjective clustering, during a multi-trial Pictorial Verbal Learning Test (PVLT).

The use of serial clustering in the first two presentations was correlated with better performance, whereas the use of subjective clustering was correlated with better performance when more than two presentations were given. Therefore, the children with the best performance (as measured with these strategies), used serial clustering, when only one or two presentations were offered. They then proceeded to use (additional) subjective clustering when more than two presentations were offered.

When the information was perceived for the first or second time, the children probably experienced this as an overload of information, perhaps as a result of unfamiliarity with the test and procedures. Possibly, they did not know what to do and were not able to anticipate. As a result, the child may have become confused, which decreased the time available for them to actively handle the information. It is of importance that our data show that with only one or two presentations, the best strategy was to simply perceive the information and try to repeat it as it was heard. The best performance was obtained when the order of the information during the recall was not changed from the presentation order. Even though the child could have used a rehearsal strategy, the order of the information was not rearranged.

With more than two presentations, the overload of the presented information appears to have become less. One explanation for this is that the child was now more familiar with the procedures of the test. This resulted in less confusion and a reduction in information overload. When the feeling of overload was reduced, there was more time to try other retrieval procedures during recall. Another reason is, that due to the first presentation, second presentation, and recall, some words were already in longterm memory. These words required less attention and time, resulting also in more time being available for other processes during recall. More time available lead to the active rearrangement of the order of the presented information into groups, such as organization or coupling. The coupling of the words is based on the active construction of a logical connection between the words. Examples are the use of the category that several words belong to, or the fact that several words share a similar sound. The benefit of the use of this strategy is that if one word of a group of coupled words is recalled, the other words also become automatically active in memory and are retrieved as well. This leads to a better performance.

Serial clustering did not differ with repeated presentations whereas subjective clustering increased. The increase was smallest for children aged 6 to 7 (group 1) and fastest and largest for children aged 10 and older (group 3). Post hoc analyses per group revealed that the increase of subjective clustering was significant for the children older than 8 . The passive -simple- strategy (serial clustering) is probably fully developed at age 6, because all children used it to the same extent. On the other hand, the more complex organizational strategy (subjective clustering) developed after the age of 7 . Children aged 8 to 9 showed a different pattern of increase of subjective 
clustering as compared to children aged 10 to 12, but reached the same extent of subjective clustering with five presentations.

The findings of the current study suggest that children above the age of seven acquire the skill of subjective clustering with repeated presentations. This development is gradual: the older the child, the faster and better the subjective clustering. This development of strategy use can explain the differences in verbal learning performance with increasing age (Bjorklund \& Douglas, 1997; Bukatko \& Daehler, 1998; DeMarie \& Ferron, 2003; Ornstein, 1999; Schneider et al., 2002; Siegler \& Wagner Alibali, 2005). The findings are compatible with recent theories on the development of various executive functions (Anderson, 2002; Brocki \& Bohlin, 2004; Casey, Giedd, \& Thomas, 2000). Functions that are needed for the execution of strategies are, for instance, working memory and planning. Working memory is required because during strategy use, information needs to be kept active while performing a strategy. Serial clustering requires less effort from working memory because the information is not actively rearranged. The sole maintenance of the information is enough to recall it in the same order as presented. On the other hand, during subjective clustering, more processes have to be executed at once. Not only must the information be kept active (i.e., maintained), it has to be rearranged at the same time (i.e., manipulated). Planning is needed to decide when and what strategy is best to use. Since executive functions are known to develop during primary school and beyond (Anderson, 2002), the use of strategies possibly develops in parallel. The development of these functions coheres with brain development, more specifically, with the frontal lobe development (Gogtay et al., 2004). It has been hypothesised that the frontal lobe is a region that is important for the executive functions (Alvarez \& Emory, 2006).

In the current study, we attempted to create a situation in which verbal learning was potentially optimal. This was accomplished by using a pictorial verbal learning test and including only children with a high level of parental education (LPE). Further studies should include verbal learning tests with several presentation modalities, such as auditory presentation in addition to a pictorial presentation. Verbal learning performance with a pictorial presentation is better than verbal learning performance with an auditory presentation (Lezak et al., 2004). This is due to the recoding of the pictorial presented information into a phonological code for processing. Information that is presented auditory, automatically has a phonological code and hence, needs less processing. The extra processing of the pictures leads to better recall (for more information see Baddeley, 1997). Additionally, better performance with a pictorial presentation is due to the activation pattern in the brain when information is presented pictorial and has to be recalled verbally. Visually presented information (i.e., pictures or written words) is processed in both the visual and the auditory processing streams. Connections between both streams lead to a better recall. In contrast, when information is presented auditory and has to be recalled verbally, the information remains in the same modality and this results in a single activation pattern, thus no connections and hence a lower recall (Beacham, Elliott, Alty, \& Al-Sharrah, 2002). 
Furthermore, children with a different LPE should be included. This is needed to be able to generalize these findings to larger populations, such as all primary school-aged children. Nevertheless, the current study presents valuable information on the processes that are involved in learning at different ages. Furthermore, the findings could be of great value for the study of learning deficits in children with potential learning problems who have an average intelligence such as children with ADHD and related conditions. If their learning problems are the result of deficits in strategy use, this can possibly be trained (Bjorklund \& Douglas, 1997; Bjorklund, Miller, Coyle, \& Slawinsky, 1997; Schneider \& Pressley, 1997; Siegler \& Wagner Alibali, 2005).

\section{Conclusion and Implications}

The verbal learning situation in the current study gives insight in learning processes in children. The results of the current study show that children aged six to seven do not actively rearrange to-be-remembered information, but that they try to remember it in the order the material is presented to them. When children above the age of seven are presented information several times, they actively handle the information by grouping it together in meaningful groups. This makes it easier to remember and leads to better recall. Children that deviate from this pattern of strategy use can be detected and possibly trained (Bjorklund \& Douglas, 1997; Bjorklund et al., 1997; Schneider \& Pressley, 1997; Siegler \& Wagner Alibali, 2005). This can lead to a better verbal learning performance. With regard to the presentation of the to-be-remembered information adjusted to the age of the child, information should be presented in such a format that simple passive strategy use is sufficient to remember the information for children under the age of eight. Information can be presented in shorter lists, and repeatedly, so the younger children have more time to reach the same performance as older children. The current findings also suggest that experimental interventions could be targeted at training children in the efficient use of learning strategies. 


\section{References}

Alvarez, J. A., \& Emory, E. (2006). Executive function and the frontal lobes: A meta-analytic review. Neuropsychology Review, 16, 17-42.

Anderson, P. (2002). Assessment and development of executive function (EF) during childhood. Child Neuropsychology, 8, 71-82.

Baddeley, A. D. (1997). Human Memory: Theory and Practice, Revised Edition. Hove: Psychology Press.

Beacham, N. A., Elliott, A. C., Alty, J. L., \& Al-Sharrah, A. (2002). Media combinations and learning styles: A dual coding approach. Paper presented at the ED-MEDIA 2002 World Conference on Educational Multimedia, Hypermedia \& Telecommunications, Denver, Colorado.

Berk, L. E. (1998). Development Through the Lifespan. Needham Heights, MA: Allyn \& Bacon.

Bjorklund, D. F., \& Douglas, R. N. (1997). The development of memory strategies. In N. Cowan \& C. Hulme (Eds.), The Development of Memory in Childhood (pp. 201-246). Hove, East Sussex, UK: Psychology Press.

Bjorklund, D. F., Miller, P. H., Coyle, T., R., \& Slawinsky, J. L. (1997). Instructing children to use memory strategies: Evidence of utilization deficiencies in memory training studies. Developmental Review, $17,411-441$.

Brand, N., \& Jolles, J. (1985). Learning and retrieval rate of words presented auditory and visually. The Journal of General Psychology, 112, 201-210.

Brocki, K. C., \& Bohlin, G. (2004). Executive functions in children aged 6 tot 13: A dimensional and developmental study. Developmental Neuropsychology, 26(2), 571-593.

Bukatko, D., \& Daehler, M. W. (1998). Child Development: a Thematic Approach (3rd ed.). Boston: Houghton Mifflin Company.

Casey, B. J., Giedd, J. N., \& Thomas, K. M. (2000). Structural and functional brain development and its relation to cognitive development. Biological Psychology, 54, 241-257.

Cohen, J. (1992). A power primer. Psychological Bulletin, 112, 155-159.

De Bie, S. E. (1987). Standaardvragen 1987: Voorstellen voor uniformering van vraagstellingen naar de achtergrondkenmerken en interviews [Standard questions 1987: Proposal for the uniformization of questions regarding background variables and interviews] (2nd ed.). Leiden, The Netherlands: Leiden University Press.

DeMarie, D., \& Ferron, J. (2003). Capacity, strategies, and metamemory: Test of a three-factor model of memory development. Journal of Experimental Child Psychology, 84, 167-193.

Gaultney, J. F. (1998). Utilization deficiencies among children with learning disabilities. Learning and Individual Differences, 10, 13-28.

Gogtay, N., Giedd, J. N., Lusk, L., Hayashi, K. M., Greenstein, D., Vaituzis, A. C., et al. (2004). Dynamic mapping of human cortical development during childhood through early childhood. Proceedings of the National Academy of the Sciences, 101, 8174-8179.

Greenberg, M. T., Lengua, L. J., Coie, J. D., \& Pinderhughes, E. E. (1999). Predicting developmental outcomes at school entry using a multiple-risk model: Four American communities. The Conduct Problems Prevention Research Group; Developmental Psychology, 35, 403-417.

Kalff, A. C., Kroes, M., Vles, J. S. H., Bosma, H., Feron, F. J. M., Hendriksen, J. G. M., et al. (2001). Factors affecting the relation between parental education as well as occupation and problem behavior in Dutch 5- to 6- year- old children. Social Psychiatry and Psychiatric Epidemiology, 36, 324-331.

Kirchhoff, B. A., \& Buckner, R. L. (2006). Functional-anatomic correlates of individual differences in memory. Neuron, 51, 263-274.

Lezak, M. D. (1995). Neuropsychological Assessment (3rd ed.). New York: Oxford University Press.

Lezak, M. D., Howieson, D. B., \& Loring, D. W. (2004). Neuropsychological Assessment (4th ed.). New York: Oxford University Press.

Linschoten, J. (1963). De La Court's Frequentietellingen van Nederlandse Woorden [De la Court's Frequency Counts of Dutch Words]. (Report 6301). Utrecht, The Netherlands: University of Utrecht, Psychologisch Laboratorium.

Lupien, S. J., King, S., Meaney, M. J., \& McEwen, B. S. (2001). Can poverty get under your skin? Basal cortisol levels and cognitive function in children from high and low socioeconomic status. Development and Psychopathology, 13, 653-676.

McCulloch, A., \& Joshi, H. E. (2001). Neighbourhood and family influences on the cognitive ability of children in the British National Child Development Study. Social Science \& Medicine, 53, 579591. 
Ornstein, P. A. (1999). Comments: Towards an understanding of the development of memory. In F. E. Weinert \& W. Schneider (Eds.), Individual Development from 3 to 12: Findings from the Munich Longitudinal Study (pp. 94-105). Cambridge, England, UK: Cambridge University Press.

Saan, R. J., \& Deelman, B. G. (1986). Nieuwe 15-woorden test A en B (15WT-A en 15WT-B) [New 15words test A and B (15WT-A and 15 WT-B)]. In A. Bouma, J. Mulder \& J. Lindeboom (Eds.), Neuropsychologisch Handboek (pp. 13-28). Amsterdam: Swets \& Zeitlinger.

Santrock, J. W. (2001). Educational Psychology. New York: McGraw-Hill.

Schlagmuller, M., \& Schneider, W. (2002). The development of organizational strategies in children: Evidence from a microgenetic longitudinal study. Journal of Experimental Child Psychology, 81, 298-319.

Schneider, W., Knopf, M., \& Stefanek, J. (2002). The development of verbal memory in childhood and adolescence: Findings from the Munich Longitudinal Study. Journal of Educational psychology, 94, 751-761.

Schneider, W., \& Pressley, M. (1997). Memory Development Between Two and Twenty (2nd ed.). Mahwah, $\mathrm{NJ}$ : Lawrence Erlbaum Associates.

Siegler, R. S., \& Wagner Alibali, M. (2005). Children's Thinking (4th ed.). Upper Saddle River, NJ: Pearson Prentice Hall.

Sternberg, R. J., \& Tulving, E. (1977). The measurement of subjective organization in free recall. Psychological Bulletin, 84, 539-566.

Suizzo, M., \& Stapleton, L. M. (2007). Home-based parental involvement in young children's education: Examining the effects of maternal education across U.S. ethnic groups. Educational Psychology, 27, 1-24.

United Nations Educational Scientific and Cultural Organisation (UNESCO). (1997). International Standard Classification of Education (ISCED). Paris: UNESCO.

Van der Elst, W., Van Boxtel, M. P. J., Van Breukelen, G., J. P., \& Jolles, J. (2005). Rey's Verbal Learning test: normative data for 1,855 healthy participants aged 24-81 years and the influence of age, sex, education, and mode of presentation. Journal of the International Neuropsychological Society, 11, 290-302.

Van Loon-Vervoorn, W. A. (1989). Voorstelbaarheidswaarden van Nederlandse Woorden [Imageability Ratings of Dutch Words]. Lisse, The Netherlands: Swets \& Zeitlinger. 



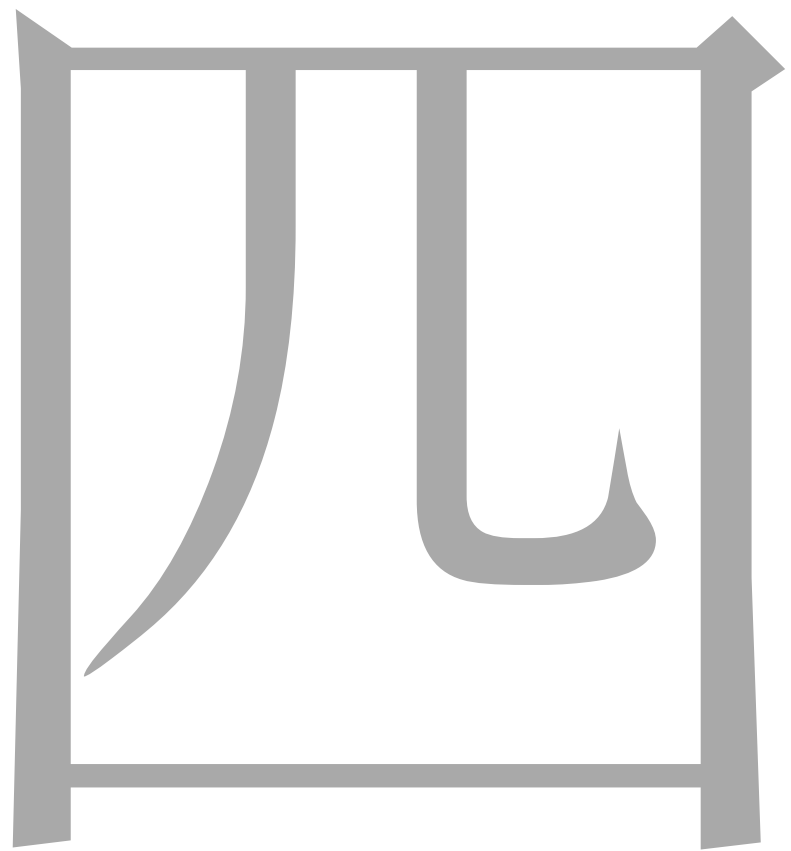




\title{
Chapter 4
}

\section{Auditory and Pictorial Verbal Learning Compared: A Cross-sectional Study of Children aged 5 - 15}

\begin{abstract}
This study compared the effect of two modalities of information presentation, i.e. auditory and pictorial, on the development of verbal learning in children and explored the relationship of these developmental patterns to sex differences. Either a Pictorial Verbal Learning Test (PVLT) or an Auditory Verbal learning test (AVLT) was given to 431 children aged 5 to 15 in order to measure working memory, learning with repeated presentations, delayed recall, and long-term recognition memory. Firstly, the presentation modality is only of influence on working memory, not on the other measures of the VLT. Moreover, it was only of influence in children that were older than kindergarten. This is related to the development of the articulatory control process that is needed for recoding of the pictures into a phonological-verbal code, which is the process that enhances recall of pictorially presented information in comparison to auditorily presented information. Secondly, with regard to the relationship between verbal learning performance and sex differences, it emerged that girls outperformed boys in delayed recall, irrespective of the presentation modality. There was no difference between girls and boys with regard to their long-term recognition memory performance. Thus, girls perform better at tests with open questions that assess the retrieval of information from long-term memory, but no sex differences are found on tests with a guided search (as with recognition tests) that assess the actual stored knowledge.
\end{abstract}

C. J. C. Meijs, P. P. M. Hurks, R. Wassenberg, F. J. M. Feron, \& J. Jolles. Manuscript submitted for publication. 


\section{Introduction}

During interaction with peers or parents, and in educational settings, the most common form of presenting information to children is in an auditory mode. It is also a noteworthy fact that most of the scientific investigations into the development of verbal learning conducted until now have used auditory presentations of to-be-remembered words in their tests (Bjorklund \& Douglas, 1997; Cox \& Waters, 1986; Lezak, Howieson, \& Loring, 2004; Schneider \& Pressley, 1997; Van Den Burg \& Kingma, 1999). As a result, very little attention has been paid to the effect of pictorially presented information on the developmental pattern of verbal learning in children, while adult studies showed that a pictorial presentation leads to better performance on verbal learning test (Lezak, 1995). A differential development of verbal learning performance with an auditory or a pictorial presentation of the words has not been studied before and the influence of the presentation modality has been neglected as a factor of both methodological and theoretical importance (Halliday, Hitch, Lennon, \& Pettipher, 1990). If a difference between pictorial and auditory verbal learning performance does exist, this could have important consequences for the optimal presentation of information to children. Studies into the influence of the presentation modality on verbal performance could lead to insights about the learning processes of children, which could help improve their learning performance at various stages of their development. Therefore, the first aim of the current study was to evaluate the influence that the presentation modality (pictorial or auditory) has on the development of learning in children if the processing of the information takes place in a verbal mode. Moreover, as there is some evidence of a relationship between verbal learning performance and whether the child is male or female, sex differences are potentially a relevant factor in this context and must be taken into account (Kramer, Delis, Kaplan, O'Donnel, \& Prifitera, 1997). As such, the effect of sex differences had not been considered extensively in earlier studies of the relationship between presentation modality and verbal learning. Therefore, the second aim of the current study was to evaluate the influence of sex differences on pictorial and auditory verbal learning performance in children.

Indications that the pictorial form of information presentation ensures better verbal learning performance than the auditory form come from the working memory model (Baddeley, 1997). Learning and memory are highly dependent on each other and are subject to the same influences (OECD). Therefore, in the study of verbal learning, the working memory model will be used to explain of verbal learning performance. This model consists of a central executive, which is a controlling attentional system, and two slave systems. The first slave system is the phonological loop and consists of a phonological store that is capable of holding speech-based information and an articulatory control process that is based on inner speech. The second slave system is the visuo-spatial sketchpad, which is responsible for setting up and manipulating visuo-spatial images. The model explains that pictorially presented information has to be recoded into a phonological code for a verbal recall by the articulatory control process. On the other hand, auditorily presented information 
automatically has a phonological code and thus needs no recoding. The recoding entails deeper processing of the pictorial information, which presumably leads to a better verbal learning performance if information is presented as pictures as compared to written or auditorily presented words (Baddeley, 1997). Studies indicate that it is around the age of seven years that the articulatory control process in the phonological loop becomes active (Baddeley \& Hitch, 2000; Cowan, 1998; Fry \& Hale, 2000; Kemps, De Rammelaere, \& Desmet, 2000; Palmer, 2000). Before that age, the processing of visually presented information takes place solely in a visuo-spatial code (Brocki \& Bohlin, 2004; Halliday et al., 1990; Henry, Turner, Smith, \& Leather, 2000). This is in agreement with the notion that children first use visual strategies, followed by both visual and verbal strategies and later use predominantly verbal strategies. This was studied by whether children spontaneously labelled pictures (Palmer, 2000) and for a pictorial presented verbal learning test, the pictures need to be labelled. Thus, differences in -verbal recall- working memory performance with a pictorial and an auditory presentation could be expected after about age seven. However, the learning process at school requires other types of learning and memory functions besides working memory, such as learning with repeated presentations, long-term free recall and recognition memory. As the working memory model does not describe the effects of the presentation modality on the latter memory aspects, it presents us with an incomplete view of the verbal learning process. Similarly, it is not clear yet whether the presentation modality has the same influence on all aspects of the verbal learning test, because working memory probably is related to the other aspects, but the extent of this relationship with regard to the presentation modality needs to be explored.

Therefore, the first aim of the current study was the assessment of a differential development of verbal learning performance with a pictorial and an auditory presentation modality among children in the ages from childhood to adolescence. This was assessed for working memory, but moreover, also for learning with repeated presentations, delayed recall and long-term recognition. A better pictorial verbal learning performance was expected for children above the age of seven, whereas no effect was expected in children under the age of seven.

When it comes to this study's second aim, namely the evaluation of the influence of sex differences on pictorial and auditory verbal learning performance in children, a lot of ground remains to be covered. In general, studies indicate that boys and girls differ in many ways that may affect verbal learning. Differences in behavioural and brain development have to be taken into account. For example, girls show a faster development of the brain than boys (Blakemore \& Frith, 2005; De Bellis et al., 2001; Giedd et al., 1999; Overman, 2004; Paus, 2005), and there appears to be a differential development of the areas that have been described to be related to verbal learning, namely the frontal and the parietal lobe (Giedd et al., 1999). Additionally, the brain of girls lateralizes earlier in life and matures faster than that of boys (Bukatko \& Daehler, 1998). Thus, in general, it can be expected that girls precede boys in the development of performance on verbal tests. However, some controversy still exists about the relationship between sex differences and verbal learning performance. Some studies have reported that sex does not affect verbal 
learning performance (Bishop, Knights, \& Stoddart, 1990; Forrester \& Geffen, 1991; Van Den Burg \& Kingma, 1999), whereas others have concluded that a relationship does exist, namely that girls perform better than boys (Vakil, Blachstein, \& Sheinman, 1998). Some of the studies that reported differences in verbal learning performance related to sex indicate that these differences are due to the use of strategies (Kramer et al., 1997). A study using verbal learning tests (VLTs) with related and unrelated words, to test children aged 6 to 11, reported that boys had a developmental lag compared to girls with regard to first use and further generalisation of memory enhancing strategies that organize information into chunks (Cox \& Waters, 1986). Organization of information enhances performance on verbal learning tests. Studies that used only lists of semantically related words reported that girls performed better than boys, and hypothesized that this was caused by better strategy use by girls, namely by better semantic clustering (Kramer et al., 1997). Regardless of the mechanism that causes sex differences in verbal learning performance, the finding remains that if sex differences are found, these indicate that girls perform better than boys. However, the relevance of these results is limited by the fact that most of these studies only made use of VLTs with an auditory presentation. Thus, besides the fact that more research is needed to determine whether sex differences influence verbal learning performance in general, insight into the relationship between sex differences and verbal learning performance with a pictorial or an auditory presentation is, as yet, almost completely lacking. Hence, the current study is the first to fill the gap and evaluate the influence of sex differences with regard to both pictorial and auditory verbal learning performance. It has been reported that boys have a better spatial short-term memory than girls (Lowe, Mayfield, \& Reynolds, 2003; Orsini et al., 1987). If pictorially presented information is processed, at least partly, as spatial information before it is recoded into a phonological code, then it might be the case that boys may compensate for their possible developmental lag in verbal learning if there is pictorial information processing. Based on this, it was expected that girls would outperform boys in all aspects of memory performance involving auditorily presented information, but that boys would outperform girls or at least perform equally to girls when the information was presented pictorially. However, if this processing in the visuo-spatial sketchpad is terminated before spatial processing takes place, then girls would perform better than boys with both the pictorial and the auditory presentation modality.

In order to study the potential differences in development of verbal learning with a pictorial and auditory presentation and the influence of sex on this, a largescale cross-sectional study of 431 children aged 5 to 15 was conducted. The verbal learning aspects assessed in the current study were: (1) working memory (i.e., trial 1 ), (2-5) learning with repeated presentations (i.e., trials 2 to 5$)$, (6) total number of words recalled (i.e., sum of trials 1 to 5), (7) delayed recall, and (8) long-term recognition memory. They were measured by use of a verbal learning test (VLT). Half of the children performed a Pictorial VLT (PVLT) in which the words were presented as pictures and the other half an Auditory VLT (AVLT) in which the words were presented orally. The range of this study had the important advantage of enabling (a) comparison of the developmental trajectories of pictorial and auditory verbal learning 
performance for several verbal learning aspects (as compared to only working memory in the working memory model), (b) coverage of a broad age-range and sex differences during primary school and secondary school, and (c) a study of the influence of sex on verbal learning performance with both presentation modalities. Two factors that have been identified to influence on verbal learning, namely, verbal IQ (Berk, 1998) and the level of parental education (LPE) were corrected for. LPE is in many studies described as part of the measure 'socio-economic status' (DeGarmo, Forgatch, \& Martinez, 1999; Greenberg, Lengua, Coie, \& Pinderhughes, 1999; Lupien, King, Meaney, \& McEwen, 2001; McCulloch \& Joshi, 2001; Suizzo \& Stapleton, 2007). Children with a higher SES have been reported to have a better cognitive development or verbal learning performance (Bishop et al., 1990; Santrock, 2001; Schneider \& Pressley, 1997; Siegler \& Wagner Alibali, 2005; Vakil et al., 1998; Van Den Burg \& Kingma, 1999).

\section{Method}

\section{Participants}

The current study was part of a large cross-sectional and longitudinal Cognitive Development Study of School-aged children (abbreviation in Dutch: COOS which stands for 'Cognitief Ontwikkelings Onderzoek bij Schoolgaande kinderen', i.e., cognitive development study in school-aged children), performed by the School for Mental Health and Neuroscience of Maastricht University (Wassenberg et al., in press). Only cross-sectional data were used in the current study. Participants were recruited from 29 regular primary and secondary schools in the city of Maastricht and surroundings (The Netherlands). The parents/caregivers (referred to as caregivers hereafter) of the children in kindergarten, grades 2, 4, 6 (primary schools), and 7 and 8 (secondary schools; ranging from lower secondary professional education to preuniversity education) received an information package via the school describing the purpose of the study, a request to participate, a questionnaire, a form to give consent for the child to participate, and a stamped-addressed envelope.

Of the 1086 caregivers who replied, $892(82 \%)$ gave consent for their child to participate. Children who met the following criteria were eligible for participation: the child (1) had not repeated and/or skipped a grade, (2) had the Dutch nationality (in view of fluency in Dutch), and (3) did not use medication that is known to influence the cognitive performance (for instance, asthma medications). An attempt was made to select children by school-grade and sex per grade and also to include children from a range of socioeconomic backgrounds. In total, 431 children (215 boys, 216 girls) in the ages of 5.67 to 15.08 years were selected to participate in the current study. From these, the data of 378 children were used in the analyses (see Table 1 for an overview of the demographic variables of these children). Sex and the LPE were divided evenly over the grades; VIQ was not (see Table 1). For details of the inclusion critera in the analyses see the section on Statistics. 
All children completed a battery of neuropsychological tests, including tests measuring verbal ability (VIQ), language comprehension, time estimation, and memory. The tests that were used for the current study were a verbal learning test (VLT) and a test for verbal ability (VIQ). The children were tested individually in a room at their schools by well-trained psychological assistants (i.e., undergraduate psychology students). Testing took approximately 1.5 hours; all tests were administered in the same order for each child. The Ethics Committee of the Faculty of Psychology of Maastricht University approved the study protocol.

Table 1. Demographics of the 378 children that were included in the analyses

\begin{tabular}{lllll}
\hline Grade & Boys & Girls & VIQ $(s d)$ & LPE $(s d)$ \\
\hline $\mathrm{K}$ & 27 & 32 & $11.08(2.848)$ & $4.97(1.757)$ \\
2 & 34 & 30 & $10.84(2.790)$ & $5.14(1.807)$ \\
4 & 30 & 42 & $10.40(2.663)$ & $5.15(1.831)$ \\
6 & 30 & 34 & $9.97(1.877)$ & $5.39(1.724)$ \\
7 & 38 & 29 & $9.94(2.095)$ & $5.52(1.894)$ \\
8 & 30 & 22 & $9.77(2.228)$ & $4.98(1.852)$ \\
\hline $\mathrm{N}=$ & Pearson Chi-square $=5.363$, & Pearson Chi-square $=.0137$, & Pearson Chi-square $=38.209$, \\
378 & $d f=5, p=.373$ & $d f=70, p=.006$ & $d f=30, p=.144$ \\
\hline
\end{tabular}

Note. $\mathrm{K}=$ kindergarten.

\section{Instruments}

\section{VLT}

A verbal learning test (VLT) is often used in clinical settings and memory research, and is one of the most sensitive verbal memory tests. Its test-retest reliability is reported to be high (Lezak, 1995; Van der Elst, Van Boxtel, Van Breukelen, \& Jolles, 2005). The test was administered as described previously (Brand \& Jolles, 1985; Van der Elst et al., 2005). The words used in the test had been checked for their frequency of use (Linschoten, 1963) and imageability (Van Loon-Vervoorn, 1989). Half of the children performed a pictorial verbal learning test (PVLT) in which the words were presented as concrete line-drawing pictures, and the other children performed an auditory verbal learning test (AVLT), in which the words were presented auditory. Per grade, the children were divided at random over the presentation modalities; the procedure was the same for both modalities. The words were presented by computer by a male voice of an experienced speaker. The pictures were also presented on a computer. Pictures and words (both will be called items hereafter) were presented at a rate of one item every two seconds and the presentation time of the pictures was the mean presentation duration of the words. The items were not presented to the children before the first trial. The PVLT and the AVLT both consisted of 5 trials of presentations of 15 items of familiar objects. All items were words acquired before the age of six (Van der Elst et al., 2005). They were presented to the children in the same order in each trial (immediate recall). After each presentation of all items, the children had to verbally recall as many items as they remembered. After about 15 to 20 minutes, during which no memory interfering tests were administered, the children 
were asked to recall as many items as possible from the list, without prompting (delayed recall). This was followed by a recognition trial, in which 30 items were presented, of which 15 items were from the immediate recall task and 15 were new items. The children had to answer 'Yes' or 'No' to whether the item belonged to the list of items presented to them in the immediate recall task. Because of the longitudinal set-up of the Cognitive Development Study, three parallel test versions were used in both presentation modalities. The memory aspects used in the current study were: trials 1 to 5 , total score summed over trials 1 to 5 , delayed recall, and recognition memory. Trial score 1 was used as a measure for working memory instead of a shortterm memory test (Unsworth \& Engle, 2006). We assumed that, comparable to a working memory test: (a) trial 1 was experienced as a processing and maintenance task by the child and (b) the child would not use active strategies during this first presentation, because of the overload of information. Recognition memory was analyzed as the number of correctly recognized words minus the number of falsely recognized words in order to correct for impulsivity, which was assumed to be expressed by the tendency of saying 'yes' (thus recognizing) to all words in the recognition test (Forrester \& Geffen, 1991).

The level of parental education (LPE)

Caregivers indicated their highest level of education attained on a commonly used Dutch educational rating scale ranging from primary school (1) to university degree (8) (De Bie, 1987; Kalff et al., 2001). This system is similar to the International Standard Classification of Education (United Nations Educational Scientific and Cultural Organisation (UNESCO), 1997).

\section{Verbal ability (VIQ)}

The estimate of verbal ability (VIQ) was the standard score of the Vocabulary subtest of the Dutch Wechsler Intelligence Scales Revised (WISC-Rn) (De Bruin et al., 1986). The WISC-Rn, rather than the WISC-III, was used because the latter became available in the Netherlands after the study had started (Wassenberg et al., in press). In this test, the children have to explain words, ranging from easy to complex. The standard score ranges from 1 to 19 (mean $=10, S D=3$ ). The reliability and validity have been described as average to good (De Bruin et al., 1986).

\section{Statistics}

Missing data and extreme values

Before data analysis, extreme values and missing data were assessed. First, we checked for unreliable testing. The children for whom the administration of the VLT ( $\mathrm{n}$ $=23)$ or VIQ $(n=30)$ was unreliable were excluded from the dataset, resulting in the inclusion of 378 children. Unreliability was due to several factors including technical problems such as failure of equipment, refusal of the child to cooperate, or low motivation (for instance due to fatigue). Missing data were not replaced because about $5 \%$ of data were missing per measure (Croy \& Novins, 2005). Second, memory performance was checked for extreme values, defined as values minimally three times 
the interquartile distance above the $75^{\text {th }}$ percentile or below the $25^{\text {th }}$ percentile (Huizingh, 2002). These were not found.

\section{Variables}

Linear regression models were fitted using a step-down hierarchical procedure for the dependent variables (1) working memory (i.e., trial score 1), (2-5) learning with repeated presentations (i.e., trials 2 to 5), (6) total score (summed over trials 1 to 5 ), and (7) long-term memory (delayed recall). Because performance scores on the recognition test were not normally distributed, Chi-square analyses were used, with the presentation modality, grade, and sex as independent variables.

Five main predictors were included in the basic regression models, namely: presentation modality (pictorial or auditory, coded as respectively 0 and 1 ); grade ( $\mathrm{k}$, 2, 4, 6, 7, and 8); sex (coded as boys: 0 and girls: 1); VIQ (standard score); and LPE (range from 1 to 8 ). Quadratic grade (grade ${ }^{2}$ ) was used to detect non-linear age effects. Furthermore, the interactions terms: 'the presentation modality $x$ grade', 'the presentation modality $x$ quadratic grade', and 'the presentation modality $x$ sex', 'grade $x$ sex', and 'quadratic grade $x$ sex' were included in the regression model to study the possible coherence between these predictors (Lupien et al., 2001; Suizzo \& Stapleton, 2007). Non-significant predictors $(p>.05)$ were excluded from the final models but were not removed if there was a significant quadratic term or interaction term that included that main predictor (Kleinbaum, Kupper, Muller, \& Nizam, 1998). It was assessed whether the residuals of the dependent variables were normally distributed.

Additionally, GLM Univariate analyses were performed for trial 1 and total score as dependent variable and grade, sex, VIQ and LPE as independent variables, to study whether there were significant increases in number of items that were recalled in the successive grades.

\section{Results}

Differential effects of the presentation modality with grade

Working memory (i.e., trial 1) and total score summed over trials 1 to 5 were, amongst others, predicted by the interaction term 'the presentation modality x grade'. For a complete overview of the significant predictions see Table 2. As can be seen in Figures 1 and 2, children that were in kindergarten recalled the same number of words on the PVLT and the AVLT, while children in the older grades recalled more words on the PVLT than on the AVLT on these measures. Additionally, there was a significant increase in the number of words that was recalled between kindergarten and grade 2 on the PVLT, but not on the AVLT for both working memory and total number of words recalled (see Table 3 ).

The trials and the delayed recall were not predicted by the interaction term 'the presentation modality $x$ grade', which indicates that the developmental patterns on these measures were similar. However, this does not imply that there were no main effects of the presentation modality. On these measures, performance on the PVLT 
was in all grades better. This will be described in the section on the main effects of the presentation modality.

Differential developmental patterns for the presentation modality could not be analyzed for recognition performance because the data were not normally distributed.

Table 2. Final Linear Regression models for the Memory Aspects

\begin{tabular}{|c|c|c|c|c|c|c|c|}
\hline Aspect of verbal learning & Predictors & $B$ & SE B & $T$ & & $\beta$ & Adjusted $R^{2}$ \\
\hline \multirow{6}{*}{ Trial 1 (Working memory) } & Constant & 2.604 & .582 & 4.474 & ** & & .402 \\
\hline & PM & .926 & .836 & 1.108 & & .222 & \\
\hline & Grade & 1.258 & .226 & 5.556 & ** & 1.669 & \\
\hline & Grade $^{2}$ & -.068 & .019 & -3.591 & ** & -.1094 & \\
\hline & $P M \times$ grade & -.836 & .319 & -.2 .621 & ** & -1.528 & \\
\hline & $P M \times$ grade $^{2}$ & .063 & .026 & 2.1391 & * & 1.050 & \\
\hline \multirow{4}{*}{ Trial 2} & Constant & 4.322 & .545 & 7.932 & ** & & .385 \\
\hline & PM & -1.198 & .206 & -5.821 & ** & -.227 & \\
\hline & Grade & 1.173 & .204 & 5.742 & ** & 1.228 & \\
\hline & Grade $^{2}$ & -.052 & .017 & -3.742 & ** & -.659 & \\
\hline \multirow{4}{*}{ Trial 3} & Constant & 3.310 & .560 & 5.914 & ** & & .440 \\
\hline & PM & -.843 & .211 & -3.984 & ** & -.148 & \\
\hline & Grade & 1.808 & .210 & 8.616 & ** & 1.758 & \\
\hline & Grade $^{2}$ & -.098 & .017 & -5.662 & ** & -1.155 & \\
\hline \multirow{5}{*}{ Trial 4} & Constant & 4.170 & .818 & 5.096 & ** & & .333 \\
\hline & PM & -.876 & .228 & -3.849 & ** & -.162 & \\
\hline & Grade & 1.443 & .230 & 6.280 & ** & 1.459 & \\
\hline & Grade $^{2}$ & -.074 & .019 & -3.957 & ** & -.919 & \\
\hline & VIQ & .096 & .047 & 2.057 & * & .088 & \\
\hline \multirow{4}{*}{ Trial 5} & Constant & 4.887 & .560 & 8.720 & ** & & .398 \\
\hline & PM & -.709 & .212 & -3.346 & ** & -.129 & \\
\hline & Grade & 1.599 & .210 & 7.613 & ** & 1.611 & \\
\hline & Grade $^{2}$ & -.084 & .017 & -4.866 & ** & -1.030 & \\
\hline \multirow{6}{*}{ Total score } & Constant & 16.591 & 2.960 & 5.604 & ** & & .517 \\
\hline & PM & -1.112 & 2.048 & -5.43 & & -.050 & \\
\hline & Grade & 6.838 & .807 & 8.476 & ** & 1.683 & \\
\hline & Grade $^{2}$ & -.311 & .066 & -4.720 & ** & -.936 & \\
\hline & PM $x$ grade & -.614 & .293 & -2.097 & * & -.213 & \\
\hline & VIQ & .355 & .163 & 2.174 & * & .079 & \\
\hline \multirow{6}{*}{ Delayed recall } & Constant & 4.742 & .840 & 5.643 & ** & & .308 \\
\hline & $\mathrm{PM}$ & -1.539 & .230 & -6.680 & $* *$ & -.288 & \\
\hline & Grade & 1.256 & .232 & 5.409 & ** & 1.290 & \\
\hline & Grade $^{2}$ & -.066 & .019 & -3.459 & ** & -.825 & \\
\hline & Sex & .720 & .231 & 3.109 & ** & .135 & \\
\hline & VIQ & .105 & .047 & 2.227 & * & .098 & \\
\hline
\end{tabular}

Note. $\mathrm{PM}=$ presentation modality. ${ }^{*} p<.05,{ }^{* \star} p<.01$ 
Figure 1. Trial score 1 per grade, separate lines for the PVLT and the AVLT

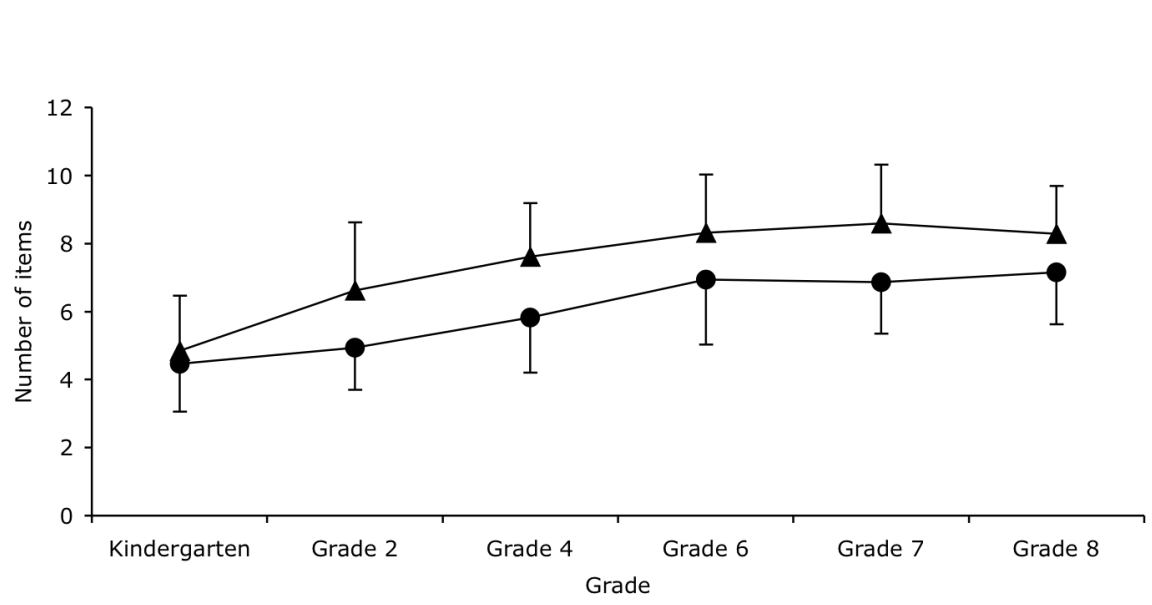

Note. Error bars reflect standard deviations. PVLT = pictorial verbal learning test, AVLT auditory verbal learning test

Figure 2. Total score per grade, separate lines for the PVLT and the VLT

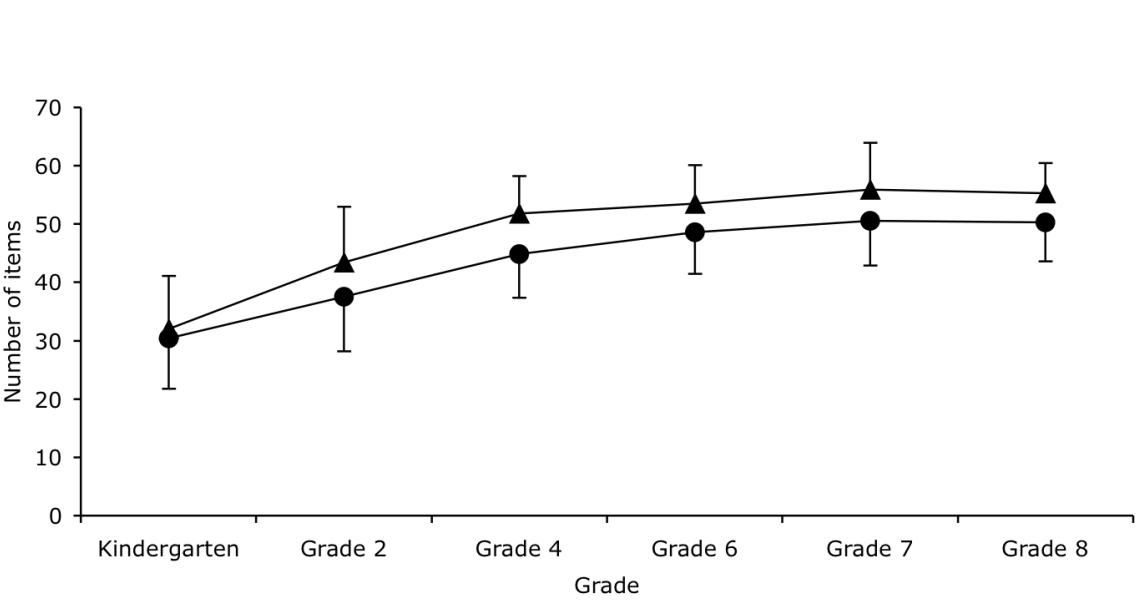

Note. Error bars reflect standard deviations. PVLT = pictorial verbal learning test, AVLT auditory verbal learning test 
Table 3. Differences in terms of significances in number of items that were recalled with increasing grade for the PVLT and the AVLT

\begin{tabular}{llll} 
& & PVLT & \multicolumn{1}{l}{ AVLT } \\
\hline Measure & Grades & \multicolumn{1}{c}{$p$} & \multicolumn{1}{c}{$p$} \\
\hline Trial 1 & K - grade 2 & $<.01^{* *}$ & $>.999$ \\
& Grade 2 - grade 4 & .245 & .361 \\
& Grade 4 - grade 6 & $>.999$ & .067 \\
& Grade 6 - grade 7 & $>.999$ & $>.999$ \\
& Grade 7 - grade 8 & $>.999$ & $>.999$ \\
\hline Total score & K - grade 2 & $<.01^{* *}$ & .240 \\
& Grade 2 - grade 4 & $<.01^{* *}$ & $<.01^{* *}$ \\
& Grade 4 - grade 6 & $>.999$ & .704 \\
& Grade 6 - grade 7 & $>.999$ & $>.999$ \\
& Grade 7 - grade 8 & $>.999$ & $>.999$ \\
\hline
\end{tabular}

Note. $\mathrm{K}=$ kindergarten. ${ }^{* *} p<.01 . \mathrm{PVLT}=$ pictorial verbal learning test, $\mathrm{AVLT}=$ auditory verbal learning test

Main effects of the presentation modality

Main effects of the presentation modality were found for trial 2 to 5 and delayed recall (see Table 2 for all predictions), with performance being better on the PVLT than on the AVLT, regardless of the participant's grade.

The non-normal distribution of the recognition performance scores had the effect that possible interactions between predictors could not be analyzed, only main effects. These indicate that long-term recognition performance was better on the PVLT: $\chi^{2}(6, n=394)=16.393, p=.002$.

Main effects of sex

The only significant prediction for sex was found on the delayed recall (see Table 2). Girls recalled more words than boys on this measure.

Main effects of grade

Grade and quadratic grade were the main predictors of performance on all memory aspects, with performance increasing sharply in younger children and levelling-off in older children (see Table 2). Older children performed better on the recognition memory task than younger children: $\chi^{2}(30, n=394)=35.109, p=.046$.

\section{Discussion}

The first aim of the current study was to evaluate the influence of the presentation modality (pictorial or auditory) on the development of verbal learning performance in school-aged children. In the analyses sex, verbal ability (VIQ) and the level of parental education (LPE) were also included to control for the influences of these variables.

First, the findings for the measures that showed a differential increase in performance with grade on the PVLT and the AVLT, namely working memory and total number of words recalled on trials 1 to 5 will be described. Children in kindergarten did not differ in their performance whether the items are presented as pictures of auditory, 
whereas children in grades 2 and higher (age seven and older) performed better on these measures when the information was presented pictorial. As a result, the increase in the number of items that was recalled between kindergarten and grade 2 was significant for the PVLT but not for the AVLT. This is related to the development of working memory. The working memory model proposed by Baddeley (1997) describes that pictorial information is recoded into a phonological code, whereas auditorily presented information automatically has a phonological code and hence needs no recoding. The recoding entails a deeper processing and this leads to better recall of the pictorially presented information. However, the system that is needed for this recoding is the articulatory control process and this process becomes active around the age of seven (Baddeley \& Hitch, 2000; Cowan, 1998; Fry \& Hale, 2000; Gathercole, 1998; Kemps et al., 2000; Palmer, 2000) and this is what the data showed in the working memory measure. Before the articulatory control process becomes active, the pictorially presented information is not recoded and is therefore probably processed in a visuo-spatial code (Halliday et al., 1990). Because the recoding does not take place, there is no deeper processing of the pictures over the auditorily presented words and hence the performance on both pictorially and auditorily presented words on working memory tests is similar. Additionally, the total number of words that were recalled summed over trials 1 to 5 showed a similar effect. If the performance on separate trials were considered, all children recalled more words on the PVLT than on the AVLT, even the children in kindergarten. However, the analyses revealed a tendency towards a differential effect of presentation modality per grade for trial $2(p=.062)$. Thus, the difference in performance on the PVLT and the AVLT in kindergarten is smaller on this trial than on the later trials. Trial 2 is less dependent on working memory than trial 1 , but more than trials 3 to 5 . In the first trials, working memory is more important, but in the later trials other processes that enhance memory take place. For example, with increasing trials, more sophisticated forms of strategies can be used (Meijs et al., under revision) and after more presentations and recall opportunities, more words are already in long-term memory. Thus, long-term memory becomes more important in the later trials, whereas the influence of working memory decreases. The finding that total number of words recalled showed a differential pattern for the PVLT and the AVLT with age reflects the summed differences that were found on the trials and the differences on trials 1 and 2 were large enough to be expressed in the total score. We take these findings to indicate that the influence of the presentation modality is important for working memory, but that for other measures that rely more on other processes such as long term memory, this is no longer important enough to lead to differences in performance.

The second aim of this study was to evaluate the influence of sex differences on pictorial and auditory verbal learning performance in children. Boys have been reported to have a better spatial short-term memory (Lowe et al., 2003; Orsini et al., 1987 ) and would therefore perform better, or at least equally to girls on the PVLT. On the other hand, girls have been reported to be better at the verbal tests in general (Kramer et al., 1997; Vakil et al., 1998). The current study indicated that the influence of the presentation modality was the same for boys and girls and that the presentation 
mode of the information did not lead to any developmental differences in verbal learning performance between boys and girls. Thus, the involvement of the spatial processing of the pictures is, if present, very small and the pictorial verbal learning test is -after recoding- processed in a phonological code similar to the auditory verbal learning test instead of in a visuo-spatial code. The results described above in the findings regarding grade and working memory indicated that in kindergarten, the pictorial information was probably less or not recoded and hence, possibly processed in the visuo-spatial sketchpad. However, post-hoc analyses into sex effects on trial 1 of the PVLT and the AVLT respectively for children in kindergarten revealed no sex differences $(F(1,28)=.000, p=.988$, Partial Eta Squared $=.000$ and $F(1,23)=.442$, $p=.513$, Partial Eta Squared $=.019$ for the PVLT and the AVLT respectively). Thus, if boys have a better spatial short-term memory, this is not before the age of 7 or more likely, the pictures are processed in a visual code but this code is different from a spatial code. This should be the subject of future research.

One significant sex difference was identified, however. Irrespective of the presentation modality, girls had a better delayed recall than boys. Delayed recall of information is comparable to the performance on tests with 'open' questions. In contrast, when boys and girls have to recognize the information, as is the case in a test with multiple-choice questions, no differences in performance between the sexes were identified. This means that there is no difference in the amount of information stored, but that boys perform lower during free recall. Active unguided retrieval plays a major role during free recall from long-term memory. Girls are probably better at this unguided search or retrieval of information from long-term memory. Another indication for this suggestion is that there was a tendency towards better performance of girls for the total number of words that were recalled during the immediate recall $(p=.053)$. Based on the findings described above, differences on free recall tests can be expected between boys and girls. These differences do not reflect their actual stored verbal knowledge of the studied information, but differences in the retrieval of the information. If the goal is to assess actual stored knowledge, a recognition test, such as a multiple-choice test, could be used best. However, if the goal is to assess the retrieval of the information, then an test with open questions can be used best, but one has to keep in mind that girls are likely to perform better on this type test based on their retrieval skills and that this is not based on more stored knowledge. 


\section{Conclusions and Implications}

To the best of our knowledge, this is the first single study with a large sample size in which the effect of two modalities of information presentation, i.e. auditory and pictorial, on the development of verbal learning in children was investigated, together with the relationship of these developmental patterns to sex differences. As such, the current study makes an important contribution towards a better understanding of verbal learning and ways to enhance performance.

Overall, it has become clear that the pictorial presentation of information combined with the verbal recall of that information yields the best learning performance. Although no differences were found for children in kindergarten with regard to verbal working memory components, in all the other aspects of memory examined here, pictorial verbal learning performance surpassed auditory verbal learning performance regardless of age. If information is presented in only one modality, a pictorial presentation modality has the preference over an auditory.

The issue of sex differences requires special attention. No differential influence of the presentation modality was found for boys and girls. Irrespective of the presentation modality, girls outperformed boys when it came to the unguided retrieval of information with long-term free recall memory; a function that is often called upon in tests with open questions. However, no difference was discovered with regard to the amount of information stored by boys and girls and with more guidance, for example by providing cues (as is the case in multiple-choice tests). Thus, in order to ensure that performance results reflect actual stored verbal knowledge and to minimise the sex disadvantages of boys in this regard, it would be advisable to opt for a recognition test (as in a multiple-choice test) rather than a free recall test (an 'open' questions test) when assessing the amount of stored information. On the other hand, a test with open questions is better to assess whether information can be retrieved from longterm memory, on which girls will perform better, but this is not due to more stored knowledge. 


\section{References}

Baddeley, A. D. (1997). Human Memory: Theory and Practice, Revised Edition. Hove: Psychology Press.

Baddeley, A. D., \& Hitch, G. J. (2000). Development of working memory: should the Pascual-Leone and the Baddeley and Hitch models be merged? Journal of Experimental Child Psychology, 77, 128-137.

Beacham, N. A., Elliott, A. C., Alty, J. L., \& Al-Sharrah, A. (2002). Media combinations and learning styles: A dual coding approach. Paper presented at the ED-MEDIA 2002 World Conference on Educational Multimedia, Hypermedia \& Telecommunications, Denver, Colorado.

Berk, L. E. (1998). Development Through the Lifespan. Needham Heights, MA: Allyn \& Bacon.

Bishop, J., Knights, R. M., \& Stoddart, C. (1990). Rey Auditory - Verbal learning Test: Performance of English and French children aged 5 to 16. The Clinical Neuropsychologist, 4, 133-140.

Bjorklund, D. F., \& Douglas, R. N. (1997). The development of memory strategies. In N. Cowan \& C. Hulme (Eds.), The Development of Memory in Childhood (pp. 201-246). Hove, East Sussex, UK: Psychology Press.

Blakemore, S. J., \& Frith, U. (2005). The Learning Brain: Lessons for Education. Oxford: USA: Blackwell Publishing.

Brand, N., \& Jolles, J. (1985). Learning and retrieval rate of words presented auditory and visually. The Journal of General Psychology, 112, 201-210.

Brocki, K. C., \& Bohlin, G. (2004). Executive functions in children aged 6 tot 13: A dimensional and developmental study. Developmental Neuropsychology, 26(2), 571-593.

Bukatko, D., \& Daehler, M. W. (1998). Child Development: a Thematic Approach (3rd ed.). Boston: Houghton Mifflin Company.

Cowan, N. (1998). Visual and auditory working memory capacity. Trends in Cognitive Sciences, 2, 77-78.

Cox, D., \& Waters, H. S. (1986). Sex differences in the use of organisation strategies: A developmental analysis. Journal of Experimental Child Psychology, 41, 18-37.

Croy, C. D., \& Novins, D. K. (2005). Methods for addressing missing data in psychiatric and developmental research. Journal of American Academy of Child \& Adolescent Psychiatry, 44, 1230-1240.

De Bellis, M. D., Keshavan, M. S., Beers, S. R., Hall, J., Frustaci, K., Masalehdan, A., et al. (2001). Sex differences in brain maturation during childhood and adolescence. Cerebral Cortex, 11, 552-557.

De Bie, S. E. (1987). Standaardvragen 1987: Voorstellen voor uniformering van vraagstellingen naar de achtergrondkenmerken en interviews [Standard questions 1987: Proposal for uniformization of questions regarding background variables and interviews] (2nd ed.). Leiden, The Netherlands: Leiden University Press.

De Bruin, E. E. J., Van der Steene, R. G., Van Haasen, P. P., Coetsier, P., Pijl, Y. L., Spelders-Claes, R., et al. (1986). Wechsler Intelligence Scale for Children (WISC-R). Lisse, The Netherlands: Swets \& Zeitlinger.

DeGarmo, D. S., Forgatch, M. S., \& Martinez, C. R. J. (1999). Parenting of divorced mothers as a link between social status and boy's academic outcomes: Unpacking the effects of socioeconomic status. Child Development, 70, 1231-1245.

Forrester, G., \& Geffen, G. (1991). Performance measures of 7- to 15-year-old children on the Auditory Verbal Learning Test. The Clinical Neuropsychologist, 5, 345-359.

Fry, A. F., \& Hale, S. (2000). Relationships among processing speed, working memory and fluid intelligence in children. Biological Psychology, 54, 1-34.

Gathercole, S. E. (1998). The development of memory. Journal of Child Psychology and Psychiatry, 39, 327.

Giedd, J. N., Blumenthal, J., Jeffries, N. O., Castellanos, F. X., Liu, H., Zijdenbos, A., et al. (1999). Brain development during childhood and adolescence: A longitudinal MRI study. Nature neuroscience, 2, 861-863.

Greenberg, M. T., Lengua, L. J., Coie, J. D., \& Pinderhughes, E. E. (1999). Predicting developmental outcomes at school entry using a multiple-risk model: Four American communities. The Conduct Problems Prevention Research Group; Developmental Psychology, 35, 403-417.

Halliday, M. S., Hitch, G. J., Lennon, B., \& Pettipher, C. (1990). Verbal short-term memory in children: The role of the articulatory loop. European Journal of Cognitive Psychology, 2, 23-38.

Henry, L. A., Turner, J. E., Smith, P., T., \& Leather, C. (2000). Modality effects and the development of the word length effect in children. memory, 1, 1-17.

Huizingh, E. (2002). Inleiding SPSS 11 voor Windows [Introduction SPSS 11 for Windows]. Schoonhoven, The Netherlands: Academic Service. 
Kalff, A. C., Kroes, M., Vles, J. S. H., Bosma, H., Feron, F. J. M., Hendriksen, J. G. M., et al. (2001). Factors affecting the relation between parental education as well as occupation and problem behavior in Dutch 5- to 6- year- old children. Social Psychiatry and Psychiatric Epidemiology, 36, 324-331.

Kemps, E., De Rammelaere, S., \& Desmet, T. (2000). The development of working memory: Exploring the complementarity of two models. Journal of Experimental Child Psychology, 77, 89-109.

Kleinbaum, D. G., Kupper, L. L., Muller, K. E., \& Nizam, A. (1998). Applied Regression Analysis and Other Multivariable Methods (3rd ed.). New York: Duxbury Press.

Kramer, J. H., Delis, D. C., Kaplan, E., O'Donnel, L., \& Prifitera, A. (1997). Developmental sex differences in verbal learning. Neuropsychology, 11, 577-584.

Lezak, M. D. (1995). Neuropsychological Assessment (3rd ed.). New York: Oxford University Press.

Lezak, M. D., Howieson, D. B., \& Loring, D. W. (2004). Neuropsychological Assessment (4th ed.). New York: Oxford University Press.

Linschoten, J. (1963). De La Court frequentietellingen van Nederlandse woorden [De la Court's frequency count of Dutch words]. Utrecht, The Netherlands: University of Utrecht, Psychologisch Laboratoruim.

Lowe, P. A., Mayfield, J. W., \& Reynolds, C. R. (2003). Gender differences in memory test performance among children and adolescents. Archives of Clinical Neuropsychology, 18, 865-878.

Lupien, S. J., King, S., Meaney, M. J., \& McEwen, B. S. (2001). Can poverty get under your skin? Basal cortisol levels and cognitive function in children from high and low socioeconomic status. Development and Psychopathology, 13, 653-676.

McCulloch, A., \& Joshi, H. E. (2001). Neighbourhood and family influences on the cognitive ability of children in the British National Child Development Study. Social Science \& Medicine, 53, 579591.

Meijs, C. J. C., Hurks, P., Kalff, A. C., Slaats-Willemse, D., Rozendaal, N., \& Jolles, J. (Manuscript under revision). Differential development of learning strategies in primary school children.

Orsini, A., Grossi, D., Capitani, E., Laiacona, M., Papagno, C., \& Vallar, G. (1987). Verbal and spatial immediate memory span: Normative data from 1355 adults an 1112 children. Italian Journal of Neurological Sciences, 8, 539-548.

Overman, W. H. (2004). Sex differences in early childhood, adolescence, and adulthood on cognitive tasks that rely on orbital prefrontal cortex. Brain and Cognition, 55, 134-147.

Palmer, S. (2000). Working memory: A developmental study of phonological recoding. Memory, 8, $179-193$.

Paus, T. (2005). Mapping brain maturation and cognitive development during adolescence. Trends in Cognitive Sciences, 9, 60-68.

Santrock, J. W. (2001). Educational Psychology. New York: McGraw-Hill.

Schneider, W., \& Pressley, M. (1997). Memory Development Between Two and Twenty (2nd ed.). Mahwah, NJ: Lawrence Erlbaum Associates.

Siegler, R. S., \& Wagner Alibali, M. (2005). Children's Thinking (4th ed.). Upper Saddle River, NJ: Pearson Prentice Hall.

Suizzo, M., \& Stapleton, L. M. (2007). Home-based parental involvement in young children's education: Examining the effects of maternal education across U.S. ethnic groups. Educational Psychology, 27(4), 1-24.

United Nations Educational, Scientific, and Cultural Organisation (UNESCO) (1997). International Standard Classification of Education (ISCED). Paris: UNESCO.

Unsworth, N., \& Engle, R. W. (2006). Simple and complex memory spans and their relation to fluid abilities: Evidence from list-length effects. Journal of Memory and Language, 54, 68-80.

Vakil, E., Blachstein, H., \& Sheinman, M. (1998). Rey AVLT: Developmental norms for children and the sensitivity of different memory measures to age. Child Neuropsychology, 4, 161-177.

Van den Burg, W., \& Kingma, A. (1999). Performance of 225 Dutch school children on Rey's Auditory Verbal Learning Test (AVLT): Parallel test-retest reliabilities with an interval of 3 months and normative data. Archives of Clinical Neuropsychology, 14, 545-559.

Van der Elst, W., Van Boxtel, M. P. J., Van Breukelen, G., J. P., \& Jolles, J. (2005). Rey's Verbal Learning test: normative data for 1,855 healthy participants aged 24-81 years and the influence of age, sex, education, and mode of presentation. Journal of the International Neuropsychological Society, 11, 290-302.

Van Loon-Vervoorn, W. A. (1989). Voorstelbaarheidswaarden van Nederlandse woorden [Imageability ratings of Dutch words]. Lisse, The Netherlands: Swets \& Zeitlinger. 


\section{Chapter 4}

Wassenberg, R., Hurks, P. P. M., Hendriksen, J. G. M., Feron, F. J. M., Meijs, C. J. C., Vles, J. S. H., et al. (in press). Age-related improvement in complex language comprehension: Results of a crosssectional study with 361 children aged 5 to 15 . Journal of Clinical and Experimental Neuropsychology. 


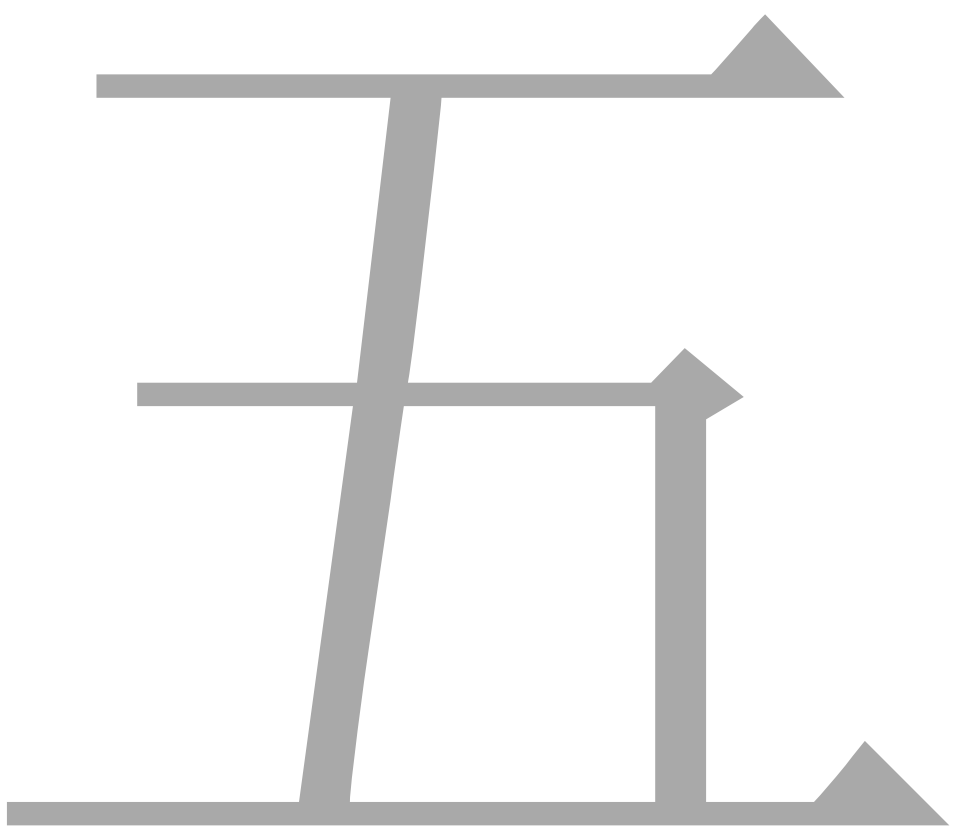




\title{
Chapter 5
}

\section{The influence of the presentation modality, the recall demands, and the content of information on verbal learning performance in children aged 6 - 16}

\begin{abstract}
The present paper describes a large-scale, cross-sectional study on verbal learning performance and the effects of age and sex. The focus was placed primarily on the effects of the presentation modality (i.e., pictorial, auditory or written), the recall demands (i.e., free and serial recall), and the content of information (i.e., words versus digits). In total, 313 children aged 6 to 16 , performed a (free recall) verbal learning test (VLT), and (serial recall) working memory tests with words (WS) and with digits (DS). We found that: (1) presentation modality differentially influenced free recall and serial recall and that this is related to the use of the articulatory rehearsal system in the phonological loop, (2) free recall performance was better than serial recall performance, regardless of age and sex, and (3) digits were recalled better than words from ten years of age onwards, regardless of sex. This implies that, when interpreting verbal learning performance in children, several factors need to be considered. These include the age of the child, the content of the information, the modality in which the information is presented, and the way in which the information has to be recalled. The most optimal presentation modality and recall demand combinations are a pictorial presentation modality with a free recall demand and no pictorial presentation modality with a serial recall demand.
\end{abstract}




\section{Introduction}

Verbal learning tests (VLT) have widespread application in research but also in clinical settings (Lezak, 1995). In a VLT, a list of items or words is presented repeatedly by an auditory or visual route, and the subject is asked to recall and mention these words either immediate or after some delay. In memory research, this test is, among others, used to study how the mode of presenting information influences recall (Brand \& Jolles, 1985; Lezak, 1995). It is also used to study sex differences in verbal learning (Gale, Baxter, Connor, Herring, \& Comer, 2007; Kramer, Delis, Kaplan, O'Donnel, \& Prifitera, 1997). The effects of the presentation modality have been extensively studied in adults, but less so in children. Studies with adults have found that VLT performance is better if the information is presented in a pictorial rather than in an auditory format (Lezak, 1995). A VLT study conducted by our own lab showed that children over seven years of age recall pictures better than words. Among children younger than seven, no differences between pictures and words were found on the first trial (Meijs, et al., submitted). Additionally, an earlier study by Brand and Jolles (1985) found no differences in VLT performance when words were presented auditorily versus visually in writing (Brand \& Jolles, 1985). The pictorial superiority effect has been ascribed to a greater and more in-depth processing of the -concretepictures. Pictures have to be named or recoded by the articulatory rehearsal system of the phonological loop (for more information, see Baddeley, 1997) and processed in both the auditory and visual processing system. Connections between these two processing streams are thought to lead to better recall (Beacham, Elliott, Alty, \& AlSharrah, 2002; Brown, Forbes, \& McConnel, 2006).

Stenberg (2006) reported that the influence of the presentation modality on recall is related to the way in which information has to be recalled (i.e., recall demands). He claimed that no pictorial superiority effect is present when the encoding situation and the recall-situation are dissimilar (for more information, see Stenberg, 2006). Another aspect of recall demands is the order in which information has to be recalled. This order can be considered irrelevant, as is the case in a VLT, which has a free recall. However, the order can also be predefined, as is the case in the Digit Span subtest of the Wechsler Intelligence Scales for Children (WISC), which has a serial recall. The difference between free and serial recall is the order in which the items have to be mentioned during recall. Thus, for free recall tests, only item information (i.e., the phonological, lexical and semantic content of the item) needs to be remembered. In contrast, serial recall tests demand that not only item information, but also the order of the information (i.e., the place of the item in the recall-list) be remembered. This is done by rehearsing of the information in the correct order (Majerus, Poncelet, Elsen, \& Van der Linden, 2006). We hypothesize that serial recall increases the load on the articulatory rehearsal system in the phonological loop and thus leads to a higher load of processing, which, in turn, leads to reduced recall.

Harvey and Beaman (2007) have also studied the relationship between the presentation modality and the recall demands. They reported a differential effect of the presentation modality in free recall and serial recall tests when different output-loads 
(i.e., the number of words that had to be recalled) were present. In the serial recall test, auditorily presented items at the end of the list were recalled more easily than items that were presented in a written form. This was found for all output loads. On the free recall test, this was only found if the output load was high. However, the tests used in Harvey and Beaman's study (2007) not only differ in recall demands, but also in the content of the information that had to be recalled. In the serial recall tests, these were digits, whereas, in the free recall test, these were words. In normal adults, the span is reported to be larger for digits than for words on tests with the same presentation modality and recall demands (Martin \& Ayala, 2004). Two explanations for this finding have been reported. They address either processing load or strategy use. The explanation that focuses on processing load ascribes performance differences to differences in the amount of information that has to be remembered for the recall. Digits apparently need less processing because they form a closed pool of possibilities, namely zero to nine. In contrast, words need more processing because they are derived from an unlimited pool (Harvey \& Beaman, 2007). Thus, the load of processing is thought to be larger for words than for digits. Similarly, Jefferies et al. (2004) have described that digits are recalled better because digits are drawn from a closed semantic set, whereas words can be drawn from many semantic categories (Jefferies, Patterson, Jones, Bateman, \& Lambon Ralph, 2004). The explanation that focuses on strategy use ascribes differences to how well the items can be organized. Numbers have been reported to form an ordered sequence whereas words do not (Jefferies et al., 2004). This explanation coincides with the work of Lezak and colleagues (2004), who have contended that digits are recalled more easily than words because digits are easier to chunk (Lezak, Howieson, \& Loring, 2004). In sum, Harvey and Beaman (2007) were not able to determine whether the effect of the presentation modality was due to the influence of the content that had to be recalled or to different recall demands. This is important to study because tests that are used to measure verbal learning often differ in one of the above-mentioned factors. This, in turn, can lead to substantial differences in performance. If test performance is to be used for comparison, the specific effects of the presentation modality, in combination with the effects of the recall demands and the content of the information need to be delineated.

The study reported in this paper has several aims. First, in order to elaborate on recent findings regarding the relationship between the effects of the presentation modality and the effects of the recall demands, we investigated the influence of the presentation modality on both a free recall and a serial recall test. We expected that the influence of the presentation modality would be dependent on the nature of the load that is placed on the articulatory rehearsal system of the phonological loop. We also expected that the need to use the articulatory rehearsal system to both recode the pictures and rehearse the order of the information would lead to interference. Thus, we hypothesized that a pictorial presentation of items would lead to better performance on the free recall test and poorer performance on the serial recall test. Additionally, we expected that, on both the free recall and the serial recall tests, visually presented written words would be recalled more easily than words that were 
presented auditorily because visually presented words are dually processed in both the visual and the auditory stream. Dual processing is thought to lead to possible connections between these streams and thus enhance recall (Beacham et al., 2002; Brown et al., 2006). To test these hypotheses, tests with auditorily presented words were used for comparisons.

Secondly, to differentiate between the influence of the recall demands and the influence of the information content on performance (regardless of the presentation modality), we compared: (1) performance on a free recall test with words to performance on a serial recall test with words and (2) performance on a serial recall test with words to performance on a serial recall test with digits. We hypothesized that performance on the free recall test would be better than performance on the serial recall test given the higher processing load that is needed for serial recall. We further hypothesized that performance on the test with words would be poorer than performance on the test with digits. This could be because word recollection generates a higher processing load or because strategies are better used with digits than with words.

In this study, the sample population was school-aged children aged 6 to 16 . This group was selected because findings on their learning processes can provide additional insight on how learning in school-aged children is affected by factors such as the mode of presentation, the recall demands and the content of the information that has to be remembered and recalled. Additionally, this information is important because high correlations between working memory tests, which are often serial recall tests, and scholastic performances have been found (St Clair-Thompson, 2007a, 2007b). Furthermore, by including both boys and girls in this study, sex differences in the effects of these factors can be detected. Sex differences in verbal learning have been reported by some studies (Cox \& Waters, 1986; Kramer et al., 1997) but not by others (Bishop, Knights, \& Stoddart, 1990; Forrester \& Geffen, 1991; Vakil, Blachstein, \& Sheinman, 1998; Van den Burg \& Kingma, 1999). Additionally, because the level of parental education (LPE) and verbal IQ (VIQ) may influence VLT performance, we included these factors in our analyses of the effects of the presentation modality.

\section{Method}

\section{Participants}

The current study is part of a large, cross-sectional and longitudinal cognitive development study of school-aged children (in Dutch, 'Cognitief Ontwikkelings Onderzoek bij Schoolgaande kinderen'; abbreviated as COOS) performed by the School for Mental Health and Neuroscience at Maastricht University (see Wassenberg et al., in press). In this study, data was collected in two rounds, with a period of approximately one year between the first and the second round. Participants were recruited from 29 regular primary and secondary schools in the city of Maastricht, the Netherlands, and the surrounding area. The parents or caregivers (hereafter referred to as caregivers) of children in kindergarten, grades two, four and six (primary school) 
and seven and eight (secondary school; ranging from lower prepatory vocational education to preparatory scientific education) received an information package via the school with letters that described the purpose of the study and asked the caregivers to allow their child to participate. This package also contained a questionnaire, an informed consent form and an addressed reply envelope (postage paid).

Of the 1086 caregivers who replied, $892(82 \%)$ agreed to have their child participate in the study and thus returned the informed consent form. Children who met the following criteria were eligible for participation: (1) the child had not repeated and/or skipped a grade (indicative of 'normal' development), (2) the child had a Dutch nationality (indicative of Dutch fluency), and (3) the child did not use medication that is known to influence cognitive performance (e.g., asthma medication). Additionally, if the child had switched schools between the first and the second data collection round, the child had to be attending a participating school.

For the first data collection round, we endeavoured to select children by grade and sex per grade. We also sought to include children from a wide range of socioeconomic backgrounds. In total, 431 children (215 boys, 216 girls) aged 5 to 15 years participated in the first data collection round. One year later, we contacted all caregivers whose children where still attending one of the participating schools $(n=$ 425). The caregivers received a second information package via the school. This package included a present for the child for cooperating the year prior, some results of the first data collection round, information on the purpose of the second data collection round, a request to allow one's child to participate in the second round, a questionnaire, an informed consent form, and an addressed reply envelope (postage paid). Of the 336 responses we received, 333 caregivers provided consent. Furthermore, among the 333 children that were allowed to participate, 4 had repeated or skipped a grade between the first and second data collection round. These four children were excluded. In total, 313 children (151 boys, 162 girls) of the 329 eligible children were tested. Evidently, not all eligible children who had been given permission by their caregivers were tested. In fact, 16 children did not participate either because they refused to cooperate (most common among older children in secondary school) or because they were not present when the testing was done (i.e., due to illness or other school-activities).

In both data collection rounds, the selected children completed different batteries of neuropsychological tests. For the purposes of this paper, we focused on: (1) the test for verbal IQ (VIQ) during the first round and (2) the verbal learning and memory tests in the second round. No longitudinal data were used. The children were tested individually in a room at their schools by well-trained undergraduate psychology students and a psychological assistant. Testing took approximately 1.5 hours and all tests were administered in the same order for each child. The Ethics Committee at the Faculty of Psychology of Maastricht University approved the study protocol. 


\section{Instruments}

Verbal ability (VIQ)

The estimate of verbal ability (VIQ) was derived from the standard score on the Vocabulary subtest of the Dutch Wechsler Intelligence Scales - Revised (WISC-Rn) (De Bruin et al., 1986). The WISC-Rn, rather than the WISC-III, was used because the latter only became available in the Netherlands after the study had started (see Wassenberg et al., in press). In this test, the subject is asked to explain words that range from easy to complex. The standard score ranges from 1 to 19 (mean = 10, SD $=3$ ). The reliability and validity have been described as average to good (De Bruin et al., 1986). This test was administered during the first data collection round.

\section{Digit Span (DS)}

To measure serial recall for digits, we used the span forward and the span backward from the WISC-Rn Digit Span subtest of the WISC-Rn (De Bruin et al., 1986). In this test, the subject is asked to repeat strings of digits. In our study, these were auditorily presented by a computer. In the span forward the digits have to be repeated in the same order as presented (i.e., a measure of short-term memory). In the span backward the digits have to be repeated in the reversed order (i.e., a measure working memory) (Unsworth \& Engle, 2006). The sequences of digits increase by one from three to eight digits forward and two to seven digits backward. The standard score, which reflects a composite of the span forward and the span backward, ranges from 1 to 19 (mean $=10, S D=3$ ). The reliability and validity have been described as average to good (De Bruin et al., 1986). In the current study, we used the digit span (DS) forward and backward separately. DS backward was used as measure of digit span with a serial recall.

\section{Word Span (WS)}

To measure serial recall for words, we used the span forward and the span backward from the Word Span test. The administration of this test is the comparable to the WISC-Rn Digit Span test. The number of items in a sequence was systematically increased from two items up until nine. All words were singly syllable words and derived from the same pool of words used in the VLT (see below). In order to study the influence of the presentation modality with a serial recall demand, the test was administered with a pictorial (PWS), auditory (AWS) and written presentation (WWS) modality. The presentation modality of this test was the same as the presentation modality that the children received for the VLT. The same modality for both tests was chosen to allow for comparison between tests, without differences in presentation modality contaminating the comparison. For all three presentation modalities, the same words were used. 


\section{$V L T$}

A verbal learning test (VLT) was administered to measure verbal learning performance of words with a free recall. This test is often used in clinical settings and memory research, and is one of the most sensitive verbal memory tests. Its test-retest reliability is reported to be high (Lezak, 1995; Van der Elst, Van Boxtel, Van Breukelen, \& Jolles, 2005). The test was administered as described previously (Brand \& Jolles, 1985; Van der Elst et al., 2005). The words used in the test had been checked for their frequency of use (Linschoten, 1963) and imageability (Van Loon-Vervoorn, 1989).

The children in our study received the test in one of three presentation modalities: pictorial (words presented in the form of pictures; PVLT), auditory (hearing the words; AVLT) or written (reading the words; WVLT). In grade one, half of the children received the PVLT and the other half received the AVLT. None were administered the WVLT because they had not yet mastered reading. For the children in grades three and above, one third of the children were administered the PVLT, another third the AVLT and a final third were administered the WVLT.

The procedure was the same for all three modalities. Each test consisted of five trials in which the same 15 unrelated words or pictures (both referred to as items hereafter) of familiar objects were presented on a computer screen. The auditory items were presented through a recording in which an experienced male native speaker spoke the items. The presentation duration of the pictures and the written words was approximately equal to the time needed to pronounce the words when spoken out loud. One item was presented one every two seconds. All items were words that should be acquired before six years of age (for more information see Van der Elst et al., 2005). These words comprised between five and eight letters. In each trial, the words were presented in the same order. Once all 15 items were presented, the participating child had to verbally recall as many items as he or she could remember (immediate recall). About 15 to 20 minutes later, the child was asked to recall as many items as possible from the list (delayed recall). This was done without prompting. In the period between the immediate and the delayed recall, no memory interfering tests were administered. Following the delayed recall task, the participating child was administered a recognition trial, in which 30 items were presented, all of which were from the initial pool. In this trial, 15 of the 30 items had also been presented in the immediate recall task. The participating child had to answer either 'Yes' or 'No' to whether the item belonged to the list of items presented to them in the immediate recall task. Given the longitudinal nature of the cognitive development study, three statistically parallel test versions were used in all three presentation modalities.

The memory aspects used in the current study were: (1) VLT trial score 1 as a measure of working memory, (2) VLT total number of words summed over trials 1 to 5 (i.e., learning with repeated presentations), and (3) VLT delayed recall. VLT trial score 1 was chosen as a measure for working memory because the correlation between VLT trial score 1 and the WS and DS backward was significant (see Table 1). Trial score $1 \mathrm{VLT}$ was used as a measure of word span with a free recall. 
Table 1. Correlations between VLT Trial score 1, WS, and DS, corrected for age, the LPE and the presentation modality

\begin{tabular}{lllll}
\hline & WS forward & WS backward & DS forward & DS backward \\
\hline VLT trial score 1 & .0620 & .1396 & .1154 & .1473 \\
& $p=.336$ & $p=.030$ & $p=.073$ & $p=.022$
\end{tabular}

Note. VLT = verbal learning test. WS = word span. DS = digit span. $\mathrm{N}$ for all analyses was 241

The level of parental education (LPE)

In the questionnaire sent out prior to the first data collection round, caregivers were asked to indicate their highest level of education attained on a commonly-used Dutch educational rating scale ranging from primary school (1) to university degree (8) (De Bie, 1987; Kalff et al., 2001). This system is similar to the International Standard Classification of Education (United Nations Educational Scientific and Cultural Organisation (UNESCO), 1997).

\section{Statistics}

\section{Missing data and extreme values}

Before conducting data analyses, we checked for missing data and unreliable testing. Test data of children for whom the administration of the VLT $(n=16)$, WS $(n=21)$ and DS $(n=22)$ was unreliable were excluded from the dataset. Unreliability was attributable to several factors including technical problems (e.g., equipment failure), refusal to cooperate on the part of the child, poor motivation (e.g., due to fatigue), or missing data due to time constraints. The missing data were not replaced because the amount of missing data was at a maximum around the acceptable $5 \%$ per measure (Croy \& Novins, 2005).

Additionally, memory performance was checked for extreme values, defined as values minimally three times the interquartile distance above the $75^{\text {th }}$ percentile or below the $25^{\text {th }}$ percentile (Huizingh, 2002). These were found for VLT trial score 1 ( $n=$ 1 ) and VLT delayed recall $(n=1)$ and these were, per analysis, deleted from the dataset.

\section{Analyses}

The first step in the analyses was the investigation of the relationship between the influence of the presentation modality and the influence of the recall demands, in relation to age and sex. This was done by generating linear regression models that, using a step-down hierarchical procedure, were fitted for: (1) verbal learning test (VLT) trial score 1, (2) VLT total number of words summed over trials 1 to 5 , (3) VLT delayed recall, (4) span forward word span (WS), (5) span backward WS. To enhance comparison, we focused only on tests with words and therefore did not include the digit span (DS) test. The main focus in the first part of the current study was placed on the predictors age, sex, the presentation modality (pictorial, auditory, or written words), 
and on the interaction terms 'the presentation modality $x$ age' and 'the presentation modality $x$ sex'. Dummies were computed for the presentation modality, with the auditory presentation modality as reference variable for both dummies. The other predictors were age (in years with two decimals; centred), quadratic age (for the study of differential effect with age; $a^{2}{ }^{2}$ ), sex (coded as boys: 0 , girls: 1), the level of parental education (LPE; range 1 to 8 ), verbal IQ (VIQ; standard score) and the interaction term 'age $x$ sex'. Other interactions were not computed to avoid low power. Age was centred (age minus mean age) before the quadratic and interaction terms were computed. This was done to avoid multicollinearity between predictors, which can lead to problems in estimating the regression coefficients (Kleinbaum, Kupper, Muller, \& Nizam, 1998). VIQ and the LPE were included to correct for the possible influence of these factors on memory performance. They have been reported to be related (Berk, 1998) but in the current study, this correlation was relatively low (.3). Therefore, both factors could be included without leading to estimation problems (i.e., multicollinearity) (Kleinbaum et al., 1998). Nonsignificant predictors $(p=<.05)$ were excluded from the final models, but were not removed if there was a significant quadratic term or an interaction term that included the main predictor. Normality was checked by inspection of the residual plots.

In the second step, we studied the influences of the recall demands (i.e., free and serial recall) and of the information content (e.g., words or digits) in relation to age and sex. This was analyzed with paired T-Tests, per grade and per sex and conducted for: (1) VLT trial score 1 with span backward WS (to study free versus serial recall) and (2) span backward WS with span backward Digit Span (DS) (to study words versus digits). In order to compare the WS with the DS without other factors such as the presentation modality creating noise in the comparison, only the data from children that completed the auditory version of the VLT and the WS were included.

\section{Results}

The presentation modality and the recall demands: free recall

Performance on the VLT measures were all significantly predicted by age and the presentation modality, but not by sex, the LPE, VIQ and the interaction terms 'the presentation modality $x$ age' and 'the presentation modality $x$ sex', and 'age $x$ sex'. The VLT total score was additionally predicted by quadratic age (see Table 2). Performance with pictorial presentation was better than performance with an auditory or written presentation. The data also showed that working memory and delayed recall increased with age linearly, whereas learning with repeated presentation levelled-off (quadratic effect) with increasing age. 
The presentation modality and the recall demands: serial recall

Span forward of the WS was significantly predicted by age, the presentation modality, and the LPE, but not by sex, VIQ and the interaction terms 'the presentation modality $x$ age', 'the presentation modality $x$ sex', and 'age $x$ sex' (see Table 2). Performance with a pictorial presentation was poorer than performance with an auditory and written presentation. Performance increased linearly with age and children with a higher LPE performed better than these with a lower LPE.

Span backward of the WS was significantly predicted by age and the presentation modality, but not by sex, the LPE, VIQ and the interaction terms 'the presentation modality $x$ age', 'the presentation modality $x$ sex', and 'age $x$ sex' (see Table 2). Performance with a written presentation was better than performance with a pictorial or auditory presentation. Performance increased linearly with age.

Table 2. Final regression models

\begin{tabular}{|c|c|c|c|c|c|c|c|}
\hline Memory Measure & Predictors & $B$ & Std. Error & $T$ & & Beta & Adjusted $R^{2}$ \\
\hline VLT trial score 1 & Constant & 6.578 & .162 & 40.587 & ** & & .285 \\
\hline \multirow[t]{3}{*}{ (Working memory) } & Age & .303 & .035 & 8.765 & $* *$ & .442 & \\
\hline & Dummy PVLT & 1.543 & .224 & 6.904 & $* *$ & .386 & \\
\hline & Dummy VVLT & .455 & .252 & 1.803 & & .102 & \\
\hline \multirow[t]{6}{*}{ VLT total score } & Constant & 50.960 & .907 & 56.158 & $* *$ & & .422 \\
\hline & Age & 1.917 & .151 & 12.725 & $* *$ & .595 & \\
\hline & $\mathrm{Age}^{2}$ & -.228 & .065 & -3.506 & $* *$ & -.165 & \\
\hline & LPE & .642 & .236 & 2.715 & $* *$ & .125 & \\
\hline & Dummy PVLT & 4.336 & .970 & 4.471 & $* *$ & .231 & \\
\hline & Dummy VVLT & .316 & 1.111 & .285 & & .015 & \\
\hline$V L T$ & Constant & 10.191 & .195 & 52.375 & ** & & .224 \\
\hline \multirow[t]{3}{*}{ delayed recall } & Age & .352 & .041 & 8.534 & $* *$ & .449 & \\
\hline & Dummy PVLT & 1.115 & .268 & 4.160 & $* *$ & .243 & \\
\hline & Dummy VVLT & $-4.392 \mathrm{E}-02$ & .302 & -.146 & & -.009 & \\
\hline$W S$ & Age & .167 & .015 & 10.950 & ** & .540 & .372 \\
\hline span forward & LPE & $6.247 \mathrm{E}-02$ & .024 & 2.566 & * & .124 & \\
\hline \multirow[t]{3}{*}{ (Short-term memory) } & Dummy PVLT & -.340 & .099 & -3.436 & $* *$ & -.188 & \\
\hline & Dummy VVLT & $-2.985 \mathrm{E}-02$ & .111 & -.268 & & -.015 & \\
\hline & Constant & 3.124 & .068 & 45.890 & $* *$ & & \\
\hline$W S$ & Age & .149 & .014 & 10.401 & ** & .520 & .311 \\
\hline \multirow{3}{*}{$\begin{array}{c}\text { span backward } \\
\text { (Working memory) }\end{array}$} & Dummy PVLT & $1.352 \mathrm{E}-02$ & .093 & .145 & & .008 & \\
\hline & Dummy VVLT & .258 & .107 & 2.417 & * & .136 & \\
\hline & Age & .215 & .017 & 12.576 & $* *$ & .595 & \\
\hline
\end{tabular}

Note. VLT $=$ verbal learning test. WS $=$ word span. ${ }^{*}=p<.05,{ }^{* *}=p<.01$ 


\section{The recall demands}

The number of words that was recalled on the free recall test was higher than on the serial recall test, in all grades and for both sexes (see Tables 3 and 4, and Figure 1). This was analysed using the number of words that were recalled on trial 1 of the VLT and the WS backward, which represent the word span with a free recall and word span with a serial recall respectively. Even though the test procedures differed, we assume that the influence of the recall demands reflect the statistical differences in span that were found.

Table 3. Paired Samples T-Test for VLT trial score 1 with WS backward, with a split-file for age

\begin{tabular}{lllll}
\hline & $n$ & $d f$ & \multicolumn{1}{c}{$T$} & $p$ \\
\hline Grade 1 & 22 & 21 & 10.140 & .000 \\
Grade 3 & 17 & 16 & 10.803 & .000 \\
Grade 5 & 15 & 14 & 7.156 & .000 \\
Grade 7 & 14 & 13 & 13.483 & .000 \\
Grade 8 & 14 & 13 & 8.483 & .000 \\
Grade 9 & 13 & 12 & 7.984 & .000 \\
\hline
\end{tabular}

Table 4. Paired Samples T-Test for VLT trial score 1 with WS backward, with a split-file for sex

\begin{tabular}{clccc}
\hline & $n$ & $d f$ & $T$ & $p$ \\
\hline Boys & 49 & 48 & 16.655 & .000 \\
Girls & 46 & 45 & 14.861 & .000
\end{tabular}

\section{The content of information}

On the serial recall tests completed by the children in grades five, seven and eight, the number of digits recalled was significantly higher than the number of words. This was not the case in children in grades one, three and nine (see Tables 5 and 6). As can be seen in Figure 1, the difference between the performance with digits and words increases with age, except for the oldest children (i.e., grade nine). These findings may suggest a ceiling effect of differences from age 10 onwards. The nonsignificant finding for grade nine may also reflect a type I error given that few children in this grade participated $(n=34)$ and also given the that the standard deviation was much larger for this grade than for others (see Figure 1). No differential effects were found for sex, which indicates that significantly more digits as compared to words were recalled by both boys and girls alike (see Table 3 ). 
Figure 1. Performance on trial score 1 VLT, WS backward, and DS backward, by age

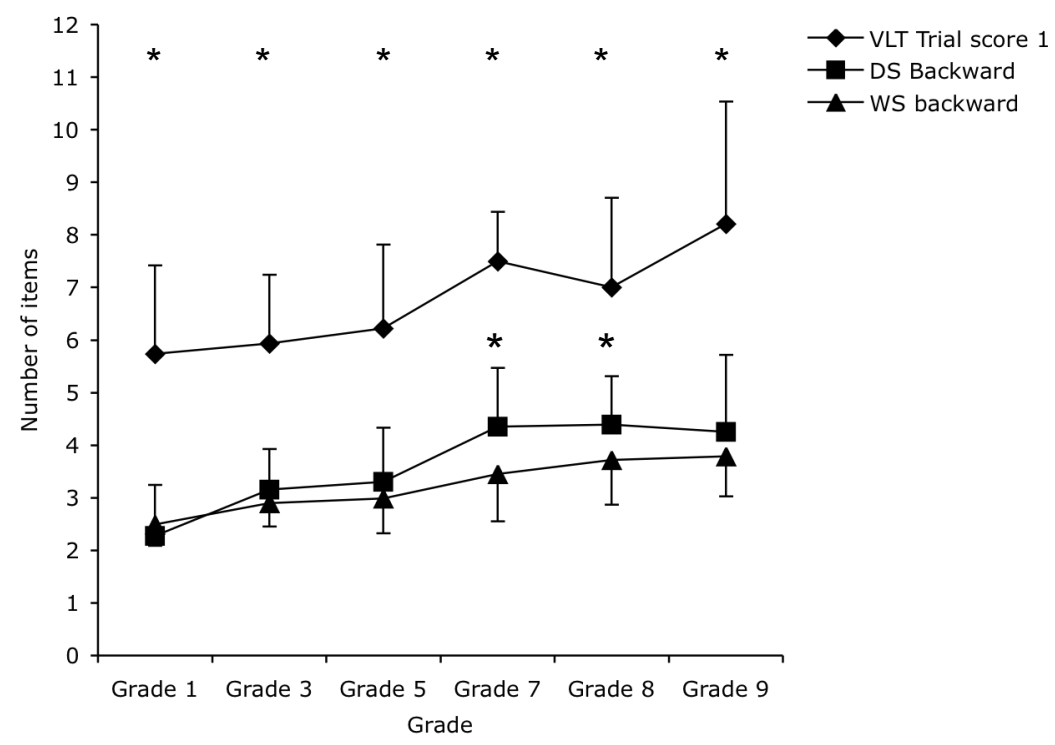

Note. $\mathrm{VLT}=$ verbal learning test. $\mathrm{WS}=$ word span. $\mathrm{DS}=$ digit span

Table 5. Paired Samples T-Test for WS backward with DS backward, with a split-file for age

\begin{tabular}{ccccc}
\hline & $n$ & $d f$ & $T$ & $p$ \\
\hline Grade 1 & 22 & 21 & -.521 & .608 \\
Grade 3 & 20 & 19 & -1.671 & .111 \\
Grade 5 & 15 & 14 & -3.925 & .002 \\
Grade 7 & 14 & 13 & -3.478 & .004 \\
Grade 8 & 14 & 13 & -3.320 & .006 \\
Grade 9 & 14 & 13 & -1.360 & .197
\end{tabular}

Note. $\mathrm{VLT}=$ verbal learning test. $\mathrm{WS}=$ word span. $\mathrm{DS}=$ digit span

Table 6. Paired Samples T-Test for WS backward with DS backward, with a split-file for sex

\begin{tabular}{ccccc}
\hline & $n$ & $d f$ & $T$ & $p$ \\
\hline Boys & 52 & 51 & -4.469 & .000 \\
Girls & 46 & 47 & -2.932 & .005
\end{tabular}

Note. $\mathrm{VLT}=$ verbal learning test. WS = word span. $\mathrm{DS}=$ digit span 


\section{Discussion}

In research and in clinical settings, test performance on verbal memory test is sometimes used to investigate verbal learning over time and between individuals. However, the tests used often differ in their presentation modality, their recall demands, or in the content of the information that has to be recalled. These variations can lead to substantial differences in performance. Thus, in order to effectively compare test performance, the specific effects of these factors need to be delineated.

Consequently, the first part of our study focused on the relationship between the influence of the presentation modality (pictures, words presented auditorily, and written) and the recall demands (free recall and serial recall), while taking age and sex into account. We found an association between the effects of the presentation modality and the recall demands. On the free recall test, performance was best if the information was presented pictorially, as compared to the written and auditory presentation. We hypothesized that pictorial superiority on the free recall test was the result of greater and more in-depth information processing because pictures have to be recoded into a phonological code by the articulatory rehearsal system (Baddeley, 1997). There was no interference with rehearsal for order information, thus the more extensive processing was expected to lead to better recall. On the serial recall test, performance with a pictorial presentation was poorer than performance with written words, and it can therefore be hypothesized that recoding pictures generates no additional benefits in terms of greater and more extensively processing. This is likely caused by interference that results from the fact that the articulatory rehearsal system is used for both the recoding of the pictures and the rehearsal of the order information.

Regardless of recall demands, four out of five outcomes in our study showed no differences between performance with words that were presented auditorily and performances with written words. We hypothesized that written words are processed in both the visual and the auditory stream and that this, in turn, leads to dual processing and more extensive connections between both processing streams which enhances recall (Beacham et al., 2002; Brown et al., 2006). However, it is possible that once the words have been identified (i.e., when they are seen), visual processing is terminated. This would lead to smaller differences in the amount of processing needed for written versus auditorily presented words. Only a few connections between the visual and auditory processing stream would be made and this could explain why almost no differences in performance were found in our study.

Thus, we conducted that optimal performance requires that the presentation modality of the information be adjusted to the recall demands. Optimal performance could be reached if no interference occurs between the use of the articulatory rehearsal system of the phonological loop for recoding and the use of this system for serial sequence information.

The relationship between the influence of the presentation modality and the recall demands was the same for children of all ages. The differences found confirm the findings of the studies that were conducted with adults. This relationship appears to be invariant for development, at least from approximately the age of six onwards. 
However, what happens before six years of age was not investigated in this study and thus should be the topic of future studies, especially given that learning is a life-long process. Additionally, no differences were found between boys and girls. This relationship appears to be invariant for sex. Evidently, age and sex were not found to impact the influence of the presentation modality on the recall demands and thus we contend that they do not need to be considered.

The second part of our study focused how recall demands (free recall and serial recall) and the information content (words and digits) influence performance, especially in relation to age and sex. Our findings showed that, on a test with words, performance on a free recall test was better than on a serial recall test. This was the case for all children, regardless of age and sex. Clearly, the recall of item information alone, as is the case in free recall, generates a lower processing load than the recall of both item- and order information, as is the case in serial recall. This difference in the number of words that was recalled was similar at all ages and for both boys and girls. Clearly, the influence of the recall demands are invariant for age and sex, at least from about the age of six onwards. As described above, what happens prior to six years of age was not investigated in the current study but should be the topic of future research.

If performance on free and serial recall tests are to be compared (which is likely when multiple testing within one subject is conducted), one must recognize that free recall performance is better than serial recall, regardless of age and sex, at least in tests with words. In our study, only the test performance of children that were provided with an auditory modality were compared because these data allowed us to compare between words and digits, as will be described in the paragraph below. However, we did perform post-hoc tests to determine whether the findings described above were also found for the pictorial and written presentations. Indeed, we found a significant difference between free and serial recall performance for each presentation modality (pictorial: $\mathrm{n}=109, T=26.154$, $d f=108 . p<.000$; auditory: $\mathrm{n}=95, T=$ 22.275, $d f=94 . p<.000$; written: $\mathrm{n}=72, T=17.726, d f=71 . p<.000)$. We, therefore, conclude that performance on a free recall test is always better than performance a serial recall test, regardless of the presentation modality.

With respect to differences related to the content of the information, our findings showed that, on a serial recall test, digits were recalled better than words and that this difference grew as children aged. The age differences may be explained from a developmental perspective. It is possible that, up until ten years of age, digits and words are processed in a similar way. Digits are possibly perceived as drawn from an unlimited pool, as are words because before age ten, digits may not yet be automated as they are in older children and adults. Consequently, this may generate similar processing loads for digits and words, and hence less differences in performance. However, while this seems likely for children up to seven years of age, we do expect that children older than seven have already automated digits as adults do. Therefore a more likely explanation for differences in performance in digit and word recall performance can be found referring to strategy use. Better performance with digits has been reported in adults, and this was, amongst other things, ascribed to a higher 
chunking of digits as compared to words (Lezak, 1995). Chunking is the organization of information into groups, and children under ten are generally less capable of using organizational strategies (Bjorklund \& Douglas, 1997; Bukatko \& Daehler, 1998; Schlagmuller \& Schneider, 2002; Schneider \& Sodian, 1997; Siegler \& Booth, 2004). The increase in differences between the recall of digits and the recall of words is thus likely attributable to the development of strategy use. Sex differences were not found. Thus, when comparing performance on tests with different content one must consider that digits are recalled more easily than words from approximately ten years of age onwards, at least in tests with a serial recall. In this study, we used a serial recall test to determine differences between performance with words and with digits. In future studies, researchers should investigate whether free recall tests generate similar effects. Additionally, future research should also attempt to distinguish between the processing load and strategy use explanations for differences in the recall of words and digits by including numbers greater than nine. However, this may lead to biases, given the number of syllables that larger digits comprise. Thus, many influencing factors may emerge in such studies. Nonetheless, we assume that the study described here gives representative findings of the problems posed.

Our findings, illustrated in Figure 1, have shown that differences in performance that are caused by the recall demands are greater than differences that are caused by the content of the information. This indicates that recall demands are more influential for performance than the content of the information as analyzed with words and digits.

\section{Conclusion}

The influence of the presentation modality is related to the recall demands of a test. This is not influenced by age or sex. Thus, the optimal way of presenting information that has to be remembered is dependent on the way in which the information has to be recalled. If the order in which the information has to be recalled is irrelevant (i.e., free recall), then the best presentation modality is pictorial. If the order of the recall is predefined (i.e., serial recall), we can expect recall to be better when the information is not presented in a pictorial form. This was found among primary and secondary school-aged children. No fundamental differences between younger and older children and between boys and girls were found.

Additionally, for all children included in this study, recall was better when the order of the information during the recall was not important. Words are harder to remember than digits, but this was only the case for children above approximately ten years of age. Among children younger than this, performance regarding the recall of words and digits was similar. Performance was influenced by both the recall demands and the content of the information. However, the influence of the recall demands was greater. 


\section{References}

Baddeley, A. D. (1997). Human Memory: Theory and Practice, Revised Edition. Hove: Psychology Press.

Beacham, N. A., Elliott, A. C., Alty, J. L., \& Al-Sharrah, A. (2002). Media combinations and learning styles: A dual coding approach. Paper presented at the ED-MEDIA 2002 World Conference on Educational Multimedia, Hypermedia \& Telecommunications, Denver, Colorado.

Berk, L. E. (1998). Development Through the Lifespan. Needham Heights, MA: Allyn \& Bacon.

Bishop, J., Knights, R. M., \& Stoddart, C. (1990). Rey Auditory - Verbal learning Test: Performance of English and French children aged 5 to 16. The Clinical Neuropsychologist, 4, 133-140.

Bjorklund, D. F., \& Douglas, R. N. (1997). The development of memory strategies. In N. Cowan \& C. Hulme (Eds.), The Development of Memory in Childhood (pp. 201-246). Hove, East Sussex, UK: Psychology Press.

Brand, N., \& Jolles, J. (1985). Learning and retrieval rate of words presented auditory and visually. The Journal of General Psychology, 112, 201-210.

Brown, L. A., Forbes, D., \& McConnel, J. (2006). Limiting the use of verbal coding in the visual patterns test. The Quarterly Journal of Experimental Psychology, 59, 1169-1176.

Bukatko, D., \& Daehler, M. W. (1998). Child Development: a Thematic Approach (3rd ed.). Boston: Houghton Mifflin Company.

Cox, D., \& Waters, H. S. (1986). Sex differences in the use of organisation strategies: A developmental analysis. Journal of Experimental Child Psychology, 41, 18-37.

Croy, C. D., \& Novins, D. K. (2005). Methods for addressing missing data in psychiatric and developmental research. Journal of American Academy of Child \& Adolescent Psychiatry, 44, 1230-1240.

De Bie, S. E. (1987). Standaardvragen 1987: Voorstellen voor uniformering van vraagstellingen naar de achtergrondkenmerken en interviews [Standard questions 1987: Proposal for the uniformization of questions regarding background variables and interviews] (2nd ed.). Leiden, The Netherlands: Leiden University Press.

De Bruin, E. E. J., Van der Steene, R. G., Van Haasen, P. P., Coetsier, P., Pijl, Y. L., Spelders-Claes, R., et al. (1986). Wechsler Intelligence Scale for Children (WISC-R). Lisse, The Netherlands: Swets \& Zeitlinger

Forrester, G., \& Geffen, G. (1991). Performance measures of 7- to 15-year-old children on the Auditory Verbal Learning Test. The Clinical Neuropsychologist, 5, 345-359.

Gale, S., D., Baxter, L., Connor, D. J., Herring, A., \& Comer, J. (2007). Sex differences on the Rey Auditory Verbal Learning test and the brief Visuospatial Memory Test-Revised in the elderly: Normative data in 172 participants. Journal of Clinical and Experimental Neuropsychology, 29, 561-567.

Harvey, A., \& Beaman, C. P. (2007). Input and output modality effects in immediate serial recall. Memory, 7 , 693-700.

Huizingh, E. (2002). Inleiding SPSS 11 voor Windows [Introduction SPSS 11 for Windows]. Schoonhoven, The Netherlands: Academic Service.

Jefferies, E., Patterson, K., Jones, R. W., Bateman, D., \& Lambon Ralph, M. A. (2004). A category-specific advantage for numbers in verbal short-term memory: Evidence from semantic dementia. Neuropsychologica, 42, 639-660.

Kalff, A. C., Kroes, M., Vles, J. S. H., Bosma, H., Feron, F. J. M., Hendriksen, J. G. M., et al. (2001). Factors affecting the relation between parental education as well as occupation and problem behavior in Dutch 5- to 6- year- old children. Social Psychiatry and Psychiatric Epidemiology, 36, 324-331.

Kleinbaum, D. G., Kupper, L. L., Muller, K. E., \& Nizam, A. (1998). Applied Regression Analysis and Other Multivariable Methods (3rd ed.). New York: Duxbury Press.

Kramer, J. H., Delis, D. C., Kaplan, E., O'Donnel, L., \& Prifitera, A. (1997). Developmental sex differences in verbal learning. Neuropsychology, 11, 577-584.

Lezak, M. D. (1995). Neuropsychological Assessment (3rd ed.). New York: Oxford University Press.

Lezak, M. D., Howieson, D. B., \& Loring, D. W. (2004). Neuropsychological Assessment (4th ed.). New York: Oxford University Press.

Linschoten, J. (1963). De La Court's Frequentietellingen van Nederlandse Woorden [De la Court's Frequency Counts of Dutch Words]. (Report 6301). Utrecht, The Netherlands: University of Utrecht, Psychologisch Laboratorium.

Majerus, S., Poncelet, M., Elsen, B., \& Van der Linden, M. (2006). Exploring the relationship between new word learning and short-term memory for serial order recall, item recall and item recognition. European Journal of Cognitive Psychology, 18, 848-873.

Martin, N., \& Ayala, J. (2004). Measurements of auditory-verbal STM span in aphasia: Effects of item, task, and lexical impairment. Brain and Language, 89, 464-483. 
Schlagmuller, M., \& Schneider, W. (2002). The development of organizational strategies in children: Evidence from a microgenetic longitudinal study. Journal of Experimental Child Psychology, 81, 298-319.

Schneider, W., \& Sodian, B. (1997). Memory strategy development: Lessons from longitudinal research. Developmental Review, 17, 442-461.

Siegler, R. S., \& Booth, J. L. (2004). Development of numerical estimation in young children. Child Development, 75, 428-444.

St Clair-Thompson, H. (2007a). The effects of cognitive demand upon relationships between working memory and cognitive skills. The Quarterly Journal of Experimental Psychology, 60, 1378-1388.

St Clair-Thompson, H. (2007b). The influence of strategies upon relationships between working memory and cognitive skills. Memory, 15, 353-365.

Stenberg, G. (2006). Conceptual and perceptual factors in the picture superiority effect. European Journal of Cognitive Psychology, 18, 813-847.

United Nations Educational Scientific and Cultural Organisation (UNESCO). (1997). International Standard Classification of Education (ISCED). Paris: UNESCO.

Unsworth, N., \& Engle, R. W. (2006). Simple and complex memory spans and their relation to fluid abilities: Evidence from list-length effects. Journal of Memory and Language, 54, 68-80.

Vakil, E., Blachstein, H., \& Sheinman, M. (1998). Rey AVLT: Developmental norms for children and the sensitivity of different memory measures to age. Child Neuropsychology, 4, 161-177.

Van den Burg, W., \& Kingma, A. (1999). Performance of 225 Dutch school children on Rey's Auditory Verbal Learning Test (ALVT): Parallel test-retest reliabilities with an interval of 3 months and normative data. Archives of Clinical Neuropsychology, 14, 545-559.

Van der Elst, W., Van Boxtel, M. P. J., Van Breukelen, G., J. P., \& Jolles, J. (2005). Rey's Verbal Learning test: normative data for 1,855 healthy participants aged 24-81 years and the influence of age, sex, education, and mode of presentation. Journal of the International Neuropsychological Society, 11, 290-302.

Van Loon-Vervoorn, W. A. (1989). Voorstelbaarheidswaarden van Nederlandse Woorden [Imageability Ratings of Dutch Words]. Lisse, The Netherlands: Swets \& Zeitlinger.

Wassenberg, R., Hurks, P. P. M., Hendriksen, J. G. M., Feron, F. J. M., Meijs, C. J. C., Vles, J. S. H., et al. (in press). Age-related improvement in complex language comprehension: Results of a crosssectional study with 361 children aged 5 to 15. Journal of Clinical and Experimental Neuropsychology. 

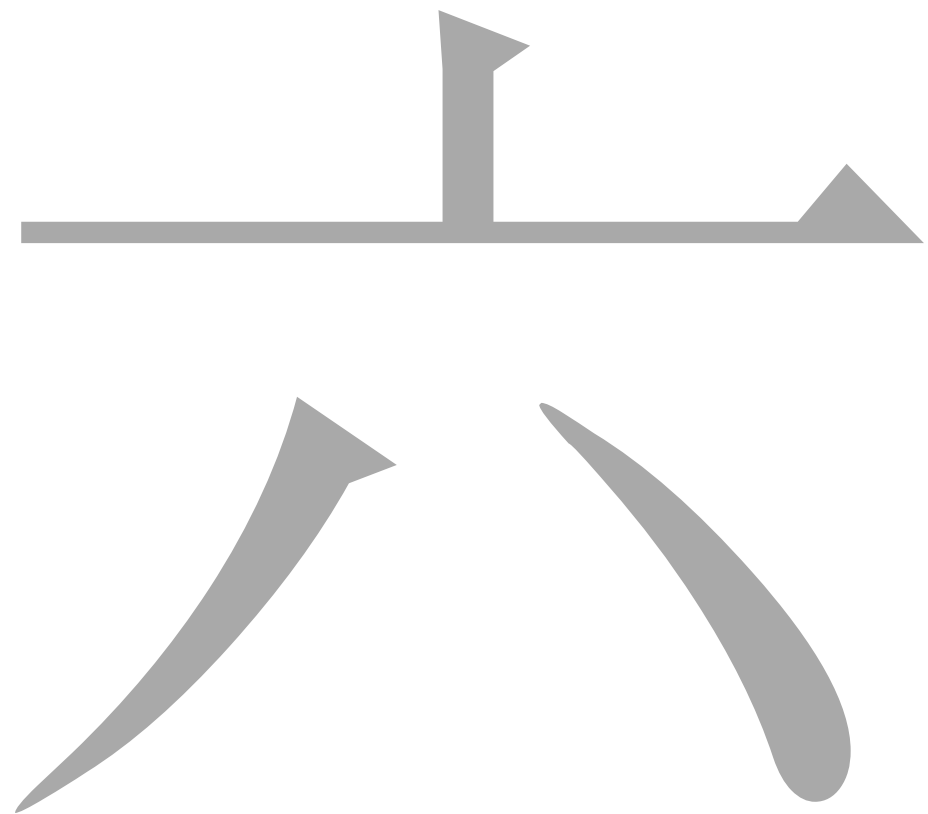


\title{
Chapter 6
}

\section{The relationship between recreational computer use and age, sex, and the level of parental education in children aged 5-16}

\begin{abstract}
Information can be presented in a game-format for educational goals. Therefore, the relationship between age, sex, the level of parental education (LPE), and recreational computer use among school-aged children was investigated. Caregivers of 910 children (aged 5-16) filled out a questionnaire that inquired into computer use, categorized as: (1) sensorimotor games, (2) information-exchange activities, and (3) strategic-planning games. It was found that age, sex, the LPE, and interactions thereof predicted prevalence and nature of computer use. Additionally, the category of recreational computer use of the children was related to the neuropsychological functions the games require, the parental influence, and the -possible- financial situation of the family.
\end{abstract}




\section{Introduction}

For many children nowadays, the use of a computer is as normal as watching TV or playing outside. Recent studies indicated that there were major differences in computer use between children above and below the age of 16 years. The younger children, who grew up with computers have been called 'The game-generation' (Sauer \& Fransen, 2006), or the 'Homo Zappiens' (Veen \& Vrakking, 2006) which is the Dutch reference to growing up with a major influence of several media.

The current study focuses on recreational computer use, which entails all uses of the computer that are for 'fun'. These can be games, but surfing the Internet, chatting or joining forums are also part of recreational computer use. An overview of the recreational computer use of children is imperative because of the possible influence that computer use can have on information processing (Veen \& Vrakking, 2006) and other neuropsychological functions, such as visual short-term memory (Green \& Bavelier, 2006a), reaction time, hand-eye coordination, manual dexterity (Green \& Bavelier, 2006b), spatial abilities (Green \& Bavelier, 2006b; Subrahmanyam \& Greenfield, 1994), and strategies for the allocation of attention (Green \& Bavelier, 2006b; Greenfield, DeWinstanley, Kilpatrick, \& Kaye, 1994). Additionally, schools and teachers utilize the increased computer use of children and adolescents, by devising specially constructed educational games in order to present information to students in such a format that motivates them most.

To get more insight into what children do when they engage in recreational computer use, the relationship between recreational computer use and age, sex, and the level of parental education (LPE) was studied. The relationship between recreational computer use and performance at school or behavioural factors is of major importance, but this is not the aim of the current study. Before possible influences of recreational computer use can be studied, it has to be determined which children make recreational use of the computer and what their computer-activities are. Therefore, this was the aim of the current study. In addition, the specific pattern of recreational computer use will be explained by various factors such as development, parental influence and financial resources. First, it is necessary to describe the three categories of recreational computer use that we used.

In the current study, the nature of computer use was divided into three categories based on the neuropsychological functions that are required to play the games. The categories, which largely correspond to the categories used in the study of Wright et al. (2001), were: (1) sensorimotor games, (2) information-exchange activities, and (3) strategic-planning games. In the first category of games -the sensorimotor games- incoming sensory information has to be judged and turned into a fine motor response performed by a game-controller or keyboard, mostly under pressure of time. Games like Formula One and DOOM belong to this category. The nature of computer use in the second category -information-exchange activities- is characterised by a structured approach that guides the child during playing. Active problem solving, such as in strategic-planning games, is only of minor importance here (Jenson \& De Castell, 2002). In this category, communication, as in 'chatting' or 
when joining forums on the Internet, and the information that has to be learned, as in educational games, are the core components. The games in the third category -strategic-planning games- are heavily loaded by higher cognitive functions including planning, setting priorities, cognitive shifting, use of strategies, and problem solving. In these games, fine motor responses are of importance too, but this is not the most dominant neuropsychological function that is recruited. These games have to be executed in real-time, in which this category differs from sensorimotor games. Two types of games, in which strategy use is of major importance, namely strategyadventure games, such as Lord of the Rings, and simulation games, such as The Sims, were placed into this category.

The factors that were studied were age, sex and the LPE. Age and sex cannot be described separately because of an interaction between these in the relation with recreational computer use. In general, recreational computer use has been reported to increase among children until age 12 (Wright et al., 2001). Among females it has been described to decrease (Comber, Colley, Hargreaves, \& Dorn, 1997; Jenson \& De Castell, 2005; Mumtaz, 2001), but the exact age of the onset of this decrease was not clear. In the early nineties, Subrahmanyam and Greenfield (1994) noted that boys made more use of computers than girls. More recently, it appeared that games that recruit sensorimotor functions were played more often with increasing age and that this rise was largest among boys (Scantlin, 2000). On the other hand, girls have been reported to prefer role-playing and collaboration in games, but they are often restricted by their parents, who stimulate them to play educational games (Jenson \& De Castell, 2002). Also, girls and younger children have been reported to be more guided in their gaming by their parents. Younger children have been reported to be under greater parental influence because they are easier to control because they play less games (Nikken \& Jansz, 2006). Additional, older children have been reported to be more difficult to control because of the influence of peers on their gaming behaviour (Nikken, Jansz, \& Schouwstra, 2007). Parental guidance of girls is reported to be greater as parents are generally more cautious when it comes to their daughters compared to their sons. Furthermore, games regarded as more appropriate for boys due to the (often) violence contents (Nikken \& Jansz, 2006). However, the earlier studies mentioned above have some limitations and need to be interpreted with some caution. For instance, some studies made use of small age ranges, reported findings for boys only or for girls only, or included a small number of children. Most importantly, a number of the studies have to be considered as 'historical' because of the rapidly changing digitalisation of the society and the larger availability of computers these days. The current study therefore included boys and girls in the broad age range of 5 to 16 years, to overcome these limitations. The inclusion of this age range has, to our knowledge, not been studied in the past and made it possible to explore the continuity of recreational computer use from primary to secondary school. Based on previous studies described above, it was expected that there would be an increase in recreational computer use by boys with age, up until age 12 with a levelling-off thereafter. For girls, it was expected to see an increase followed by a decrease after 
the age of 12. It was presumed that these sex differences were dependent on the category of recreational computer use.

The level of parental education (LPE) is a third important factor that is possibly relevant for the evaluation of recreational computer use. The LPE, which in many studies has been used as part of the construct for socio-economic status (SES; Greenberg, Lengua, Coie, \& Pinderhughes, 1999), represents the intellectual status within a family. The LPE is related to occupation and family income (DeGarmo, Forgatch, \& Martinez, 1999), and gives as such an indication of the financial situation. Moreover, the LPE has been related to the perspective that parents have on the recreational computer use of their children (Nikken \& Jansz, 2006; Nikken et al., 2007). Even though LPE and SES represent different concepts (i.e., LPE is a part of the construct SES), they are related. Therefore, the reported influences in the literature of both measures will be considered. Children with a low SES have been reported to make less use of computers compared to children with a high SES (Li \& Atkins, 2004; Wright et al., 2001). Families with a low SES have probably less access to computers or fewer resources to buy them. It is important to note that the study of Wright et al. was executed in 1997 and the study of Li and Atkins in 2001-2002, and as described above, computers are more available these days. Additionally, children with a low SES were reported to play more games that included violence (Wright et al., 2001). It is possible that these latter findings were the result of stimulation by high SES parents to play games without violence, such as educational games (Attewel \& Battle, 1999; Mumtaz, 2001; Wright et al., 2001). In contrast, Nikken and Jansz (2006) and Nikken et al. (2007) reported that parents who were highly educated, paid less attention to suitability ratings of games and were less restrictive in gaming, than lower educated parents. They ascribe this, for one, to the finding that lower educated parents themselves played games more often, therefore, they had more knowledge of the contents of the games and were more restrictive. Also, highly educated parents have been reported to be less interested in content-descriptions of games because they expect that their children will not be influenced by playing the games (Nikken et al., 2007). Based on previous studies, it was expected that children with a low LPE would make less use of a computer and that the nature of computer use would differ for children with various LPE.

The current study into recreational computer use was part of a recent largescale cross-sectional study in school age children. The availability of computers and games could be controlled for over a given period of time as the data were all gathered in the same year. Even though longitudinal studies have advantages such as controlling of the availability of computers during growing up, this study concerned the present recreational computer use. Longitudinal data of computer use could be flawed by the increase in availability, for instance by the lowering of costs of game-gear over time, which makes them easier to purchase, and by the fact that more computers are present at schools. A second advantage of the current study is the large age-range of the children with a span covering from 5 to 16 years. This includes the transition from primary to secondary school. The age of 16 was chosen as an upper limit, because children are in secondary school at least until they are 16 years of age. Most studies 
include a narrower age-range, such as only children from primary schools or only adolescents, which results in a discontinuity during school-transition as mentioned above. A third advantage is that the large sample (910 children) increases generalisation of the findings.

\section{Method}

\section{Participants}

The current study was part of a large Cognitive Development Study of School-aged Children (abbreviation in Dutch: COOS which stands for 'Cognitief Ontwikkelings Onderzoek bij Schoolgaande kinderen', i.e., cognitive development study in schoolaged children), performed by the School for Mental Health and Neuroscience of the Maastricht University (Wassenberg et al., in press). Participants were recruited from 29 regular primary and secondary schools in the city of Maastricht and surroundings (The Netherlands). The parents/caregivers (referred to as caregivers hereafter) of the children in kindergarten, grades 2, 4, 6 (primary schools), and 7 and 8 (secondary schools; ranging from lower secondary professional education to pre-university education) received an information package via the school describing the purpose of the study, a request to participate, a questionnaire, a form to give consent for the child to participate, and a stamped-addressed envelope. The Ethics Committee of the Faculty of Psychology of the Maastricht University approved the study protocol.

Of the 1086 caregivers who replied, 910 filled out the questionnaire. The other caregivers did not give consent for the child to participate $(n=175)$ or gave consent but did not fill out the questionnaire $(n=1)$. The children ( 458 boys [50.3\%] and 452 girls) were aged 5 to 16 . Table 1 gives the distribution of age and sex.

Table 1. The distribution of age and sex of the 910 included children

\begin{tabular}{lrrrr}
\hline Age $^{a}$ & Boys & Girls & \multicolumn{1}{c}{$n$} & \multicolumn{1}{c}{$\%$} \\
\hline 6 & 56 & 78 & 134 & 14.7 \\
7 & 30 & 26 & 56 & 6.2 \\
8 & 67 & 50 & 117 & 12.9 \\
9 & 37 & 27 & 64 & 7.0 \\
10 & 44 & 52 & 96 & 10.5 \\
11 & 27 & 33 & 60 & 6.6 \\
12 & 33 & 34 & 67 & 7.4 \\
13 & 66 & 57 & 123 & 13.5 \\
14 & 64 & 69 & 133 & 14.6 \\
15 & 30 & 22 & 52 & 5.7 \\
16 & 4 & 4 & 8 & 0.9 \\
age was coded 2005 minus year of birth. \\
Data were collected in May, therefore \\
year of age stands for the range of that \\
age year minus 7 months and plus 5 months
\end{tabular}




\section{Instruments}

Questionnaire to inquire into recreational computer use.

The appendix includes the translated part of the questionnaire that inquired into recreational computer use. The caregivers filled out these questions. The first question inquired whether the child played computer games. If he/she did, the category/categories of games that was/were played could be indicated in the second question. There were four options (1) fighting/sports/race/shooting games, (2) story/adventure games, (3) educational games and (4) other. More than one category could be indicated. The games that were indicated by 'other' were looked up by the investigators and, if possible, placed in one of the three other categories. If not possible, the game was scored 'unknown', and not included in the analyses. The games placed in the category sensorimotor games were games such as the fightinggame Mortal Combat, sports-games such as FIFA, race-games such as Formula One and (first-person) shooting-games such as DOOM. The games that were placed in the category story/adventure games were adventure-games such as Lord of the Rings and strategic-games comparable to the board game RISK, but also simulation games such as SIMS and Rollercoaster Tycoon. The games placed in the category educational games were games that teach for instance math or reading, but also communication and information-exchange activities such as 'chatting' and Habbo Hotel. These activities may seem different -for instance to the degree in that social skills are recruited- however the most important component is information-exchange. The categories are comparable to the categories used in the study of Wright et al. (2001).

The level of parental education (LPE)

Caregivers indicated their highest level of education attained on a commonly used Dutch educational rating scale ranging from primary school (1) to university degree (8) (De Bie, 1987; Kalff et al., 2001). This system is similar to the International Standard Classification of Education (United Nations Educational Scientific and Cultural Organisation (UNESCO), 1997). Table 2 gives the distribution of the LPE in the sample of the current study.

Table 2. Distribution of Level of Parental Education (LPE) of the 910 included children

\begin{tabular}{lrr}
\hline $\mathrm{LPE}^{\mathrm{a}}$ & $n$ & $\%$ \\
\hline 1 (Lowest) & 5 & 0.6 \\
2 & 53 & 5.9 \\
3 & 74 & 8.2 \\
4 & 189 & 20.9 \\
5 & 87 & 9.6 \\
6 & 315 & 34.9 \\
7 & 17 & 1.9 \\
8 (Highest) & 163 & 18.1 \\
\hline
\end{tabular}

Note. LPE = Parental Level of Education

aLPE was missing for 7 children 


\section{Statistics}

Multiple logistic regression analyses were fitted using a step-down hierarchical procedure for the dependent variables. These were: (1) use of a computer (coded: $0=$ no use, $1=$ use), (2) playing one category of games (coded: $0=$ one category, $1=$ more than one category), (3) playing sensorimotor games (coded: $0=$ not playing, $1=$ playing), (4) using the computer for information-exchange activities (coded: $0=$ no use, $1=$ use), and (5) playing strategic-planning games (coded: $0=$ not playing, $1=$ playing).

Three main predictors were included in the basic models of the regression analyses: age (range 6 to 16), sex (coded: $0=$ boys, $1=$ girls) and the LPE (range from 1 to 8 ). The inclusion of the children was made by grade, but for analyses the variable 'age' was used because we were interested in the prevalence and the preference of recreational computer use over age rather than over grades. Age was coded 2005 minus year of birth. Data were collected in May, therefore the year of age stands for the range of that age minus seven months and plus five months. Due to this coding, an age range of 6 to 16 years will be reported during the descriptions of the results and the discussion. Even though LPE was not distributed evenly over the categories, the regression analyses compensate for this during analysis. Interactions between main predictors were included in the basic models to correct for possible coherences between these. Additional, quadratic age $\left(\mathrm{age}^{2}\right)$ was included to explore differential effects with age. Age and the LPE were centred (i.e., [age minus mean age] and [LPE minus mean LPE]) before quadratic and interaction terms were computed. This was done to avoid multicollinearity between predictors, which can lead to problems in estimating the regression coefficients (Kleinbaum, Kupper, Muller, \& Nizam, 1998). Non-significant predictors $(p>.05)$ were excluded from the final models, but were not removed if that particular predictor was part of a significant interaction-term or a significant quadratic-term (Kleinbaum et al., 1998). An $\alpha$ level of .05 was used for all analyses.

\section{Results}

\section{Recreational computer use}

Firstly, the number of children who used the computer recreationally was studied. It appeared that of all included children, $83.0 \%$ used a computer recreationally, $16.3 \%$ did not and for $0.8 \%$ it was unknown. Of all boys, $92.1 \%$ recreationally used a computer compared to $73.7 \%$ of all girls. Recreational use of a computer was significantly predicted by the interactions 'quadratic age $x$ sex' and 'age $x$ sex' (see Table 3). This indicated that boys and girls showed a differential pattern of recreational computer use over age. There was an increase in use from $67.8 \%$ of the girls about age 6 to $83.3 \%$ about age 10, followed by a decrease to $37.2 \%$ about age 16 . For boys, there was an increase in use from $83.9 \%$ of the boys about age 6 , to a stabilization of over the $90 \%$ after age 7 (see Figure 1). The percentage of children who made recreational use of a computer was not predicted by the LPE. Thus children of parents with various LPE made as much recreational use of a computer. 


\section{Number of categories of computer games}

The next study determined what category of computer use was scored most often, regardless of whether this was a single category or whether this was in combination with other categories. The three categories of nature of computer use were: (1) sensorimotor games, (2) information-exchange activities, and (3) strategic-planning games. Strategic-planning games were played most often, namely by $47.5 \%$ of the children. The computer was used for information-exchange activities by $36.7 \%$ of the children and sensorimotor games were played least, namely by $32.7 \%$ of the children. The percentages of these categories of games were not significantly different (Kolmogorov-Smirnov $Z=.490, n=3, p>.05$ ).

Table 3. Final regression models for predicting recreational computer use and nature of computer use

\begin{tabular}{|c|c|c|c|c|c|c|c|}
\hline Dependent Variables & Predictors & $B$ & $S E(B)$ & Wald & & $\operatorname{Exp}(B)$ & Nagelkerke $R^{2}$ \\
\hline \multirow[t]{5}{*}{ Recreational computer use } & Age & .192 & .063 & 9.156 & ** & 1.211 & \multirow[t]{5}{*}{.173} \\
\hline & $\mathrm{Age}^{2}$ & -.057 & .013 & 19.731 & ** & .945 & \\
\hline & Sex & -1.730 & .242 & 51.283 & ** & .177 & \\
\hline & Age $x$ Sex & -.205 & .071 & 8.304 & ** & .814 & \\
\hline & (Constant) & 3.336 & .255 & 171.189 & ** & 28.116 & \\
\hline \multirow{4}{*}{$\begin{array}{l}\text { Playing } \\
\text { one category of games }\end{array}$} & Age & -.068 & .028 & 5.894 & * & 1.070 & \multirow[t]{4}{*}{.051} \\
\hline & $\mathrm{Age}^{2}$ & $\begin{array}{l}-.034 \\
-\end{array}$ & .011 & 9.173 & ** & 1.035 & \\
\hline & LPE & .145 & .046 & 10.083 & ** & .865 & \\
\hline & (Constant) & -.209 & .119 & 3.107 & & 1.233 & \\
\hline \multirow[t]{4}{*}{ Sensorimotor games } & Age & .332 & .036 & 86.563 & ** & 1.394 & \multirow[t]{4}{*}{.517} \\
\hline & Sex & -3.597 & .263 & 186.655 & ** & .027 & \\
\hline & LPE & .075 & .034 & 4.953 & * & 1.078 & \\
\hline & (Constant) & .212 & .105 & 4.070 & * & 1.236 & \\
\hline \multirow[t]{5}{*}{ Information-exchange activities } & Age & -.320 & .043 & 55.906 & ** & .726 & \multirow[t]{5}{*}{.174} \\
\hline & $\mathrm{Age}^{2}$ & -.027 & .011 & 6.177 & * & .974 & \\
\hline & Sex & .799 & 154 & 26.872 & ** & 2.223 & \\
\hline & Age $x$ Sex & .130 & .054 & 5.879 & * & 1.139 & \\
\hline & (Constant) & -.763 & .139 & 30.166 & ** & .466 & \\
\hline \multirow{7}{*}{ Strategic-planning games } & Age & -.083 & .034 & 6.010 & * & .921 & \multirow[t]{7}{*}{.093} \\
\hline & $\mathrm{Age}^{2}$ & -.059 & .010 & 35.371 & ** & .943 & \\
\hline & Sex & -.035 & .138 & .063 & & .966 & \\
\hline & LPE & 110 & .040 & 7.648 & ** & 1.116 & \\
\hline & Age $x$ Sex & .145 & .047 & 4.673 & * & 1.156 & \\
\hline & Age $\times$ LPE & .029 & .014 & 4.673 & * & 1.030 & \\
\hline & (Constant) & .479 & .128 & 14.069 & ** & 1.615 & \\
\hline
\end{tabular}

Note. LPE $=$ Level of Parental Education. Coding of the predictors: Age $=$ year of birth $-2005 ; \mathrm{Age}^{2}=($ year of birth $)^{2}$; Sex: Male $=1$, Female $=0 ;$ LPE = range 1 (Lowest) to 8 (Highest)

${ }^{*} p<.05 ;{ }^{* *} p<.01$ 
Children could use the computer for more than one category (range 1 to 3 ). This was dichotomised to: $(0)$ if children used the computer for only one category versus (1) if children used the computer for more than one category. Children who played no games or from whom this was unknown were not included in the analyses. Playing one versus more than one category was significantly predicted by quadratic age, age, and the LPE (see Table 3). As can be seen in Figure 2, children aged nine were most likely to use the computer for one nature, whereas older children focused on more than one nature of use. Overall, children with a high LPE were more likely to use the computer for more than one nature as compared to children with a low LPE.

Overall, $61.9 \%$ of the children used the computer for one nature of recreational computer use. If they used the computer for more than one nature, the strategic-planning games were predominantly included in the combinations of the categories (see Figure 3).

\section{Nature of recreational computer use}

Finally, the factors that predicted the nature of recreational computer use were investigated. All children who used the computer for a category were included in the analyses, regardless of whether they were also using the computer for the other categories.

Playing sensorimotor games was significantly predicted by age, sex, and the LPE (see Table 3). This indicated that (a) boys played these games more often than girls, (b) the percentage of children who played sensorimotor games increased with age, and (c) the prevalence of children with a high LPE who played these games was higher than the prevalence of children with a low LPE. The courses of prevalence in Figure 4 suggest interactions, but these were not statistically significant.

Use of a computer for information-exchange activities was significantly predicted by the interaction 'age $x$ sex', quadratic age, age, and sex (see Table 3). Figure 5 shows that there was a decrease with age in the prevalence of playing these games. The percentage girls who used the computer for this category was at all ages higher than the percentage boys, but this difference varied with age. It was smallest at age 6 , increased up till age 12 and decreased after that. The decrease for boys started at an earlier age than for girls. 
Figure 1. Predicted percentage of recreational computer use among children aged 6-16, separate lines for boys and girls
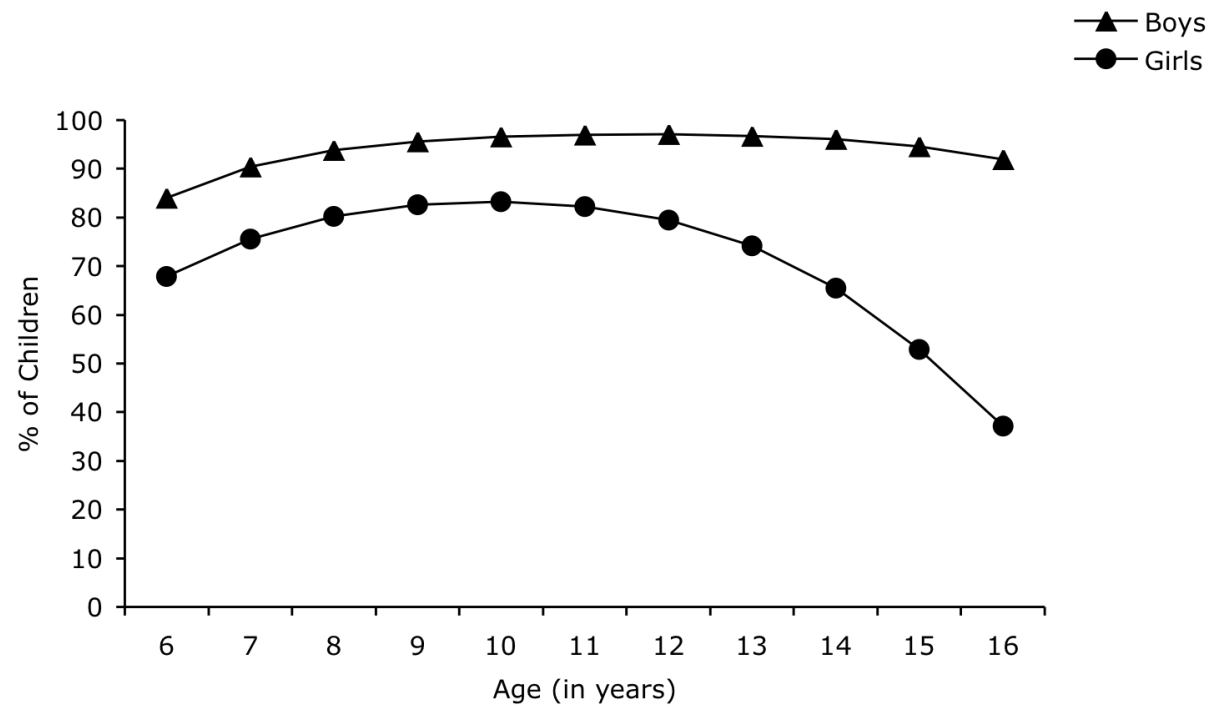

Figure 2. Predicted percentage of playing only one category of games among children aged 616, separate lines for children with the lowest Level of Parental Education (LPE) of 1 and the highest LPE of 8

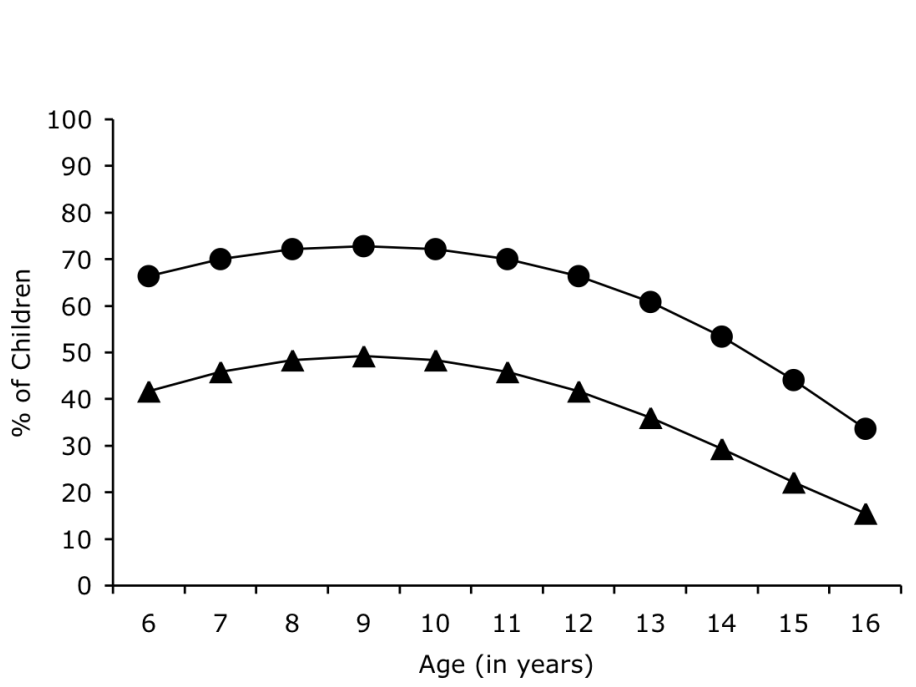


Chapter 6

Figure 3. Percentage of children per nature of computer use and combinations of these

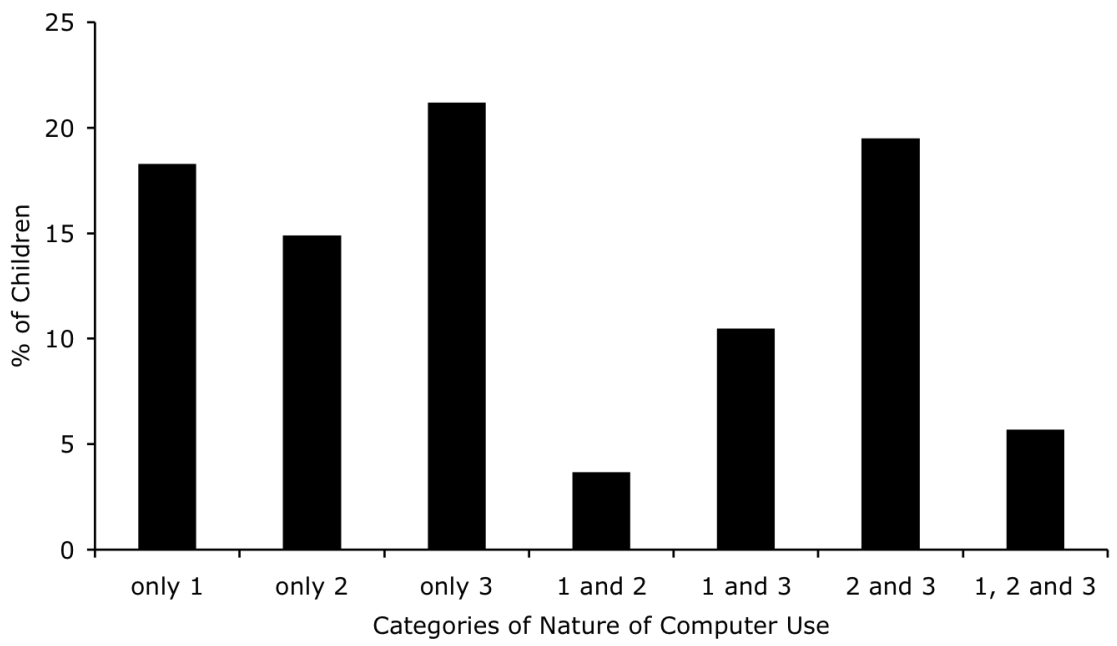

Note. Categories of Nature of Computer Use: 1 = Sensorimotor games, 2 = Information-exchange activities, $3=$ Strategic-planning games

Figure 4. Predicted percentage of playing sensorimotor games among children aged 6-16, separate lines for boys and girls with the lowest Level of Parental Education (LPE) of 1 and the highest LPE of 8

$-\mathrm{O}-$ Girls lowest LPE

- Girls highest LPE

$\neg$ Boys lowest LPE

$\longrightarrow$ Boys highest LPE

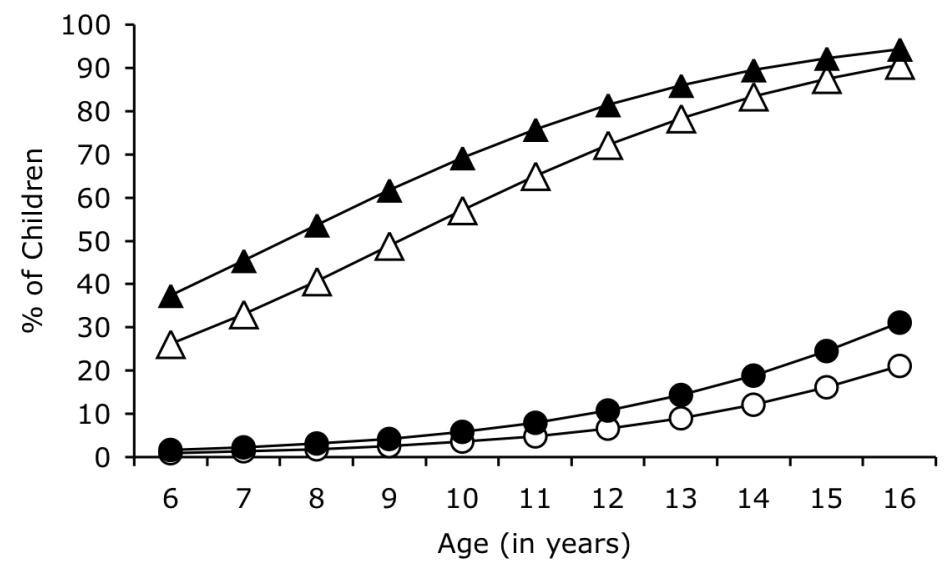


Figure 5. Predicted percentage of computer use of information-exchange activities among children aged 6-16, separate lines for boys and girls
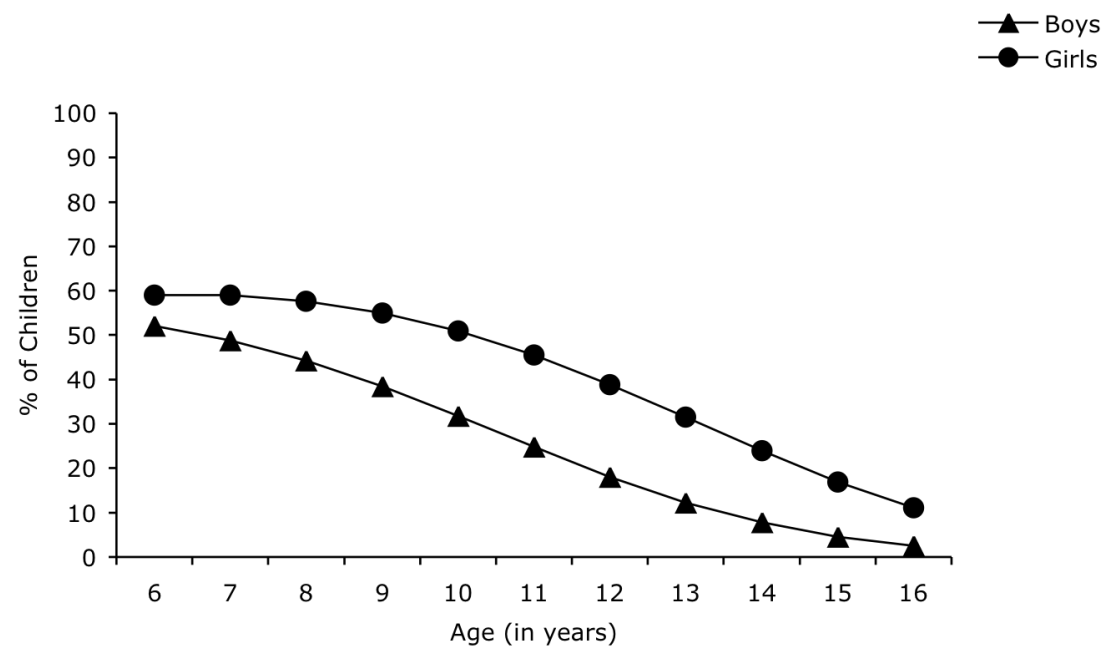

Figure 6. Predicted percentage of playing strategic-planning games among children aged 6-16, separate lines for boys and girls with the lowest Level of Parental Education (LPE) of 1 and the highest LPE of 8
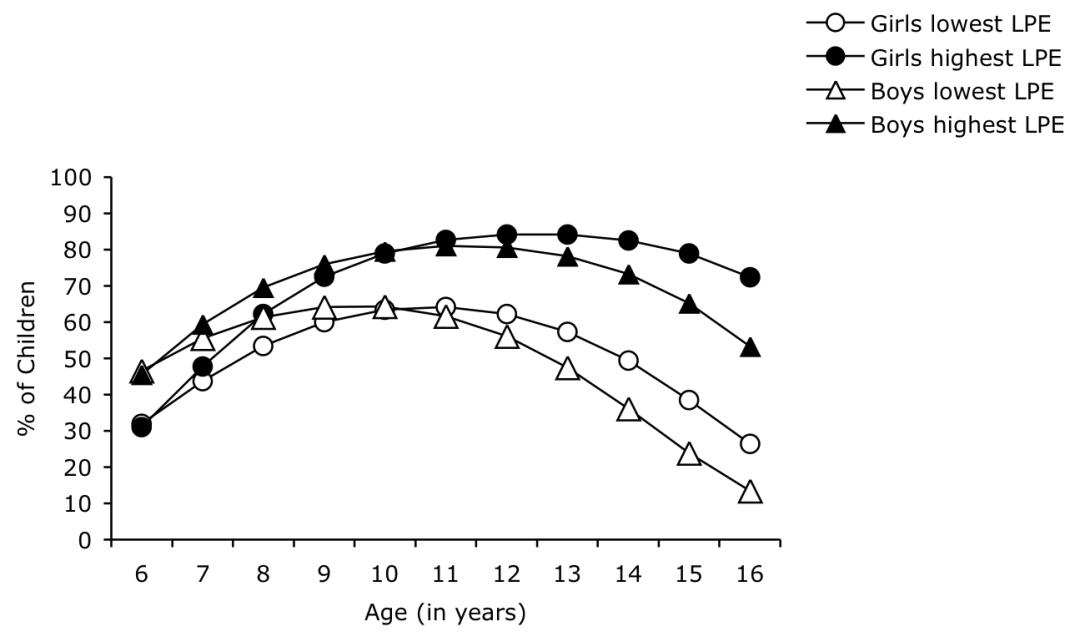
Playing strategic-planning games was significantly predicted by the interactions 'age $x$ sex', 'age $x$ the LPE', quadratic age, age and the LPE (see Table 3 ). This indicated that (a) up until the age of 10 , the prevalence of boys that played this game was higher than the prevalence of girls, (b) the relationship between recreational computer use and the LPE became larger with increasing age, and (c) for both boys and girls, the prevalence of children that played this type of games was largest between 10 and 13 years of age (see Figure 6).

\section{Discussion}

The aim of the current study was to explore the relationship between recreational computer use and age, sex, and the level of parental education (LPE). An overview of the recreational computer use of children is imperative because of the possible influence that computer use can have on information processing (Veen \& Vrakking, 2006) and other neuropsychological functions, such as visual short-term memory (Green \& Bavelier, 2006a), reaction time, hand-eye coordination, manual dexterity (Green \& Bavelier, 2006b), spatial abilities (Green \& Bavelier, 2006b; Subrahmanyam \& Greenfield, 1994), and strategies for the allocation of attention (Green \& Bavelier, 2006b; Greenfield et al., 1994).

Additionally, it is important to choose the correct game-format, when computer games are used to present information that has to be remembered. Because $83 \%$ of the children made recreational use of a computer, mostly gaming, presenting information in a game-format could most likely optimize learning. The prevalence of recreational computer use and the nature of the use were predicted by age, sex, and the LPE. Age and sex will be discussed together because of the interaction between these factors in the prediction of recreational computer use. Additionally, the relation between the LPE and computer use will be discussed in a separate paragraph.

\section{Age and sex}

Computer use increased with age and the percentage of boys who recreationally used a computer was at all times higher than the percentage of girls. This study indicates that the prevalence of computer use remained at approximately the same level after the age of 7 among boys, but it decreased after the age of 10 among girls. This decrease among girls is explained in the literature by stereotypical behaviour of girls. Traditionally, gaming has been seen as a 'boys' activity (Funk, Buchman, \& Germann, 2000). Girls would therefore be less likely to play computer games. However, this image is fading and younger girls are catching up with boys in prevalence of recreational computer use (Comber et al., 1997). 
The increase in recreational computer use with age (regardless of sex) can be the result of the development of the neuropsychological functions that are needed for playing games. For instance, educational games are constructed in such a manner that even the youngest children can understand and play the game. On the other hand, most strategic-planning and sensorimotor games need more complex knowledge and/or (neuropsychological) functions such as, (a) the ability to read, in order to understand the instructions, (b) executive functions such as selecting the correct strategies to tackle the problems in the game and to set long-term and shortterm -often diverting- goals (Anderson, 2002), (c) the development of motor functions that permit better coordination, and (d) sensory integration of incoming information that is needed for a quicker and correct response. Thus, when these functions develop, more games can be played and the recreational computer use can increase.

Sensorimotor games were played more often with increasing age. In order to be able to play sensorimotor games, the neuropsychological functions that are needed, such as processing speed and reverting sensory information to a motor response, have to be developed. With regard to sex, we found that the prevalence of boys that played these games was higher than the prevalence of girls. According to Subrahmanyam and Greenfield (1994), boys play sensorimotor games more often because they are able to identify with the main characters in these games, which are predominantly male. Nowadays, many games contain also female characters that often play the same roles as males (e.g. Lara Croft in Tomb Raider). Even though girls are able to identify with these characters, the course of prevalence of playing sensorimotor games has not changed. This leads to the suggestion that identification is certainly not the only explanation for the differences between boys and girls with respect to playing these games. Other explanations are: (a) that girls do not play these games because the violence, that is often present in these games, deters girls (Subrahmanyam \& Greenfield, 1998), (b) that they are restricted by their parents not play these games (Nikken \& Jansz, 2006), (c) that they are stimulated to play educational games (at least more than boys) (Jenson \& De Castell, 2002), and (d) that boys are more attracted to these games because of the competitive nature of the games (Agosto, 2004; Subrahmanyam \& Greenfield, 1998).

A potent explanation is derived from a neuropsychological perspective. Sensorimotor games recruit visual-spatial and psychomotor abilities. It is known that boys outperform girls in some spatial abilities, although sometimes just marginally (Anderson, 2002; Lowe, Mayfield, \& Reynolds, 2003), which can possibly explain the preference for these games among boys (Agosto, 2004; Greenfield, 1994; Subrahmanyam \& Greenfield, 1994). Nevertheless, Jenson and De Castell (2005) showed that girls in the age of 12-13 and women in the age of 22-23 sometimes play race games. However, they found that if girls and women play typical 'boys' games, they rather do so in the company of a boy or male (e.g. a brother or a friend) than alone. Thus, they possibly play these games because they play together with boys, instead of choosing to play the game on their own. In summary, sensorimotor games can only be played with increasing age because of the complex neuropsychological functions that are needed to play. The mechanism of the preference of playing 
sensorimotor games by boys is possibly a combination of several factors in which the components of violence, competition and the better psychomotor and visual-spatial development are most important. It remains to be established whether identification with the main character -once considered the most relevant- is important in this respect.

The findings in the current study showed that the use of computers for information-exchange activities decreased with age and that this was stronger and occurred earlier in life among boys. Jenson and De Castell (2002) described that these differences are the result of parental influence on girls to play educational games. Agosto (2004) also reported that girls have stronger preference for educational games. At a young age, educational games are probably one of the few games that children can play. This is based on the neuropsychological functions that are needed to play educational games. These games often need fewer complex functions than sensorimotor or strategy-planning games. With increasing age, the ability to play other categories of games increases and with this, the preference for these games changes. As described above, boys have a strong preference for sensorimotor games and this can explain the decrease in playing educational games with increasing age for boys. Possibly, this preference also decreases for girls. They are likely to prefer other natures of computer use such as communication ('chatting') or information-exchange via forums on the Internet. It is likely that the prevalence of 'chatting' and joining forums was underestimated, because it was not explicitly asked for in the questionnaire. We assume that girls would engage more in this nature of computer use with increasing age, because of the preference of girls for social interactions with peers (Jenson \& De Castell, 2002; Subrahmanyam \& Greenfield, 1998; Wright et al., 2001).

Before the age of 10 , the prevalence of boys who played strategic-planning games was higher than the prevalence of girls. Beyond this age, girls played them more often. The category of strategic-planning games included two types of games. We assume that boys played adventure-games (strategic-planning games) up until age ten, and thereafter played sensorimotor games more often. Boys probably like to play adventure-games because of some overlapping components with sensorimotor games such as identification, violence, competition and neuropsychological functions such as visual-spatial and psychomotor functions. However, in the adventure games, the strategies that have to be used are of more importance in order to succeed. Further, we assumed that girls played more often simulation games (a kind of strategic-planning games also) as compared to boys. The topics of these games -such as the simulation of a family-life in for instance, The Sims- will be more attractive for girls because they like social settings (Jenson \& De Castell, 2002, 2005; Sauer \& Fransen, 2006). Thus, in summary, the preference for games differs with age and sex. It is likely that this is in parallel with the development of neuropsychological functions and the demands of playing the games. 


\section{The level of parental education (LPE)}

The current study showed that there were no differences in the percentage of children with a diverse LPE who made recreational use of a computer. Therefore, in the Netherlands, in 2005, differences in the LPE were probably less important for the percentage children who recreationally made use of a computer. The LPE was more important for the number of categories of nature of computer use. In order to play more categories of games, more games need to be in possession. Thus, having access to a computer is the same for families with diverse LPE, but the number of games probably is not.

The prevalence of children of all ages who played sensorimotor games and for older children who played strategic-planning games was higher for children with a higher LPE. As described above, no differences in the frequency of children who made use of a computer were found for the LPE, thus the availability of a computer to play these games did not explain these findings. A large number of the children who played strategic-planning games were the children who played more categories of games. As described before, if there was more than one category of nature of computer use, then strategy-planning games were predominantly part of the combinations of games played. Since children with a higher LPE were most likely to use the computer for more than one nature, this group played the strategy-planning games more often.

Wright et al. (2001) reported that children with a low SES played more games with violence. The current study showed the opposite effect: the prevalence of the children who played sensorimotor games (which includes amongst others violent games) was higher among children with a high LPE. Possibly, as described by Nikken and Jansz (2006) and Nikken et al. (2007), highly educated parents were less influential on children's game behaviour, whereas the parents with a lower education, who more often played games themselves, were more restrictive when it came to playing sensorimotor games.

Additionally, no differences were found in using the computer for informationexchange activities, whereas the literature reported that parents with a high SES would stimulate the playing of educational games (Attewel \& Battle, 1999; Jenson \& De Castell, 2002; Mumtaz, 2001). Chatting and joining forums were also part of this category, but they were of minor importance because of a lower prevalence than playing educational games. This is taken to indicate that the parental influence to play educational games by parents with a high SES and/or LPE has become less over the years, or that the parental influence to play educational games by parents with a low SES and/or LPE increased.

There are some considerations in the interpretation of these results. Firstly, questionnaires were used in which the caregivers had to indicate what games their children played. Therefore, the categorization of the games was dependent on the ability of the caregivers to judge in which category the game belonged. An improvement of this is that in future studies, the caregivers only name the game and that the researchers place them into categories. Additionally, caregivers -especially for older children- might not be aware of what their children actually do on the computer. 
It would be better to ask the children what games they play or for what other activities they use the computer. However, it is likely that this factor does not influence the findings because it is likely that the caregivers asked the child if they were not sure what computer activities the child was engaged in. Another possible influence could have been a tendency for socially desirable answers. However, given the findings regarding sensorimotor games, it is unlikely that this was the case in the current study. Furthermore, the term 'game' in the questionnaire could have lead to an underestimation of the information exchange activities. However, in the category 'other', a fairly amount of caregivers indicated for instance 'chatting'. Nevertheless, it is possible that this is an underestimation in the current study.

A second consideration is that the categories of computer use were based on the neuropsychological functions that the games recruited the most. These categories were comparable with the categories used in the study of Wright et al. (2001). Some categories included more types of games and in future studies, more differentiated categories need to be used such as separate categories for race- and sports games, adventure- and simulation games and for educational games, chatting and joining forums. This is the topic in a follow-up study that is currently running.

A third point is that the LPE was not evenly distributed. Parents with a relatively high education are more likely to cooperate in studies and if children of parents with a low education participated in the study then these were children of motivated parents. Thus, this possibly leads to a bias. Even though the regression analyses used in the current study compensated for this bias (Kleinbaum et al., 1998), a better distribution of the LPE would lead to more solid conclusions.

\section{Conclusion}

Younger children (up until approximately the age of 10) play educational games, but this is less suited for older children. Older girls (after approximately the age of 10) play games or use the computer in which they are able to work in cooperation with others or play games that simulate situations in a social network. Boys, when they are older than approximately seven, play games that contain some form of competition and sensorimotor execution. Strategic-planning games are played by boys and girls between 10 and 13 years. The peak of playing these games is earlier in life for boys compared to girls. Thus, when considering using games during education, educational games can be used for younger children, sensorimotor and to a lesser degreestrategic-planning games such as adventure games can be used for older boys and information-exchange activities that require collaboration and -to a lesser degreestrategic-planning games such as simulation games can be used for older girls as format in the presentation of information. 


\section{References}

Agosto, D. (2004). Girls and gaming: A summary of the research with implications for practice. Teacher Librarian, 31(3), 8-14.

Ainley, M. (2006). Connecting with learning: Motivation, affect and cognition in interest processes. Educational Psychology Review, 18, 391-405.

Anderson, P. (2002). Assessment and development of executive function (EF) during childhood. Child Neuropsychology, 8, 71-82.

Attewel, P., \& Battle, J. (1999). Home computers and school performance. The Information Society, 15(1), $1-10$.

Comber, C., Colley, A., Hargreaves, D. J., \& Dorn, L. (1997). The effects of age, gender and computer experience upon computer attitudes. Educational Research, 39, 123-133.

De Bie, S. E. (1987). Standaardvragen 1987: Voorstellen voor uniformering van vraagstellingen naar de achtergrondkenmerken en interviews [Standard questions 1987: Proposal for uniformization of questions regarding background variables and interviews] (2nd ed.). Leiden, The Netherlands: Leiden University Press.

DeGarmo, D. S., Forgatch, M. S., \& Martinez, C. R. J. (1999). Parenting of divorced mothers as a link between social status and boy's academic outcomes: Unpacking the effects of socioeconomic status. Child Development, 70, 1231-1245.

Funk, J. B., Buchman, D. D., \& Germann, J. N. (2000). Preference for violent electronic games, selfconcept, and gender differences in young children. The American Journal of Orthopsychiatry, 70, 233-241.

Green, C. S., \& Bavelier, D. (2006a). Enumeration versus multiple object tracking: The case of action video players. Cognition, 101, 217-245.

Green, C. S., \& Bavelier, D. (2006b). The cognitive neuroscience of video games. In P. Messaris \& L. Humphreys (Eds.), Digital media: Transformations in Human Communication. New York: Peter Lang.

Greenberg, M. T., Lengua, L. J., Coie, J. D., \& Pinderhughes, E. E. (1999). Predicting developmental outcomes at school entry using a multiple-risk model: Four American communities. The Conduct Problems Prevention Research Group; Developmental Psychology, 35, 403-417.

Greenfield, P. M. (1994). Video games as cultural artifacts. Journal of Applied Developmental Psychology, 15(11), 3-12.

Jenson, J., \& De Castell, S. (2002). Serious Play: Challenges of educational game design. Paper presented at the AERA Annual Meeting, New Orleans, Louisiana.

Jenson, J., \& De Castell, S. (2005). Her own boss: Gender and the pursuit of incompetent play. Paper presented at the DiGRA 2005 Conference: Changing Views - Worlds in Play, Vancouver: Vancouver University.

Kalff, A. C., Kroes, M., Vles, J. S. H., Bosma, H., Feron, F. J. M., Hendriksen, J. G. M., et al. (2001). Factors affecting the relation between parental education as well as occupation and problem behavior in Dutch 5- to 6- year- old children. Social Psychiatry and Psychiatric Epidemiology, 36, 324-331.

Kleinbaum, D. G., Kupper, L. L., Muller, K. E., \& Nizam, A. (1998). Applied Regression Analysis and Other Multivariable Methods (3rd ed.). New York: Duxbury Press.

Li, X., \& Atkins, M. S. (2004). Early childhood computer experience and cognitive and motor development. Pediatrics, 113, 1715-1722.

Lowe, P. A., Mayfield, J. W., \& Reynolds, C. R. (2003). Gender differences in memory test performance among children and adolescents. Archives of Clinical Neuropsychology, 18, 865-878.

Mumtaz, S. (2001). Children's enjoyment and perception of computer use in the home and the school. Computers \& Education, 36, 347-362.

Nikken, P., \& Jansz, J. (2006). Parental mediation of children's videogame playing: A comparison of the reports by parents and children. Learning, Media and Technology, 31, 181-202.

Nikken, P., Jansz, J., \& Schouwstra, S. (2007). Parents' interest in videogame ratings and content descriptors in relation to game mediation. European Journal of Communication, 22, 315-336.

Sauer, I., \& Fransen, J. (2006). Deelonderzoeken naar de virtuele wereld: Het leren van games [Partial studies to the virtual world: Learning from games]. In G. Wijngaards, J. Fransen \& P. Swager (Eds.), Jongeren en hun Digitale Wereld (pp. 24-39). Assen: Van Gorcum.

Scantlin, R. M. (2000). Interactive media: An analysis of children's computer and video game use. Dissertation Abstracts International: Section B: The Sciences and Engineering, 60, 6400. 
Chapter 6

Subrahmanyam, K., \& Greenfield, P. M. (1994). Effect of video game practice on spatial skills in girls and boys. Journal of Applied Developmental Psychology, 15, 13-32.

Subrahmanyam, K., \& Greenfield, P. M. (1998). Computer games for girls: What makes them play? In J. Cassel \& H. Jenkins (Eds.), From Barbie to Mortal Kombat: Gender and Computer Games. Cambridge (pp. 46-71), MA: MIT Press.

Suizzo, M., \& Stapleton, L. M. (2007). Home-based parental involvement in young children's education: Examining the effects of maternal education across U.S. ethnic groups. Educational Psychology, 27(4), 1-24.

United Nations Educational Scientific and Cultural Organisation (UNESCO) (1997). International Standard Classification of Education (ISCED). Paris: UNESCO.

Veen, W., \& Vrakking, B. (2006). Homo Zappiens, Growing up in a digital age. The Learning Citizen, 7.

Wassenberg, R., Hurks, P. P. M., Hendriksen, J. G. M., Feron, F. J. M., Meijs, C. J. C., Vles, J. S. H., et al. (in press). Age-related improvement in complex language comprehension: Results of a crosssectional study with 361 children aged 5 to 15 . Journal of Clinical and Experimental Neuropsychology.

Wright, J. C., Huston, A. C., Vandewater, E., A., Bickham, D. S., Scantlin, R. M., Kotler, J. A., et al. (2001). American children's use of electronic media in 1997. Journal of Applied Developmental Psychology, 22, 31-47. 


\section{Appendix 1}

\section{Used questions from the questionnaire (translated from Dutch)}

$\square$ Yes $\square$ No Does your child play computer games?

What sort of computer games does your child play?

$\square$ Fighting/sports/race/shooting games (for instance, GTA, FIFA, Mortal Combat)

$\checkmark$ Story/adventure games (for instance Harry Potter, LOTR, Finding Nemo)

$\square$ Educational games (learning math, spelling, writing etc.)

$\square$ Other: namely 



$$
\text { 七 }
$$




\title{
Chapter 7
}

\section{The relationship between gaming and verbal learning: A large-scale cross-sectional study in 200 children aged 5-15 years}

\begin{abstract}
Verbal learning performance and factors that are known to play a major role in this (i.e., strategy use, metamemory, processing speed, and retrieval of words from semantic memory) were studied in 200 children (aged 5-15) who played one category of games. Children who played strategic-planning games had a better verbal learning performance and serial clustering than children who used the computer for information-exchange activities. Children who played sensorimotor games had intermediate performances. The results of this study showed a positive relationship between playing specific kinds of games and verbal learning and strategy use. This implies that active engaging in gaming by children might be a potent factor in the incidental stimulation of verbal learning performance.
\end{abstract}




\section{Introduction}

A large survey study has indicated that $83 \%$ of Dutch children make recreational use of a computer ('gaming') (Meijs, Hurks, Feron, Wassenberg, \& Jolles, submitted). This is important because gaming may have an impact on the (cognitive) development of children, in the positive as well as in the negative sense. Relatively more is known about the negative impact that gaming can have. Examples are the time spent sitting behind a computer, and the fact that many children prefer gaming above playing outside (which decreases the amount of physical exercise they get) and homework. In addition, the violent nature of some computer games is often mentioned (Funk, Buchman, \& Germann, 2000). Less is known about the possible positive influence that the use of the computer can have. Studies report that gaming can have a stimulating effect on visual short-term memory (Green \& Bavelier, 2006a), reaction time, handeye coordination, manual dexterity (Green \& Bavelier, 2006b), spatial abilities (Green \& Bavelier, 2006b; Subrahmanyam \& Greenfield, 1994), and strategies for the allocation of attention (Green \& Bavelier, 2006b; Greenfield, DeWinstanley, Kilpatrick, \& Kaye, 1994). The stimulation is incidental because it occurs unconsciously. It is therefore different from the effect of conscious training of cognitive abilities. It is not known whether gaming has an incidental positive influence on verbal learning and factors that influence verbal learning. Verbal learning development depends on the changes in memory capacity, knowledge base (i.e., information in long-term memory), metamemory (i.e., knowledge about memory, for instance what strategies can be used best in a given situation), and strategy use (Schneider \& Pressley, 1997). In addition, working memory is influenced by processing speed (Fry \& Hale, 2000). Because explicit training of working memory leads to a better verbal learning performance (Bjorklund \& Douglas, 1997; Bjorklund, Miller, Coyle, \& Slawinsky, 1997; Schneider \& Pressley, 1997; Siegler \& Wagner Alibali, 2005), we are interested in assessing whether there is a relationship between gaming, verbal learning, and factors that influence verbal learning. Such verbal learning-influential factors include strategy use, metamemory, processing speed, and retrieval of words from semantic memory. Since verbal learning processes are basic to the majority of other cognitive functions (Lezak, Howieson, \& Loring, 2004), it is surprising that this relationship has, at least to our knowledge, not yet been studied.

The relationship between gaming and verbal learning is hypothesized to be dependent on the type of game being played. Gaming involves several higher-order, effortful neuropsychological functions (Pillay, Brownlee, \& Wilss, 1999). For example, gaming can require the game-player to simultaneously: (1) pay attention to relevant topics, (2) integrate incoming auditory and visual information, (3) store incoming information and manipulate it in working memory, (4) solve cognitive problems by using strategies, and (5) enact a motor response as quickly as possible. While most games recruit similar cognitive functions, this is not necessarily the case for specific neuropsychological functions. In the current study, we have assessed computer use in children and adolescents aged 5 to 15 years and related computer use to neurocognitive performance. We grouped many games that are used in this age group 
into three categories according to the nature of computer use. These were based on the neuropsychological functions that are predominantly required to play the games: (1) sensorimotor games, (2) information-exchange activities, and (3) strategic-planning games. These categories largely correspond to these used in the study of Wright et al. (2001).

In the first category of games -the sensorimotor games (such as Formula One and DOOM)- incoming sensory information has to be judged and turned into a fine motor response performed using a keyboard or game-controller, mostly under pressure of time. This type of game, possibly more than other types of games, probably stimulates processing speed, because of the time pressure that is involved in these games. As processing speed influences working memory (Fry \& Hale, 2000), the faster information is processed or words are articulated, the better the working memory performance.

Computer use in the second category -information-exchange activities (educational games, 'chatting', surfing the Internet, or joining Internet forums)- is characterized by a structured approach that guides the child during playing. The core component of these activities is 'communication'. In this category, active problem solving by the gamer (Jenson \& De Castell, 2002), strategy search, and speed are of minor importance. Gaming and computer use in this category are notably characterized by the need to use language to communicate. This may stimulate the development of the lexicon and the active availability of words in memory. If more words are available in memory (i.e., larger vocabulary), more words may be retrieved from semantic memory, which enhances memory (Majerus, Poncelet, Greffe, \& Van der Linden, 2006).

Games of the third category -strategic-planning games (strategy-adventure games, such as Lord of the Rings, and simulation games, such as The Sims)- draw heavily on specific higher cognitive functions, namely, planning, making priorities, cognitive shifting, use of strategies, and problem solving. In addition, they make demands on fine motor function. These games could stimulate strategy use and metamemory, factors known to improve memory (DeMarie \& Ferron, 2003). Because the games are played in real-time, there is less time pressure than with games in the sensorimotor category.

We focused on the performance of children on tests of verbal learning (working memory, learning with repeated presentations, and delayed recall; on a verbal learning test [VLT]) and verbal learning-influential factors (strategy use, metamemory, processing speed, and retrieval of words from semantic memory). We expected that: (1) children who played sensorimotor games would have a better performance on tests that measured processing speed because of the need to respond rapidly in these games; (2) children who used the computer for informationexchange activities would have a better performance on the test of retrieval of words from semantic memory because of the language component of these activities; and (3) children who played strategic-planning games would have a better performance on tests of strategy use and metamemory, because of the need to use strategies in the computer games and the possible improvement in the knowledge of strategies. 
Strategy use was measured with serial and subjective clustering calculations (a relatively simple, passive and a more complex, organizational strategy) during the recall of the VLT. Metamemory was measured as active prospective metamemory (i.e., what can be done not to forget something in a situation yet to come) and passive and active retrospective metamemory (the recall of what strategies have been executed in a past situation).

Next, we compared the relationship between game category and the performance on tests of memory influential factors and on the VLT. We hypothesized that if an aspect of memory function was better in children who played a specific type of game, then (a) working memory and processing speed would be better in children who played sensorimotor games; (b) working memory, learning with repeated presentations, long-term memory, and retrieval of words from semantic memory would be better in children who played games involving information-exchange activities; and (c) learning with repeated presentations, long-term memory, strategy use, and metamemory would be better in children who played strategic-planning games.

Thus, the aim of the current study was to evaluate whether there is a relationship between playing different types of computer games on one hand and verbal learning (working memory, learning with repeated presentations, and delayed recall) and factors that influence verbal learning on the other. A relationship was expected based upon the notion that computer use is a potent factor in the incidental stimulation of the verbal learning-influential factors: strategy use, metamemory, processing speed, and retrieval of words from semantic memory. To our knowledge, this is the first study into this topic. It was executed to evaluate a relationship and it had not the intention to establish causality. This study is new with regard to the fact that this was neuropsychological study, that in the longer term and in cooperation with educational sciences, could have implications for verbal learning and, in general, learning.

\section{Method}

\section{Procedure}

The current study was part of a large cross-sectional and longitudinal Cognitive Development Study of School-aged Children (abbreviation in Dutch: COOS which stands for 'Cognitief Ontwikkelings Onderzoek bij Schoolgaande kinderen', i.e., cognitive development study in school-aged children), performed by the School for Mental Health and Neuroscience of Maastricht University (Wassenberg et al., in press). Only cross-sectional data were used in the current study. Participants were recruited from 29 regular primary and secondary schools in the city of Maastricht and surroundings (The Netherlands). The parents/caregivers (referred to as caregivers hereafter) of the children in kindergarten, grades 2, 4, 6 (primary schools), and 7 and 8 (secondary schools; ranging from lower secondary professional education to preuniversity education) received an information package via the school describing the 
purpose of the study, a request to participate, a questionnaire, a form to give consent for the child to participate, and a stamped-addressed envelope.

All children completed a battery of neuropsychological tests including tests measuring verbal ability (VIQ), language comprehension, time estimation, and memory. Well-trained undergraduate psychology students tested the children individually in a room at their schools. Testing took approximately 1.5 hours; all tests were administered in the same order for each child. The Ethics Committee of the Faculty of Psychology of Maastricht University approved the study protocol.

\section{Participants}

Of the 1086 caregivers who replied, 892 (82\%) gave consent for their child to participate. Children who met the following criteria were eligible for participation: the child (1) had not repeated and/or skipped a grade, (2) had the Dutch nationality (in view of fluency in Dutch), and (3) did not use medication that is known to influence cognitive performance (for instance, asthma medications). The children were selected by school-grade and sex per grade and children were included from a wide range of socioeconomic backgrounds. In total, 431 children (215 boys, 216 girls) aged 5 to 15 years participated in the Cognitive Development Study for School-aged Children. From these, we selected these children that played only one category of game ( $n=$ 200) for the current study, i.e., either games from category 1 , category 2 , or category 3. This was done because we wanted to be able to ascribe effects purely to a specific category of game. Table 1 shows the demographics of these children.

Table 1. Demographics of the 200 included children

\begin{tabular}{lcccccc} 
& \multicolumn{2}{c}{$n$} & Age (mean[sd]) & \multicolumn{3}{c}{ Category of games } \\
& Boys & Girls & & 1 & 2 & 3 \\
\hline Kindergarten & 18 & 18 & $6.17(.30)$ & 4 & 8 & 24 \\
Grade 2 & 14 & 13 & $8.39(.37)$ & 10 & 9 & 8 \\
Grade 4 & 19 & 11 & $10.32(.40)$ & 14 & 13 & 3 \\
Grade 6 & 20 & 14 & $12.32(.51)$ & 14 & 15 & 5 \\
Grade 7 & 25 & 12 & $13.45(.40)$ & 20 & 13 & 4 \\
Grade 8 & 25 & 11 & $14.43(.35)$ & 28 & 5 & 3 \\
\hline Note. Category of games: 1 & sensorimotor games; 2 planning-strategic games; \\
3 = information-exchange activities
\end{tabular}

\section{Instruments}

Questionnaire about recreational computer use

Appendix 1 shows the translated part of the questionnaire about recreational computer use, which was completed by the caregivers. The first question inquired whether the child played computer games. If he/she did, caregivers were asked to classify the games played into (1) fighting/sports/race/shooting games (in the current study categorized as sensorimotor games, such as Mortal Combat, FIFA, Formula One, and DOOM), (2) story/adventure games (in the current study categorized as strategic-planning games, such as Lord of the Rings, SIMS, and Rollercoaster 
Tycoon), (3) educational games (in the current study categorized as informationexchange activities, such as games teaching math or reading, communication, and information exchange, such as chatting and Habbo Hotel), and (4) other. We reviewed games in the last category, to see whether they could be included in one of the other three categories. If not, information about these games was not analyzed. More than one category could be indicated. The categories are comparable to the categories used in the study of Wright et al. (2001).

Caregivers were asked how much time the children played during (a) a school day and (b) a day in the weekend. The total number of minutes that a child spent playing computer games $(5 \times$ number of minutes during a school day $+2 x$ number of minutes during a day in the weekend) was included as factor to correct for possible exposure time differences between children (Subrahmanyam \& Greenfield, 1994).

\section{Level of parental education (LPE)}

The LPE is an indication of the intellectual climate within a family, the complexity of the language used, the books read, and the level of ambitions against which the parents position their developing child. The importance of the family environment of the child is that it has a large impact on his or her psychological -and thus cognitive and social-emotional- development. In a number of studies, the LPE has also been used as part of a measure for socio-economic status (SES) (Greenberg, Lengua, Coie, \& Pinderhughes, 1999; Lupien, King, Meaney, \& McEwen, 2001; McCulloch \& Joshi, 2001; Suizzo \& Stapleton, 2007). Caregivers indicated their highest level of education attained on a commonly used Dutch educational rating scale ranging from primary school (1) to university degree (8) (De Bie, 1987; Kalff et al., 2001). This system is similar to the International Standard Classification of Education (United Nations Educational Scientific and Cultural Organisation (UNESCO), 1997). Although SES -as a measure for the LPE- is known to influence verbal learning performance (Bjorklund \& Douglas, 1997), we did not correct for it because the distribution of the LPE was the same for all categories of games.

\section{$V L T$}

A verbal learning test (VLT) was administered to measure verbal learning. This test is often used in clinical settings and memory research, and is one of the most sensitive verbal memory tests. Its test-retest reliability is reported to be high (Lezak, 1995; Van der Elst, Van Boxtel, Van Breukelen, \& Jolles, 2005). The test was administered as described previously (Brand \& Jolles, 1985; Van der Elst et al., 2005). The words used in the test had been checked for their frequency of use (Linschoten, 1963) and imageability (Van Loon-Vervoorn, 1989). In relation to another study, which is outside the scope of the current study (Meijs, Hurks, Wassenberg, Feron, \& Jolles, submitted), half of the children performed the test with a pictorial presentation modality, in which the words were presented as pictures, and the other children performed the test with an auditory presentation, in which the same words were presented auditory. Per grade, the children were divided at random over the presentation modalities; the procedure was the same for both modalities. Both consisted of 5 trials of presentations 
of 15 words or pictures (both will be called items hereafter) of familiar objects. The items were presented by use of a computer. The auditory-presented items were recorded by an experienced, native male speaker. The presentation duration of the pictures and the written words was the average duration of pronunciation time of the auditory presented words. The items were presented one every 2 seconds. All items were words acquired before six years of age (Van der Elst et al., 2005). They were presented to the children in the same order in each trial. After each presentation of all items, the children had to verbally recall as many items as they remembered (immediate recall). After about 15 to 20 minutes, during which no memory interfering tests were administered, the children were asked to recall as many items as possible from the list, without prompting (delayed recall). This was followed by a recognition trial, in which 30 items were presented, of which 15 items were from the immediate recall task and 15 were new items. The children had to answer 'Yes' or 'No' to whether the item belonged to the list of items presented to them in the immediate recall task. Because of the longitudinal set-up of the Cognitive Development Study, three statistically parallel test versions were used in both presentation modalities. The memory aspects used in the current study were: (1) trial score 1 (number of correctly recalled items on trial 1) as a measure of working memory (Alloway, Gathercole, \& Pickering, 2006), (2) total score (number of correctly recalled items summed over trials 1 to 5) as a measure of learning with repeated presentations, and (3) delayed recall score (number of correctly recalled items on the delayed recall) as a measure of longterm memory. Although presentation modality influences verbal learning (Lezak, 1995; Meijs, Hurks, Wassenberg et al., submitted), we did not correct for it because it was divided evenly over the categories of games.

\section{Serial clustering}

Serial clustering was used to study passive strategy execution. It was calculated by dividing the number of observed serial clusters by the number of serial clusters that could be expected by chance. The number of observed serial clusters was the number of times that two items that were presented sequentially were recalled sequentially. The number of chance serial clusters in a trial was the maximum number of possible serial clusters divided by the sum of the number of items recalled correctly, plus the number of repetitions and intrusions (i.e., items that did not belong to the presented items) on that trial. The maximum possible number of serial clusters was calculated as follows. All items were given a ranking (1 to 15) according to the place of the item in the presentation order. Intrusions had no ranking, because they were not in the presentation list and repetitions had the same ranking as the first recall of that particular item. Then, the recalled items were placed in ascending order according to their ranking. If there were adjacent numbers in the ranking, this was a possible serial cluster. The number of possible item clusters was divided by the total number of items recalled correctly, plus the number of repetitions and intrusions. For example, if item 5 , item 7 , item 8 , item 2 , item 15 , and item 1 were recalled (in that order) and placed according to their ranking in the order $1-2-5-7-8-15$, then two possible item clusters were recalled, namely, items 1 and 2, and items 7 and 8 . The maximum 
number of possible serial clusters in this example was 2 . Thus the number of chance clusters in this example is $2 / 6=.33$. The number of observed clusters in this sample is 1 (items 7 and 8 in the recall order). This leads to a serial clustering of $1 / .33=$ 3.03. This calculation is a modification of the calculation described by Saan and Deelman (1996), in that we included intrusions in the calculation, in order to limit 'noise' in the serial clustering calculation. 'Noise' could be caused by the false detection of serial clusters because of the omission of intrusive items between otherwise adjacent words. There were five serial clustering calculations, one for each trial of the VLT. In the current study, the sum of the serial clustering calculations over the trials was used.

Subjective clustering

Subjective clustering was used to study organizational strategy execution. It was calculated as follows:

$S C=I T R-\left[\frac{2 \mathrm{C}(\mathrm{C}-1)}{\mathrm{H} \times \mathrm{K}}\right]$

In this calculation: (1) SC stands for Subjective Clustering; (2) ITR stands for the number Inter-Trial Repetitions (i.e., the number of groups of two clustered items that were recalled on trial $t$ and the subsequent trial $t+1$ ) that were not serial clusters; (3) $\mathrm{C}$ stands for the number of items recalled on trial $t$ but also on trial $t+1 ;(4) \mathrm{H}$ stands for the sum of the number of items recalled correctly, repetitions, and intrusions on trial $t$; and (5) $\mathrm{K}$ stands for the sum of the number of items recalled correctly, repetitions, and intrusions on trial $t+1$. The calculation was a modification of the calculation described by Saan and Deelman (1996) and Sternberg and Tulving (1977), in that we included intrusions in the calculation in order to limit 'noise' in the subjective clustering calculation that could be caused by the false detection of subjective clusters because of the omission of intrusive items between otherwise clustered items. Additionally, in order to distinguish between serial and subjective clustering, couples of words that were clustered based on word order (i.e., serial clustering) were excluded from the subjective clustering measure. There were four subjective clustering calculations, one for each trial-pair of the VLT, because the recall-orders of two adjacent trails were compared. In the current study, the sum of the subjective clustering calculations over the trial pairs was used.

\section{Verbal ability (VIQ)}

The estimate of verbal ability (VIQ) was the standard score of the Vocabulary subtest of the Dutch Wechsler Intelligence Scales Revised (WISC-Rn) (De Bruin et al., 1986). The WISC-Rn, rather than the WISC-III, was used because the latter became available in the Netherlands after the study had started (Wassenberg et al., in press). In this test, the children have to explain words, ranging from easy to complex. The standard score ranges from 1 to 19 (mean $=10, S D=3$ ). The reliability and validity 
have been described as average to good (De Bruin et al., 1986). The standard score was included as covariate in the analyses to correct for a possible influence of VIQ.

Metamemory test-1 (prospective): Preparation Objects (Sports bag) Test

This test is an adapted version of the 'Preparation Object (SKATES)' subtest of the Metamemory Battery developed by Belmont and Borkowski (1988). It assesses a child's flexibility in thinking of ways to remember in a situation yet-to-come (hence prospective). We used sports bag instead of skates to make the test more appropriate to the Dutch situation because children keep their sports bags at home in the Netherlands. The children had to name as many different methods they knew that they would use, one evening, to remind them to take their sports bag to school the following morning. Responses were scored according to seven unique classes of method: (1) make written or pictorial reminders, (2) have somebody else remind them, (3) strategically place the sports bag, (4) rehearse or use some other in-the-head method (such as making a story with it), (5) set up an external reminder other than discussed in (3) and (4) (for instance, an alarm that goes off), (6) attach a reminder to oneself (for instance, a cross on their hand), and (7) seek additional methods (that were scored as unique methods). The number of categories of the first seven answers was used as outcome measure for active prospective metamemory.

\section{Metamemory test-2 (retrospective): Attribution of recall on the VLT to the use of strategies}

This test assessed whether the child attributed recall on the VLT to the use of strategies. It was derived from metamemory questions used in other studies (DeMarie \& Ferron, 2003; Fabricius \& Cavalier, 1989; Fabricius \& Hagen, 1984). The categories were different from the Preparation Objects Test described above because of the retrospective nature of the test to inquire about strategy use during the VLT. The test consisted of two parts. The first part was active, because it was an 'open' question. The child was asked if he/she did something to remember the items during the VLT and if so, what he/she did. The second part was passive because the child was asked whether he/she had used predefined strategies or actions, namely, (1) listening to the words or looking at the pictures (included as an 'easy' action that even the youngest children would have done), (2) mentally rehearsing the items, (3) paying extra attention to the items that were not recalled in a previous trial, (4) paying attention to specific features of the item (e.g., features of the pictures or sounds of the words), (5) grouping items, (6) thinking of something that would make it easier to remember the items, and (7) doing something else. To correct for the tendency of -especially younger- children to say 'Yes', the children had to describe what they did and/or how they did it after each 'Yes' answer. The number of categories recalled in the 'open' part and the number of categories they replied 'Yes' to in the 'closed' part were used as a measure of active retrospective metamemory and passive retrospective metamemory, respectively. 
The Letter Digit Substitution Test (LDST)

The LDST is based on earlier developed substitution tests (e.g., Digit Symbol Substitution Test) (Van der Elst, Van Boxtel, Van Breukelen, \& Jolles, 2006b; Wechsler, 1951, 1981). In the LDST, letters were presented and the child had to respond by writing the corresponding digit in a blank space, according to a key. The number of correct associations within 60 seconds was used as a measure of processing speed (Van der Elst et al., 2006b).

\section{Verbal Fluency (Animal naming) (VF)}

In the VF, the children were required to generate, within 60 seconds, as many animal names as possible. The test is a part of verbal fluency tests often used in clinical settings (Korkman, Kirk, \& Kemp, 1998; Lezak et al., 2004; Van der Elst, Van Boxtel, Van Breukelen, \& Jolles, 2006a). The words were scored as correct if they were existing or non-imaginary animals. Scored as incorrect were words that were not animals, fantasy-animals, repetitions, or morphological variants (such as cat - cats) of an animal that was named before. The number of correctly generated animals within 60 seconds was used as measure of words retrieved from semantic memory (Hurks et al., 2006).

\section{Statistics}

Differences in aspects of verbal learning and verbal learning-influential factors between children that played one of the three game categories were studied using GLM Univariate Analyses of Variance. The independent variables were: (1) category of games that the child played (sensorimotor games, information-exchange activities, or strategic-planning games), (2) age group (coded: kindergarten, grades 2 and 4 versus grades 6, 7 and 8), (3) sex, (4) the interaction term 'games $x$ age group', and (5) the interaction term 'games $x$ sex' for the analyses of verbal learning aspects only. The independent variables 'sex' and the interaction term 'games $x$ sex' were not included in the analyses of the verbal learning-influential factors because preliminary analyses showed that sex did not influence these factors. No interaction term 'category of games $x$ age $x$ sex' was calculated, because this would lead to too small groups. Age and sex were included in the analyses as independent factors because recent studies have shown that they affect game preference (Meijs, Hurks, Feron et al., submitted). Also, verbal learning and verbal learning-influential factors have been reported to be influenced by age (Schneider \& Pressley, 1997). Therefore we formed two age groups of children, namely, younger children up about 10 years of age (kindergarten and grades 2 and 4) and older children (grades 6, 7, and 8). Some studies have shown that girls perform better than boys on tests of verbal learning (Cox \& Waters, 1986; Kramer, Delis, Kaplan, O'Donnel, \& Prifitera, 1997; Vakil, Blachstein, \& Hoofien, 1991), but others have not (Bishop, Knights, \& Stoddart, 1990; Forrester \& Geffen, 1991; Van den Burg \& Kingma, 1999). To correct for possible sex or age differences on verbal learning performance, we included age and sex as main variables and tested for interactions between 'games $x$ age', and 'games $x$ sex' for the tests of the aspects of verbal learning, and age and the interaction between 'age $x$ 
games' for the tests of verbal learning-influential factors. However, the main effects of age and sex will not be discussed further.

The dependent variables were: (1) trial score 1 (i.e., working memory), (2) learning with repeated presentations, (3) delayed recall, (4) serial clustering (i.e., passive strategy use), (5) subjective clustering (i.e., organizational strategy use), (6) active prospective memory, (7) active retrospective metamemory, (8) passive retrospective metamemory, (9) processing speed, and (10) retrieval of words from semantic memory.

We corrected for VIQ (Bjorklund \& Douglas, 1997; Schneider, Knopf, \& Stefanek, 2002) and the time that children spent gaming during a week (Castel, Pratt, \& Drummond, 2005) because these factors have been reported to influence performance on tests of verbal learning and verbal learning-influential factors, respectively, and were not divided evenly over the groups.

\section{Results}

Game category had a significant effect on trial score 1 (i.e., working memory) $(F(2,148)=5.412, p=.005$; Partial Eta Squared $=.068)$, learning with repeated presentations $(F(2,148)=3.519, p=.032$; Partial Eta Squared $=.045)$, and delayed recall $(F(2,147)=4.807, p=.009$; Partial Eta Squared $=.014)$. Post-hoc analyses indicated that children who played strategic-planning games recalled more words on the VLT than the children who used the computer for information-exchange activities ( $p=.006, p=.027, p=.035$, Bonferroni corrected). The memory performance of the children who played sensorimotor games did not differ from that of the children who played strategic-planning games $(p=.254, p=1.000, p=1.000$, Bonferroni corrected) or that of the children who used the computer for information-exchange activities ( $p=$ $.516, p=.214, p=.090$, Bonferroni corrected). This was because the performances of these children were intermediate between that of the children in the other two categories.

Game category also had a significant effect on serial clustering (i.e., passive strategy use) $(F(2,150)=3.445, p=.034$; Partial Eta Squared $=.044)$. Post-hoc analyses indicated that children who played strategic-planning games had a better serial clustering than the children who used the computer for information-exchange ( $p$ $=.035$, Bonferroni corrected) (see Figure 1). Serial clustering of the children who played sensorimotor games did not differ from that of the children who played strategic-planning games $(p=.295$, Bonferroni corrected) or that of children who used the computer for information-exchange activities $(p=.571$, Bonferroni corrected). This was because the performances of these children were intermediate between that of the children in the other two categories. 
Figure 1. Serial clustering per category of games

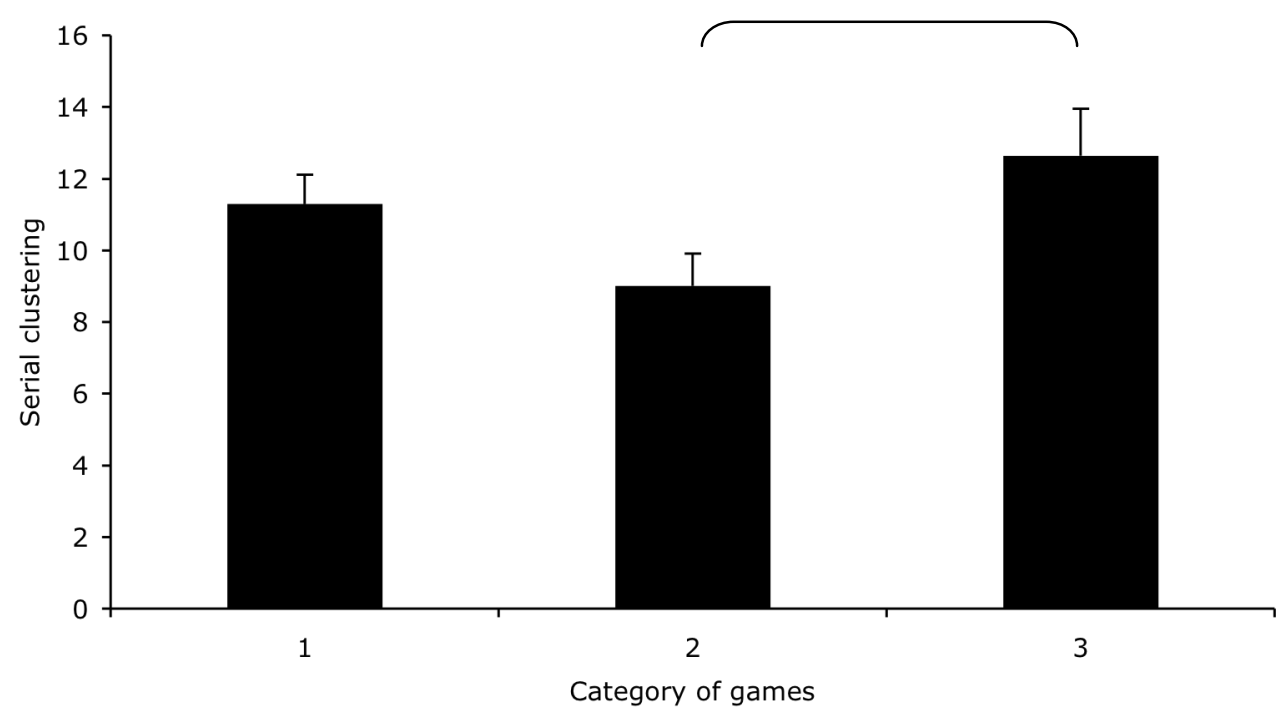

Note. Category of games: 1 = sensorimotor games; 2 = information exchange activities; 3 = strategicplanning games

The interaction term 'games $\mathrm{x}$ age group' had a significant effect on active prospective metamemory $(F(2,158)=3.875, p=.023$; Partial Eta Squared $=.047)$ and processing speed $(F(2,138)=8.272, p=.000$; Partial Eta Squared $=.107)$. For prospective metamemory, post-hoc analyses with a split-file for game category indicated that there were significant performance differences between the younger and older children who used the computer for information-exchange activities $(F(1,27)=21.530, p=.000$; Partial Eta Squared $=.444)$, but not between the younger and older children who played sensorimotor games $(F(1,78)=1.870, p=.175$; Partial Eta Squared $=.023)$, or strategic-planning games $(F(1,49)=3.069, p=.086$; Partial Eta Squared $=.059)$. For processing speed, post-hoc analyses with a split-file for game category indicated that there were significant differences between the younger and the older children for all categories of games: sensorimotor games, $(F(1,67)=38.945, p=.000$; Partial Eta Squared $=.368)$, information-exchange activities $(F(1,24)=55.588, p=.000$; Partial Eta Squared $=.698)$, and strategic-planning games $(F(1,43)=66.265, p=.000$; Partial Eta Squared $=.606$ ). The difference between the younger and the older children in performance on tests of active prospective metamemory and processing speed was larger for the children who used the computer for information exchange activities than for the children that played strategic-planning games or sensorimotor games (see Figures 2 and 3). Game category did not affect subjective clustering (i.e., organizational strategy use), active and passive retrospective metamemory, or retrieval of words from semantic memory. 
Figure 2. Number of strategies named in the active prospective metamemory test per category of games, classified for younger and older children

Younger children

Older children

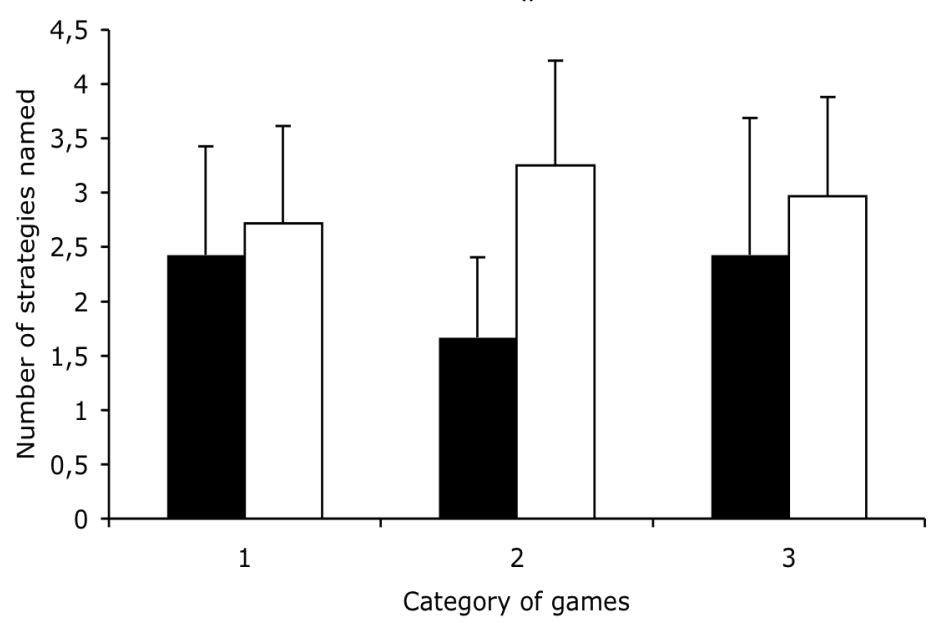

Note. Category of games: $1=$ sensorimotor games; $2=$ information exchange activities; $3=$ strategicplanning games. Younger children $=$ kindergarten, grades 2 and 4 ; Older children $=$ grades 6,7 and 8

Figure 3. Number of correct associations in the processing speed test per category of games, classified for younger and older children

*

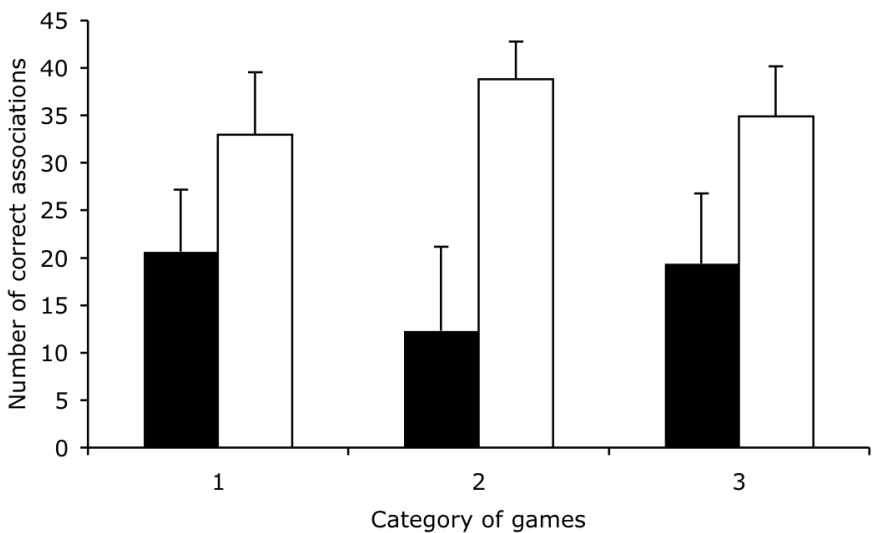

Note. Category of games: 1 = sensorimotor games; $2=$ information exchange activities; $3=$ strategicplanning games. Younger children $=$ kindergarten, grades 2 and 4 ; Older children $=$ grades 6,7 and 8 


\section{Discussion}

The aim of the current study was to evaluate whether there was a relationship between playing games and verbal learning (working memory, learning with repeated presentations, and delayed recall), and verbal learning-influential factors (strategy use, metamemory, processing speed, and retrieval of words from semantic memory). Games were clustered into three categories namely, sensorimotor games, use of a computer for information-exchange activities, and strategic-planning games. We hypothesized that: (1) children who played sensorimotor games would have a better performance on tests that measured processing speed because of the need to respond rapidly in these games; (2) children who used the computer for informationexchange activities would have a better performance on the test of retrieval of words from semantic memory because of the language component of these activities; and (3) children who played strategic-planning games would have a better performance on tests of strategy use and metamemory because of the need to use strategies in these computer games and the possible improvement of knowledge of strategies.

We found that (a) children who played strategic-planning games had a better serial clustering than the children who played sensorimotor games or used the computer for information-exchange activities; (b) among children who used the computer for information-exchange activities, older children ( $>10$ years) had a better active prospective memory than younger children ( $<10$ years); and (c) although posthoc analyses revealed no differential age effect on processing speed between the children that played the different categories of games, the predictive power (i.e., as measured with Partial Eta Squared) showed that these age differences were strongest in children who used the computer for information-exchange activities or played strategic-planning games compared with children who played sensorimotor games. These findings $(a-c)$ are partly in line with the hypotheses and will be described in detail below.

Independent of age, children who played strategic-planning games made better use of serial clustering than children who used the computer for informationexchange activities. We take this to indicate that there is a relationship between playing strategic-planning games and serial clustering. The nature of this relationship could be based on an incidental stimulation by gaming of the development of executive skills, but a definite answer cannot be obtained from the current crosssectional study. Interestingly, subjective clustering, which is a more active, organizational strategy, was not executed better by the children who played these games. Apparently, the possible incidental stimulation is sufficient for a better use of a simple, passive strategy but not enough for a better use of a more complex, organizational strategy. It is possible that if children would be made more aware of the implementation of strategies, that the use of complex, organizational strategies would be stimulated too, as in explicit training (Bjorklund \& Douglas, 1997). 
In line with these results, metamemory (i.e., knowledge about the memory and/or strategies; Schneider \& Pressley, 1997) was not better for children that played strategic-planning games as compared to the other categories of games. In the current study we measured knowledge of strategies that could be used or were used in a given situation. Subjects had to be aware that, instead of simply paying attention to the items that have to be remembered, it is possible to improve memory by doing something special, for instance by using strategies. For understanding this, subjects had to be consciously aware of the use and benefits of strategies. They also had to be aware that they might have used strategies, which can be done unconsciously. Metamemory is therefore a more complex cognitive function than strategy use.

Of the children who used the computer for information-exchange activities, the older children had a better active prospective metamemory than the younger children. Children younger than 10 years who use the computer for information-exchange activities most often play educational games, whereas older children most often 'chat' or surf the Internet (Meijs, Hurks, Feron et al., submitted). We take this to indicate that playing educational games does not stimulate active prospective metamemory whereas 'chatting' and surfing the Internet do. These children also had a better active prospective metamemory than the children who played strategic-planning games, which was contrary to our expectations. It is probable that, when chatting or surfing the Internet, a person needs to remember what he/she is looking for and to stop searching when it is found. In the same way, children must be able to find ways to remember what to do or when to act in a situation yet to come. This appears to be more demanding during these computer activities than during playing strategicplanning games. However, although metamemory, and hence knowledge about memory, was better in these children, the use of strategies was not. Thus, knowledge of strategies does not automatically lead to their use, at least in this age group of children and adolescents. This means that knowledge alone is not sufficient for a possible incidental stimulation, but that the child needs to actively use strategies to actually increase use.

The post-hoc analyses revealed that age did not have a differential effect on processing speed regardless of the category of game played. However, the predictive power (i.e., as measured with Partial Eta Squared) was strongest for children who used the computer for information-exchange activities or played strategic-planning games. As mentioned above, we assumed that, in the category of informationexchange activities, older children would 'chat' or join a forum (Meijs, Hurks, Feron et al., submitted). Because these activities require a person to understand the information provided, think of their response, and write quickly, a fast reaction and processing of information may be, contrary to our expectations, more important to these activities than language per se. In contrast, most educational games, which are played by one person and which we assumed were played by younger children (Meijs, Hurks, Feron et al., submitted), are less demanding in terms of processing speed, being instead focused on the information provided. The same age effect was seen for processing speed among the children that played strategic-planning games. The games in this category are more homogeneous than the games in the information- 
exchange category, and thus differences in processing speed in this category may reflect a main age effect. We expected that playing sensorimotor games would enhance processing speed, but our findings suggest that 'chatting', joining forums, and surfing the Internet are more demanding in terms of information processing than sensorimotor games.

Thus, only the children who played strategic-planning games had a better verbal learning performance than the children who used the computer for informationexchange activities. One of the interpretations of this major finding is that verbal learning was improved by the stimulation of the use of the passive strategy by playing strategic-planning games. An alternative interpretation will be given below. On the other hand, the lack of relationship between processing speed and active prospective metamemory and playing a category of games can be taken to indicate that these cognitive functions were not stimulated by playing sensorimotor games or using the computer for information-exchange activities respectively. We expected strategy use to influence learning with repeated presentation and long-term memory, but serial clustering (i.e., the recall of the words in the same order as they were presented) was related to working memory too. This indicates that serial clustering can be used in working memory tests that include one presentation of an overload of information and in which the order of the recall of the items is not relevant. This is in line with previous studies that indicated that serial clustering use on the first trial of a verbal learning test (VLT) was correlated with better verbal learning performance (Meijs, Hurks, Kalff et al., submitted).

The other explanation is that the relationship is the other way around. The most probable hypothesis is that gaming incidentally stimulates neuropsychological functions (i.e., memory-influential factors). However, it is possible that children who excel in certain neuropsychological functions have a preference for playing the games that require these functions for proper execution. However, even though they may play these games more often than the other children, they are still exposed to possible incidental stimulation. Because other factors could also influence both game preference and neuropsychological functions, we were not able to study whether there is a causal relationship between incidental stimulation by gaming and verbal learning and/or other aspects of cognition, but that was not the goal of the current study. The most important finding is that there was a relationship between gaming, verbal learning, and strategy use. This indicates that active engagement in gaming by children has a positive impact on their behaviour and neurocognitive functioning. Future research should be devoted to the closer investigation of the exact relationship between playing games and the direction of causality.

Verbal learning performance and serial clustering did not significantly differ between children who played sensorimotor games and children who played strategicplanning games. This was the result of the intermediate performance of the children that played sensorimotor games. The use of strategies is, against expectations, probably more important in sensorimotor games than the need for processing speed. Sensorimotor games, probably also require the use of strategies, but to a lesser degree than strategic-planning games. 
Our study had some potential limitations. We used questionnaires completed by caregivers, so that the categorization of the games was dependent on caregivers' ability to judge to which category a game belonged. It might be better when caregivers would provide the name of the game and that the researchers categorizes the game. In addition, the caregivers of the children -especially older children- might not be aware of what their children actually do when they are behind the computer. Thus, in the future, older children could be asked about which games they play or for what other activities they use the computer.

In conclusion, there was a relationship between playing strategic-planning games, verbal learning and strategy use. This is, to our knowledge, the first study into the possible relationship between gaming and verbal learning performance. These results showed that gaming could have a positive effect on cognitive development, especially on verbal learning. A possible implication is that active use of particular computer games might have a stimulatory influence on strategy use. Future studies should evaluate the causal direction of this relationship and investigate whether games could be implemented in applied settings as a tool for the training of strategy use and hence, improve verbal learning. 


\section{References}

Alloway, T. P., Gathercole, S. E., \& Pickering, S. J. (2006). Verbal and visuospatial short-term and working memory in children: Are they separable? Child Development, 77(6), 1698-1716.

Belmont, J. M., \& Borkowski, J. G. (1988). A group-administered test of children's metamemory. Bulletin of the Psychonomic Society, 26, 206-208.

Bishop, J., Knights, R. M., \& Stoddart, C. (1990). Rey Auditory - Verbal learning Test: Performance of English and French children aged 5 to 16. The Clinical Neuropsychologist, 4, 133-140.

Bjorklund, D. F., \& Douglas, R. N. (1997). The development of memory strategies. In N. Cowan \& C. Hulme (Eds.), The Development of Memory in Childhood (pp. 201-246). Hove, East Sussex, UK: Psychology Press.

Bjorklund, D. F., Miller, P. H., Coyle, T., R., \& Slawinsky, J. L. (1997). Instructing children to use memory strategies: Evidence of utilization deficiencies in memory training studies. Developmental Review, $17,411-441$.

Brand, N., \& Jolles, J. (1985). Learning and retrieval rate of words presented auditory and visually. The Journal of General Psychology, 112, 201-210.

Castel, A. D., Pratt, J., \& Drummond, E. (2005). The effects of action video game experience on the time course of inhibition of return and efficiency of visual search. Acta Psychologica, 119, 217-230.

Cox, D., \& Waters, H. S. (1986). Sex differences in the use of organisation strategies: A developmental analysis. Journal of Experimental Child Psychology, 41, 18-37.

De Bie, S. E. (1987). Standaardvragen 1987: Voorstellen voor uniformering van vraagstellingen naar de achtergrondkenmerken en interviews [Standard questions 1987: Proposal for the uniformization of questions regarding background variables and interviews] (2nd ed.). Leiden, The Netherlands: Leiden University Press.

De Bruin, E. E. J., Van der Steene, R. G., Van Haasen, P. P., Coetsier, P., Pijl, Y. L., Spelders-Claes, R., et al. (1986). Wechsler Intelligence Scale for Children (WISC-R). Lisse, The Netherlands: Swets \& Zeitlinger

DeMarie, D., \& Ferron, J. (2003). Capacity, strategies, and metamemory: Test of a three-factor model of memory development. Journal of Experimental Child Psychology, 84, 167-193.

Fabricius, W. V., \& Cavalier, L. (1989). The role of causal theories about memory in young children's memory strategy choice. Child Development, 60, 298-308.

Fabricius, W. V., \& Hagen, J. W. (1984). Use of causal attributions about recall performance to assess metamemory and predict strategic memory behavior in young children. Developmental Psychology, 20, 975-987.

Forrester, G., \& Geffen, G. (1991). Performance measures of 7- to 15-year-old children on the Auditory Verbal Learning Test. The Clinical Neuropsychologist, 5, 345-359.

Fry, A. F., \& Hale, S. (2000). Relationships among processing speed, working memory and fluid intelligence in children. Biological Psychology, 54, 1-34.

Funk, J. B., Buchman, D. D., \& Germann, J. N. (2000). Preference for violent electronic games, selfconcept, and gender differences in young children. The American Journal of Orthopsychiatry, 70, 233-241.

Green, C. S., \& Bavelier, D. (2006a). Enumeration versus multiple object tracking: The case of action video players. Cognition, 101, 217-245.

Green, C. S., \& Bavelier, D. (2006b). The cognitive neuroscience of video games. In P. Messaris \& L. Humphreys (Eds.), Digital media: Transformations in Human Communication. New York: Peter Lang.

Greenberg, M. T., Lengua, L. J., Coie, J. D., \& Pinderhughes, E. E. (1999). Predicting developmental outcomes at school entry using a multiple-risk model: Four American communities. The Conduct Problems Prevention Research Group; Developmental Psychology, 35, 403-417.

Greenfield, P. M., DeWinstanley, P., Kilpatrick, H., \& Kaye, D. (1994). Action video games and informal education: Effects on strategies for dividing visual attention. Journal of Applied Developmental Psychology, 15, 105-123.

Hurks, P. P. M., Vles, J. S. H., Hendriksen, J. G. M., Kalff, A. C., Feron, F. J. M., Kroes, M., et al. (2006). Semantic category fluency versus initial letter fluency over 60 seconds as a measure of automatic and controlled processing in healthy school-aged children. Journal of Clinical and Experimental Neuropsychology, 28, 684-695.

Jenson, J., \& De Castell, S. (2002). Serious Play: Challenges of educational game design. Paper presented at the AERA Annual Meeting, New Orleans, Louisiana. 
Kalff, A. C., Kroes, M., Vles, J. S. H., Bosma, H., Feron, F. J. M., Hendriksen, J. G. M., et al. (2001). Factors affecting the relation between parental education as well as occupation and problem behavior in Dutch 5- to 6- year- old children. Social Psychiatry and Psychiatric Epidemiology, 36, 324-331.

Korkman, M., Kirk, U., \& Kemp, S. (1998). NEPSY. A Developmental Neuropsychological Assessment. San Antonio: TX: Psychological Corporation.

Kramer, J. H., Delis, D. C., Kaplan, E., O'Donnel, L., \& Prifitera, A. (1997). Developmental sex differences in verbal learning. Neuropsychology, 11, 577-584.

Lezak, M. D. (1995). Neuropsychological Assessment (3rd ed.). New York: Oxford University Press.

Lezak, M. D., Howieson, D. B., \& Loring, D. W. (2004). Neuropsychological Assessment (4th ed.). New York: Oxford University Press.

Linschoten, J. (1963). De La Court's Frequentietellingen van Nederlandse Woorden [De la Court's Frequency Counts of Dutch Words]. (Report 6301). Utrecht, The Netherlands: University of Utrecht, Psychologisch Laboratorium.

Lupien, S. J., King, S., Meaney, M. J., \& McEwen, B. S. (2001). Can poverty get under your skin? Basal cortisol levels and cognitive function in children from high and low socioeconomic status. Development and Psychopathology, 13, 653-676.

Majerus, S., Poncelet, M., Greffe, C., \& Van der Linden, M. (2006). Relations between vocabulary development and verbal short-term memory: The relative importance of short-term memory for serial order and item information. Journal of Experimental Child Psychology, 93, 95-119.

McCulloch, A., \& Joshi, H. E. (2001). Neighbourhood and family influences on the cognitive ability of children in the British National Child Development Study. Social Science \& Medicine, 53, 579591.

Meijs, C. J. C., Hurks, P., Kalff, A. C., Slaats-Willemse, D., Rozendaal, N., \& Jolles, J. (Manuscript under revision). Differential development of learning strategies in primary school children.

Meijs, C. J. C., Hurks, P., Wassenberg, R., Feron, F. J. M., \& Jolles, J. (Submitted). Auditory versus pictorial verbal learning in 431 children aged 5 to 15: A cross-sectional study.

Meijs, C. J. C., Hurks, P. P. M., Feron, F. J. M., Wassenberg, R., \& Jolles, J. (Submitted). The relation between age, sex, the level of parental education (LPE), and preferences in recreational computer use in 910 school-aged children aged 5-16.

Pillay, H., Brownlee, J., \& Wilss, L. (1999). Cognition and recreational computer games: Implications for educational technology. Journal of Research on Computing in Education, 32, 203-216.

Saan, R. J., \& Deelman, B. G. (1986). Nieuwe 15-woorden test A en B (15WT-A en 15WT-B) [New 15words test A and B (15WT-A and 15 WT-B)]. In A. Bouma, J. Mulder \& J. Lindeboom (Eds.), Neuropsychologisch Handboek (pp. 13-28). Amsterdam: Swets \& Zeitlinger.

Schneider, W., Knopf, M., \& Stefanek, J. (2002). The development of verbal memory in childhood and adolescence: Findings from the Munich Longitudinal Study. Journal of Educational Psychology, 94, 751-761.

Schneider, W., \& Pressley, M. (1997). Memory Development Between Two and Twenty (2nd ed.). Mahwah, $\mathrm{NJ}$ : Lawrence Erlbaum Associates.

Siegler, R. S., \& Wagner Alibali, M. (2005). Children's Thinking (4th ed.). Upper Saddle River, NJ: Pearson Prentice Hall.

Sternberg, R. J., \& Tulving, E. (1977). The measurement of subjective organization in free recall. Psychological Bulletin, 84, 539-566.

Subrahmanyam, K., \& Greenfield, P. M. (1994). Effect of video game practice on spatial skills in girls and boys. Journal of Applied Developmental Psychology, 15, 13-32.

Suizzo, M., \& Stapleton, L. M. (2007). Home-based parental involvement in young children's education: Examining the effects of maternal education across U.S. ethnic groups. Educational Psychology, 27(4), 1-24.

United Nations Educational Scientific and Cultural Organisation (UNESCO). (1997). International Standard Classification of Education (ISCED). Paris: UNESCO.

Vakil, E., Blachstein, H., \& Hoofien, D. (1991). Automatic temporal order judgment: The effect of intentionality of retrieval on closed-head-injured patients. Journal of Clinical and Experimental Neuropsychology, 13, 291-298.

Van den Burg, W., \& Kingma, A. (1999). Performance of 225 Dutch school children on Rey's Auditory Verbal Learning Test (AVLT): Parallel test-retest reliabilities with an interval of 3 months and normative data. Archives of Clinical Neuropsychology, 14, 545-559.

Van der Elst, W., Van Boxtel, M. P. J., Van Breukelen, G., J. P., \& Jolles, J. (2005). Rey's Verbal Learning test: normative data for 1,855 healthy participants aged 24-81 years and the influence of age, 
sex, education, and mode of presentation. Journal of the International Neuropsychological Society, 11, 290-302.

Van der Elst, W., Van Boxtel, M. P. J., Van Breukelen, G., J. P., \& Jolles, J. (2006a). Normative data for the animal, profession and Letter $m$ naming Verbal Fluency Tests for Dutch speaking participants and the effects of age, education, and sex. Journal of the International Neuropsychological Society, $12,80-89$.

Van der Elst, W., Van Boxtel, M. P. J., Van Breukelen, G. J. P., \& Jolles, J. (2006b). The Letter Digit Substitution Test: Normative data for 1,858 healthy participants aged 24-81 from the Maastricht Aging Study (MAAS): influence of age, education and sex. Journal of Clinical and Experimental Neuropsychology, 28, 998-1009.

Van Loon-Vervoorn, W. A. (1989). Voorstelbaarheidswaarden van Nederlandse Woorden [Imageability Ratings of Dutch Words]. Lisse, The Netherlands: Swets \& Zeitlinger.

Wassenberg, R., Hurks, P. P. M., Hendriksen, J. G. M., Feron, F. J. M., Meijs, C. J. C., Vles, J. S. H., et al. (in press). Age-related improvement in complex language comprehension: Results of a crosssectional study with 361 children aged 5 to 15. Journal of Clinical and Experimental Neuropsychology.

Wechsler, D. (1951). Manual for the Wechsler Adult Intelligence Scale. New York: Psychological Corporation.

Wechsler, D. (1981). Manual for the Wechsler Adult Intelligence Scale-Revised. New York: Psychological Corporation.

Wright, J. C., Huston, A. C., Vandewater, E., A., Bickham, D. S., Scantlin, R. M., Kotler, J. A., et al. (2001). American children's use of electronic media in 1997. Journal of Applied Developmental Psychology, 22, 31-47. 
Chapter 7

\section{Appendix 1}

\section{Used questions from the questionnaire (translated from Dutch)}

$\square$ Yes $\square$ No Does your child play computer games?

What sort of computer games does your child play?

$\square$ Fighting/sports/race/shooting games (for instance, GTA, FIFA, Mortal Combat)

$\square$ Story/adventure games (for instance Harry Potter, LOTR, Finding Nemo)

$\checkmark$ Educational games (learning math, spelling, writing etc.)

$\square$ Other: namely 


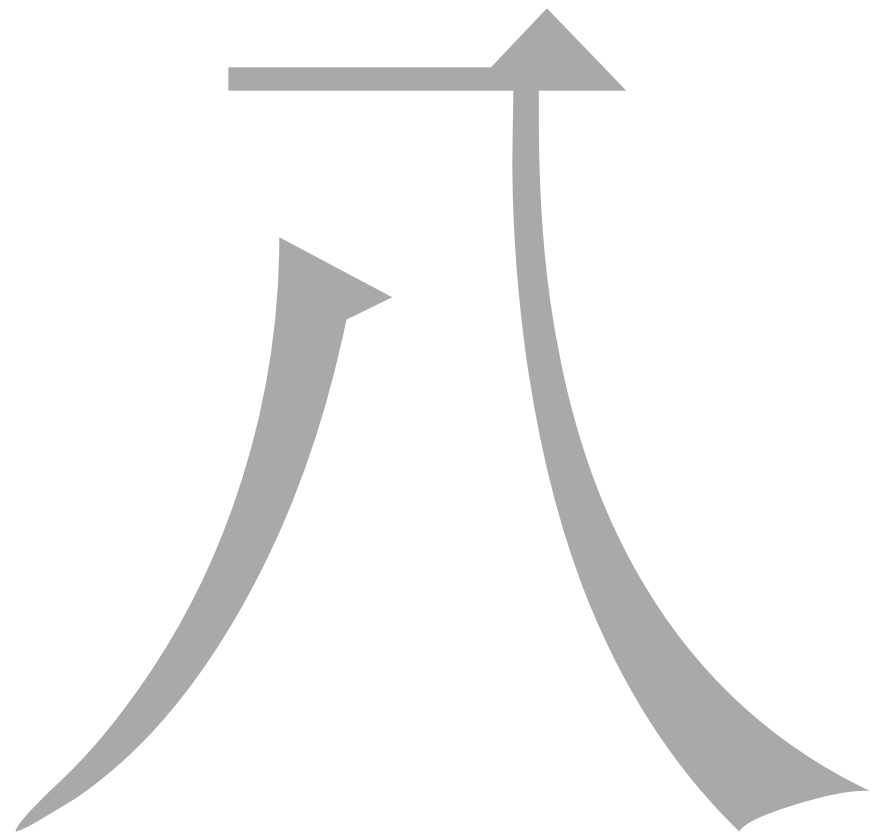




\section{Chapter 8}

\section{Concluding Remarks}

\section{Introduction}

As described in Chapter 1, the research into brain mechanisms and learning is rapidly expanding. Most notable are studies investigating the functioning of the brain in relation to language and reading, the neuroscientific aspects of numeracy, and studies that provide evidence that learning processes are mediated by environmental factors (OECD, 2007). In general, the studies performed to date indicate that learning is influenced by various biological factors, factors related to brain development, as well as psychosocial factors. In addition, learning has a multi-dimensional nature and involves biological, psychological and contextual factors. Therefore, when attempting to evaluate the influence of various factors on learning it is essential to adopt a multidimensional approach. The discipline 'neuropsychology' has potential in such an approach because neuropsychology is both a neuroscience and a behavioural science, with its emphasis both on insights gained from studies into the structure and functions of the brain and on psychological processes. Neuropsychological investigations into learning processes in relation to biological, cognitive and contextual variables could, in the longer term, yield insights that are relevant for education. However, to be able to use this information, studies in other fields of science, such as educational psychology, are needed to evaluate the potential application of the neuropsychological findings in educational interventions. To integrate these findings, we need to adopt a trans-disciplinary approach. The OECD (notably its Centre for Educational Research and Innovation [CERI]) refers to this as a particular approach in the cooperation between the various sciences and has been described in their report 'Birth of a learning science' (2007) and its predecessor in 2002. Important scientific publications also describe this endeavour in terms of 'bridging the gap between neuroscience and education' (Ansari \& Coch, 2006; Goswami, 2006; Jolles et al., 2006; see also www.hersenenenleren.nl or www.brainandlearning.eu).

The present thesis aimed to gain more insight into the multi-factorial influences on verbal learning, where the choice for this factor was based upon its major importance for psychological development and education. Emphasis in this thesis was on the influence of child- and test-related factors, and learning in a natural context. The child-related factors included here were age, sex, the level of parental education (LPE), and verbal ability (VIQ). The test-related factors were strategy use, the presentation modality, the recall demands, and the content of the information. To assess the influence of learning from experiences gained in a natural context, we studied the relationship between playing computer games and verbal learning. The unique contributions of these factors on verbal learning were studied, but the relationships between the factors and their influence on verbal learning were equally interesting and potentially important. As described in Chapter 1, we studied the influences of these factors on verbal learning and memory, because memory 
processes are intimately linked to learning, and the persistence of material learnt is dependent upon the efficiency of memory consolidation, memory retrieval, memory search strategies, resistance to memory interference, and to processes in working memory (see for more information in Ormrod, 1999). Learning and memory are so intimately related that memory is subject to the same factors which influence learning per se (OECD, 2007). In our descriptions of the results, we have mostly referred to both in terms of verbal learning. The tests that were primarily used in this thesis were derived from a verbal learning test (VLT), a word span test (WS), and a digit span test (DS). For descriptions of the tests, we refer to the chapters of the experimental studies (Chapters 2-7).

We focused on children aged 5 to 16, because children within this age-range experience several developmental changes such as the 'milestones' described by Anderson (2002). The milestones he focused on were the developmental patterns of, amongst others, attentional control, information processing, cognitive flexibility, and goal setting (see Chapter 1). Korkman et al. (2001) describe that there is a rapid increase in performance of several functions up about 8 years, and that this increase levels-off between 9 and 12 years (Korkman, Kemp, \& Kirk, 2001). This finding shows that development is not gradual. Additionally, neuroscientific studies regarding brain research indicate that brain development continues until at least 16 years (Alvarez \& Emory, 2006; Gogtay et al., 2004; Klingberg, 2006; Paus, 2005). These findings motivated a further investigation of the development of verbal learning within the agerange defined in the introductory chapter in this thesis: 5 to 16 years. A possible relationship between the development of the cognitive functions that are needed for cognitive performance in general and verbal learning in particular makes this agerange of relevance for the studies described.

The findings presented in this thesis reveal that verbal learning performance in the age-range investigated was influenced by the factors age, sex, the level of parental education (LPE), VIQ, strategy use, the presentation modality, the recall demands (i.e., the order in which the information has to recalled), the content of information (i.e., whether words or digits have to be remembered), and recreational computer use. Moreover, the studies showed that there were relationships between these factors in their influence on verbal learning. Thus, the findings strongly support the notion that development of verbal learning in childhood and early adolescence is not a process that can be seen in isolation, but that it has to be interpreted multidimensionally with a focus upon child-related and test-related factors, as well as learning in a natural context. The findings yield some new insights into the relationship between various factors and their influence on verbal learning development. More specifically, interesting findings refer to: the development of a specific pattern of strategy use with repeated presentations, the relationship that exists between the influence of the presentation modality and the recall demands, the developmental pattern of the differences in performance due to the content of the information, the relationship between gaming and strategy use, and the influence of the LPE on verbal learning. Specific findings will be described in the next paragraphs. 


\section{Influences of the factors}

\section{Child-related factors}

The child-related factors we focused on were age, sex, the level of parental education (LPE), and verbal ability (VIQ). These factors are referred to as 'child-related' because they represent characteristics for each individual child. The combination of these factors (and other factors, such as the number of children within a family, neighbourhood, sleep patterns, eating habits, and many others) ensures that all children are different, unique individuals. In this paragraph, the main influences of the factors of our thesis are reported, without considering their relationship to the other factors. We acknowledge that some of the described influences on verbal learning have been studied in the past, but a detailed description of these influences is needed before the relationships (i.e., 'interactions' in statistical terms) with other factors can be studied. Thus, besides the findings regarding the LPE, most of the findings in this paragraph will be replications of known findings and/or clarifications of inconsistent findings in the literature. However, a new addition -and also an advantage of the studies in this thesis- is that the broad age-range of 5 to 16 years was taken and that the numbers of subjects were large (i.e., the largest of our studies included 910 children). The sample studied was homogenous in many respects and all children received the same tests and were evaluated by the same procedures. Moreover, they were all tested by the same team of investigators. Our studies therefore provide new information to reported findings in the literature, with the notation that most studies in the literature have been using -mostly- a combination of several different studies to come to these conclusions.

The first factor that was studied was age. It has been known that verbal learning performance increases with age (Bjorklund \& Douglas, 1997; Schneider, Knopf, \& Stefanek, 2002; Schneider \& Pressley, 1997; Siegler \& Wagner Alibali, 2005). The findings in this thesis indicated that verbal learning indeed improved when children grew older. Moreover, the increase in performance is more profound in younger children and it levels-off when children become older, which started after the age of 10 , dependent of the aspect of verbal learning. This is an experimental proof for hypotheses generated in studies with narrower age-ranges that showed the same developmental patterns (Korkman et al., 2001). This can be seen in the figures that show verbal learning performance with increasing age, as presented in Chapters 2 and 4. This pattern indicates that the development of verbal learning shows the steepest increase in the primary school years and that the development reaches maturity early in secondary school. This developmental pattern is consistent with that of other cognitive functions such as processing speed and intelligence (Fry \& Hale, 2000) and suggests that these functions might be related. The findings also indicated that although the patterns showed the same developmental curves with respect to an increase and a levelling-off, the age at which the optimal performance was reached was different for the various aspects of verbal learning measured. As can be seen in the figures in Chapter 4 and the data in Chapter 5, on the VLT with an auditory presentation, working memory showed an increase in performance at least up to 15 
years, whereas performance with repeated presentations and delayed recall matured at an earlier age. Thus, working memory with an auditory presentation is related to, or is more dependent on, functions that mature later in life as compared to the other aspects of verbal learning. We assume that the simultaneous maintenance and manipulation of information is the complex factor that causes the developmental differences between the aspects of verbal learning, and the cognitive function that is needed for this is probably strategic planning and organization. These have been described by Anderson (2002), as functions that develop last, and that are mature at about 15 years. We also found that the efficient use of complex strategies increases probably beyond 15 years. This is in line with Hanten et al. (2007) who note that complex strategy use increases up till late adolescence (note: the development of efficient strategy use will be described further in the paragraph on strategy use). The figures in Chapter 4 also show that the presentation modality in which the information is presented has an influence on the moment in time that the optimal performance is reached. VLT performance with a pictorial presentation gave the best performance at an earlier age than VLT performance with an auditory presentation, and lead to better VLT performance at all ages. Thus, the processing of pictorially presented information has an advantage over information presented auditory. This will be described in more detail in the paragraph on the influence of the presentation modality.

The second factor that was studied was sex. Sex differences in verbal learning have been studied before, but past research showed inconsistencies in the conclusions regarding their existence (Bishop, Knights, \& Stoddart, 1990; Forrester \& Geffen, 1991; Vakil, Blachstein, \& Sheinman, 1998; Van den Burg \& Kingma, 1999). The findings showed that girls performed better than boys only on delayed recall (VLT) (see Chapter 4). No differences between boys and girls were found on the other aspects of verbal learning that were included in the studies: i.e., short-term and working memory, learning with repeated presentations, and recognition. These findings are taken to indicate that boys and girls do not differ in the amount of information that they consolidate and store. This is because they recognize the same amount of information after a delay (i.e., recognition memory is the same). Thus, the difference between boys and girls in delayed recall (VLT) must be caused by a difference in the ability to retrieve the words from long-term memory. The data indicate that girls have a superior performance in this respect to boys in the developmental phase studied (see Chapter 4). These findings are of importance as they indicate that the efficiency of verbal learning is better in girls, and that they are better able to retrieve information that has been stored on an earlier occasion. It is probable that the mechanism underlying this boy-girl difference has to do with verbal strategies used in deep consolidation, due to the verbal advantage, which girls this age have. The finding has possible implications for use in applied settings: to help boys in adopting a more efficient retrieval strategy might help them to overcome this disadvantage. This is of importance because of the rapidly growing difference between boys and girls in scholastic performance in the Netherlands (and other Western countries) in that girls outperform boys in many respects. The present findings suggest that evidence based interventions should be developed and tested in educational settings. 
Additionally, interactions between the child-related factors age and sex were studied, but were not found. The possibility exists that sex differences would have been larger or present in older children, because of the hormonal differences that rapidly develop between boys and girls when they reach their teen years and puberty. Our findings indicate that this was not the case. The sex differences in verbal learning performance on delayed recall (VLT) were the same at all ages studied. Therefore, there will be no further discussion on the interaction between age and sex. Other interactions between child-related factors, such as interactions between the LPE and VIQ, were not studied. We chose not to study these to avoid that the power of the analyses would become too low, due to the inclusion of too many factors. With the exception of age and sex, we gave priority to the study of the interactions between child-related factors and test-related factors and learning in a natural context and between several test-related factors.

The third factor that was studied was the level of parental education (LPE). The influence of the LPE on verbal learning has not yet received much attention. The LPE is an indication of the intellectual climate within a family, the complexity of the language used, the books read and the level of ambitions against which the parents position their developing child. The focus was specifically on the LPE because we assume that this 'intellectual climate', including the social-emotional and motivational support for learning, has a major influence on psychological and cognitive development. In some studies, it has also been used as part of a measure for socioeconomic status (SES) (Greenberg, Lengua, Coie, \& Pinderhughes, 1999). It is known that children with a higher SES have a better verbal learning performance than children with a lower SES (Bukatko \& Daehler, 1998; Santrock, 2001; Schneider \& Sodian, 1997; Siegler \& Wagner Alibali, 2005) and we were interested in assessing whether this could also be found for the LPE. With these findings we can investigate whether differences in verbal learning were the result of influences in the intellectual climate or whether other factors such as family income or neighbourhood also influence verbal learning. Unfortunately, the findings of the studies in this thesis have shown inconsistent results regarding the influence of the LPE on verbal learning performance. We found differences that seemed to be related to the age-range we studied. As described in the approach in Chapter 1, the Cognitive Development Study in School-aged Children (COOS) consisted of two data collection rounds, with an interval of one year between the data collection rounds. In the study that included children in the age-range of 5 to 15 (see Chapter 5), no effects of the LPE were found on the verbal learning variables: working memory, learning with repeated presentations, and delayed recall on a VLT (note: serial recall was not studied in this age-range). In the study that included the same children one year later, in (age-range of 6 to 16), children with a higher LPE had a better performance on the variables learning with repeated presentations (VLT) and short-term memory (with a serial recall) as compared to children with a lower LPE. No influence of the LPE was found for working memory and delayed recall (VLT) (see Chapters 2 and 4). Thus, these findings show no consistent influence of the LPE on verbal learning and we were not able to determine possible differences between the influences of the LPE and SES. 
However, the findings regarding VIQ, as described below, may shed some light on these findings.

Children with a higher VIQ have been reported to give better verbal learning and memory performances (Bjorklund \& Douglas, 1997; Schneider et al., 2002; Schneider \& Pressley, 1997). Our findings showed inconsistent results regarding the influence of VIQ on verbal learning performance. As was found for the influence of the LPE, these findings also seemed to be related to the age-range that was studied. In the study that included children in the age-range of 5 to 15 (see Chapters 2 and 4), children with a higher VIQ had a better performance on some measures of working memory, learning with repeated presentations and delayed recall on the VLT (tests with a serial recall were not studied) as compared to children with a low VIQ. In the study that assessed the same children one year later, (age-range of 6 to 16) (see Chapter 5), no effects of VIQ were found for all included verbal learning aspects: i.e., working memory, learning capacity, and delayed recall on the VLT and short-term and working memory with a serial recall. The findings of these studies suggest an influence of VIQ on some verbal learning measures that were included in the agerange of the first data collection round, but no influence on all aspects of verbal learning in the age-range of the second data collection round.

These age-range related findings regarding the influences of the LPE and VIQ suggest that there is a relationship between these factors. This has been reported in the literature, namely that children from parents with a lower income, on average, score 9 points lower on an intelligence test than children from parents with middle income (Berk, 1998). The present studies showed that the LPE and VIQ were only moderately positively correlated (approximately around the .3), thereby excluding multicollinearity (Kleinbaum, Kupper, Muller, \& Nizam, 1998). The findings of the LPE and VIQ reported in the literature have shown influences in the same direction. As described before, a higher LPE and VIQ are both reported to be related to better verbal learning and memory performances. Striking findings in the studies in this thesis were the differential effects with age. The LPE was of influence on performances in the second data collection round (the children were aged 6 to 16), whereas VIQ was of influence on performances in the first data collection round (the children were aged 5 to 15). VIQ was only measured during the first data collection round. Interestingly, VIQ has until now been reported to be an enduring personal trait and to have a predictive value with respect to an individual's future level of intelligence (Fry \& Hale, 2000). VIQ is supposed to give a ranking of the verbal ability of the child compared to same-age peers and it has been assumed that VIQ therefore is a stable measure for, at least, two years. The present findings show that VIQ is not that stable and possibly changes within a year in children within the age-range tested. This could explain the absence of the influence of $\mathrm{VIQ}$ on all the aspects of verbal learning that were included in the second data collection round. It is probably because of this absence of an effect of VIQ that the influence of the LPE has come to expression. Note that the effect of the LPE is possibly smaller but as described before, slightly correlated to VIQ. However, post-hoc analyses indicated that the deletion of VIQ did not lead to statistically significant findings for the influence of the LPE. Another 
possibility -to be investigated in future research- is that the test we used to measure VIQ is not stable enough and that there should be a more extensive determination of VIQ for its possible use as indicator for a longer period. Thus, we have an interesting finding with respect to the fact that VIQ is less stable in predicting performance over a one-year period than expected. This finding warrants more extensive research in order to find the mechanisms involved and use more elaborate IQ testing.

The findings show that the four child-related factors described above, have differential influences on verbal learning. For the study of the verbal learning performance of a specific child, all the influences of these separate factors need to be considered. It leads to the addition and deduction of influences of the factors respectively, in the prediction of the average verbal learning performance for a specific child. Yet, these findings already contribute to a better understanding of possible influences on verbal learning. The most interesting findings are the multi-dimensional relationships/interactions of these child-related factors with the test-related factors and learning in a natural context. Some of these have been mentioned above briefly, and these and others will be described in the paragraphs below.

\section{Test-related factors}

As described before, there are other factors that have to be taken into account when considering verbal learning performance. One category of factors is called test-related factors. These factors are referred to as 'test-related' because the influence on verbal learning is determined by characteristics of the test that is used. The findings showed that strategy use, the presentation modality, the recall demands, and content of the information that has to be recalled all influenced verbal learning performance. Moreover, the findings indicated that there were relationships between these testrelated factors and with the child-related factors. In the following paragraphs, we first explain the test-related factors, then describe the most important influences of the test-related factors, and end with a description of the relationships between testrelated factors and the child-related factors.

\section{Strategy use}

Strategies, such as rehearsal or organization require mentally effortful activities that can be regarded as goal directed processes that are meant to enhance memory performance. Learning strategies are used in order to improve the consolidation of new information into memory and retrieve old information from long-term stores (Bjorklund \& Douglas, 1997). Learning performance is, therefore, at least partly, determined by strategy use. Strategy use was studied by means of serial clustering, which is a simple, passive strategy, and subjective clustering, which is a more complex, organizational strategy. In serial clustering, the information is recalled in the same order as presented, whereas in subjective clustering, information is recalled in self-constructed groups of words (see Chapters 2 and 3). With increasing age, children are able to use more different strategies during a test and they are able to use more complex strategies (Bjorklund \& Douglas, 1997; Schlagmuller \& Schneider, 2002; Siegler \& Wagner Alibali, 2005). This has been shown before from a 
combination of different studies and in this thesis we replicated these findings in one sample of children. The study of multiple strategy use gives an indication of the processes that take place during learning. It gives insight in what children do to remember the information better, whether there are differences in the use of the two strategies, and how this develops with age. Furthermore, we studied the strategy use in a situation in which information is presented repeatedly (see Chapter 3 ). This gives insight in what children do to remember when information is presented several times. We expected that there would be a change in the use of strategies during subsequent presentations and that this would differ for children of several ages. Our findings showed that there was a pattern in the use of serial and subjective clustering with more presentations and that this differed with age. Serial clustering was used on all trials approximately as much by all children. Older children used subjective clustering in addition to serial clustering, especially on the later trials. Probably, this additional use of a strategy is one of the underlying causes of better VLT performance with increasing age. Thus, there were age differences in the processing of information that was presented repeatedly. All children tried to remember the information in the order that the information was presented. With more presentations older children, additionally, clustered information into groups, which made it easier to recall.

These findings also show that older and younger children used serial clustering as frequently on the trials where the older children additionally used subjective clustering. Thus, passive (simple) strategy use (i.e., serial clustering) was not replaced, but complemented by organizational (complex) strategy use (i.e., subjective clustering). This shows that older children are indeed able to use more different strategies during the execution of one and the same verbal learning test, and that they are able to use more complex strategies than younger children. This could suggest that older children divide the presented list of words that has to be remembered during the recall. Some words are recalled in the same order as they were presented. This is more likely to occur for the words that have been presented as the first and last words of the list (i.e., primacy and recency effects). The other words, which are the words of the middle part of the list, are possibly remembered by an active grouping of the information. This explains the use of both strategies during recall, instead of the replacement of the use of the simple strategy (i.e., serial clustering). The study of the use of clustering/strategy use per part of the word-list could give more insight in the exact use of the strategies and needs to be investigated in future research. Possible implications from these findings could be that information is presented in such a manner that children can handle the information in a way appropriate to their age, i.e., shorter lists for younger children and classifiable information for the older children.

In addition to the developmental differences, our findings showed that strategy use was influenced by the child-related factor VIQ (see Chapter 2). Children with a higher VIQ had, overall, a better and more efficient strategy use. This could explain why children with a higher VIQ have a better VLT performance as described above. Strategy use can be trained (Bjorklund \& Douglas, 1997), and children with a lower VIQ could benefit from explicit training to make more efficient use of especially the 
organizational strategy to enhance verbal learning. This is an example of a finding with potential for application in educational settings in the future.

\section{Presentation modality}

The second test-related factor that was studied was the effect of the presentation modality. This was a focus of our interest because it has been reported to have an influence on verbal learning performance (Lezak, 1995). The presentation modality is the mode in which information that has to be remembered is offered. The presentation of information in the best possible presentation modality, given a correct combination with other influencing factors, results in better verbal learning performance. Differences in verbal learning performance with various presentation modalities are reported to be caused by differences in the processing of information. Words that are presented auditorily automatically have a phonological-verbal code and are processed in the auditory stream only. Visually presented -i.e., pictorial and written words- induce more processing than words presented auditory because they were hypothesized to result in dual processing, namely in the visual and the auditory system. Paivio first described this in the dual coding theory (Beacham, Elliott, Alty, \& Al-Sharrah, 2002; Brown, Forbes, \& McConnel, 2006; Ginns, 2005; Kelley et al., 1998). He describes that processing in two modalities -generally- leads to better performance than processing in one modality. Causes for this better performance are connections between the auditory and visual processing streams, which enhances recall. However, this was not found for the information presented in the studies in this thesis. Additionally, the difference between pictorially presented (concrete) words and words that are presented in written or auditory form is that pictorially presented words need to be labelled or recoded into a phonological code by the articulatory rehearsal process in the phonological loop (Baddeley, 1997). Thus, the processing of pictures of concrete words leads to greater and more in-depth processing because of the recoding by articulatory rehearsal system.

First, we studied the effects of the presentation modality on a VLT with a free recall (i.e., a test in which the order of the recall of the words is not relevant), with a pictorial and an auditory presentation of the words (see Chapter 4). Lezak (1995) reported that verbal learning with a free recall was better with a pictorial presentation as compared to an auditory presentation. Our findings showed that the influence of presentation modality on VLT performance depends on the age of the child and the aspect of verbal learning, at least, if tests of free recall are considered. For aspects that relate less to working memory such as learning with repeated presentations, delayed recall (VLT), and long-term recognition memory, the presentation of words as pictures (as compared to an auditory presentation of the words) lead to better VLT performances regardless of age. For aspects that are more related to working memory (VLT), this pictorial superiority was only found if the children were above the age of seven. No differences in performance on pictorially presented information and auditorily presented information were found on the aspect of working memory (VLT) in children below the age of seven. This was the result of the development of the articulatory rehearsal process that is needed for the recoding of the pictures. At about 
seven years, this system becomes active (Kemps, De Rammelaere, \& Desmet, 2000; Palmer, 2000) and it is after that age that the deeper processing takes place. In tests with a free recall, such as the VLT, deeper processing leads to a larger amount of processing and this leads to a better recall. Thus, before seven years of age, the recoding does not take place yet, and this leads to a similar recall of pictures as compared to auditorily presented words. We found this effect only for working memory related aspects. This indicates that in learning with repeated presentations and delayed recall (VLT), and long-term recognition memory, other processes take place that compensate for the beneficial effects of recoding in children younger than seven.

Even though no difference in performance with the two presentation modalities was found for working memory in children below the age of seven, a pictorial presentation of information has an advantage over an auditory and written presentation, if the order of the recall is free. Thus, a possible implication is that information -if the order of recall is not important- can better be presented as pictures as compared to an auditory presentation. It is important to keep in mind that the above-described influence of the presentation modality was studied with a test that had a free order of recall. The optimal presentation modality for children in one learning situation is not the optimal presentation modality in another learning situation. Our findings showed that the influence of the presentation modality is different if there were other recall demands such as a serial recall. Because information on recall demands is needed for the description of this relationship, this will be described in the next paragraph on recall demands.

\section{Recall demands}

The third test-related factor that was studied was the influence of the recall demands (see Chapter 5). The term, 'recall demands', refers to the specific way the information has to be recalled. We were interested in this factor because it provides insight into the influence of how information has to be recalled on VLT performance. We focused on the recall demands: free recall (i.e., the order of the words during the recall is not relevant; with the VLT) and serial recall (i.e., the order of recall is predefined, such as recall of the items in the same order as presented or in reversed order; with the WS and DS). In tests with a free recall, only information about the content of the words has to be remembered, whereas in tests with a serial recall, next to information about the content of the words, additional information about the place of the word in presentation list has to be remembered (Majerus, Poncelet, Elsen, \& Van der Linden, 2006; Majerus, Poncelet, Greffe, \& Van der Linden, 2006). Thus, serial recall requires that more information has to be remembered during the recall as compared to free recall. This leads to larger load of processing during serial recall tests as compared to free recall tests. 
Two child-related factors that we studied in relation to the recall demands were age and sex. Our findings showed that at all ages, recall of information was better if the order of the recall was free as compared to a recall in a predefined order (see Chapter 5). This means that the effect of the order of recall does not develop, and that this effect remains at the same level, at least from age six on. Whether it develops before six years could not be studied in this thesis, but we assume that this is not the case, and that the effect of the recall demands is age-invariant. Additionally, the findings showed that this effect was the same for boys and girls. Thus, at all ages and for boys and girls, verbal learning performance is better if the load of processing is lowest, which is when the order of the recall of the information is not relevant.

As described in the paragraph on the presentation modality, a relationship was found between the test-related factor presentation modality and the test-related factor recall demands. Pictorial superiority was, in our studies, found in tests with a free recall (i.e., the VLT). Moreover, our results showed that in tests where there was a predefined order of recall of the words (i.e., serial recall; WS and DS), the performance was worse if information was presented as pictures (see Chapter 5). Thus, the influence of the presentation modality was dependent on the way in which information had to be recalled. As described above, the recall demands determine the processing load by means of the amount of information that has to be remembered: item information in free recall vs. item- and order information in serial recall. We assume that a higher processing load interacts with the amount of processing that is needed for the different presentation modalities. We described earlier that pictorial information needs to be labelled or recoded, and we assume that this labelling or recoding interferes with the processing of the order information, because the articulatory rehearsal system that is needed for the recoding of the pictures is also needed for the rehearsal of the information in the predefined order. This leads to lower performance on serial recall tests with a pictorial presentation. Thus, not only is the presentation modality of information important to consider when interpreting verbal learning performance, but also the recall demands are inextricably related to this.

\section{Content of information}

The content of the information refers to whether the information that has to be remembered is expressed in words, letters or digits. In adults, digits are recalled better than words (Harvey \& Beaman, 2007; Martin \& Ayala, 2004). We were interested in the influence of this factor because it gives insight in how children process different contents of information. Our findings showed that there was differential development with age for the recall of words and digits. Before the age of 10 , the number of words and the number of digits that were recalled were similar, whereas after the age of 10 , digits were recalled better. One hypothesis was that before the age of 10 , words and digits were both processed as if they need to be retrieved from an unlimited pool. Thus, the processing of digits was not yet automated. After the age of 10, the processing of digits became more automated and during recall, this called for a reduced amount of processed information due to a smaller search for retrieval in a smaller pool of possibilities. This would be consistent with the explanation of 
differences in processing load between words and digits (Harvey \& Beaman, 2007; Jefferies, Patterson, Jones, Bateman, \& Lambon Ralph, 2004). Another possibility is that, after the age of 10 , strategy use increases, and that this leads to increasing differences with age in the performance of tests with digits vs. tests with words. This would be consistent with the reported hypothesis that digits can be more easily organized (Jefferies et al., 2004; Lezak, Howieson, \& Loring, 2004), and we assume that this is what happens. This indicates that there is a relationship between the development of organizational strategy use and the influence of the content of the information on performance. The second factor we studied was the child-related factor sex. Our findings showed no differential performance on tests with words or digits for boys and girls. Thus, boys and girls process words and digits in the same manner. We acknowledge that, even though this is often the case in clinical studies, we compared digits with words and this means, a closed pool and an open pool. To study the effects in more detail, studies are needed that use an open pool of digits, (i.e., digits above 9 ), but this leads yet to other limitations such as word-length effects. A possible implication of our findings is that during education, the content of information has to be considered, because this can lead to differences in performance because of differences in strategy use.

\section{Learning in a natural context}

Another factor that has to be taken into account is learning in natural contexts. This means that children may learn from situations they experience. In this thesis, we focused on the relationship between recreational computer use, which is learning from gaming in the home situation, and verbal learning and the development of neuropsychological functions. Veen (2000) reported that there is a new generation of children that grew up surrounded by, amongst others, computers. Even though, he stated this in 2000, this is still relevant (see for more information http://elearning.surf.nl/e-learning/onderzoek/1833). He reports that these children have a different way of information processing than children from before the so-called 'e-generation'. In another study these children are referred to as the 'game-generation' (Sauer \& Fransen, 2006). The results of the questionnaire in this thesis indicated that $83 \%$ of the children made recreational use of the computer. Because of this large amount of children that plays games, the consequences of the relationship between playing games and verbal learning could be considerable. In this thesis, we categorized the games children played in three major categories: sensorimotor games, information-exchange activities by use of a computer, and strategic-planning games. For more information about this categorization we refer to the Chapters 6 and 7 and the Introduction of this thesis. 
We studied the relationship between age, sex, and the LPE and recreational computer use (see Chapter 6). Our findings indicated that age and sex were related in their prediction of the games children played. Recreational computer use, regardless of the game that was played, increased among boys until age seven, and stabilized after that age. Girls showed a different pattern, namely that there was an increase in use until age 10 , followed by a decrease. The games that were played most often at a younger age were educational games; girls played these more often than boys and the prevalence of playing these games decreased for both sexes with age. Boys played sensorimotor games and this increased with age, whereas girls, even though they showed a slight increase with age in use, played these games much less than boys. At age 16 , approximately $35 \%$ of the girls as compared to approximately $90 \%$ of the boys played sensorimotor games. Strategic-planning games were played most often between the ages of 10 to 13 , with a peak earlier in life for boys than for girls. We hypothesized that playing certain kinds of games is partly dependent on the abilities that are needed to play, and therefore, on the development of neuropsychological functions that the games require. Thus, younger children, with less developed neuropsychological functions have to play 'easier' games than older children who can play more complex games. The differences between boys and girls can be related to preferences for competition in games for boys as in sensorimotor games, and preferences for social aspects in girls as in simulation games. Other influences on gaming have been described to be the determination of the parents and SES or LPE. Children with a lower LPE played fewer categories of games than children with a higher LPE. It is probable that the LPE has no influence on whether there is a computer available for the child to play, but that it influences the number of games that can be purchased (see Chapter 6). These findings could be of great relevance if games are used for educational goals. The purpose of using games is that it increases the motivation of the child to learn the information that is offered in the game format. However, our results indicated that not all children play the same games and that the game format that is used has to be adapted to individual children.

The study with respect to recreational computer use and verbal learning (see Chapter 7) indicated that children who played games in which strategy use and planning are required (such as in simulation games like The Sims or adventure games like Lord of the Rings) had a better verbal learning performance on the aspects working memory, learning capacity, and delayed recall, and that these children also had a better simple, passive strategy use than children that used the computer for information-exchange activities (such as educational games and chatting). Children who played games that require fast sensorimotor responses (such as in fighting-, shooting-, race-, and sports games) had intermediate performances. These relationships give an indication that children may learn from gaming and possibly also from other situations and, more importantly, that this might contribute to better learning at school (see Chapter 7). One cautionary remark should be made regarding this matter: It is important to acknowledge that order of the causality could be reversed. It could be that children chose to play certain kinds of games because they are good in the skills that the games require. In other words, game playing follows better skills, 
according to this argument. Yet, even if this is the case, the notion stands that the children develop better skills by a possible positive training. This will further stimulate skill development and allows that differences in the neuropsychological functions between children that play different kinds of games will be accentuated. Thus, it is a new and important finding -never before reported in the literature- that there was a relationship between playing certain kinds of games and verbal learning. This indicates routes for applied research in the future and implementation in educational interventions in children with verbal learning deficiencies, but also in normally developing children.

\section{Concluding remarks regarding the need for a multi-dimensional focus and trans-disciplinary studies}

The findings described in this thesis underscore the notion that a multi-dimensional approach, with emphasis on more factors and input from widely differing disciplines, can provide important new information when 'normal' verbal learning is studied in children aged 5 to 16 years. The studied child-, and test-related factors as well as learning in natural context are only a few of a pool of factors that could be related to and influence verbal learning performance. Among the relevant other factors -that are not studied in this thesis- are sleep and dieting patterns, and the pedagogical approach used at school and at home. The term 'multi-dimensional' refers to the various factors described above, indicating that children are unique in their backgrounds, but that this uniqueness is also related to child-extrinsic factors. Thus, if verbal learning is considered -and eventually learning in educational settings and at home- the influence of several factors needs to be included to aid in the interpretation of the findings. This means that the influences of the factors described above need to be summed up to determine the expected verbal learning performance for a specific child. To our knowledge, the present study is new: similar studies executed according to a multi-dimensional approach with the above-described factors, have not been executed before.

Fundamental and applied neuropsychological research has its foundation in clinical settings, where behaviour or performances that deviate from the 'normal' standard have to be determined. The focus in clinical child neuropsychology has been on individual differences and on factors that can explain deviations found in behaviour and/or performance. Not only are these factors a major target in neuropsychological research and practice, but also the functions and/or processes that are involved in the determination of a specific outcome or performance. With these, we mean for instance test-related factors such as strategy use. The combination of the inclusion of a multidimensional view on neuropsychological processes and the influencing factors makes neuropsychology a valuable tool for the study of learning and the various factors that influence it. In addition, neuropsychological findings can, on the longer term and in cooperation with educational science and educational settings, have implications to improve the conditions and procedures according to which education is given in 
schools. This was not the aim of the studies in the current thesis and the data presented here are not intended as advice or recommendations that can be implemented in education. Yet, the findings do indicate that sensible studies can be done which eventually could have applied value when related to the knowledge and insights from educational psychology and educational science. Thus, neuropsychology can, together with other sciences that are working in the broad educational domain, be used to create a trans-disciplinary science that has the further development and optimization of education as goal.

Also, based upon the recommendations from the CERI project on educational sciences and the brain, an emerging field of 'educational neuropsychology' can be envisaged. This is a trans-disciplinary science, where the term 'trans-disciplinary' refers to the active cooperation of several scientific disciplines. For instance, neuropsychology gives insight in learning processes and factors that have an influence on individual children, given the large number of factors it takes into consideration. On the other hand, one of the topics that educational psychologists study is the possibility of implementation of special interventions in school settings. The findings in this thesis do not have large claims, but they are consistent with the visions expressed in the book 'Birth of a learning science' published by the OECD's Centre for Educational Research and Innovation (CERI) in July 2007 (OECD, 2007). The recommendations in this book were based upon the multi-dimensional networks on the domains of 'literacy', 'numeracy', and 'lifelong learning' that have stimulated an exchange between many different disciplines in the domain of learning and the brain in the period 2002-2007.

The major topic in this thesis was the study of the development of verbal learning and the influences that a multitude of factors have on this development. These findings are neuropsychological in nature, but bear the promise that this type of knowledge could in the future be translated to applied settings. Such a transdisciplinary cooperation as seen from the angle of investigation taken in the present thesis could be referred to as 'educational neuropsychology'. An example of a possible implication is the screening and selection of children who could benefit from dedicated training in the use of learning strategies, and to train these children. It is imperative that this type of study be executed in a trans-disciplinary way in cooperation with educational sciences. 


\section{References}

Alvarez, J. A., \& Emory, E. (2006). Executive function and the frontal lobes: A meta-analytic review. Neuropsychology Review, 16, 17-42.

Ansari, D., \& Coch, D. (2006). Bridges over troubled waters: Education and cognitive neuroscience. Trends in Cognitive Sciences, 10, 146-151.

Baddeley, A. D. (1997). Human Memory: Theory and Practice, Revised Edition. Hove: Psychology Press.

Beacham, N. A., Elliott, A. C., Alty, J. L., \& Al-Sharrah, A. (2002). Media combinations and learning styles: A dual coding approach. Paper presented at the ED-MEDIA 2002 World Conference on Educational Multimedia, Hypermedia \& Telecommunications, Denver, Colorado.

Berk, L. E. (1998). Development Through the Lifespan. Needham Heights, MA: Allyn \& Bacon.

Bishop, J., Knights, R. M., \& Stoddart, C. (1990). Rey Auditory - Verbal learning Test: Performance of English and French children aged 5 to 16. The Clinical Neuropsychologist, 4, 133-140.

Bjorklund, D. F., \& Douglas, R. N. (1997). The development of memory strategies. In N. Cowan \& C. Hulme (Eds.), The Development of Memory in Childhood (pp. 201-246). Hove, East Sussex, UK: Psychology Press.

Brown, L. A., Forbes, D., \& McConnel, J. (2006). Limiting the use of verbal coding in the visual patterns test. The Quarterly Journal of Experimental Psychology, 59, 1169-1176.

Bukatko, D., \& Daehler, M. W. (1998). Child Development: a Thematic Approach (3rd ed.). Boston: Houghton Mifflin Company.

Forrester, G., \& Geffen, G. (1991). Performance measures of 7- to 15-year-old children on the Auditory Verbal Learning Test. The Clinical Neuropsychologist, 5, 345-359.

Fry, A. F., \& Hale, S. (2000). Relationships among processing speed, working memory and fluid intelligence in children. Biological Psychology, 54, 1-34.

Ginns, P. (2005). Meta-analysis of the modality effect. Learning and Instruction, 15, 313-331.

Gogtay, N., Giedd, J. N., Lusk, L., Hayashi, K. M., Greenstein, D., Vaituzis, A. C., et al. (2004). Dynamic mapping of human cortical development during childhood through early childhood. Proceedings of the National Academy of the Sciences, 101, 8174-8179.

Goswami, U. (2006). Neuroscience and education: From research to practice. Nature Reviews Neuroscience, 7, 406-413.

Greenberg, M. T., Lengua, L. J., Coie, J. D., \& Pinderhughes, E. E. (1999). Predicting developmental outcomes at school entry using a multiple-risk model: Four American communities. The Conduct Problems Prevention Research Group; Developmental Psychology, 35, 403-417.

Hanten, G., Xiaoqi, L., Chapman, S. B., Swank, P., Gamino, J., Roberson, G., et al. (2007). Development of verbal selective learning. Developmental Neuropsychology, 32, 585-596.

Harvey, A., \& Beaman, C. P. (2007). Input and output modality effects in immediate serial recall. Memory, 7, 693-700.

Jefferies, E., Patterson, K., Jones, R. W., Bateman, D., \& Lambon Ralph, M. A. (2004). A category-specific advantage for numbers in verbal short-term memory: Evidence from semantic dementia. Neuropsychologica, 42, 639-660.

Jolles, J., De Groot, R., Van Benthem, J., Dekkers, H., De Glopper, C., Uijlings, H., et al. (2006). Brain Lessons. Maastricht, The Netherlands: Neurpsych Publishers.

Kelley, W. M., Miezin, F. M., McDermott, K. B., Buckner, R. L., Raichle, M. E., Cohen, N. J., et al. (1998). Hemispheric specialisation in human dorsal frontal cortex and medial temporal lobe for verbal and nonverbal memory encoding. Neuron, 20, 927-936.

Kemps, E., De Rammelaere, S., \& Desmet, T. (2000). The development of working memory: Exploring the complementarity of two models. Journal of Experimental Child Psychology, 77, 89-109.

Kleinbaum, D. G., Kupper, L. L., Muller, K. E., \& Nizam, A. (1998). Applied Regression Analysis and Other Multivariable Methods (3rd ed.). New York: Duxbury Press.

Klingberg, T. (2006). Development of a superior frontal-intraparietal network for visuo-spatial working memory. Neuropsychologica, 44, 2171-2177.

Korkman, M., Kemp, S. L., \& Kirk, U. (2001). Effects of age on neurocognitive measures of children ages 5 to 12: A cross-sectional study on 800 children from the United States. Developmental Neuropsychology, 20, 331-354.

Lezak, M. D. (1995). Neuropsychological Assessment (3rd ed.). New York: Oxford University Press.

Lezak, M. D., Howieson, D. B., \& Loring, D. W. (2004). Neuropsychological Assessment (4th ed.). New York: Oxford University Press. 
Majerus, S., Poncelet, M., Elsen, B., \& Van der Linden, M. (2006). Exploring the relationship between new word learning and short-term memory for serial order recall, item recall and item recognition. European Journal of Cognitive Psychology, 18, 848-873.

Majerus, S., Poncelet, M., Greffe, C., \& Van der Linden, M. (2006). Relations between vocabulary development and verbal short-term memory: The relative importance of short-term memory for serial order and item information. Journal of Experimental Child Psychology, 93, 95-119.

Martin, N., \& Ayala, J. (2004). Measurements of auditory-verbal STM span in aphasia: Effects of item, task, and lexical impairment. Brain and Language, 89, 464-483.

OECD. (2002). Understanding the Brain: Towards a New Learning Science. Paris: OECD

OECD. (2007). Understanding the Brain: The Birth of a Learning Science. Paris: OECD.

Ormrod, J. E. (1999). Human Learning (3rd ed.). Upper Saddle River, NJ: Prentice-Hall Inc.

Palmer, S. (2000). Working memory: A developmental study of phonological recoding. Memory, 8, $179-193$.

Paus, T. (2005). Mapping brain maturation and cognitive development during adolescence. Trends in Cognitive Sciences, 9, 60-68.

Santrock, J. W. (2001). Educational Psychology. New York: McGraw-Hill.

Sauer, I., \& Fransen, J. (2006). Deelonderzoeken naar de virtuele wereld: Het leren van games [Partial studies to the virtual world: Learning from games]. In G. Wijngaards, J. Fransen \& P. Swager (Eds.), Jongeren en hun Digitale Wereld (pp. 24-39). Assen: Van Gorcum.

Schneider, W., Knopf, M., \& Stefanek, J. (2002). The development of verbal memory in childhood and adolescence: Findings from the Munich Longitudinal Study. Journal of Educational Psychology, 94, 751-761.

Schneider, W., \& Pressley, M. (1997). Memory Development Between Two and Twenty (2nd ed.). Mahwah, NJ: Lawrence Erlbaum Associates.

Schneider, W., \& Sodian, B. (1997). Memory strategy development: Lessons from longitudinal research. Developmental Review, 17, 442-461.

Siegler, R. S., \& Wagner Alibali, M. (2005). Children's Thinking (4th ed.). Upper Saddle River, NJ: Pearson Prentice Hall.

Vakil, E., Blachstein, H., \& Sheinman, M. (1998). Rey AVLT: Developmental norms for children and the sensitivity of different memory measures to age. Child Neuropsychology, 4, 161-177.

Van den Burg, W., \& Kingma, A. (1999). Performance of 225 Dutch school children on Rey's Auditory Verbal Learning Test (AVLT): Parallel test-retest reliabilities with an interval of 3 months and normative data. Archives of Clinical Neuropsychology, 14, 545-559. 
Summary 


\section{Summary}

Verbal learning is important for scholastic performance over a long period, from early primary school through to higher education. It is known that learning performance develops with age, but the underlying cognitive mechanisms have not yet been studied in sufficient detail to understand learning in daily life situations, such as in the educational setting. This lack of insight applies especially to age-extrinsic factors and test-related factors in their effect on verbal learning. This thesis devotes itself to this research domain and to children in the age-range of 5 to 16 years. Within this agerange, particular cognitive processes develop in their own time-courses (Anderson, 2002), whereas the brain is reported to mature until after the age of 20 years (Alvarez \& Emory, 2006; Anderson, 2002; Giedd et al., 1999; Gogtay et al., 2004; Klingberg, 2006; Paus, 2005).

The aim of this thesis was the study of the influence of three factors on verbal learning, namely child-related factors, test-related factors, and learning in a natural context. The studied child-related factors were: age, male/female sex, the level of parental education (LPE), and VIQ. The test-related factors were: strategy use, the presentation modality, the recall demands, and the content of the information that has to be remembered. Learning in a natural context was studied by means of recreational computer use. Two cognitive development studies were executed. The first study was cross-sectional and included 107 children aged 6 to 12 years. The second study was a large-scale study and consisted of a cross-sectional and a longitudinal part. It included questionnaire data from 910 children and neuropsychological test data from 431 children aged 5 to 15 years in the first data collection round, and neuropsychological test data and questionnaire data from 313 children aged 6 to16 years in the second data collection round. 
Chapter 1 gives an introduction into the studies that were described in this thesis. These are based upon the trans-disciplinary cooperation between several sciences, including neuropsychology. The goal was to provide insights into particular cognitive and neuropsychological mechanisms underlying verbal learning and, in general, learning in school settings. The factors that possibly have an influence on verbal learning are described. These were divided over three categories: child-related factors, test-related factors, and learning in a natural context. The child-related factors that were included were: age, sex, the level of parental education (LPE), and verbal ability (VIQ). The test-related factors were: strategy use, the presentation modality, the recall demands, and the content of information. Learning in a natural context was studied by means of gaming at home. The main influences of these factors are described, as are the relationships/interactions between them. This is followed by the aim of this thesis and the approach of the studies. Lastly, the outline of the thesis is given.

Chapter 2 describes the influence of various factors on verbal learning and strategy use. The influences of age, sex, the level of parental education (LPE), and the presentation modality on efficient strategy use were studied by administering a verbal learning test (VLT) to 431 normally developing children aged 5 to 15 years. Serial clustering (a relatively simple, passive strategy) and subjective clustering (a more complex, organizational strategy) were assessed during the recall of the VLT. Efficient use of both strategies was calculated by means of the order of the words during recall. The results showed, firstly, that efficient strategy use of both strategies was predicted by age, quadratic age and/or VIQ, but not by sex, the LPE, and the presentation modality. A second finding was that efficient serial and subjective clustering predicted VLT performance differentially with age. The findings indicate that efficient strategy use leads to better verbal learning. This implies that an intervention in which efficient serial clustering is stimulated, could possibly contribute to better verbal learning performance. In addition, stimulation of efficient subjective clustering is probably more effective, at least until age 14. Serial clustering use and execution level did not appear to increase after the age of 11 . Thus, although clustering was still beneficial after that age, the optimal level of efficient serial clustering was probably already reached. Subjective clustering use and execution level increased beyond the age of 15 . These findings suggest that children with a lower verbal learning performance -provided that this is due to improper strategy use- could be trained to efficiently use subjective clustering to enhance verbal learning performance at least until age 14. Additionally, our findings indicate that children with a lower VIQ have a lower execution level of subjective clustering. Therefore, it is probable that these children will benefit most from training in subjective clustering. No differences in efficient strategy use were found for boys and girls, for children of parents with different educational levels, nor did efficient strategy use differ with presentation modality. 
Chapter 3 describes the results of an investigation that showed developmental differences in the use of learning strategies. Serial and subjective clustering in a multitrial Pictorial Verbal Learning Test (PVLT) were compared in 79 children aged 6 to 12 years. Correlation analyses indicated that serial clustering yielded better performance in the first trials of this test. Subjective clustering was superior when information was presented repeatedly. Analysis of variance indicated that there was no increase in the use of serial clustering with age and with repeated presentations. Subjective clustering, on the other hand, was used more often in older children, in case of repeated presentations. Children aged six to seven did not actively rearrange to-beremembered information, but they tried to remember the information in the order in which the material is presented to them. When information was presented several times -after more than two trials- to children above the age of seven years actively handled the information by grouping it together in meaningful groups. This makes it easier to remember and leads to better recall. This implies that children who deviate from the pattern of the use of strategies can be detected. Training these children in efficient strategy use could potentially lead to a better performance on a verbal learning test and possibly verbal learning in general. The differential use of strategies has implications for the way information should be presented. To children younger than eight years, information should be presented in shorter lists, to accomplish that simple passive strategy use is sufficient to remember the information.

Chapter 4 describes the differential development of performance on a verbal learning test $(\mathrm{VLT})$ in relation to the presentation modality. A comparison was made between two modalities, i.e. auditory and pictorial. In addition, the study described here investigated the relationship of these developmental patterns to sex differences. Either a Pictorial Verbal Learning Test (PVLT) or an Auditory Verbal learning test (AVLT) was administered to 431 children aged 5 to 15 in order to measure: working memory, learning with repeated presentations, delayed recall, and long-term recognition memory. Firstly, the presentation modality is only of influence on working memory, not on the other measures of the VLT. Moreover, it was only of influence in children that were older than kindergarten. For working memory, there was no difference in performance on the PVLT and the AVLT in children below the age of seven years. Above the age of seven years, performance was better with a pictorial presentation for all measures. This is related to the development of the articulatory control process that is needed for recoding of the pictures into a phonological-verbal code, which is the process that enhances recall in comparison to auditory presented information.

Secondly, no differential influence of presentation modality was found for boys and girls. Irrespective of the presentation modality, girls outperformed boys when it came to the unguided retrieval of information during the delayed recall. These findings are taken to indicate that boys and girls do not differ in the amount of information that they consolidate and store. This is because they recognize the same amount of information after a delay (i.e., recognition memory is the same). Thus, the difference between boys and girls in delayed recall must be caused by a difference in the ability 
to retrieve the words from long-term memory. This has some implications. It is suggested that a recognition test should be used (as in a multiple-choice test) rather than a free recall test (an 'open' questions test) when assessing the amount of stored information. This approach may ensure that the performance that is measured reflects verbal knowledge that is actually stored and minimizes the sex disadvantages of boys in this regard. However, a test with open questions assesses the retrieval of information from long-term memory, in which girls will perform better than boys.

Chapter 5 describes the relationship between the effects of the presentation modality (i.e., pictorial, auditory or written), the recall demands (i.e., free and serial recall), and the content of information (i.e., words and digits) in their effects on verbal learning performance. This was studied in relation to age and sex. In total, 313 children aged 6 to 16 years, performed a (free recall) verbal learning test (VLT), and (serial recall) working memory tests with words (WS) and with digits (DS). The findings were that, firstly, the presentation modality differentially influenced free recall and serial recall. We assume that this is due to the involvement of the articulatory rehearsal system of the phonological loop. Secondly, free recall performance appeared to be better than serial recall performance, regardless of age and sex. Thirdly, the digits were recalled better in children aged 10 years and older, regardless of sex. In clinical settings and research, performances on tests are sometimes compared without considering the characteristics of the tests and the child. We conclude that this can lead to errors in the explanations of the differences between performances.

Chapter 6 describes the relationship between age, sex, the level of parental education (LPE) and recreational computer use among school-aged children. Because many children play games, presentation of information in a game-format might increase the motivation of children in educational settings. Therefore, it is relevant to study what games children play. The caregivers of 910 children (aged 5-16) filled out a questionnaire that inquired into recreational computer use. This was categorized in three types of games or activities: (1) sensorimotor games, (2) information-exchange activities, and (3) strategic-planning games. We found that age, sex, the LPE and interactions thereof predicted prevalence and nature of computer use. The most important findings regarding age and sex showed that recreational computer use increased from age 6 on, for both boys and girls. After the age of 7 , the prevalence of boys who played games stabilized, whereas, for girls there was a decrease in use of the computer after the age of 10 . There was an increase with age in the prevalence of children who played sensorimotor games. This was much stronger in boys than in girls. There was a decrease in the use of the computer for information-exchange activities with age and this was much stronger in boys than in girls. Strategic-planning games were played most between the ages of 10 and 13 and this peak came at earlier age in boys than in girls. The most important finding regarding the LPE was that children with a lower LPE played fewer categories of games than children with a 
higher LPE. Playing certain kinds of games was related to the development of neuropsychological functions that are required for the proper execution of the game, the influences of parents on gaming, and the financial support that is needed to acquire multiple game gear.

Chapter 7 describes findings that indicate that there was a positive relationship between playing specific computer games (i.e., sensorimotor games, informationexchange activities, or strategic-planning games) and verbal learning (i.e., working memory, learning with repeated presentations, and delayed recall). The relationship was expected because gaming may stimulate factors that are important for the efficiency of verbal learning (i.e., serial and subjective clustering use, metamemory, processing speed, and retrieval of words from semantic memory). This was studied by comparing the test-performances of 200 children aged 5 to 15 years who played only one category of games. Children who played strategic-planning games had a better verbal learning performance and had a better serial clustering than children who used the computer for information-exchange activities. Children who played sensorimotor games had intermediate performances. This suggests that active engagement in computer games that require strategy use and planning might stimulate abilities that lead to better verbal learning. The present findings cannot yet be interpreted in terms of causality, which should be evaluated in future studies.

Chapter 8 describes the most important findings of the studies in this thesis, with possible implications for 'educational neuropsychology'. The findings indicate that when verbal learning is studied, a multitude of factors needs to be considered. These factors are within the domain of several sciences, including neuropsychology, educational psychology, and cognitive psychology. It is imperative that a multidimensional approach is taken when verbal learning and the various mechanisms underlying it are studied. This is especially the case when possible implementations in applied settings -such as education- are at stake. The active cooperation of various sciences, such as those mentioned, could lead to a trans-disciplinary approach. The angle of investigation adopted in this thesis can be described in terms of 'educational neuropsychology' and in a broader sense in terms of 'educational neuroscience'. Such a trans-disciplinary approach has been promoted in the report: 'Understanding the brain: The birth of a learning science' of the OECD (OECD, 2007). The results in this thesis showed that such an approach can yield insights that could be of relevance for both fundamental research and applied settings, such as in education. 


\section{References}

Alvarez, J. A., \& Emory, E. (2006). Executive function and the frontal lobes: A meta-analytic review. Neuropsychology Review, 16, 17-42.

Anderson, P. (2002). Assessment and development of executive function (EF) during childhood. Child Neuropsychology, 8, 71-82.

Giedd, J. N., Blumenthal, J., Jeffries, N. O., Castellanos, F. X., Liu, H., Zijdenbos, A., et al. (1999). Brain development during childhood and adolescence: A longitudinal MRI study. Nature Neuroscience, 2, 861-863.

Gogtay, N., Giedd, J. N., Lusk, L., Hayashi, K. M., Greenstein, D., Vaituzis, A. C., et al. (2004). Dynamic mapping of human cortical development during childhood through early childhood. Proceedings of the National Academy of the Sciences, 101, 8174-8179.

Klingberg, T. (2006). Development of a superior frontal-intraparietal network for visuo-spatial working memory. Neuropsychologica, 44, 2171-2177.

OECD. (2007). Understanding the Brain: The Birth of a Learning Science. Paris: OECD.

Paus, T. (2005). Mapping brain maturation and cognitive development during adolescence. Trends in Cognitive Sciences, 9, 60-68. 

Samenvatting 


\section{Samenvatting}

Verbaal leren is, over een lange tijdsperiode die strekt van vroeg op de basisschool tot later in het hoger onderwijs, belangrijk voor het aanleren van diverse schoolse vaardigheden. Het is bekend dat de leerprestatie beter wordt met toenemende leeftijd. Echter, de onderliggende cognitieve en neuropsychologische mechanismen hiervan zijn nog niet in voldoende detail bestudeerd om leren te begrijpen zoals dat optreedt in het dagelijks leven, zoals in het onderwijs. Dit gebrek aan inzicht betreft vooral de invloed van factoren buiten de leeftijd, de zogenaamde 'leeftijds-extrinsieke variabelen' en factoren die te maken hebben met de aanbieding van leerstof op het domein van verbaal leren. In dit proefschrift richten we ons op dit onderzoeksterrein en worden kinderen in de leeftijd van 5 tot 16 jaar bestudeerd. In deze leeftijdsrange ontwikkelen zich vele cognitieve functies, elk volgens een eigen ontwikkelingstraject (Anderson, 2002). De theoretische stellingname waarop het proefschrift en het erin beschreven onderzoek is gebaseerd zijn recente onderzoeksbevindingen waaruit blijkt dat diverse hersenstructuren pas na de leeftijd van 20 jaar zijn uitgerijpt (Alvarez \& Emory, 2006; Anderson, 2002; Giedd et al., 1999; Gogtay et al., 2004; Klingberg, 2006; Paus, 2005).

Het doel van dit proefschrift was om de invloed van drie groepen factoren op verbaal leren te bestuderen. Het ging om 'kind-gerelateerde factoren', 'test-gerelateerde factoren' en 'leren in een natuurlijke context'. De onderzochte kind-gerelateerde factoren zijn: leeftijd, geslacht, de hoogst genoten opleiding van de ouders en verbaal $I Q$ van het kind. De onderzochte test-gerelateerde factoren zijn: strategiegebruik, de presentatiemodaliteit, de manier waarop informatie opgenoemd moet worden tijdens de recall en de inhoud van de informatie die onthouden moet worden. Leren in een natuurlijke context werd bestudeerd door middel van het leren van het spelen van bepaalde computerspellen.

Twee cognitieve ontwikkelingsstudies zijn uitgevoerd. De eerste omvatte 107 kinderen in de leeftijd van 6 tot 12 jaar. De tweede studie was grootschalig en bestond uit een cross-sectioneel en een longitudinaal deel. Gebruik is gemaakt van vragenlijstgegevens van 910 kinderen in de leeftijd van 5 tot 16 jaar en van neuropsychologische gegevens van 431 van die kinderen in de leeftijd van 5 tot 15 jaar (op het eerste meetmoment). Op het tweede meetmoment, een jaar later, zijn 313 van die kinderen nog eens onderzocht met wederom een vragenlijst en met behulp van neuropsychologische tests. 
In hoofdstuk 1 worden de studies die beschreven zijn in dit proefschrift geïntroduceerd. De studies zijn gebaseerd op een transdisciplinaire samenwerking tussen verschillende onderzoeksgebieden, waaronder de neuropsychologie. Het doel van de studies was om inzicht te krijgen in cognitieve en neuropsychologische mechanismen die onderliggend zijn aan het proces van verbaal leren en aan het leren zoals dat plaatsvindt op school. De factoren die hierop mogelijk een invloed hebben zijn beschreven. Deze zijn verdeeld over drie categorieën: kind-gerelateerde factoren, test-gerelateerde factoren en leren in een natuurlijke context. De onderzochte kindgerelateerde factoren zijn: leeftijd, geslacht, de hoogst genoten opleiding van de ouders en het verbaal IQ van het kind. De onderzochte test-gerelateerde factoren zijn: strategiegebruik, de presentatiemodaliteit, de manier van waarop informatie opgenoemd moet worden tijdens de recall en de inhoud van de informatie die onthouden moet worden. Leren in een natuurlijke context werd bestudeerd door middel van het thuis spelen van computerspellen. De algemene invloeden van deze factoren op verbaal leren worden beschreven in dit hoofdstuk, net als de relaties die de factoren onderling hebben. In dit hoofdstuk wordt een nadere beschrijving gegeven van het doel van het proefschrift en de aanpak van de studies, gevolgd door de introductie van de overige hoofdstukken van het proefschrift.

In hoofdstuk 2 wordt de invloed van diverse factoren op verbaal leren beschreven. Hierbij ging het om de factoren leeftijd, geslacht, hoogst genoten opleiding van de ouders en van de presentatiemodaliteit op het efficiënt gebruik van strategieën. Dit is onderzocht door 413 kinderen in de leeftijd van 5 tot 15 jaar een verbale leertest (VLT) uit te laten voeren. Seriële clustering is een relatief eenvoudige strategie waarbij de woorden tijdens de recall in dezelfde volgorde opgenoemd worden als dat ze zijn aangeboden. Subjectieve clustering is een meer complexe strategie waarbij woorden tijdens het opnoemen aan elkaar gekoppeld worden. Beide strategieën, die zijn gericht op de organisatie van het te onthouden materiaal, werden berekend. Hiervoor werd gebruik gemaakt van de volgorde waarin de woorden tijdens de VLT werden opgenoemd. Ten eerste toonden de resultaten aan dat efficiënt gebruik van beide strategieën voorspeld werd door leeftijd, kwadratische leeftijd en/of verbaal IQ, maar niet door geslacht, de hoogst genoten opleiding van de ouders en de presentatiemodaliteit. Een tweede bevinding was dat efficiënt gebruik van seriële en subjectieve clustering met toenemende leeftijd een differentiële invloed hadden op VLT prestatie.

Het efficiënt gebruiken van strategieën leidt tot beter verbaal leren. Dit houdt in dat een interventie die gericht is op het efficiënter gebruik van seriële clustering mogelijk kan bijdragen tot beter verbaal leren. Echter, stimulatie van efficiënt gebruik van subjectieve clustering is waarschijnlijk effectiever, in ieder geval totdat de kinderen 14 jaar zijn. Het gebruik en het uitvoeringsniveau van de strategie van seriële clustering lijken niet meer toe te nemen na de leeftijd van 11 jaar. Dus ook al wordt het optimale niveau van efficiënt gebruik van deze strategie al op 11-jarige leeftijd bereikt, na die 
leeftijd hebben de kinderen er nog steeds profijt van. Gebruik en uitvoeringsniveau van subjectieve clustering nemen nog toe na de leeftijd van 15 jaar.

De bevindingen van deze studie suggereren dat als kinderen met een lagere verbale leerprestatie -mits dit door onjuist strategiegebruik veroorzaakt wordt- getraind zouden kunnen worden in het efficiënte gebruik van subjectieve clustering, dan zou mogelijk hun verbaal leren verbeteren, in ieder geval tot de leeftijd van 14 jaar.

Tevens laten de bevindingen zien dat kinderen met een lager verbaal IQ slechter presteren op gebied van subjectieve clustering. Mogelijk zouden deze kinderen daarom meer kunnen profiteren van een training in efficiënt subjectief clusteren.

Er werden geen verschillen gevonden in efficiënt strategiegebruik tussen jongens en meisjes. Ook waren er geen verschillen tussen kinderen wiens ouders verschillen in opleidingsniveau. Tevens bleek dat efficiënt strategiegebruik niet samenhing met de modaliteit waarin de informatie aangeboden werd.

In hoofdstuk 3 worden de resultaten van de studie naar ontwikkelingsverschillen in het gebruik van leerstrategieën beschreven. Hiervoor werd het gebruik van seriële en subjectieve clustering tijdens de recall van een multi-trial pictoriale verbale leertest (PVLT) onderzocht van 79 kinderen in de leeftijd van 6 tot 12 jaar.

Correlatieanalyses toonden aan dat seriële clustering samenhing met betere prestaties op de eerste trials. Subjectieve clustering was het beste om te gebruiken bij het herhaaldelijk aanbieden van de informatie. Variatieanalyse toonde aan dat er geen toename was in het gebruik van seriële clustering met toenemende leeftijd of met herhaalde aanbiedingen. Subjectieve clustering daarentegen werd door de oudere kinderen, na herhaalde aanbiedingen, vaker gebruikt.

Kinderen in de leeftijd van 6 tot 7 jaar maken geen gebruik van actieve organisatie van de informatie, maar proberen te informatie te herinneren in de volgorde waarin het is aangeboden. Als informatie herhaaldelijk wordt aangeboden, na twee trials of meer, aan kinderen van 7 jaar of ouder, organiseren ze deze informatie tot betekenisvolle groepjes. Dit maakt het makkelijker om informatie te onthouden en dit leidt tot een betere prestatie tijdens het oproepen van de informatie. Deze gegevens tonen aan dat kinderen die een afwijkende informatieverwerkings-strategie hebben kunnen worden opgespoord. Training van deze kinderen in het gebruik van strategieën zou kunnen leiden tot een betere prestatie op tests voor verbaal leren en mogelijk voor verbaal leren in het algemeen.

Het verschillend gebruiken van strategieën heeft implicaties voor de presentatie van informatie aan kinderen onder de 7 jaar. Voor deze kinderen zou de informatie in korte lijsten aangeboden moeten worden. De informatie kan dan onthouden worden door het passief oproepen van de informatie in dezelfde volgorde als aangeboden. 
Hoofdstuk 4 beschrijft de differentiële ontwikkeling van de prestatie op een verbale leertest (VLT) in relatie tot de aanbiedmodaliteit. Een vergelijking werd gemaakt tussen pictoriale en auditieve aanbieding. Ook beschrijft de studie deze ontwikkelingspatronen in relatie tot geslachtsverschillen. De helft van de 431 kinderen in de leeftijd van 5 tot 15 jaar voerde een pictoriale VLT (PVLT) uit en de andere helft een auditieve VLT (AVLT). Hiermee werden: (1) werkgeheugen, (2) leren met herhaalde aanbiedingen, (3) uitgestelde herinnering en (4) lange termijn herkenningsgeheugen gemeten.

Het effect van de presentatiemodaliteit is niet gelijk voor alle kinderen op alle maten. Op het gebied van werkgeheugen was er geen verschil in de prestatie van kinderen onder de 7 jaar op de PVLT en AVLT, maar op de andere maten was de prestatie op de PVLT beter. Kinderen boven de 7 jaar presteerden beter op de PVLT op alle maten.

Geslachtseffecten in relatie met de presentatiemodaliteit werden niet gevonden. Los van de presentatiemodaliteit werd gevonden dat meisjes beter presteerden op de uitgestelde herinnering dan jongens. Op de uitgestelde herkenning werden deze geslachtseffecten niet gevonden. Dus jongens en meisjes verschillen niet in de hoeveelheid informatie die ze kunnen consolideren en opslaan (herkenning is gelijk), maar wel in het ophalen van informatie uit het geheugen, waarbij de informatie zonder een begeleidende aanwijzing uit het geheugen teruggehaald moet worden. Dit kan gevolgen hebben voor de manier van testen van kennis over geleerde informatie. De suggestie is dat een multiple-choice test beter is dan een test met 'open' vragen om de ware opgeslagen kennis te testen. Een test met open vragen is beter om te beoordelen hoe efficient de kinderen de kennis kunnen oproepen. Hierbij moet in het achterhoofd worden gehouden dat meisjes beter presteren op dit type taken en dat dit veroorzaakt wordt door een grotere efficiëntie in het terughalen van de informatie en niet door verschillen in opgeslagen kennis.

In Hoofdstuk 5 wordt de relatie tussen de presentatiemodaliteit (pictoriaal of auditief aangeboden of via geschreven tekst), de manier waarop informatie opgehaald moet worden (vrij of in een voorgeschreven volgorde) en de inhoud van de informatie die onthouden moet worden (woorden of cijfers) in hun effecten op verbaal leren beschreven. Dit werd onderzocht in relatie met leeftijd en geslacht. Hiervoor voerden 313 kinderen in de leeftijd van 6 tot 16 jaar een verbale leertest (VLT) uit met een vrije recall en twee werkgeheugen testen met een seriële recall: een woordenspanne test (WS) en een cijferspanne test (DS). De bevindingen waren dat, ten eerste, de invloed van de presentatiemodaliteit afhangt van de manier waarop informatie herinnerd moet worden. Dit hangt waarschijnlijk samen met de betrokkenheid van het articulatoire herhalingssysteem in de fonologische loop. Ten tweede, de prestatie op een test met een vrije recall is, ongeacht leeftijd en geslacht, hoger dan de prestatie op een test met een seriële recall. Ten derde, cijfers worden beter onthouden dan woorden vanaf een leeftijd van ongeveer 10 jaar, ongeacht geslacht. 
In de klinische praktijk en in wetenschappelijk onderzoek worden prestaties op tests soms vergeleken zonder dat er gelet wordt op de bovenbeschreven kenmerken van de test. De in dit hoofdstuk beschreven gegevens tonen aan dat deze kenmerken niet zomaar genegeerd kunnen worden, net zomin als de leeftijd van kind. Vergelijkingen die gemaakt worden zonder deze factoren in acht te nemen kunnen leiden tot foute interpretaties.

Hoofdstuk 6 gaat over de relatie tussen leeftijd, geslacht, de hoogst genoten opleiding van de ouders en recreatief computer gebruik van schoolgaande kinderen. Computerspellen kunnen gebruikt worden in het onderwijs als manier om informatie te presenteren aan kinderen. Het is daarom van belang om vast te stellen welke spellen de kinderen spelen om te weten te komen wat het kinderen het meest motiveert.

De ouders/verzorgers van 910 kinderen in de leeftijd van 5 tot 16 jaar hebben een vragenlijst ingevuld waarin ze aangaven welke computerspellen hun kind speelde. De spellen en activiteiten waren ingedeeld in de categorieën: sensomotorische spellen, informatie-uitwisselingsactiviteiten en strategische planningsspellen. Gevonden werd dat een interactie tussen leeftijd en geslacht voorspelde welke computerspellen er gespeeld werden en dat het hoogste opleidingsniveau van de ouders het aantal spellen voorspelde.

De meest belangrijke bevindingen zijn dat het spelen van computerspellen bij zowel jongens als meisjes toenam vanaf de leeftijd van 6 jaar. Na de leeftijd van 7 jaar stabiliseerde het aantal jongens dat computerspellen speelde terwijl meisjes na het 10 e levensjaar juist minder gebruik maakten van computerspellen. Met toenemende leeftijd speelden meer kinderen sensomotorische spellen en deze toename was sterker voor jongens dan voor meisjes. Oudere kinderen maakten minder gebruik van de computer voor informatie-uitwisselingsactiviteiten en dit was sterker voor jongens dan voor meisjes. Strategische planningsspellen werden het meeste gespeeld tussen de 10 en de 13 jaar, waarbij de piek bij jongens vroeger kwam dan bij meisjes. De belangrijkste bevinding wat betreft hoogst genoten opleiding van de ouders was dat kinderen met ouders met een hoge opleiding meer verschillende categorieën spellen speelden.

Het spelen van de spellen werd gerelateerd aan de neuropsychologische vaardigheden die nodig zijn om bepaalde spellen te kunnen spelen, de invloed die de ouders hebben op welke spellen gespeeld worden en de financiële middelen die aanwezig zijn om meerdere spellen te kopen. 
In hoofdstuk 7 worden gegevens beschreven waaruit blijkt dat er een positieve relatie bestaat tussen het spelen van bepaalde computerspellen (sensomotorische spellen, informatie-uitwisselingsactiviteiten en strategische planningsspellen) en verbaal leren. Deze relatie werd verwacht omdat het spelen van computerspellen mogelijk vaardigheden kan stimuleren die belangrijk zijn voor efficiënt verbaal leren zoals seriëel en subjectief clusteren, metageheugen, de verwerkingssnelheid en het ophalen van woorden uit het semantisch geheugen.

Dit werd bestudeerd door de testprestaties van 200 kinderen in de leeftijd van 5 tot 15 jaar te vergelijken. Deze kinderen speelden slechts één soort spellen speelden.

Kinderen die strategische planningspellen speelden presteerden beter op de verbale leertest (VLT) en hadden een beter seriële clustering dan kinderen die zich via de computer bezig hielden met informatie-uitwisselingactiviteiten. Kinderen die sensomotorische spellen speelden presteerden ertussen in. Dus het actief spelen van strategische planningspellen stimuleert mogelijk vaardigheden die leiden tot beter verbaal leren. Met deze studie kan er echter geen causale relatie onderzocht worden en dit zou het onderwerp moeten zijn van verder onderzoek.

In Hoofdstuk 8 worden de meest belangrijke bevindingen van de studies in dit proefschrift beschreven, met hun mogelijke implicaties voor de zogenaamde 'educational neuropsychology'. De bevindingen tonen aan dat meerdere factoren in ogenschouw moeten worden genomen wanneer verbaal leren bestudeerd wordt. Deze factoren komen uit verschillende onderzoekdomeinen zoals de neuropsychologie, de onderwijspsychologie en de cognitieve psychologie. Het is noodzakelijk dat er een multi-dimensionele aanpak gehanteerd wordt in de bestudering van verbaal leren en van de factoren die ten grondslag liggen aan verbaal leren. Dit is vooral van belang als er gekeken wordt naar mogelijke implicaties voor gebruik in toegepaste settings, zoals het onderwijs. De samenwerking tussen de hierboven beschreven onderzoeksdomeinen kan leiden tot een transdisciplinaire aanpak. De invalshoek die in dit proefschrift beschreven wordt kan gezien worden als die van de 'educational neuropsychology', en in bredere zin die van de 'educational neuroscience'. Een nader pleidooi voor zo'n transdisciplinaire aanpak is beschreven in het rapport: 'Understanding the brain: The birth of a learning science' van de OECD (OECD, 2007). De resultaten in dit proefschrift tonen aan dat een dergelijke aanpak inzichten kan opleveren die relevant zijn voor zowel fundamenteel onderzoek als voor toepassing in het onderwijs. 


\section{Referenties}

Alvarez, J. A., \& Emory, E. (2006). Executive function and the frontal lobes: A meta-analytic review. Neuropsychology Review, 16, 17-42.

Anderson, P. (2002). Assessment and development of executive function (EF) during childhood. Child Neuropsychology, 8, 71-82.

Giedd, J. N., Blumenthal, J., Jeffries, N. O., Castellanos, F. X., Liu, H., Zijdenbos, A., et al. (1999). Brain development during childhood and adolescence: A longitudinal MRI study. Nature Neuroscience, 2, 861-863.

Gogtay, N., Giedd, J. N., Lusk, L., Hayashi, K. M., Greenstein, D., Vaituzis, A. C., et al. (2004). Dynamic mapping of human cortical development during childhood through early childhood. Proceedings of the National Academy of the Sciences, 101, 8174-8179.

Klingberg, T. (2006). Development of a superior frontal-intraparietal network for visuo-spatial working memory. Neuropsychologica, 44, 2171-2177.

OECD. (2007). Understanding the Brain: The Birth of a Learning Science. Paris: OECD.

Paus, T. (2005). Mapping brain maturation and cognitive development during adolescence. Trends in Cognitive Sciences, 9, 60-68. 
Dankwoord 


\section{Dankwoord}

Wist-u-dat er zonder scholen, ouders en leerlingen die meewerken aan onderzoeken er geen studies uitgevoerd kunnen worden? Op pagina 182 staan de namen van de scholen die hebben meegewerkt aan de studies in dit proefschrift. Bedankt alle scholen, ouders en leerlingen!

Wist-u-dat de rol van de promotor en copromotor onontbeerlijk zijn voor een promotie? Bedankt: Jelle voor je begeleiding en sturing die het proefschrift hebben gemaakt tot wat het nu is en Petra voor de goede begeleiding, alle goede adviezen, steun en een duwtje in de goede richting als ik het spoor weer eens een beetje bijster was. Chocolaatjes zijn onderweg!

Wist-u-dat ik drie paranimfen had? Twee die in hun zwangerschapsverlof zitten en één back-up die niet in de luiers zit maar wel in een verbouwing/verhuizing. Bedankt: Simone van der Mierden, Aukje Aben en Natalie Marchetta, voor alle steun en regelwerk.

Wist-u-dat het doen van onderzoek en het schrijven erover niet iets is dat je alleen doet? Naast de promotor en copromotor zijn co-auteurs bij het schrijven betrokken. Bedankt: Renske Wassenberg voor de kritische maar verhelderende kijk en de fijne samenwerking tijdens COOS, Frans Feron voor de goede adviezen en de samenwerking vanuit de GGD, Ariane Kalff en Dorine Slaats-Willemse voor hun dataverzameling en goede adviezen en Nico Rozendaal voor het betere rekenwerk.

Wist-u-dat er naast het schrijven veel praktisch werk gedaan moet worden om een onderzoek tot uitvoer te brengen? Bedankt voor de helpende handjes van: Marieke van Gompel, Suzanne Korste, Elke Rous, Floortje Smeets, Martine Smeets, Leonie Steenis, Hagar Stollman, Sandy Swieringa, Daphne Teerling, Priscilla Theunissen, Miranda Treur en Gwenny Zeles (dat hadden we niet gedacht hè, vroeger tijdens het verstoppertje spelen ()$\left._{)}\right)$.

Wist-u-dat er naast de praktische uitvoer ook veel papier-, administratie- en regelwerk bij komt kijken? Bedankt: Netty Buys, Marco van Hertrooy, Ankie Hochstenbach, Laurent Louwies, Inez Martens (en Bart), Ron Mengelers, Elsa Misdom, Desiree Morales, Anita van Oers (voor de programmering van de testen), Netty Ramaekers, Nico Rozendaal, Dick Willems (voor de eerste opzet van de formule) en een speciaal bedankje voor (ook al vindt ze dit niet leuk) Lindy Dullens (we hyven wel weer !). 
Wist-u-dat kamergenootjes een goede werkomgeving vormen? Bedankt: Annemarie Boschloo, Ellen Gerrits, Natalie Marchetta, Rosa Martens en Renske Wassenberg voor de wetenschappelijke uitwisselingen maar vooral ook de gezellige tussendoortjes! Een speciaal bedankje voor Annemarie en Rosa voor het doorlezen van mijn proefschrift. Leuk werkje hè (-)! Bedankt, natuurlijk, ook alle andere collega's van de afdeling Psychiatrie en Neuropsychologie en van de capgroep Neuropsychologie en Psychofarmacologie.

Wist-u-dat het boekje er niet zou zijn zonder de hulp van diegenen die verstand hebben van opmaak en drukken? Bedankt: Pedro Smeets voor het drukken van het boekje, Bjorn Nelissen voor alle goede tips en de hulp bij het omzetten van het bestand en andere technische en grafische dingen waar ik geen verstand van heb ;) en Ron Mengelers voor het bewerken van de plaatjes (fijn hè, al die verschillende pagina-groottes, kop- en voetteksen en ik kan nog wel even doorgaan).

Wist-u-dat vrienden heel belangrijk zijn om over het onderzoek te praten, maar vooral ook om even af te kunnen afschakelen? Bedankt alle lieve vrienden die geluisterd hebben en kritische vragen hebben gesteld waardoor ik weer goed ging nadenken over wat ik eigenlijk deed. Vooral ook erg bedankt voor de ontspanning tijdens de vrije dagen, bezoekjes en weekenden. Ik ga niet al jullie namen opschrijven, dat zouden er veel te veel zijn en de kans is groot dat ik dan iemand per ongeluk vergeet. Vandaar, als je dit leest dan weet je wel dat ik jou bedoel!!!

Wist-u-dat mijn familie me altijd gesteund en gestimuleerd heeft? Bedankt: pap en mam, oma, Simone en Pascal, Gijs, Maarten en Kim, Jan en Marlou, Rik en Karin en de rest van de familie die altijd geduldig luisterden als ik weer eens aan het vertellen was over mijn onderzoek. En natuurlijk Jeroen, mijn hubbie, bedankt voor alles, je weet het wel ;) ! NEXT! 
Anne Frankschool te Maastricht

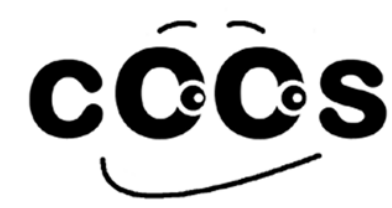

\author{
OBS Berg te Berg en Terblijt \\ BS St Brigida te Noorbeek \\ OBS Broekhem te Valkenburg \\ OBS De Binnenstad te Maastricht \\ OBS De Burght te Maastricht \\ BS De Cramignon te Eijsden
}

Emile Weslyschool te Maastricht

BS St Getrudis te Sint Geertruid

BS Heilig Hart te Eckelrade

BS Joppenhof te Maastricht

BS St Joseph te Mheer

BS St Jozef te Eijsden

BS St Jozef te Moorveld

OBS De Koelebösch te Bemelen

OBS De Kring te Maastricht

BS Maurice Rose te Margraten

OBS Mesch te Eijsden

Montessorischool Binnenstad te Maastricht

BS De Montessori West te Maastricht

OBS De Perroen te Maastricht

BS In het Riet te Geulle

BS Scharn te Maastricht

BS Vilt te Berg en Terblijt

BS Wyck te Maastricht

Bonnefanten College te Maastricht

St Maartenscollege te Maastricht

Porta Mosana te Gronsveld - Maastricht

Stella Maris College te Meerssen - Valkenburg

Sophianum te Gulpen

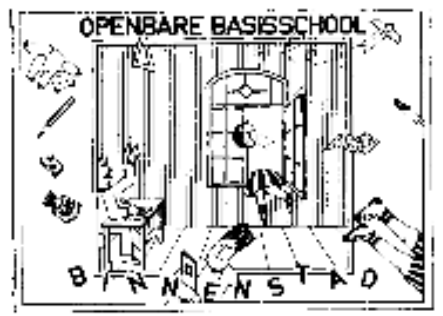





\section{Curriculum Vitae}




\section{Curriculum Vitae}

Celeste Johanna Coleta Meijs is geboren op 9 januari 1977 te Roermond. Na het behalen van haar HAVO diploma aan het Bisschoppelijk College Schöndeln te Roermond (1994) heeft zij gestudeerd aan de Pedagogische Academie voor BasisOnderwijs (PABO) te Roermond. Hier behaalde zij haar lesbevoegdheid voor de basisschool in 1998. Hierna ging zij naar de Universiteit Maastricht om Psychologie te studeren. In 2002 behaalde ze haar diploma op het gebied van de Neuropsychologie en tevens de basisaantekening psychodiagnostiek van het NIP. Na haar afstuderen heeft Celeste gewerkt als psychologisch medewerker in een instelling voor sterk gedragsgestoorde licht verstandelijk gehandicapten verbonden aan stichting 'de Wendel' te Oostrum en daarnaast als invalleerkracht op een school voor moeilijk lerende kinderen (MLK) te Heel. In 2004 is ze begonnen als 'AIO', tegenwoordig promovendus, aan de Universiteit Maastricht bij de Faculteit Psychologie, tegenwoordig Faculty of Psychology and Neuroscience en bij de Faculteit Geneeskunde, tegenwoordig Faculty of Health, Medicine and Life Sciences. Op het moment is zij werkzaam als post-doc onderzoeker aan de Universiteit Maastricht, Faculty of Psychology and Neuroscience, waar zij in het kader van 'Talentenkracht' onderzoek doet. 


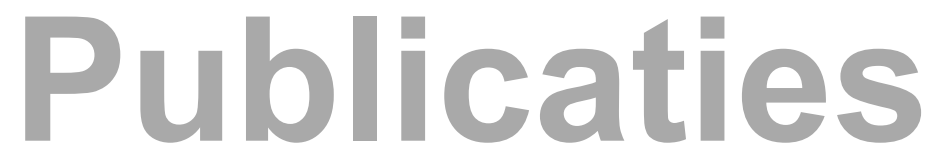


Jelicic, M., Meijs, C., Merckelbach, H., \& Stapert, S. (2003). De 15 woorden-leertest: niet geschikt om het simuleren van geheugenstoornissen te detecteren. Nederlands Tijdschrift voor de Psychologie, 58, 63-68.

Wassenberg, R., Hurks, P. P. M., Hendriksen, J. G. M., Feron, F. J. M., Meijs, C. J. C., Vles, J. S. H., et al. (in press). Age-related improvement in complex language comprehension: Results of a crosssectional study with 361 children aged 5 to 15. Journal of Clinical and Experimental Neuropsychology.

Meijs, C. J. C., Hurks, P. P. M., Kalff, A. C., Slaats-Willemse, D., Rozendaal, N., \& Jolles, J. Differential development of learning strategies on a Pictorial Verbal Learning Test (PVLT) in primary school children. Manuscript under revision. [Chapter 3 of this thesis]

Meijs, C. J. C., Hurks, P. P. M., Feron, F. J. M., Wassenberg, R., Rozendaal, N., \& Jolles, J. Verbal learning performance and the relation with efficient strategy use in children aged 5-15: the influence of age, sex, the level of parental education, and the presentation modality. Manuscript submitted for publication. [Chapter 2 of this thesis]

Meijs, C. J. C., Hurks, P., Wassenberg, R., Feron, F. J. M., \& Jolles, J. Auditory and Pictorial Verbal Learning Compared: A Cross-sectional Study of Children aged 5 - 15. Manuscript submitted for publication. [Chapter 4 of this thesis]

Meijs, C. J. C., Hurks, P. P. M., Feron, F. J. M., Wassenberg, R., \& Jolles, J. The influence of the presentation modality, the recall demands, and the content of information on verbal learning performance in children aged $6-16$. Manuscript submitted for publication. [Chapter 5 of this thesis]

Meijs, C. J. C., Hurks, P. P. M., Feron, F. J. M., Wassenberg, R., \& Jolles, J. The relationship between recreational computer use and age, sex, and the level of parental education in children aged 5-16. Manuscript submitted for publication. [Chapter 6 of this thesis]

Meijs, C. J. C., Hurks, P. P. M., Feron, F. J. M., Wassenberg, R., \& Jolles, J. The relationship between gaming and verbal learning: A large-scale cross-sectional study in 200 children aged 5-15 years. Manuscript submitted for publication. [Chapter 7 of this thesis]

Hurks, P. P. M., Schrans, D., Meijs, C. J. C., Wassenberg, R., Feron, F. J. M., \& Jolles, J. Semantic category fluency over 60 seconds as a measure of automatic and controlled processing in healthy children aged 6-16 year. Manuscript submitted for publication.

Marchetta, N. D. J., Hurks, P. P. M., Meijs C. J. C., Scholtissen-In de Braek, D., Rozendaal, N., \& Jolles, J. Verbal learning and organisational strategies in adults with ADHD: ADHD subtypes and the impact of comorbidity. Manuscript submitted for publication.

Ramakers, I. G. H. B., Visser, P. J., Aalten, P., Maes, H. L., Landsdaal, H. G. M., Meijs, C. J. C., et al. The predictive value of memory strategies for Alzheimer's disease in subjects with Mild Cognitive Impairment. Manuscript submitted for publication. 
